\title{
Development of Ontario ShakeMaps
}

\author{
by
}

\author{
SanLinn Isma'il Kaka
}

\begin{abstract}
A thesis submitted to
the Faculty of Graduate Studies and Research in partial fulfillment of the requirements for the degree of Doctor of Philosophy
\end{abstract}
Department of Earth Sciences
Carleton University
Ottawa, Ontario, Canada
December, 2005




$\begin{array}{ll}\begin{array}{l}\text { Library and } \\ \text { Archives Canada }\end{array} & \begin{array}{l}\text { Bibliothèque et } \\ \text { Archives Canada }\end{array} \\ \begin{array}{l}\text { Published Heritage } \\ \text { Branch }\end{array} & \begin{array}{l}\text { Direction du } \\ \text { Patrimoine de l'édition }\end{array} \\ \begin{array}{l}\text { 395 Wellington Street } \\ \text { Ottawa ON K1A ON4 }\end{array} & \begin{array}{l}\text { 395, rue Wellington } \\ \text { Ottawa ON K1A ON4 } \\ \text { Canada }\end{array}\end{array}$

Your file Votre référence ISBN: 0-494-13393-7

Our file Notre référence

ISBN: 0-494-13393-7

NOTICE:

The author has granted a nonexclusive license allowing Library and Archives Canada to reproduce, publish, archive, preserve, conserve, communicate to the public by telecommunication or on the Internet, loan, distribute and sell theses worldwide, for commercial or noncommercial purposes, in microform, paper, electronic and/or any other formats.

The author retains copyright ownership and moral rights in this thesis. Neither the thesis nor substantial extracts from it may be printed or otherwise reproduced without the author's permission.
AVIS:

L'auteur a accordé une licence non exclusive permettant à la Bibliothèque et Archives Canada de reproduire, publier, archiver, sauvegarder, conserver, transmettre au public par télécommunication ou par l'Internet, prêter, distribuer et vendre des thèses partout dans le monde, à des fins commerciales ou autres, sur support microforme, papier, électronique et/ou autres formats.

L'auteur conserve la propriété du droit d'auteur et des droits moraux qui protège cette thèse. $\mathrm{Ni}$ la thèse ni des extraits substantiels de celle-ci ne doivent être imprimés ou autrement reproduits sans son autorisation.
In compliance with the Canadian

Privacy Act some supporting forms may have been removed from this thesis.

While these forms may be included in the document page count, their removal does not represent any loss of content from the thesis.
Conformément à la loi canadienne sur la protection de la vie privée, quelques formulaires secondaires ont été enlevés de cette thèse.

Bien que ces formulaires aient inclus dans la pagination, il n'y aura aucun contenu manquant.

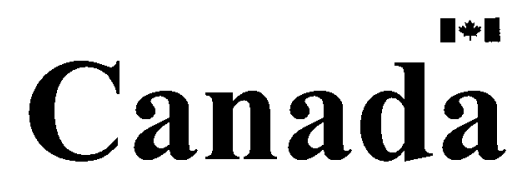




\begin{abstract}
A methodology to generate simple, reliable ShakeMaps showing earthquake ground shaking in Southern Ontario is developed using the near-real-time data from Ontario POLARIS (Portable Observatories for Lithospheric Analysis and Research Investigating Seismicity) stations. ShakeMaps have been implemented in California and the western United States (Wald et al, 1999b), but this is the first ShakeMap development in eastern North America. The eastern ground motion characteristics and sparse network pose new challenges for ShakeMap development in this region.
\end{abstract}

The ground motion parameters selected to display in the near-real-time ShakeMaps include peak ground acceleration (PGA), peak velocity (PGV), Pseudoacceleration (PSA) amplitude at periods of $0.1 \mathrm{~s}, 0.3 \mathrm{~s}$ and $1.0 \mathrm{~s}$, and an instrumentally derived felt-intensity. The ground motion values are plotted on a map and contour lines are added to show areas of equally-strong shaking.

In the ShakeMaps, PGA, PGV, and PSA values are assigned to map grid points by using a combination of the recorded ground motions and values estimated using the empirical relations developed in Chapter 6. Intensity values are estimated from the peak ground velocity using relations developed in Chapter 5 , where the intensity is a qualitative measure of the strength of shaking and damage based on the Modified Mercalli scale.

A grid of site amplification factors to account for the appropriate level of soil amplification is incorporated, by using interpolations of currently-available site conditions. The site classification is based primarily on the average shear-wave velocity of the top 30 meters $\left(\mathrm{V}_{\mathrm{s}}^{30}\right)$ wherever possible. Since shear-wave velocity measurements 
are not available for most grid points, I assume $\mathrm{V}_{\mathrm{s}}^{30}=500 \mathrm{~m} / \mathrm{s}$ for sites with unknown properties.

An important component of ShakeMap is its potential use as a rapid earthquake warning system. ShakeMap sends email notifications to subscribers immediately (within 3 minutes) following an earthquake, giving information on motions experienced at specific sites of interest, such as nuclear power plant sites. Near-real time ShakeMaps are automatically produced and posted within 7 minutes at (http://www.shakemap.carleton.ca). This development is a significant step forward in the development of near-real-time seismic information relevant to post-earthquake rapid warning systems in Canada. 


\section{Acknowledgments}

I would like to thank my supervisor, Dr. Gail Atkinson, for her guidance, support, and patience as well as for providing various opportunities.

This work could not have accomplished without the collaborative efforts of David McCormack, John Adams, and Tim Cote of the Geological Survey of Canada and Bill Jack of Carleton University. I thank Siew Ling Soh, Jianling Hua, Sathyanarayanan

Sivadas and Niruban Kandasamy for computer programming and Eleanor Sonley, Maurice Lamontagne, David Wald and James Hunter for their useful comments and suggestions. I thank Jim Lyons, Janet Drysdale, Nina Markova, Sylvia and Stephen Halchuk from the Geological Survey of Canada for providing me with data and Aaron Snider and Curtis Brett for their support in the field.

I would also like to thank all members in the department of Earth Sciences particularly Eleanor Sonley, Sharon Carr, George Dix, Juan Carlos Afonso, Dariush Motazedian, John Blenkinsop, Giorgio Ranalli, and Chris Rogers for their support.

My special thanks to my parents for their constant moral support, my wife for her tremendous patience and my children for their love. 


\section{Original Contribution}

This thesis contains only the results of the research conducted by the candidate under the supervision of his supervisor. The original contributions are summarized as follows:

Acquiring all the necessary computer software programs needed for the thesis, installing and testing them. Incorporating region-specific features into the software such as origin point of the estimate grid, station parameters/locations/names, contour interval, topography and major city names. Computing science students assisted with programming for these tasks, under my direction.

Retrieving data from various sources as follows.

Instrumental data:

- Geological Survey of Canada (GSC), Automatic Data Request Manager facility (www.seismo.nrcan.gc.ca/nwfa/autodrm).

- Ground Motion Database complied by Atkinson and Mereu (1992)

- Strong Motion records for the Saguenay earthquake of November 25, 1988 by Munro and Weichert (1989) (available at GSC, Open File 1996).

- The U.S. Geological Survey's Automatic Data Request Manager (http://neic.usgs.gov/neis/autodrm).

MMI data:

- Geological Survey of Canada, Observatory Crescent (info@seismo.nrcan.gc.ca).

- National Oceanic and Atmospheric Administration (NOAA), United States Department of Commerce (http://www.noaa.gov/). 
- Modified Mercalli Intensity (MMI) data of the 1811-1812 New Madrid earthquakes given by Hough et al. (2000).

Developing a new relationship between Modified Mercalli Intensity (MMI) and peak ground motions (PGV and PSA (f)) by comparing instrumentally-recorded and inferred-historical PGV values to observed MMI for eighteen significant earthquakes from eastern North America (ENA).

Developing empirical relations that describe ground-motion amplitudes from earthquakes of $2<M<6$ at regional distances of $10-500 \mathrm{~km}$ in southeastern Canada and the northeastern United States, for ShakeMap applications.

Developing an automated earthquake detection algorithm to continuously detect events and trigger ShakeMap in a sparse network.

Modifying and implementing a version of the ground-motion centroid program developed by Kanamori (1993) to locate earthquakes and estimate magnitude in nearreal-time.

Defining a grid of site amplification correction factor by:

- studying the surficial geologic maps of the region

- calculating horizontal-to-vertical component ratios of recorded ground motions

- compiling available shear-wave velocity and borehole information

- carrying out shear-wave velocity survey at two POLARIS sites

The material presented in Chapter 2 is compiled from various documentation, including a paper by Wald et al. (1999b) of the U.S. Geological Survey, and information 
available at various ShakeMap web sites including the web site developed in this thesis and maintained by Carleton University http://www.shakemap.carleton.ca/about.html.

The material presented in Chapter 3 is compiled mainly from the Geological Survey of Canada (GSC), Ontario Geological Survey (OGS), the Ontario Ministry of Northern Development and Mines and other documentation. Appropriate references are provided in the text.

The material presented in Chapter 4 is being prepared for submission to Seismological Research Letters for possible publication.

The materials presented in Chapter 5 and 6 have been published in Bulletin of Seismological Society of America and Seismological Research Letters (SRL) respectively and are listed in the references as Kaka and Atkinson (2004) and Kaka and Atkinson (2005). Material presented in Chapter 8 has been accepted for publication in SRL. 


\section{Table of Contents}

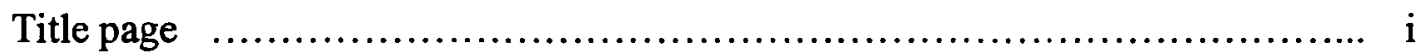

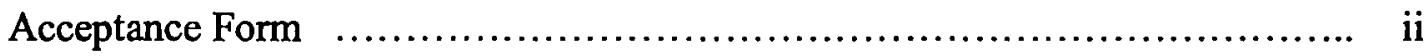

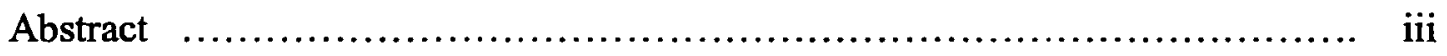

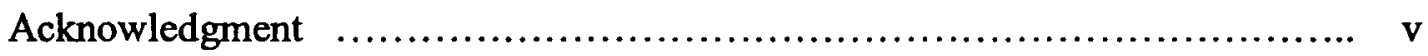

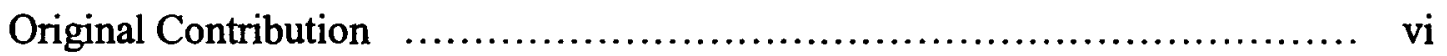

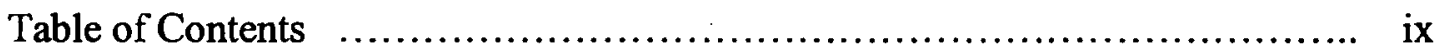

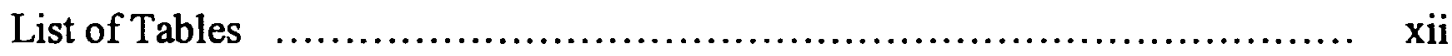

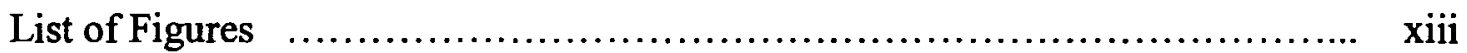

List of Abbreviation ........................................................ xvi

\section{Chapter 1}

\section{General Introduction}

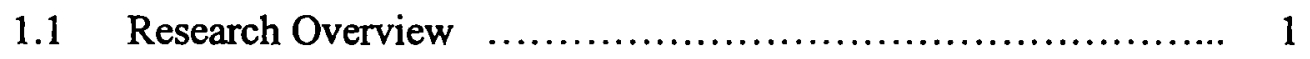

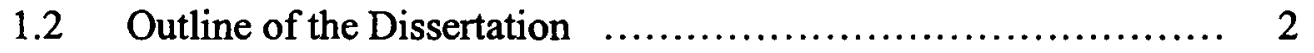

\section{Chapter 2}
About ShakeMaps
$2.1 \quad$ Introduction ................................................ 4
$2.2 \quad$ History and Developments …............................... 5

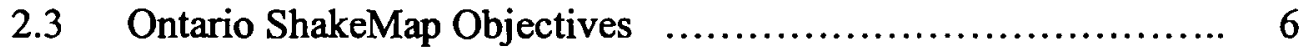
2.4 Requirements for Implementing ShakeMap in Ontario............. 8

\section{Chapter 3}

Overview of Seismicity and the Geology of Ontario

3.1 Overview of Seismicity .................................... 12

3.1.1 Western Quebec Seismic Zone (WQU) .................. 13

3.1.2 Charlevoix Seismic Zone (CHV) .................... 14

3.1.3 Lower St. Lawrence Seismic Zone (BSL) ............. 15

3.2 Geology of Ontario 16

3.2.1 The Canadian Shield …............................ 16

3.2.2 The Borderlands .................................. 18

3.2.2 The Recent Deposits .............................. 18 


\section{Chapter 4}

Implementation of Event Detector and Centroid Programs

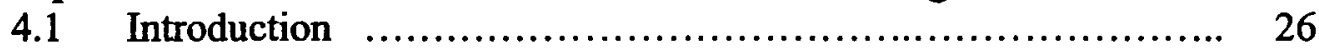

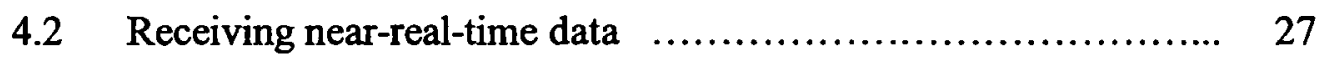

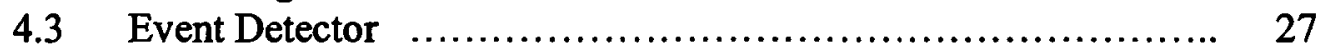

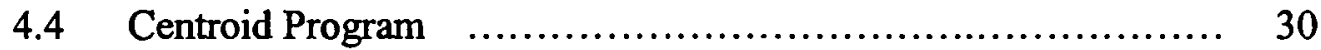

4.4.1 Centroid Location and Magnitude .................... 30

4.5 Accuracy of PGV-estimation ................................. 32

4.6 Performance of ShakeMap ..................................... 35

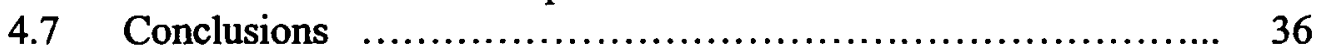

\section{Chapter 5}

Relationships between Instrumental Ground Motion Parameters and Modified Mercalli Intensity for ShakeMaps

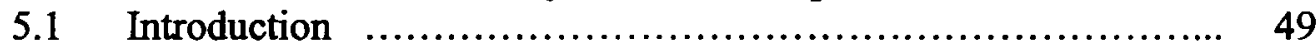

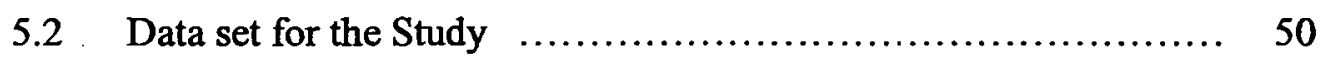

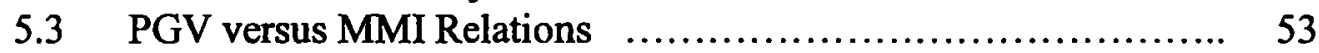

5.4 Comparison to other Relations ................................ 55

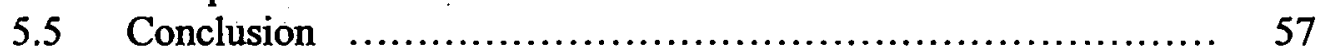

\section{Chapter 6}

Empirical Ground-Motion Relations for ShakeMap Applications

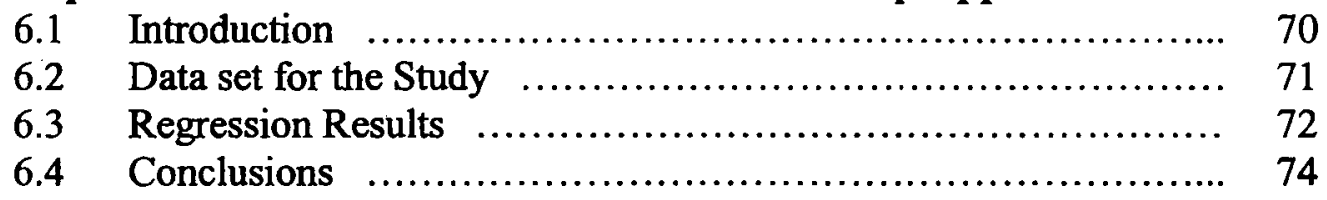

\section{Chapter 7}

Estimation of Site Amplification Factors at Ontario POLARIS Stations for ShakeMaps

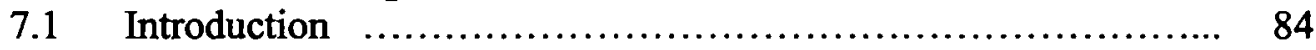

7.2 Methodology for Site Amplification Factors .................... 84

7.2.1 Amplification of Ground Motion Amplitude............. 86

7.2.2 Ontario POLARIS Network Site Conditions.............. 88

7.3 Shear-wave Velocity Survey at Two Polaris Sites................ 89

7.3.1 Data Processing and Results ......................... 90

7.4 Data Processing and Calculation of $\mathrm{H} / \mathrm{V} \ldots \ldots \ldots \ldots \ldots \ldots \ldots . . \ldots$

7.5 Amplification Results Based on $\mathrm{H} / \mathrm{V}$........................ 92

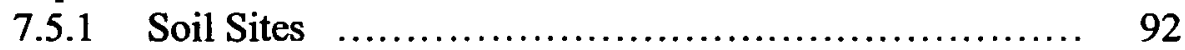

7.5.2 Rock Sites ......................................... 94

7.5.3 $\mathrm{H} / \mathrm{V}$ values for Peak Ground Velocity ............... 95 
7.5.4 Conclusions ........................................... 96

7.6 Site Classification for the Ontario ShakeMap Network .......... 98

7.6.1 Introduction ......................................... 98

7.6.2 Methodology in Classifying Sites ..................... 99

7.6.3 Site Amplification Factors .......................... 100

7.7 Integration of Site Response Information in ShakeMaps ........... 103

7.7.1 Bias Correction .................................. 103

7.7.2 Site Corrections ................................. 104

\section{Chapter 8}

ShakeMap for the MN 5.4 March 6, 2005 Riviere-du-Loup, Quebec

Earthquake

8.1 Introduction

$8.2 \quad$ Performance of ShakeMap ........................................ 130

8.2 .1 Location and magnitude .............................. 130

8.2 .2 Ground Motions ................................ 130

8.2.3 Felt-Intensity ShakeMap ........................... 131

\section{Chapter 9}

\section{Scenario ShakeMaps}

9.1 Introduction ............................................. 144

9.2 Magnitude $\mathbf{M}=5$ Scenario .................................. 145

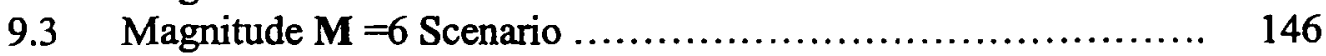

9.4 Magnitude $\mathbf{M}=7$ Scenario....................................................... 147

9.5 Repeat of Historical Cornwall- Massena and Temiskaming

Earthquakes ................................................... 149

\section{Chapter 10}

Outstanding Problems and Future Directions for ShakeMaps

10.1 Broadening the Station Coverage for Ontario ShakeMaps ......... 159

10.2 Addressing Uncertainties in ShakeMaps ....................... 159

10.3 More Shear-wave Velocity Data Across Ontario ................. 160

10.4 Linking ShakeMap with "Did you feel it" website ............... 161

10.5 Possibility of Providing other Earthquake Parameters along with ShakeMaps .................................................... 161

10.6 Implementing ShakeMaps in Western Canada .................. 162

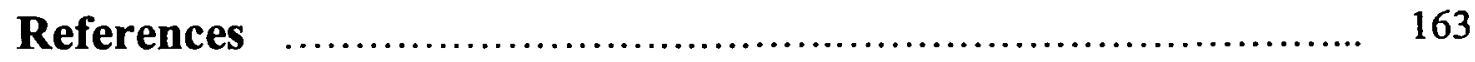




\section{List of Tables}

Table 2.1 Description of MMI scale ................................... 10

Table 4.1a Teleseismic Events ................................................. 38

Table 4.1b Local/Regional Events ..................................... 38

Table 4.2 Comparing ShakeMap with the Canadian National Earthquake Database (NEDB) Solution................................................................ 39

Table $5.1 \quad$ Study Earthquakes ............................................. 59

Table 5.2 Mean PGV and PSA-values for each MMI level ................... 60

Table 5.3 Coefficients of Equations (and their standard errors) to predict MMI from Instrumental Ground Motion Parameters ................. 60

Table $6.1^{\circ} \quad$ Study Earthquakes ............................................ $\quad 75$

Table 6.2 Regression Coefficients (and their standard errors) ................. 79

Table 7.1 POLARIS stations, their locations and known information on site conditions............................................................ 107

Table 7.2 Shear-wave data recording parameters .............................. 109

Table 7.3 Station locations and geology ....................................... 109

Table 7.4 One-dimensional velocity models .................................... 109

Table 7.5 List of events used in the $\mathrm{H} / \mathrm{V}$ study ............................ 110

Table 7.6a Fourier Spectra Amplification Factors for Soil Sites .................. 112

Table 7.6b Fourier Spectra Amplification Factors for Rock Sites ................ 112

Table 7.7a Average/Maximum Amplification Factors at Soil Sites .............. 113

Table 7.7b Average/Maximum Amplification Factors at Rock Sites ............. 113

Table 7.8a Mean Log H/V Ratio for PGV at Soil Sites ................................. 114

Table 7.8b Mean Log H/V Ratio for PGV at Rock Sites ......................... 115

Table 7.9 Site Categories (BSSC, 1997) ...................................... 116

Table 7.10 Average Shear-wave Velocity in top $30 \mathrm{~m}\left(\mathrm{~V}_{\mathrm{s}}{ }^{30}\right)$ for POLARIS sites 116

Table 7.11a General Soil Response Factors Adopted for ShakeMap

Applications ........................................................ 117

Table 7.11b Specific Soil Response Factors for POLARIS Stations based on $\mathrm{H} / \mathrm{V}$ ratios ....................................................... 117

Table 7.12 Soil Response Factors for NEHRP B, based on H/V at 4-NEHRP B Sites ................................................................... 118

Table 7.13 Comparing Soil Response Factors for NEHRP C .................... 118

Table 8.1 Observed Ground Motion Amplitudes ................................ 134

Table 9.1 A comparison of total felt- area between Isoseismal map and ShakeMap for Cornwall-Messena earthquake ....................... 151

Table 9.2 A comparison of total felt- area between Isoseismal map and ShakeMap for Temiskaming earthquake ........................... 151 


\section{List of Figures}

Figure 3.1a Seismicity map of Canada $\quad 22$

Figure 3.1b Seismicty map of eastern Canada $\quad 22$

Figure 3.2 Major Seismic Zones in eastern Canada

b) Charlevoix Seismic Zone $\quad 23$

c) Lower St. Lawrence Seismic Zone $\quad 23$

$\begin{array}{lll}\text { Figure 3.3 Simplified Geology map of Ontario } & 24\end{array}$

$\begin{array}{lll}\text { Figure 3.4 Surficial Materials for Ontario Region } & 25\end{array}$

Figure 4.1 Locations of Ontario Polaris stations along with $\mathrm{Mn} \geq 2.8$ events reported by the Geological Survey of Canada during $2004 \quad 40$

Figure 4.2 The recorded vertical component PGV is plotted as a function of 41 magnitude and distance for:

a) more than 24 recorded events occurred in the region since 2003

b) five typical felt-events in the region

Figure 4.3 Flowchart of the automated procedures to produce ShakeMap in near-real-time

Figure 4.4 The normalized standard deviation of the PGV (normalized to the mean) plotted against local/regional events (filled square) and teleseismic events (circle) to discriminate between local/regional and teleseismic events. An event is considered teleseismic if NSD $\leq 0.7$.

Figure 4.5 Ratio of actual recorded PGV to estimated PGV as a function of distance: a) PGV-estimated from centroid location and magnitude, b) VGV-estimated from epicentre location and magnitude

Figure 4.6 Ratio of actual recorded PGV to estimated PGV as a function of magnitude: a) PGV-estimated from centroid location and magnitude, b) VGV-estimated from epicentre location and magnitude

Figure 4.7 Observed PGV plotted as a function of distance. Filled circles denote PGV dataset used to derive empirical ground motion relations in Chapter 6 while open squares are regional dataset used in this chapter.

Figure 4.8 Comparing near-real-time ShakeMap location (centroid) with that of the Canadian National Earthquake Database (NEDB) solution (epicentre) to evaluate the performance of ShakeMap. The epicentre is plotted as grey square, while the ShakeMap centroid location is denoted as filled square. Number represents the corresponding event shown in Table 4.2

Figure 4.9 Solutions for local and regional events listed in Table 4.2, along with the contoured PGV values from ShakeMap. The epicentre is plotted as red circle, while the centroid is denoted as an orange square. Small red triangles are the location of recording station. 
Horizontal component $\mathrm{PGV}$ value at each station is given in $\mathrm{mm} / \mathrm{s}$.

Figure 5.1a MMI observations for the 2002 M 5.0 Au Sable Forks, N. Y

Earthquake and locations of seismographic monitoring stations that recorded the PGV and PSA values. Star shows epicentre. Numbers are MMI values. Triangles are stations.

Figure 5.1b MMI observations for the 1997 M 4.2, Charlevoix Earthquake, and locations of seismographic monitoring stations that recorded the PGV and PSA values. Star shows epicentre. Numbers are MMI values. Triangles are stations.

Figure 5.2 Observed MMI versus PGV for all data with squares representing recorded $P G V$ and circles representing inferred values, using the Atkinson and Boore, 1995 (AB95) relations. PGV ranges based on laboratory measurements of McDaniel and Horton (2001) are also shown. Slight offsets from actual MMI values used for clarity.

Figure 5.3 Ratio of actual recorded PGV to PGV value inferred using the AB95 relation: a) versus distance; b) versus magnitude. Slight offsets from actual magnitude values used for clarity.

Figure 5.4 Observed MMI plotted against log PGV in order to obtain a simple MMI-PGV relationship. As a comparison, MMI-PGV relationships developed by Wald et al. (1999a) and Atkinson and Sonley (2000) are also shown in the figure. The Wald et al. (1999a) relation is truncated at MMI 5 because it is not applicable for lower intensity levels). PGV ranges based on laboratory measurements of McDaniel and Horton (2001) are also shown.

Figure 5.5 MMI-residuals (= Observed MMI - Predicted MMI from equation 5.1) plotted as a function of distance.

Figure 5.6 Distance corrected MMI residuals (obtained by subtracting off distance trends in MMI residuals as described in the text) as a function of magnitude.

Figure 5.7 Comparison between MMI residuals for a) PGV-based predictions; b) PSA (1Hz)-based predictions; c) PSA (5Hz)-based predictions; d) PSA (10Hz)-based predictions, using relations of this study (circles), and the California relations of Atkinson \& Sonley (triangles) and Wald et al., (squares). (The Wald et al. (1999a) relation was not applied for MMI <5).

Figure 5.8 ShakeMap intensities for the 2002 Au Sable Forks, New York M 5.0 earthquake. These maps use the AB95 ENA ground motion relations with a) relations between PGV/PGA and intensity developed by Wald, et al. (1999a); b) relation between PGV and intensity developed in this study. Top panel shows observed intensities.

Figure 6.1 Locations of the study earthquakes and recording stations 80

Figure 6.2 Distribution of compiled recorded ground-motion data set (vertical-component) in moment magnitude (M) and hypocentral distance (R).

Figure 6.3 Log residuals ( $=\log$ observed ground motion $-\log$ predicted 
Figure 6.4 Comparison of ground-motion amplitudes predicted by the empirical relations developed in this study (thick line) with that of the Atkinson and Boore relations (thin line) using observed data of the 2003/10/12 M 4.0 earthquake near Maniwaki, Quebec.

Figure 7.1 Example of stacked raw data collected from source impacts in the two opposite directions at ALGO site

Figure 7.2 Locations of the study earthquakes and recording stations for $\mathrm{H} / \mathrm{V}$ analyses

Figure 7.3 Signal and noise window selections of time series data from MN 5.4 March 6, 2005 Riviere-du-Loup, Quebec Earthquake

Figure 7.4 Log H/V for Soil Sites. Mean $\log H / V$ and $95 \%$ confidence limits on mean for Soil Sites also shown.

Figure 7.5 Log $\mathrm{H} / \mathrm{V}$ for Rock Sites. Mean $\log \mathrm{H} / \mathrm{V}$ and $95 \%$ confidence limits on mean for Bedrock Sites also shown.

Figure 7.6 Log H/V for PGV and 95\% confidence limits for Soil Sites

Figure 7.7 Log H/V for PGV and 95\% confidence limits for Rock sites

Figure 7.8 Site Classification Map for Ontario ShakeMap Grid

Figure 7.9 Amplification versus Frequency for NEHRP C sites by various methods. Amplification versus Frequency for NEHRP C sites by various methods. The heavy solid line is the proposed factor to be used in our ShakeMap application. The thin solid line with $95 \%$ confidence level is calculated using the H/V method. The greyscale solid line is computed using the quarter-wavelength approximation. The dashed line is from Adams and Halchuck (2003)

Figure 7.10 Intensity ShakeMaps for the MN 5.4 March 6, 2005 Riviere-duLoup, Quebec Earthquake. Generated (a) before and (b) after applying the site correction factors

Figure 8.1 Location of Riviere-du-Loup epicentre (grey square) and ShakeMap centroid (filled square). Triangles show station locations. Inset is zoomed Charlevoix region.

Figure 8.2 Ground-motion amplitudes for the M5.0 Riviere-du-Loup earthquake compared to the predictions (for rock) of Equation 4.1 (thick line) and Atkinson and Boore, 1995 (thin line)

Figure 8.3 Felt-intensity ShakeMap for M5.0 Riviere-du-Loup earthquake distance bins $0.1 \mathrm{log}$ units in width (open squares), based on the mean MMI for each zip code or city location (grey dots), weighted by the number of observations for that location. Filled symbols show MMI predicted from horizontal-component PGV values based on Equation 8.1.

Figure 9.1 M5 Scenario Earthquakes Near (a) Ottawa; (b) Toronto. Scenario Intensity ShakeMap based on ground-motion relations developed 
in Chapter 6 and relation between PGV and MMI developed in Chapter 5.

Figure 9.2 M6 Scenario Earthquakes Near (a) Ottawa; (b) Toronto. Scenario Intensity ShakeMap based on ground-motion relations developed in Chapter 6 and relation between PGV and MMI developed in Chapter 5.

Figure 9.2c Damage caused by the M6.5 San Simeon earthquake. Photos by Joshua Marrow, Simpson Gumpertz Heger (taken from http://www.eeri.org/ffe/usa_san_simeon.html)

Figure 9.3 M7 Scenario Earthquakes in the Charlevoix Seismic Zone.

Scenario Intensity ShakeMap based on ground-motion relations developed in Chapter 6 and relation between PGV and MMI developed in Chapter 5.

Figure 9.3b Damage caused by the M6.9 1989 Loma Prieta earthquake

(taken from http://wrgis.wr.usgs.gov/dds/dds29/web pages/oakland.html)

Figure 9.4 Repeat of Cormwall Earthquake compared to Isoseismal Map taken from the GSC

(http://www.seismo.nrcan.gc.ca//damage/1935 e.php).

Note the differences in colour scheme between the historical and ShakeMap intensities. Lower panels plotted on similar geographic scale.

Figure 9.5 Repeat of Temiskaming Earthquake Compared to Isoseismal map taken from the GSC

(http://www.seismo.nrcan.gc.ca//damage/1944 e.php)

Note the differences in colour scheme between the historical and ShakeMap intensities. Lower panels plotted on similar geographic scale.

\section{List of Abbreviation}

$\begin{array}{ll}\text { ANSS } & \text { United States Advanced National Seismic System } \\ \text { AUTODRM } & \text { Automatic Data Request Manager } \\ \text { BSL } & \text { Lower St. Lawrence Seismic Zone } \\ \text { BSSC } & \text { Building Seismic Safety Council } \\ \text { CHV } & \text { Charlevoix Seismic Zone } \\ \text { CIIM } & \text { Community Internet Intensity Map } \\ \text { CNSN } & \text { Canadian National Seismographic Network } \\ \text { ECTN } & \text { Eastern Canada Telemetered Network } \\ \text { ENA } & \text { Eastern North America } \\ \text { ENO } & \text { Eastern Northern Ontario } \\ \text { GMT } & \text { Generic Mapping Tool }\end{array}$




$\begin{array}{ll}\text { GSC } & \text { Geological Survey of Canada } \\ \text { H/V } & \text { Horizontal-to-Vertical ratio } \\ \text { LSP } & \text { Laurentian Slope Seismic Zone } \\ \text { M } & \text { Moment Magnitude } \\ \text { MMI } & \text { Modified Mercalli Intensity } \\ \text { MN } & \text { Nuttli Magnitude } \\ \text { NAN } & \text { Northern Appalachians Seismic Zone } \\ \text { NEDB } & \text { Canadian National Earthquake Database } \\ \text { NEHRP } & \text { National Earthquake Hazard Reduction Program } \\ \text { NOAA } & \text { National Oceanic and Atmospheric Administration } \\ \text { NSD } & \text { Normalized Standard Deviation } \\ \text { PERL } & \text { Practical Extraction and Reporting Language } \\ \text { PGA } & \text { Peak Ground Acceleration } \\ \text { PGV } & \text { Peak Ground Velocity } \\ \text { POLARIS } & \text { Portable Observatories for Lithospheric } \quad \text { Analysis } \quad \text { and } \quad \text { Research } \\ & \text { Investigating Seismicity } \\ \text { PSA } & \text { Pseudo-acceleration (peak response spectra) } \\ \text { SD } & \text { Standard Deviation } \\ \text { SGL } & \text { Southern Great Lakes } \\ \text { SNAQS } & \text { Seismic Network Acquisition Systems } \\ \text { UNSN } & \text { United States National Seismic Network } \\ \text { V 30 } & \text { average shear-wave velocity of the top 30 meters } \\ \text { WNA } & \text { Western North America } \\ \text { WQU } & \text { Western Quebec Seismic Zone } \\ \end{array}$




\section{Chapter 1 \\ General Introduction}

\subsection{Research Overview}

I have developed and implemented a method to produce "ShakeMaps" in nearreal-time for earthquakes in southern and central Ontario; solutions are automatically posted to www.shakemap.carleton.ca. The ShakeMap concept was originally conceived by Wald et al. (1999b) and implemented in California using a dense strong-motion network. In Ontario, I must use the sparse seismographic network, which poses new challenges.

ShakeMaps are web-based near-real-time maps that show the spatial distribution of recorded and estimated peak ground motions (velocity, acceleration, and response spectra) and estimate the corresponding felt-intensity at locations throughout the region, for purposes of providing rapid public, planning and emergency response information in the immediate aftermath of local and regional earthquakes. Ontario ShakeMap is based on seismographic data from the POLARIS network (www.polarisnet.ca) and aims to provide rapid ground-shaking information on small-to-moderate regional earthquakes. This information is of interest for public information and to owners of critical or sensitive equipment, such as nuclear power plant.

When an earthquake is detected, ShakeMap uses the recorded ground motions to find the centroid location and magnitude of the event. The centroid is a geographic location near the largest recorded ground motion, from which the ground motion appears to radiate (based on the pattern of observed amplitudes in the region). In most cases, the centroid is near the epicenter, but not identical in location. The centroid magnitude is the 
earthquake magnitude that best explains the observed ground motions, given the centroid location and regional ground motion relations. A new region-specific empirical ground motion relation, developed in Chapter 6, giving peak ground velocity (PGV) as a function of magnitude and distance, is used in the determination of the centroid's location and magnitude. ShakeMap uses a combination of computed ground motions that are based on the centroid and the regional PGV ground-motion relation, along with the actual measured ground motions at all stations, to create a contour map of PGV, peak ground acceleration (PGA) and peak response spectra (PSA) amplitude at periods of $0.1 \mathrm{~s}, 0.3 \mathrm{~s}$ and 1.0s. Response spectra are a measure of the amplitude that would be experienced by a damped single-degree-of-freedom oscillator of a given natural period; they are useful input for typical engineering analyses. The PGV map is also translated into a map of felt intensity/damage, using a relationship between PGV and Modified Mercalli Intensity (MMI) developed in Chapter 5.

My current focus is to obtain the highest-possible reliability of the system during regional earthquakes that are strong enough to be felt, while avoiding false triggers due to cultural noise or teleseismic signals.

Implementing ShakeMap in Ontario is a significant step forward in the development of near-real-time seismic information, particularly for nuclear utilities and other critical services that must provide timely information on all felt events.

\subsection{Outline of the Dissertation}

In this dissertation, I describe the development of Ontario ShakeMaps. The following chapter provides an overview of the history and development of ShakeMap, 
Ontario ShakeMap objectives and a brief summary of requirements for implementing Ontario ShakeMaps. Chapter 3 summarizes the seismicity and geology of Ontario. Details of the implementation of the event detector and centroid programs are then presented in the following chapter. Chapter 5 describes the relationships between shaking intensity (damage potential of motions) and instrumental ground motion parameters (peak ground velocity and response spectra) that were developed in order to allow ShakeMap to accurately calculate felt -effects for Ontario earthquakes. Chapter 6 describes the development of new region-specific empirical ground-motion relations to predict peak ground velocity, peak ground acceleration and, Pseudo-acceleration (PSA) amplitude at various frequencies as a function of magnitude and distance, with an emphasis on the low-to-moderate magnitude events that are common in Ontario. Various steps in the integration of site amplification factors across the grid to produce a map of soil amplification are discussed in Chapter 7. This is an important step for ShakeMap implementation in Ontario; it is a key step forward in developing a reliable portrayal of the extent of shaking. In Chapter 8, I evaluate the performance of ShakeMap for the Nuttli magnitude (MN) 5.4 earthquake that occurred $17 \mathrm{~km}$ southwest of Riviere-duLoup, Quebec on March 6, 2005. This event was the first moderate well-recorded event since the implementation of the Ontario ShakeMap project and provided a good opportunity to evaluate the performance of ShakeMap. In Chapter 9, I generate a number of scenario ShakeMaps that provide a perspective on the potential consequences of moderate to large regional earthquakes. Finally, outstanding problems and future directions for implementing ShakeMaps are presented in Chapter 10. 


\section{Chapter 2}

\section{About ShakeMaps}

\subsection{Introduction}

Magnitude and epicentral location are the two most widely available parameters immediately following an earthquake in Ontario. These parameters are routinely calculated by the Geological Survey of Canada (GSC) within about 15 minutes of the occurrence on earthquake. Neither of these parameters provides direct information on the shaking levels produced by an earthquake or its damage potential. Consequently, it is not feasible to ascertain the shaking pattern in the region immediately after a damaging earthquake with this information alone (Wald et al., 1999b). There is a need to generate maps that represent the ground shaking levels throughout the region in order to assist in efforts to provide rapid ground-shaking information on regional earthquakes in Ontario. Even the shaking from small-to-moderate events is of interest to the operators of critical facilities, who must be able to verify that motions were below the levels of concern, and to provide timely information to the public and to regulatory authorities.

To date in Ontario, the generation of such maps following an earthquake has been hindered by the sparse distribution of real-time recording stations. However, with recent installation of the POLARIS (Portable Observatories for Lithospheric Analysis and Research Investigating Seismicity) network, it is now technically feasible to develop systems to display ground motions in an informative manner within minutes following an earthquake, for events within Southern Ontario. 
Ground shaking maps indicate that an earthquake has occurred, identify the area affected, and provide an estimate of potential damage or felt effects. Generating such maps is an excellent tool for providing lack of early information immediately after an earthquake.

\subsection{History and Developments}

ShakeMap was originally developed and implemented using a dense strong motion network in California (Wald et al., 1999b) as part of research and development efforts of the "TriNet" group (California Institute of Technology, the California Division of Mines and Geology, and the U.S Geological Survey). Due to its real-time utility, ShakeMap technology has been rapidly spreading as part of the United States Advanced National Seismic System (ANSS) with collaboration from regional seismic networks in the U.S. ShakeMaps are available for the US Pacific northwest, central Utah and Nevada. This is the first ShakeMap development in Canada, and the first in eastern North America.

The information ShakeMap presents is fundamentally different from that provided by the basic seismological parameters of magnitude and location. Earthquake magnitude is a single number, which represents the energy released in an earthquake, on a logarithmic scale. Felt-intensity, on the other hand, is a measure of the strength of the shaking based on the Modified Mercalli Intensity (MMI) scale at a particular site. Thus any earthquake has one magnitude, but a distribution of intensity. The MMI scale, developed by Wood and Newmann (1931) takes into account how the earthquake was 
perceived by humans and structures in a geographic location. The impact of the earthquake shaking on the ground, whether cracks or displacements occurred, or in some cases landslides, is also a feature of measured MMI. This scale uses Roman numerals to represent progressively greater shaking from MMI I in which "people do not feel any earth movement" to $\mathrm{MMI} X$ in which "most buildings and their foundations are destroyed, bridges and dams are severely damaged and large landslides occur". A full description of the MMI scale is presented in Table 2.1. In the past, MMI values were compiled in the weeks following an earthquake through questionnaires sent to post offices in the affected region. With the development of ShakeMap, near-real-time feltintensity maps are generated automatically as a function of the ground motion parameters as recorded by seismometers.

\subsection{Ontario ShakeMap Objectives}

The main objective of this research is to develop a methodology to generate simple, reliable near-real-time ShakeMaps to provide rapid ground-shaking information on small-to-moderate regional earthquakes in Ontario. The development of new empirical region-specific ground-motion relations to predict ground motion parameters as a function of magnitude and distance with emphasis on small-to-moderate events is a crucial building block for accurate ShakeMap implementation. Moreover, I am also interested in creating felt-intensity ShakeMaps for the frequent small-to-moderate events that may be widely felt, but cause little to no damage (in addition to our interest in the larger events). Such maps are useful for public information purposes; particularly to nuclear utilities that must provide timely information on all felt events. Existing relations 
between Modified Mercalli Intensity (MMI) and PGV/PGA (e.g. Wald et al., 1999a; Atkinson and Sonley, 2000) are not necessarily applicable in Ontario because they were developed from California data. Thus developing a new empirical relationship between PGV and observed MMI that is applicable in Ontario was another important step for Ontario ShakeMaps.

A particular challenge in ShakeMap development in Ontario is developing algorithms that are effective in a sparse network. One of the algorithms I modified was that of a centroid program which was originally developed by Kanamori (1993) to locate earthquakes using ground-motion amplitude data. An important advantage in using the centroid program is near real-time estimation of the ground motion centroid (rather than waiting until an epicentre becomes available), thus speeding the generation of ShakeMaps. The use of the centroid approach is a departure from practice in California and other regions of the U.S., where the epicentre is used. To my knowledge, the centroid concept has not actually been implemented in any other region, possibly because more rapid and reliable epicentres may be available elsewhere, where stations are more densely distributed.

Another important objective is to develop an event detection program: "EventDetector" that continuously reads data, detects events and triggers ShakeMap while screening out false triggers, such as teleseismic events or other spurious signals. The EventDetector is keyed to ShakeMap objectives, in that it detects events based on the exceedence of specified ground motion amplitudes at five or more stations. An additional component of the event detector is the development of automatic email alert capability. A "ShakeMail" alert is automatically sent to ShakeMail subscribers whenever ShakeMap is 
triggered. ShakeMail provides the magnitude, location, and PGV/PGA/PSA (f) values along with an expected MMI value for all stations. For subscribers who have a POLARIS station on-site (e.g. such as the POLARIS station at the Pickering Nuclear Power Plant), ShakeMail provides rapid direct information on shaking experienced by on-site facilities.

\subsection{Requirements for Implementing ShakeMap in Ontario}

The basic software needed to generate ground-shaking maps is the ShakeMap software package and its related programs developed by a group of researchers from the U.S Geological Survey, the California Institute of Technology and the Califomia Division of Mines and Geology (available at $\mathrm{ftp}: / /$ seismo.gps.caltech.edu/pub/shake). The ShakeMap software package consists of a number of modules written in Practical Extraction and Reporting Language (PERL). Within the PERL scripts other software packages are needed such as the Generic Mapping Tool (GMT; Wessel and Smith, 1991) to generate maps. All components of ShakeMap software were built from freely available, open-source packages (see ShakeMap Manual for details, available at http://pubs.usgs.gov/tm/2005/12A01/). ShakeMap was initially developed for southern California and needs a number of modifications in order to create ShakeMaps for earthquakes in Ontario.

Modifications include:

1. incorporation of region-specific features such as origin point of the estimate grid, station parameters/locations/names, contour interval, topography and major city name 
2. installing the Canadian SNAQS program (Seismic Network Acquisition Systems) developed by the Geological Survey of Canada (GSC) in order to stream near-real-time data from all Ontario stations into the program

3. incorporation of an event detector to determine when a significant event has occurred based on the real-time input stream

4. development of empirical relations that are appropriate for prediction of ground-motion amplitudes of events in Ontario over a wide range of magnitude and distance (M 2.0-6.0; distance 10-500 km)

5. development of relations between instrumental ground-motion parameters and felt-intensity (MMI) that are appropriate for Ontario

6. modification and implementation of the centroid program (Kanamori, 1993) to provide an initial estimate of magnitude and location

7. development of a grid of site amplification factors to describe typical soil response across Ontario

8. creating a web-site to display results in near-real-time

9. implementing an automatic email alert system 
Table 2.1 Description of MMI scale

(http://www.abag.ca.gov/bayarea/eqmaps/doc/mmi.html)

\begin{tabular}{|c|c|c|c|}
\hline MMI Value & \begin{tabular}{|c|} 
Description of \\
Shaking \\
Severity \\
\end{tabular} & $\begin{array}{c}\text { Summary } \\
\text { Damage } \\
\text { Description }\end{array}$ & Full Description \\
\hline I & & & $\begin{array}{l}\text { Not felt. Marginal and long period effects of large } \\
\text { earthquakes. }\end{array}$ \\
\hline II & & & $\begin{array}{l}\text { Felt by persons at rest, on upper floors, or } \\
\text { favorably placed. }\end{array}$ \\
\hline III & & & $\begin{array}{l}\text { Felt indoors. Hanging objects swing. Vibration like } \\
\text { passing of light trucks. Duration estimated. May } \\
\text { not be recognized as an earthquake. }\end{array}$ \\
\hline IV & & & $\begin{array}{l}\text { Hanging objects swing. Vibration like passing of } \\
\text { heavy trucks; or sensation of a jolt like a heavy ball } \\
\text { striking the walls. Standing motor cars rock. } \\
\text { Windows, dishes, doors rattle. Glasses clink. } \\
\text { Crockery clashes. In the upper range of IV, } \\
\text { wooden walls and frame creak. }\end{array}$ \\
\hline $\mathrm{V}$ & Light & Pictures Move & $\begin{array}{l}\text { Felt outdoors; direction estimated. Sleepers } \\
\text { wakened. Liquids disturbed, some spilled. Small } \\
\text { unstable objects displaced or upset. Doors swing, } \\
\text { close, open. Shutters, pictures move. Pendulum } \\
\text { clocks stop, start, change rate. }\end{array}$ \\
\hline VI & Moderate & Objects Fall & $\begin{array}{l}\text { Felt by all. Many frightened and run outdoors. } \\
\text { Persons walk unsteadily. Windows, dishes, } \\
\text { glassware broken. Knickknacks, books, etc., off } \\
\text { shelves. Pictures off walls. Furniture moved or } \\
\text { overturned. Weak plaster and masonry D cracked. } \\
\text { Small bells ring (church, school). Trees, bushes } \\
\text { shaken (visibly, or heard to rustle). }\end{array}$ \\
\hline VII & Strong & $\begin{array}{l}\text { Nonstructural } \\
\text { Damage }\end{array}$ & $\begin{array}{l}\text { Difficult to stand. Noticed by drivers of motor cars. } \\
\text { Hanging objects quiver. Furmiture broken. Damage } \\
\text { to masonry D, including cracks. Weak chimneys } \\
\text { broken at roof line. Fall of plaster, loose bricks, } \\
\text { stones, tiles, cornices (also unbraced parapets and } \\
\text { architectural ornaments). Some cracks in masonry } \\
\text { C. Waves on ponds; water turbid with mud. Small } \\
\text { slides and caving in along sand or gravel banks. } \\
\text { Large bells ring. Concrete irrigation ditches } \\
\text { damaged. }\end{array}$ \\
\hline VIII & Very Strong & $\begin{array}{l}\text { Moderate } \\
\text { Damage }\end{array}$ & $\begin{array}{l}\text { Steering of motor cars affected. Damage to } \\
\text { masonry C; partial collapse. Some damage to } \\
\text { masonry B; none to masonry A. Fall of stucco and } \\
\text { some masonry walls. Twisting, fall of chimneys, } \\
\text { factory stacks, monuments, towers, elevated tanks. } \\
\text { Frame houses moved on foundations if not bolted } \\
\text { down; loose panel walls thrown out. Decayed } \\
\text { piling broken off. Branches broken from trees. }\end{array}$ \\
\hline
\end{tabular}




\begin{tabular}{|c|l|l|l|}
\hline & & & $\begin{array}{l}\text { Changes in flow or temperature of springs and } \\
\text { wells. Cracks in wet ground and on steep slopes. }\end{array}$ \\
\hline IX & Violent & $\begin{array}{l}\text { Heavy } \\
\text { Damage } \\
\text { heneral panic. Masonry D destroyed; masonry C } \\
\text { heavily damaged, sometimes with complete } \\
\text { collapse; masonry B seriously damaged. (General } \\
\text { damage to foundations.) Frame structures, if not } \\
\text { bolted, shifted off foundations. Frames racked. } \\
\text { Serious damage to reservoirs. Underground pipes } \\
\text { broken. Conspicuous cracks in ground. In alluvial } \\
\text { areas sand and mud ejected, earthquake fountains, } \\
\text { sand craters. }\end{array}$ \\
\hline X & Very Violent & $\begin{array}{l}\text { Most masonry and frame structures destroyed with } \\
\text { their foundations. Some well-built wooden } \\
\text { structures and bridges destroyed. Serious damage } \\
\text { to dams, dikes, embankments. Large landslides. } \\
\text { Water thrown on banks of canals, rivers, lakes, etc. } \\
\text { Sand and mud shifted horizontally on beaches and } \\
\text { flat land. Rails bent slightly. }\end{array}$ \\
\hline XI & & $\begin{array}{l}\text { Rails bent greatly. Underground pipelines } \\
\text { completely out of service. }\end{array}$ \\
\hline XII & & $\begin{array}{l}\text { Damage nearly total. Large rock masses displaced. } \\
\text { Lines of sight and level distorted. Objects thrown } \\
\text { into the air. }\end{array}$ \\
\hline
\end{tabular}

Masonry A: Good workmanship, mortar, and design; reinforced, especially laterally, and bound together by using steel, concrete, etc.; designed to resist lateral forces.

Masonry B: Good workmanship and mortar; reinforced, but not designed in detail to resist lateral forces.

Masonry C: Ordinary workmanship and mortar; no extreme weaknesses like failing to tie in at corners, but neither reinforced nor designed against horizontal forces.

Masonry D: Weak materials, such as adobe; poor mortar; low standards of workmanship; weak horizontally.

Full descriptions are from: Richter, C.F., 1958. Elementary Seismology. W.H. Freeman and Company, San Francisco, pp. 135-149; 650-653. 


\section{Chapter 3 \\ Overview of Seismicity and the Geology of Ontario}

\subsection{Overview of Seismicity}

Figure 3.1 provides a nation-wide overview of the seismicity of Canada. While the Pacific Coast is the most earthquake-prone region in Canada, eastern Canada experiences a significant number of moderate-to-large earthquakes. The Geological Survey of Canada (GSC) (http://www.seismo.nrcan.gc.ca/nedb) locates an average of 300 earthquakes each year in eastern Canada. Only about fifteen of these measure greater than magnitude 3.0 or are reportedly felt by humans.

Eastern Canada, as part of intraplate eastern North America (ENA), is generally regarded as a tectonically stable region. There is no plate boundary within the region and no identified active faults. However, it still experiences significant moderate-to-large events. Among the significant ENA events were the M7.25, M7.0 New Madrid, Missouri, 1811 and 1812, M6.4 Charlevoix, 1925, M7.2 Grand Banks, 1929, M6.2 Temiskaming, 1935, M 5.8 Cornwall-Massena, 1944, M5.8 Saguenay, 1988, and M5.0 Au Sable Falks, 2002 events (where $\mathbf{M}$ is moment magnitude). All of these events, with the exception of the Saguenay and Au Sable Forks events, occurred before the installation of modern digital seismograph networks.

The causes of earthquakes in eastern Canada are not well understood. Most researchers attribute earthquakes in eastern Canada to movement along ancient fractures or regions of weakness in the earth's crust formed during pervious tectonic episodes, such as ancient rift structures (see Adams and Basham, 1989). The seismicity of eastern 
Canada is clustered in several regions as seen in Figure $3.1 \mathrm{~b}$ along a number of preweakened tectonic zones namely: the Western Quebec Seismic Zone (WQU), the Charlevoix Seismic Zone (CHV), the Lower St. Lawrence Seismic Zone (BSL), Northern Appalachians Seismic Zone (NAN), Laurentian Slope Seismic Zone (LSP), Eastern Northern Ontario (ENO) and Southern Great Lakes (SGL) (see Figure 3.1b).

In the following section I describe the WQU, CHV and BSL seismic zones due to their higher concentration of the earthquake clusters in the region. Moderate-to large eastern Canadian earthquakes are most likely to originate in one of these zones.

\subsubsection{Western Quebec Seismic Zone (WQU)}

The WQU seismic zone encloses the Ottawa Valley from Montreal to Temiskaming as well as the seismic activity in the Laurentians and eastern Ontario. Montreal, Ottawa, Hull and Cornwall are within this zone (see Figure 3.2a). It was in this zone that the M6.2 1935 Temiskaming and the M5.8 1944 Cornwall-Massena earthquakes occurred (felt-intensity ShakeMaps for both events are generated in Chapter 9). Most events in this zone concentrate along the Ottawa River and in the region from Montreal to Maniwaki. Forsyth (1981) suggests that most of the events of this zone are located near or within the boundaries of northeastern part of a Grenville (section 3.2.1) metasedimentary belt and near the junction of rift structures following the Ottawa and St. Lawrence Rivers and Lake Champlain. He concludes that although the seismicity may reflect adjustment to the resultant stress fields from regional density variations, continental deglaciation and intraplate forces, the reason for the greater seismic activity in the Grenville terrain than along the younger fault zones remains unclear. Adams and 
Basham (1989) proposed that the activity along the Ottawa Valley represents reactivation of Iapetan rift structures. They further proposed a hotspot traverse as a tectonic mechanism for the activity clustered in Western Quebec, by citing the presence of two sub-parallel mountain chains (i.e. the Monteregian and the New England Seamount). However, Lamontagne et al. (1994) refute the hotspot theory by citing a seismic void in one of the mountain chains (Monteregian chain), and further show that there is no such chain in the metasedimentary belt.

\subsubsection{Charlevoix Seismic Zone (CHV)}

Seismically, CHV is the most active zone in eastern Canada. This zone encloses an elongated region along the St. Lawrence River containing a number of cities and towns: Baie-St-Paul, La Malbaie, La Pocatiere and Riviere-de-Loup are with the active zones (see Figure 3.2b), while Quebec City lies just to its southwest. Figure 3.1c shows that most events in this zone are concentrated between La Malbaie and Riviere-de-Loup. In fact, a recent moderate earthquake of MN5.4 of March 6, 2005 occurred near Rivierede-Loup. Chapter 8 describes the Riviere-de-Loup event in detail. This zone has experienced a number of larger historical earthquakes: $M 7.0$ in 1663, M 6.0 in 1791, M 6.0 in 1860, M 6.5 in 1870, (www.seismo.nrcan.gc.ca/historic_eq/charpage_e.php) as well as moderate events: M 5.6 in 1939, M 5.2 in 1952, M 5.0 in 1979, M 4.2 in 1996 (Adams and Basham, 1989). Ellsworth (2000) showed that conditions are favourable for fault reactivation in this zone. Lamontagne and Ranalli (1997) suggest that within the $\mathrm{CHV}$, numerous pre-existing fractures are reactivated by local stress and or strength variations. They further indicate that not all CHV events are uniquely produced by pure 
reverse faulting, as is often the case in most of eastern Canada. They also implied that small magnitude earthquakes might be related to local stress variations, possibly in areas where high pore-fluid pressures are present. On the other hand, Wu and Hasegawa (1996) suggest that earthquakes in the region are likely triggered by rebound stress induced by the deglaciation of the late Pleistocene ice sheets, when optimally oriented pre-existing faults created by past tectonic processes and kept close to failure by current tectonic stress are reactivated by postglacial rebound.

\subsubsection{Lower St. Lawrence Seismic Zone (BSL)}

Every year, there are approximately 60 reported earthquakes of $M \geq 1$ in the Lower St. Lawrence seismic zone. Most of the events occur under the St. Lawrence River, along or between the St. Lawrence paleo-rift faults beneath the Logan's line and the Appalachians. (see Figure 3.2c). The St. Lawrence Valley represents an enormous break in the earth's crust. Daneshfar and Benn (2002) investigated the spatial relationships between the St.Lawrence fault zone and Lake Ontario and found that faults with NW-SE strikes are more likely to be seismically active than faults with other orientations. Their results suggest that a correlation can be made between surface expressions of faulting and patterns of recorded epicentres.

It is to be noted that due to attenuation and regional geological differences, eastern Canadian earthquakes are felt at much greater distances than those in western North America. For example, the M5.8 1988 Saguenay earthquake was felt to distance of $1000 \mathrm{~km}$; for comparison, the 1989 M6.9 Loma Prieta, Califormia earthquake was felt 
to similar distances $(965 \mathrm{~km})$, despite being 1.3 magnitude units larger (factor of more than 50 larger in energy).

\subsection{Geology of Ontario}

In this section, I summarize the general geology of Ontario, which is relevant to ShakeMap site amplifications. Most of the material discussed in this section, including the geology map, are taken from the resident geology program posted by the Ontario Ministry of Northern Development and Mines at http://www.mndm.gov.on.ca/mndm/mines/resgeol/provgeo_e.asp.

Ontario is characterized by diverse geology, whose rocks span an age range of about three billion years.

In general, Ontario can be subdivided into two geological regions, as shown in Figure 3.3.

1. the older, rugged Canadian Shield which underlies most of Ontario and

2. the younger, relatively flat-lying Borderlands which include the Hudson and James Bay Lowlands bordering the Canadian Shield on the north, and the Western and Central St. Lawrence Lowlands bordering the Canadian Shield to the south.

Within these broad regions, there are a number of sub-regions distinguished by their overall geological character.

\subsubsection{The Canadian Shield}

The Canadian Shield is subdivided into three main provinces (see Figure 3.3): 
1. the largest and oldest ( $>2.5$ billion years) Superior province which consists of alternating belts of volcanic, sedimentary and gneiss rocks. They represent the accreted remains of ancient continents and ocean basins. The Superior province is further subdivided into a number of subprovinces (shown in Figure 3.3) which will not be discussed. Rocks of this province contain plenty of metallic mineral wealth such as copper, zinc, gold as well as industrially useful materials (e.g. building stones).

2. the relatively younger (600 million to 2.5 billion) Proterozoic Southern province, which represents a zone of orgenesis that occurred about 1.8 billion years ago (i.e. mountain building such as large-scale folding, faulting and thrusting). They include the 1.8 million years old Sudbury Igneous complex which is rich in nickel as well as various other deposits of gold, silver, uranium, copper, industrial minerals and kimberlite, which is a major host rock for diamonds.

3. the youngest Grenville province (formed between 1200 and 1000 million, see details at http://brysonburke.com/grenville_arc_back_arc.html) which extends from near Philadelphia and New York City in the U.S. to the shores of Labrador in the north. It was the Grenville province where the first gold in Ontario was discovered and it also hosts deposits of various industrial minerals, building stone, iron, lead, zinc and uranium. Most earthquakes in eastern Canada, particularly in the WQU zones, are located in this province as discussed in Section 3.1.1 


\subsubsection{The Borderlands}

The borderlands represent sequences of younger ( $<600$ million years old) Phanerozoic sedimentary rocks deposited in basins during the periodic inundation of the early North America continent by inland seas. This deposition occurred in four major basins a) the Appalachian, b) Michigan, c) Moose River and d) Hudson Bay basins. In Ontario, they border the Canadian Shield on its northern, eastern and southern sides (the flat-lying sedimentary rocks beneath the Canadian Prairies represent another such basin on the western side of the Shield, outside of Ontario). These rocks contain deposits of a wide range of industrial minerals, salt, oil and gas.

\subsubsection{The Recent Deposits}

The recent deposits (Quaternary epoch) are primarily the products of multiple episodes of glaciation during the last 1.8 million years. These recent deposits include widespread layers of various sediments and landform deposits such as; glacial tills, drumlins, moraines, sand dunes and glacial escarpments. Quaternary deposits cover the majority of Ontario's bedrock. Some sediments were entrained by glaciers and deposited at a distance without being sorted. Other sediments were picked up and reworked by glacial melt water, or transported and deposited by river or wind action. Some sediments are organic or volcanic in origin. Sediments are classified according to the manner in which they were transported and deposited.

In this section, I briefly describe the various surficial materials of Ontario, as seen on Figure 3.4. Please note that Figure 3.4 is taken from the Atlas of Canada website (http://atlas.gc.ca/site/english/maps/environment/land/surficialmaterials). The properties of these materials are relevant to ShakeMap site amplifications. 
Glacial Deposits were transported by glaciers. The glaciers eroded outcrops as they encountered them, striating and polishing their surfaces. As they advanced, they pried up and carried away fragments of rock as well as most of the loose earth, which they later deposited as they melted.

Till is sediment that is transported and deposited by a glacier without being sorted by meltwater. It consists of clay, sand and large rock fragments that are deposited in irregular sheets or in ridges called moraines.

Fluvioglacial Deposits are glacial sediments that have been reworked by glacial meltwater. These features are produced by meltwater and ice. As the glacier recedes, the ice breaks into stagnant masses separated by lakes or flowing water. Sediments accumulate on, under and within these ice masses and are reworked by the meltwater to produce various features such as eskers, drumlins, kames, sheet deposits, terraces and deltas. In general, fluvioglacial sediments consist of sorted sand and gravel. Drumlins are elongated hills oriented in a direction parallel to the line of flow of the ice. Drumlins are found in large groups. They are composed of glacial materials and shaped by the passage of the overriding ice.

Glaciolacustrine Deposits are sediments deposited in glacial lakes. Glacial lakes form when meltwater is trapped between the front of a glacier and a moraine or rock wall that prevents drainage. Glaciolacustrine deposits consist primarily of well-stratified fine sand, silt and clay.

Glaciomarine Deposits are materials that are deposited on the sea floor by glacial meltwater, by debris flows from the surface of a glacier or by melting icebergs. Once the continent was relieved of the weight of the ice, it gradually rebounded and the ocean 
waters withdrew to form the shoreline we are familiar with today. As a result of this rebound effect, which is still a factor today, glaciomarine deposits are now exposed at places which may be far from the nearest modern-day oceans.

Colluvium or Colluvial Deposits consist of material that is produced by the erosion of rock walls and accumulates at the base of slopes under the action of gravity. These sediments may descend the slopes rapidly, as in the case of a rock fall, a landslide or solifluction, or slowly, as a result of freeze-thaw cycles, in a phenomenon known as creep.

Alluvium or Fluvial Deposits are sediment that is deposited by running water. It is comprised primarily of gravel, sand and silt. Alluvial sediments are sorted and sometimes stratified. They are found along current and ancient watercourses, in channels, alluvial plains, terraces, alluvial fans and deltas. These sediments are not glacial in origin.

Marine and Lacustrine Deposits have undergone the same sedimentation processes as glaciolacustrine and glaciomarine deposits but have accumulated in a non-glacial environment. Silts and clays are found in deep water, and gravels and sands in littoral zones. Coarse sediments (gravel and boulders) are deposited where currents are stronger, whereas fine sediments (sand, silt, clay) are characteristic of weaker currents.

Organic Deposits are rich in partially decomposed plant matter. They usually form and accumulate in poorly drained environments such as swamps and peat bogs.

Eolian Deposits are sediments that have been transported by wind. When the wind's speed drops and it can no longer hold sediment grains suspended in the air, the too-heavy grains are deposited in dunes or in a blanket over the surface of the ground. 
Volcanic Sediments include ash, lava and coarser debris ejected by erupting volcanoes. Sediments of this type were deposited in Canada thousands of years ago during the eruption of volcanoes in western Oregon, in Washington State, in southwestern British Columbia and in Alaska.

Sediment types in Ontario are predominantly glacial deposits. Glaciolacustrine silt and sand or silty clay till (some drumlinized) are common throughout southern Ontario. I will return to the subject of surficial materials in Ontario and their effects on ground motions in Chapter 7. 


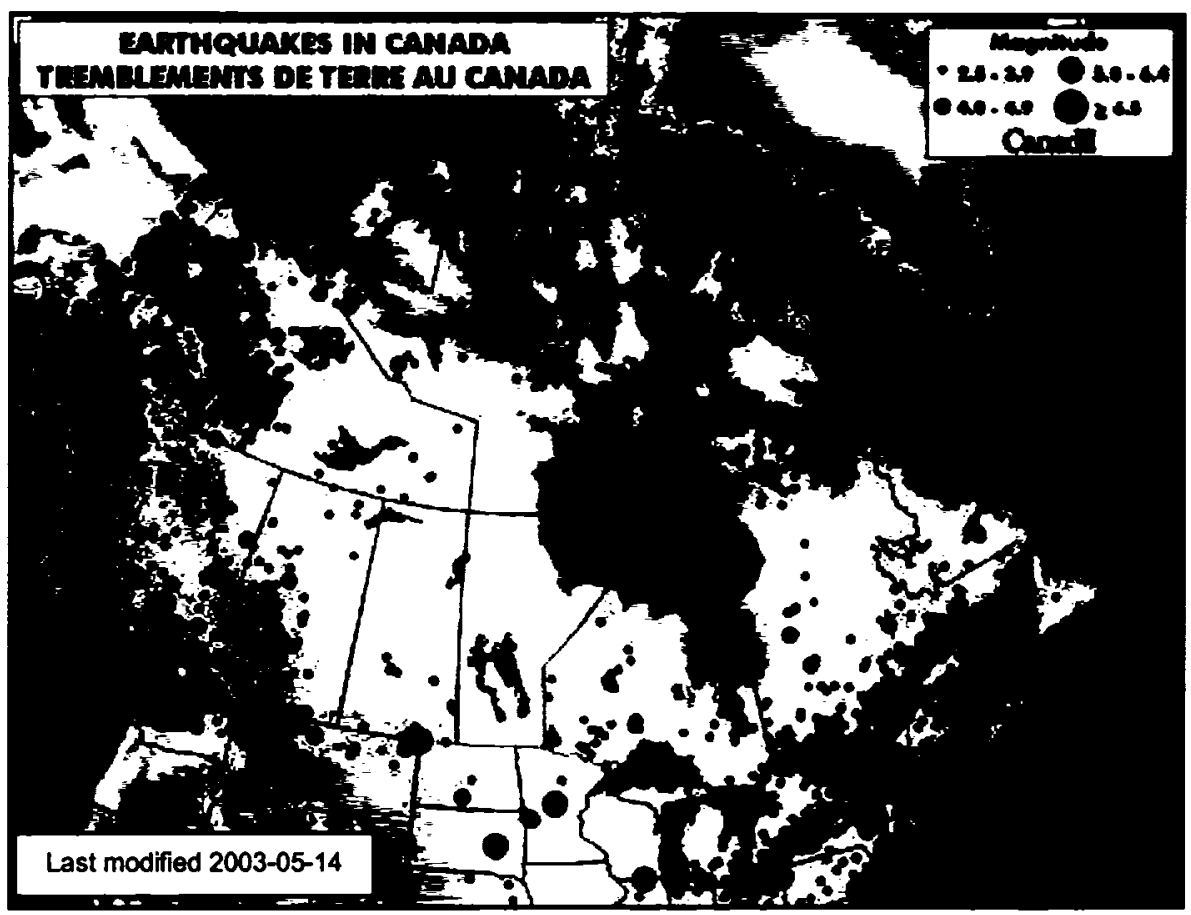

Figure 3.1 a Seismicity map of Canada (from http://www.seismo.nrcan.gc.ca/)

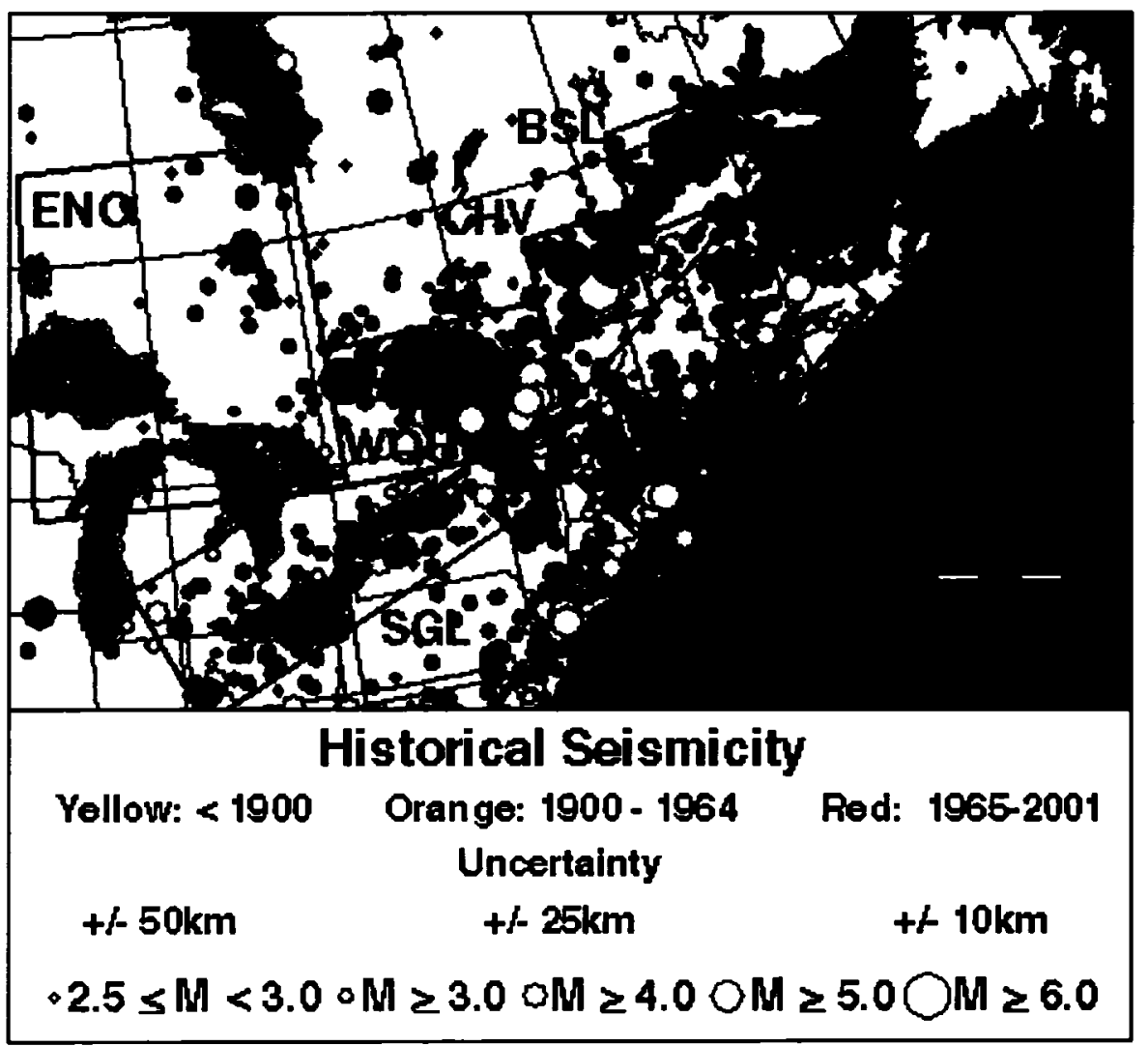

Figure 3.1 b. Seismicty map of eastern Canada (http://www.seismo.nrcan.gc.ca) 


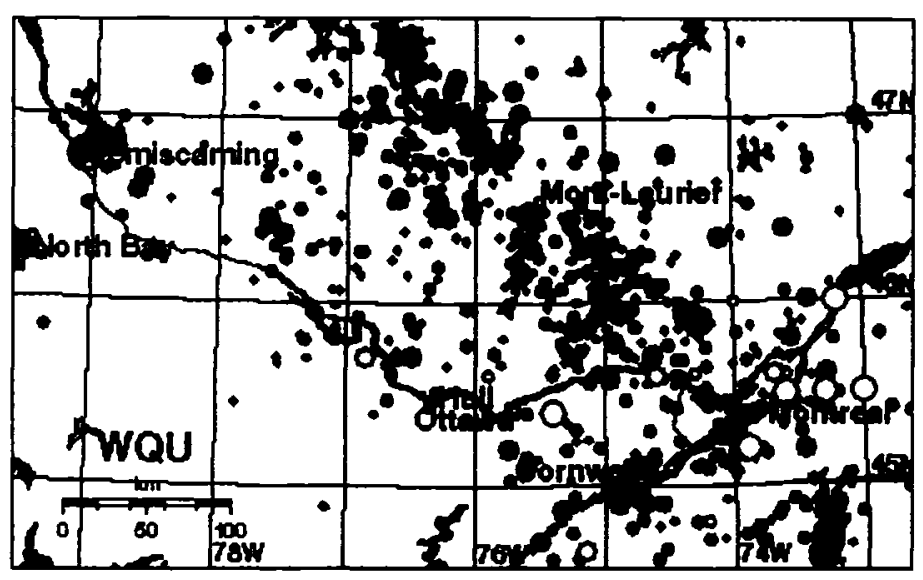

a) Western Quebec Seismic Zone

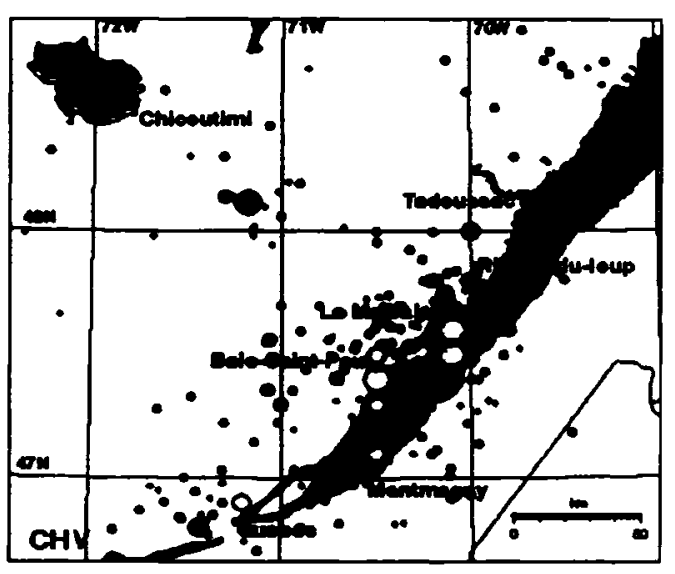

b) Charlevoix Seismic Zone

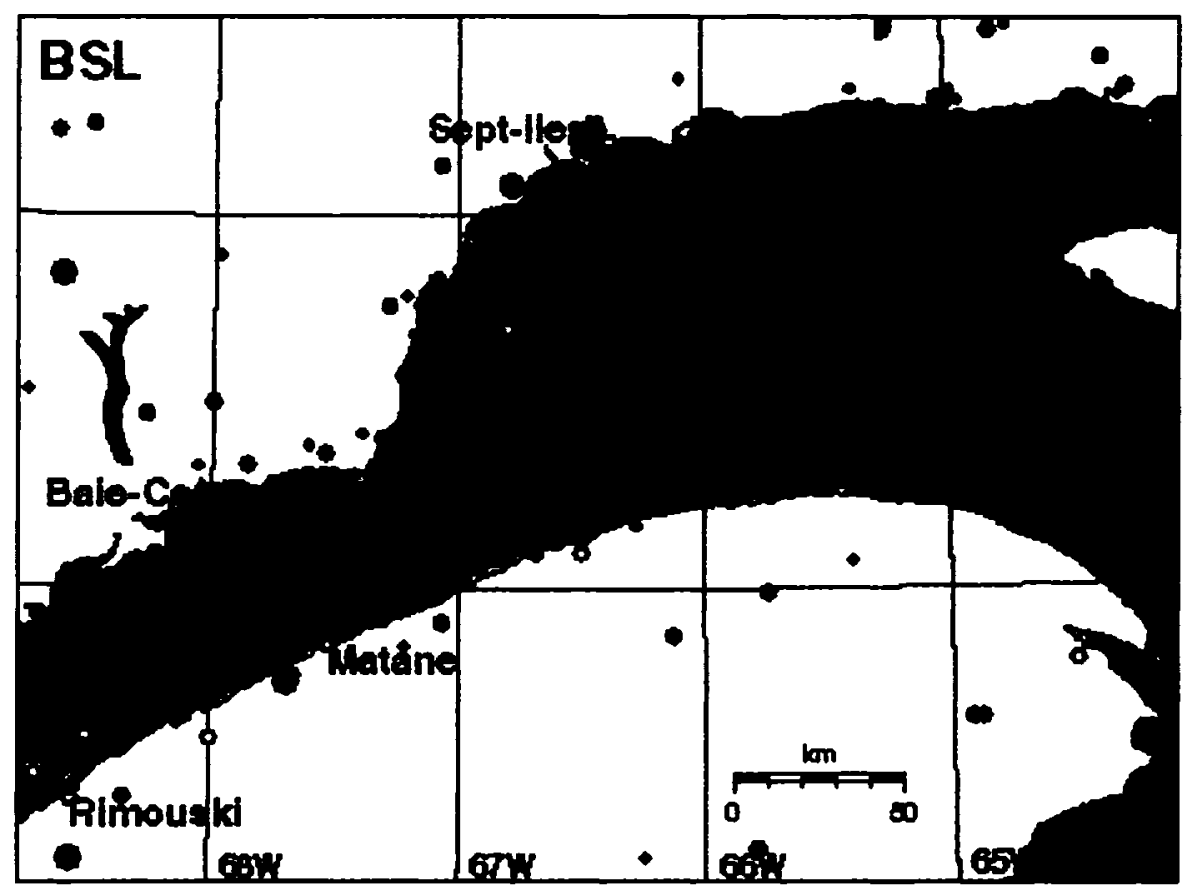

c) Lower St. Lawrence Seismic Zone

Figure 3.2 Major Seismic Zones in eastern Canada (from http://www.seismo.nrcan.gc.ca/) 


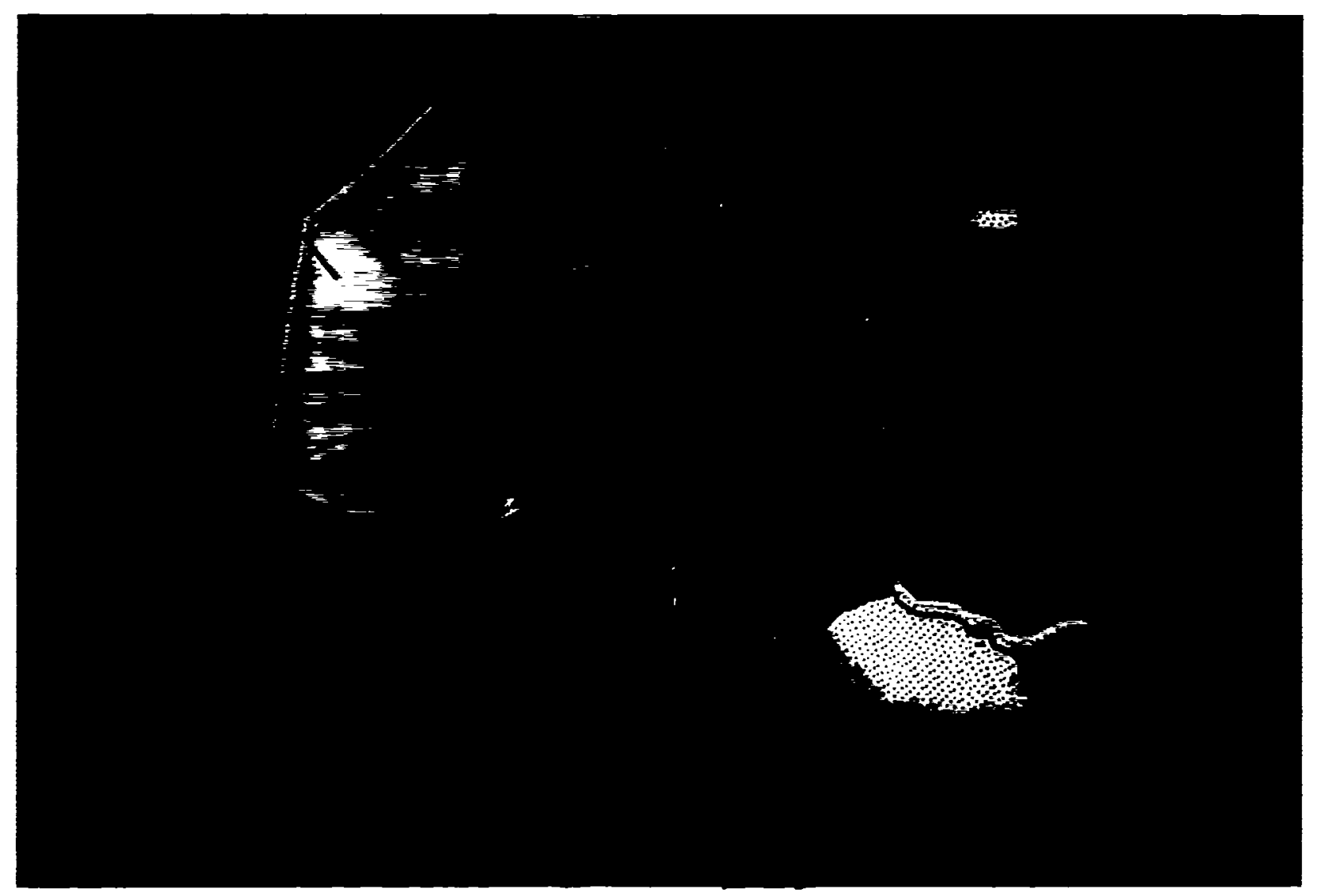

Figure 3.3 Simplified Geology map of Ontario

(http://www.mndm.gov.on.ca/mndm/mines/resgeol/provgeo e.asp) 


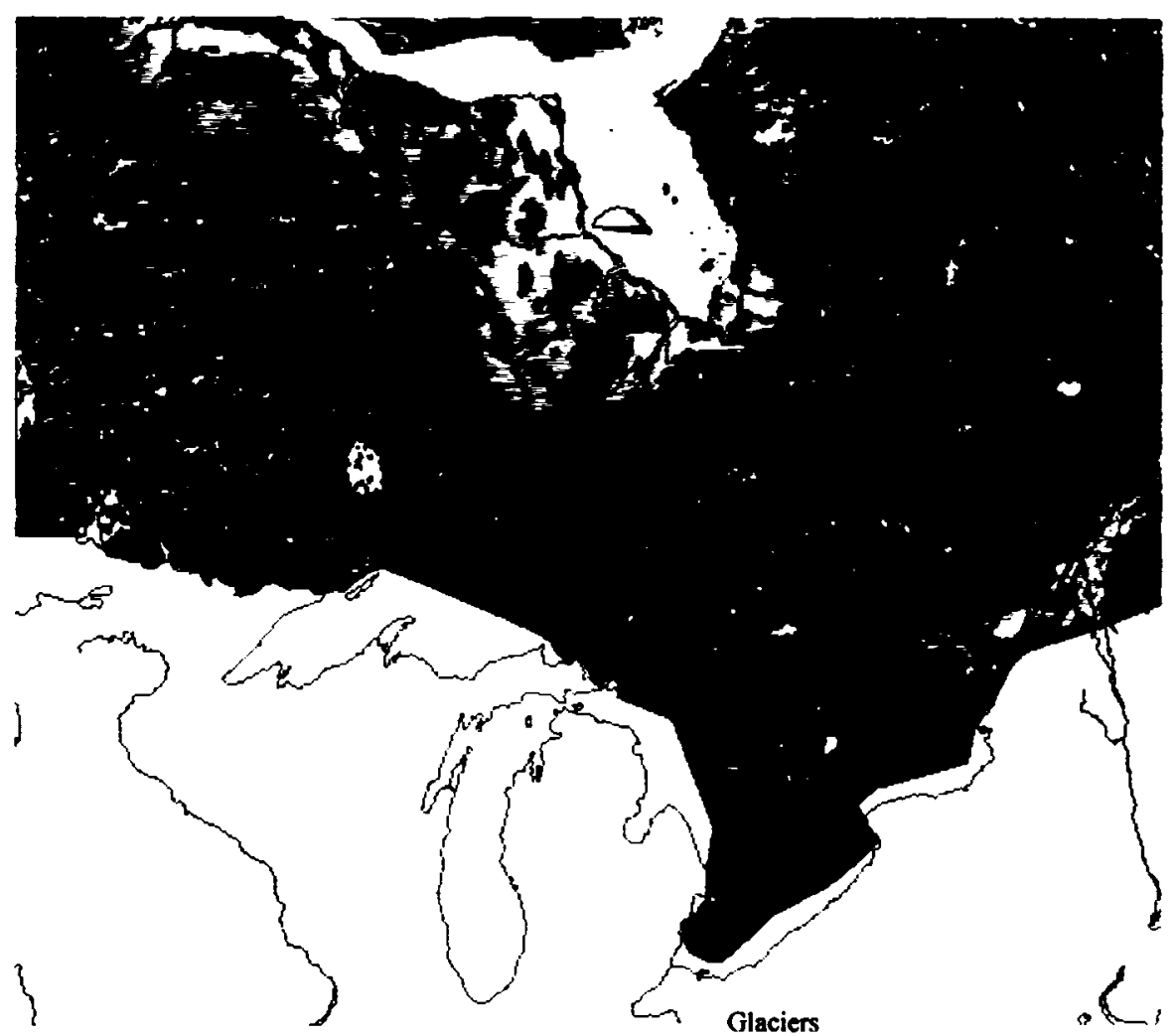

Figure 3.4 Surficial Materials for Ontario Region

(http://atlas.gc.ca/site/english/maps/environment/land/surficialmaterials)

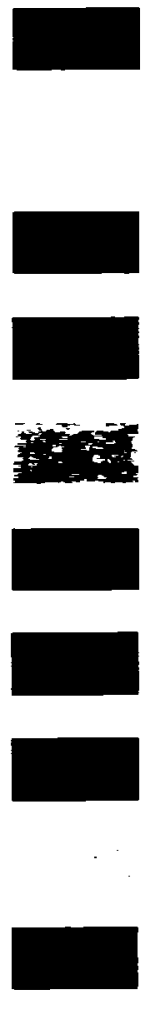

Glaciers

Alluvial

Marine Mud

Lacustrine Mud

Organic Deposits

Colluvial Blocks and Rubble

Fine Grained

Glaciolacustrine

Coarse Grained Glaciolacustrin

Fine Grained

Glaciomarine

Coarse Grained Glaciomarine

Lag Glaciomarine

Glaciofluvial Plain

Till Blanket

Till Veneer

Quatemary Volcanic Rock

Alpine Complexes

Undivided 


\section{Chapter 4}

\section{Implementation of Event Detector and Centroid Programs}

\subsection{Introduction}

Ontario ShakeMap requires continuous access to near-real-time data from the POLARIS network, and automated procedures to detect and locate earthquakes as they occur. Thus I developed an automated earthquake detection program "EventDetector" to detect events based on the incoming ground motion signals. An estimate of the earthquake location and magnitude is needed in calculating ground motion amplitudes in areas where there are no seismographic recording stations. I modified Kanamori's ground motion centroid program (Kanamori 1993) to locate the earthquake centroid and determine its magnitude for ShakeMap in Ontario. The focus in this application is on the prediction of ground motion amplitudes, rather than the actual earthquake magnitude and location. A particular challenge in ShakeMap development in Ontario and other areas of eastern North America is developing algorithms that are effective in a sparse network.

In this chapter, I describe an automated earthquake detection program "EventDetector" to continuously detect events and trigger ShakeMap in a sparse network. I also discuss the implementation of the centroid program to estimate the earthquake ground motion centroid and its moment magnitude in near-real-time once EventDetector detects an event. 


\subsection{Receiving Near-real-time Data}

The SNAQS program (Seismic Network Acquisition Systems) developed by the Geological Survey of Canada (GSC) is used to stream near-real-time data from Ontario POLARIS (Portable Observatories for Lithospheric Analysis and Research Investigating Seismicity) stations into the ShakeMap program. The locations of POLARIS stations that we currently monitor in near-real-time are shown, along with Nuttli magnitude (Mn) $\geq$ 2.8 events reported by the Geological Survey of Canada during 2004, in Figure 4.1. The data come in packets of six-seconds in duration and are saved in circular 'ringbuffers'. The SNAQS distribution contains a program called 'ringsniffer' that looks at the ringbuffer for one component of one station and organizes information about data packets to ensure that the data is read in time-contiguous order (as opposed to the raw unordered signal that comes over the network connection) (T. Cote, 2003, GSC, pers. Comm.).

\subsection{Event Detector}

"EventDetector" continuously reads data, detects events and triggers ShakeMap. It is designed to detect events based on the exceedence of specified ground motion amplitudes at five or more stations. We use the vertical component of peak ground velocity (PGV) as the amplitude parameter to define an event. Velocity is chosen because the instruments measure velocity. The vertical component is chosen because the site amplification of the vertical component is small enough to be neglected in most cases. (Note: the horizontal -to vertical component ratio technique for estimating site response is based on this assumption; see Beresnev and Atkinson, 1997; Siddiqqi and Atkinson, 2002). When the vertical component amplitude of PGV exceeds $0.008 \mathrm{~mm} / \mathrm{s}$ at any 
POLARIS Ontario station, after removal of long period noise and any linear trends, EventDetector examines the incoming data at all stations for a two-minute window. The length of the time window was chosen by determining the length of time required for seismic waves to reach the majority of the stations within the network, assuming that the first triggering station was nearest to the event. The amplitude of $0.008 \mathrm{~mm} / \mathrm{s}$ is near the felt threshold (Figure 4.2). ShakeMap is configured such that if five or more stations (including the trigger station) record $P G V \geq 0.003 \mathrm{~mm} / \mathrm{s}$, or eight or more stations record PGV $\geq 0.002 \mathrm{~mm} / \mathrm{s}$ within the 2-minute window, then the EventDetector will initiate the centroid program to calculate the location and magnitude. This initial triggering criteria is based on correlations between PGV, magnitude and distance of past recorded events as shown in Figure 4.2. Figure 4.2 (a) shows the recorded vertical component PGV as a function of distance and magnitude for more than 24-recorded events occurred in the region since 2003. Figure 4.2 (b) plots the recorded vertical component PGV for five typical felt-events in the region as a function of distance. For our network configuration (Figure 4.1), we can deduce by inspection of Figure 4.2 that all felt-events should be detected if we achieve a PGV threshold of $0.003 \mathrm{~mm} / \mathrm{s}$ at five or more stations. ShakeMap is configured such that if the centroid location is inside the network (42-48 N and $76-82 \mathrm{~W}$ ) and the centroid magnitude is above 2.8 , the ShakeMap program will be triggered. If the centroid falls outside the network, ShakeMap will only be triggered if the centroid magnitude is greater than 4.5. Figure 4.3 depicts a flowchart of the automated procedures to produce ShakeMap in near-real- time.

An important challenge in event detection is to screen out false triggers, such as teleseismic events or spurious signals. The normalized standard deviation of the PGV 
(normalized to the mean), denoted NSD, can be used to discriminate between local/regional and teleseismic events in most cases.

$$
N S D=\frac{\sqrt{\frac{1}{N} \sum_{i=1}^{N}\left(P G V_{i}-\overline{P G V}\right)^{2}}}{\overline{P G V}}
$$

where NSD is the normalized standard deviation and $\overline{P G V}$ is the mean PGV.

The NSD is a simple way to discriminate teleseismic events because such events should produce similar ground motions across the network. By contrast, regional events will produce large motions at nearby stations and small motions at distance, resulting in a large NSD. Observationally, I determined that events which have NSD $\leq 0.7$ can be considered teleseismic events (with a rate of $10 \%$ false triggers), as shown in Figure 4.4 and Tables 4.1 a and 4.1b. The NSD discriminant was added to EventDetector prior to the initiation of ShakeMap.

An additional component of the event detector is the development of an automatic email alert capability. Currently, there are two optional email alert systems. A rapid PGV alert is issued by email to interested parties, such as Ontario Power Generation (OPG), when the recorded $P G V$ exceeds $1 \mathrm{~mm} / \mathrm{s}$ (about $\mathrm{MMI} \cong 3$ ) at any specified stations of concern; the email provides the PGV values and the time it was recorded at each of the stations. A "shakemail" alert is automatically sent whenever ShakeMap is triggered. More detailed information is contained in the "shakemail" message, including the estimated magnitude and location, and PGV values along with an expected MMI value for all stations. An alternative to this "shakemail" capability is to $\log$ on to 
www.shakemap.carleton.ca and get full details on the ShakeMap events as they are posted. Both systems can be configured according to the needs of the recipient.

\subsection{Centroid Program}

The centroid program was originally developed by Kanamori (1993) to locate earthquakes using ground-motion amplitude data. The program aims to determine the centroid of the ground motions, which is the point from which the ground motions appear to radiate. This may not coincide with the actual epicentre, particularly in the case of an extended source. Kanamori (1993) used peak ground acceleration (PGA) as the amplitude parameter while we use the vertical component of peak ground velocity (PGV). PGV was chosen because it is the simplest and most rapidly available ground-motion parameter from our network stations. An important advantage in using the centroid program is near real-time estimation of the ground motion centroid (rather than waiting until an epicentre becomes available), thus speeding the generation of ShakeMaps. Our use of the centroid approach is a departure from practice in California and other regions of the U.S., where the epicentre is used. To my knowledge, the centroid concept has not actually been implemented in any other region, possibly because more rapid and reliable epicentres may be available elsewhere, where stations are more densely distributed.

\subsubsection{Centroid Location and Magnitude}

When an earthquake is detected, the "Centroid" program uses the vertical component peak amplitude data at all stations within the 2-minute window to find the 
location and magnitude of the event. The centroid is a geographic location near the largest recorded PGV, from which the ground motion appears to radiate, based on the pattern of observed amplitudes. The centroid magnitude is the earthquake magnitude that best explains the observed ground motion amplitudes, given the centroid location and regional ground motion relations that give $\mathrm{PGV}$ as a function of magnitude and distance.

To determine the centroid location and magnitude, I fit the vertical component PGV values recorded for the event to the empirical ground-motion relations developed in Chapter 6 (see also Kaka and Atkinson, 2005):

$$
\log Y=1.496+0.899(M-4)+0.029(M-4)^{2}-1.268 \log R-9.146 e-5 R
$$

where $\mathrm{Y}$ is the vertical-component $\mathrm{PGV}$ in $\mathrm{mm} / \mathrm{s}, \mathrm{R}$ is hypocentral distance in $\mathrm{km}$, and $\mathrm{M}$ is moment magnitude. A grid search technique is used to find the magnitude and location that minimizes the misfit to Equation 4.1.

Then, the ShakeMap program creates a rectangular grid of "phantom" stations, spaced at 0.3 degrees apart. The PGV values are estimated for all phantom stations using Equation 4.1, based on the centroid magnitude and location. The PGV estimation at "phantom" stations is necessary to constrain ShakeMap interpolations in areas where no actual records are available. However, phantom stations are ignored if there is an actual record available within $10 \mathrm{~km}$ of a phantom station. ShakeMap then uses a combination of the estimated PGV at phantom stations and the actual measured PGV at all seismographic recording stations to create a contour map of PGV.

Before creating a contour map, the vertical component PGV values are converted to the equivalent horizontal component in order to generate a horizontal component PGV map. This is done because the felt effects will be determined by the horizontal component 
motions. I use the average horizontal-to-vertical ratio ( $\mathrm{H} / \mathrm{V}$-ratio) of $\mathrm{PGV}$ at each POLARIS station to convert from the vertical to the horizontal component.

The horizontal-component PGV map is translated into a map of felt intensity, using the relation developed in Chapter 5 (see also Kaka and Atkinson, 2004):

$$
\mathrm{MMI}=4.08+1.79 \log \mathrm{Y}-0.28 \log \mathrm{R}
$$

where MMI is Modified Mercalli Intensity, $\mathrm{Y}$ is the horizontal-component $\mathrm{PGV}$ in $\mathrm{mm} / \mathrm{s}$ and $\mathrm{R}$ is hypocentral distance in $\mathrm{km}$. At this stage of development, it is assumed when predicting intensity that all sites across Ontario are a uniform firm-ground condition referred to as "NEHRP C" (Borcherdt, 1994); and amplifications are assigned accordingly, as described in Chapter 7. An exception is made for the locations of POLARIS stations, which are amplified according to their $\mathrm{H} / \mathrm{V}$ ratio. This will be refined as more surficial geology information becomes available to develop a grid of NEHRP site classification and corresponding site amplifications across the province. This is expected to be an ongoing project developed over the next several years. This aspect of the study is discussed in Chapter 7.

\subsection{Accuracy of PGV-estimation}

For ShakeMap, we are interested in the prediction of ground motions rather than the determination of the earthquake epicentre and magnitude. To examine how well the centroid program estimates PGV values, I analyzed thirty local/regional earthquakes of magnitude of 2.5 to 5.0 , comparing estimated PGV values obtained using the centroid location to those obtained using the epicentral location. In Figure 4.5, I plot the PGVresiduals (calculated by dividing each observed PGV by the predicted PGV) for the 
centroid and the epicentre as a function of distance for all stations. In Figure 4.6, PGVresiduals are plotted as a function of moment magnitude (M). $\mathbf{M}$ values for most of the events are taken from Atkinson (2004). However, for some small events, $M$ values were estimated from the empirical relationship given by Atkinson (1993a).

Figure 4.5 shows an apparent trend of decreasing residuals with increasing distance, for both the epicentral and centroid representations. Note that there is a significant underprediction of PGV near the earthquake source for the centroid solutions, but that this is partly due to the inaccuracy of the centroid in representing the actual location of the earthquake. For the epicentre case, the near-source residuals are more satisfactory, although the overall trend with distance is of course the same, resulting in overprediction of amplitudes at distances beyond $200 \mathrm{~km}$. This suggests that for cases where the centroid is close to the epicenter, the bias in estimated ground motion at distances less than $200 \mathrm{~km}$ will be small.

Similar residual trends with distance have been inferred by studying Fourier amplitude data from POLARIS stations in southern Ontario, in comparison to values expected based on regional ground motion models derived for all of eastern North America (Snider, 2005). Snider (2005) did not find any such trend when examining just those stations from eastern Ontario, which suggests that the residual-distance trend may be attributable to attenuation in southern Ontario that is slightly different from the average attenuation for all of ENA.

In order to interpret this unexpected residual-distance trend, I prepared a number of plots of the data trends of PGV with distance in various magnitude bins. Figure 4.7 shows typical plots (other magnitude bins indicate similar trends), in which I compare the 
attenuation of PGV for the data just in southern Ontario, with the attenuation of data from the larger eastern North America dataset used in deriving empirical ground-motion relations in Chapter 6. The corresponding simple equation used to predict PGV from distance and magnitude, for the upper and lower magnitude values of the data plotted, is also shown (equation as per Chapter 6).

Figure 4.7 suggests that there are two factors that cause the residual trends noted in southern Ontario. The first is an apparent "Moho bounce" effect (e.g. Atkinson, 2004) that makes the actual attenuation more complicated than the simple functional form used; this is manifested by a flattening in the observed decay of PGV near $100 \mathrm{~km}$, as waves reflected from the Moho join the direct waves at sites in this distance range. The equation smooths through this detail, leading to inaccuracies in the prediction. This is likely responsible for the larger ground-motion amplitudes seen at distance closer to epicentre. This trend implies an underestimate of intensity (by up to $1 \mathrm{MMI}$ unit) at close distances $(<30 \mathrm{~km})$. A second factor is that it appears that attenuation in southern Ontario is somewhat faster with distance than for ENA as a whole, particularly in the near-source region. The near-source data are still sparse, and this observation needs to be verified with additional data collected over time. Figure 4.7 has highlighted two specific issues that were not addressed in the development of empirical ground-motion relations (which were performed in an earlier phase of the study). The issue of "Moho bounce" complications in the shape of the attenuation function, and the apparently faster regional decay of ground-motion amplitudes in southern Ontario. Furthermore, the database used in deriving the empirical relations on which ShakeMap was founded does not include 22 recent significant small to moderate regional events (see Table 4.2). This highlights the 
need to continue to refine the models of attenuation that are included in ShakeMap as additional data are gathered by the program. The relations currently used in ShakeMap are the "first-generation" and can be significantly improved over the next year or two as data of this type make the definition of regional attenuation trends more robust. In the meantime, it should be kept in mind that limitations in the current relations imply that MMI may be underestimated by ShakeMap in the near-source region by up to 1 unit, and overestimated at large distances (hundreds of $\mathrm{km}$ ) by a similar amount.

No significant trend of residuals with magnitude is observed (see Figure 4.6). Overall the centroid performance in terms of predicting recorded ground motions appears to be satisfactory, subject to the caveats above. In fact, the MN 5.4 March 6, 2005 Riviere-du-Loup earthquake demonstrates that predicted PGV agree quite well with the recorded PGV (see Chapter 8). Use of the epicentre would not improve the residuals on average, but may better predict motions near the epicentre, in case no nearby stations are available. However, the centroid is available in near-real-time while the epicentre is not.

\subsection{Performance of ShakeMap}

Since the beginning of June 2004, prototype near-real-time ShakeMaps have been produced for earthquakes of $\mathrm{M}>2.8$ and are posted at our web site (http://www.shakemap.carleton.ca) within minutes of occurrence. Since our ShakeMap grid region is not as seismically active as other areas of Canada, we use a relatively low magnitude threshold (M 2.8); this typically results in 1-3 events per month. Information on moderate events is important in this region due to its high population and 
concentration of critical facilities. Since the events are generally small, ShakeMap is primarily an information service, rather than an emergency response tool.

In Table 4.2 and Figure 4.8 , we compare automatically posted near-real-time ShakeMap Centroid locations to those of the epicentral solutions/earthquake locations produced by the Canadian National Earthquake Database (NEDB) (http://www.seismo.nrcan.gc.ca/nedb/eq_db_e.php). Note that $\Delta \mathbf{M}$ in the table was calculated by converting NEDB Nuttli magnitude $(\mathrm{Mn})$ to $\mathbf{M}$ using the empirical relationship given by Atkinson (1993a):

$$
\mathbf{M}=-0.39+0.98 \mathrm{Mn}
$$

In Figure 4.9 we plot both solutions for local and regional events listed in Table 4.2, along with the contoured PGV values from ShakeMap. It is apparent from Figures 4.7 and 4.8 that the centroid provides a good location estimate in most cases, even with a limited number of recording stations. Reliable ShakeMaps can be produced for events of $\mathbf{M} \geq 2.8$ located within the network. If the epicentre falls outside the network, the centroid location will not generally coincide with the actual earthquake location; in this case ShakeMap will not provide a reliable estimate of the event location. However, ShakeMap still provides reasonable estimates of PGV and intensity values across the network.

\subsection{Conclusions}

For generating reliable near-real-time ShakeMaps for earthquakes in Ontario, I conclude that: 
1. events of $\mathbf{M} \geq 2.8$ within the network (42-48 $\mathrm{N}$ and $76-82 \mathrm{~W})$ can be detected based on the exceedence of peak ground motion amplitude of 0.003 $\mathrm{mm} / \mathrm{s}$ at five or more stations with NSD $>0.7$ (where NSD is the normalized standard deviation of the PGV normalized by the mean).

2. the ground motion centroid provides a suitable estimate of magnitude and location to estimate peak ground motion values for sparsely instrumented areas within the network. 
Table 4.1a. Teleseismic Events

\begin{tabular}{|r|l|r|r|r|r|r|}
\hline EventII & Region & Magnitude & Latitude & Longitude & NSD & $\begin{array}{r}\text { Distance } \\
\text { (in degree) }\end{array}$ \\
\hline 30526 & Japan & 6.9 & 38.93 & 141.51 & 0.2951 & 88.352 \\
\hline 30521 & Northern Nigeria & 6.7 & 36.89 & 3.78 & 0.2803 & 58.78 \\
\hline 30427 & Western Brazil & 5.9 & -8.14 & -71.51 & 0.6045 & 51.27 \\
\hline 30528 & Peru & 5.6 & -12.38 & -77.00 & 0.6950 & 55.028 \\
\hline 30429 & Kuril Islands & 6.0 & 43.72 & 147.73 & 0.3737 & 82.06 \\
\hline 30616 & Kamchatka,Russia & 6.8 & 55.54 & 159.9 & 0.3043 & 67.732 \\
\hline 30623 & Rat Islands, Aleutian Islands & 6.9 & 51.58 & 176.67 & 0.3284 & 63.2 \\
\hline 30620 & Central Chile & 6.9 & -30.55 & -71.32 & 0.2716 & 73.437 \\
\hline 30526 & Halmahera, Indonesia & 7.0 & 2.42 & 128.8 & 0.4065 & 126.83 \\
\hline 30514 & North Atlantic Ocean & 6.4 & 18.24 & 58.61 & 0.3996 & 104.85 \\
\hline 30518 & Argentina & 5.5 & -31.28 & -68.66 & 0.3116 & 74.442 \\
\hline 30519 & Colima, Mexico & 5.7 & 17.46 & -105.53 & 0.4463 & 33.335 \\
\hline 30524 & Central Peru & 5.6 & -14.52 & -71.44 & 0.7526 & 57.57 \\
\hline 30317 & Rat Islands, Aleutian Islands & 6.8 & 51.49 & 177.87 & 0.6353 & 62.662 \\
\hline 30310 & Indonesia & 6.1 & 1.74 & 127.25 & 0.3733 & 127.509 \\
\hline 30302 & Japan & 5.5 & 37.81 & 141.65 & 0.1821 & 90.15 \\
\hline 30429 & Alabama, US & 4.5 & 34.55 & -85.5 & 0.4457 & 9.384 \\
\hline 30507 & Mongolia & 5.5 & 48.53 & 89.54 & 0.4027 & 85.28 \\
\hline 30527 & Argentina & 5.7 & -31.23 & -68.21 & 0.3408 & 74.448 \\
\hline 30620 & Brazil & 6.7 & -7.5 & -71.62 & 0.5475 & 50.625 \\
\hline
\end{tabular}

Table 4.1b. Local/Regional Events

\begin{tabular}{|l|l|c|r|r|r|r|}
\hline EventID & \multicolumn{1}{|c|}{ Region } & Magnitude & Latitude & Longitude & NSD & $\begin{array}{r}\text { Distance } \\
\text { (in degree) }\end{array}$ \\
\hline 30323 & LakeErie, Ontario & 2.3 & 42.19 & -80.19 & 1.1425 & 0.771 \\
\hline 30121 & PortHope, Ontario & 2.9 & 43.76 & -77.97 & 1.04817 & 0.35 \\
\hline 30417 & Maniwaki, Ontario & 2.9 & 46.08 & -75.69 & 0.8838 & 0.407 \\
\hline 30128 & Comwall, Ontario & 3 & 45.31 & -74.92 & 1.5345 & 0.401 \\
\hline 21107 & Belleville, Ontario & 3 & 44.07 & -77.44 & 1.1839 & 0.354 \\
\hline 30225 & Maniwaki, Québec & 3 & 46.6 & -76.53 & 1.1025 & 0.462 \\
\hline 30314 & Pembroke, Ontario & 3.1 & 45.66 & -77.36 & 1.8057 & 0.08 \\
\hline 30228 & La Malbaie, Québec & 3.3 & 47.5 & -70.03 & 3.0152 & 0.0333 \\
\hline 30209 & Mont-Laurier, Québec & 3.3 & 46.51 & -75.2 & 1.8397 & 0.466 \\
\hline 20528 & Renfrew, Ontario & 3.4 & 45.63 & -76.62 & 0.6182 & 0.67 \\
\hline 30413 & Quebec & 3.4 & 46.94 & -71.16 & 1.1355 & 0.724 \\
\hline 30630 & Ohio, USA & 3.6 & 41.7 & -81.11 & 1.1343 & 1.454 \\
\hline 30408 & Cornwall, Ontario & 3.7 & 44.63 & -74.36 & 1.2261 & 0.752 \\
\hline 20420 & Plattsburg,NX, USA & 5.1 & 44.51 & -73.7 & 1.184 & 0.66 \\
\hline 30613 & Charlevoix, Québec & 4.1 & 47.7 & -70.09 & 2.5222 & 0.007 \\
\hline 30104 & Baie-Comeau, Québec & 3.4 & 49.6 & -67.24 & 1.9147 & 0.08 \\
\hline 30323 & Matane, Québec & 3.3 & 48.86 & -67.87 & 2.0465 & 0.4623 \\
\hline 30109 & Lachute, Québec & 2.9 & 45.59 & -74.46 & 0.6598 & 0.6 \\
\hline
\end{tabular}




\section{Table 4.2. Comparing ShakeMap with the Canadian National}

Earthquake Database (NEDB) Solution

\begin{tabular}{|c|c|c|c|c|c|c|c|}
\hline \multirow[t]{2}{*}{ No } & \multirow{2}{*}{$\frac{\text { Event }}{\text { Date and Time }}$} & \multicolumn{2}{|c|}{ ShakeMap-solution } & \multicolumn{2}{|c|}{ NEDB-solution } & \multirow[b]{2}{*}{$\Delta \mathbf{M}$} & \multirow[b]{2}{*}{$\Delta \mathrm{R}(\mathrm{km})$} \\
\hline & & $\mathbf{M}$ & Centroid & $\mathrm{Mn}$ & Epicentre & & \\
\hline 1 & $2004 / 06 / 1606: 31: 27$ & 2.8 & $42.66 \mathrm{~N} 79.25 \mathrm{~W}$ & 3.1 & $42.79 \mathrm{~N} 79.08 \mathrm{~W}$ & 0.15 & 20 \\
\hline 2 & $2004 / 06 / 2106: 10: 59$ & 2.3 & $46.60 \mathrm{~N} 81.20 \mathrm{~W}$ & 2.8 & $46.47 \mathrm{~N} 81.16 \mathrm{~W}$ & -0.05 & 15 \\
\hline 3 & $2004 / 06 / 2806: 10: 52$ & 3.5 & $43.96 \mathrm{~N} 82.99 \mathrm{~W}$ & 4.7 & $41.35 \mathrm{~N} 89.03 \mathrm{~W}$ & -0.72 & 572 \\
\hline 4 & $2004 / 06 / 3004: 03: 16$ & 3.2 & $42.76 \mathrm{~N} 82.13 \mathrm{~W}$ & 3.3 & $41.84 \mathrm{~N} 81.19 \mathrm{~W}$ & 0.36 & 128 \\
\hline 5 & $2004 / 07 / 01 \quad 19: 41: 43$ & 2.1 & $43.49 \mathrm{~N} 79.60 \mathrm{~W}$ & 2.1 & $43.49 \mathrm{~N} 79.50 \mathrm{~W}$ & 0.43 & 8 \\
\hline 6 & $2004 / 07 / 1506: 29: 39$ & 3.4 & $46.54 \mathrm{~N} 81.33 \mathrm{~W}$ & 3.5 & $46.49 \mathrm{~N} 81.16 \mathrm{~W}$ & 0.36 & 14 \\
\hline 7 & $2004 / 08 / 0423: 55: 26$ & 3.7 & $44.05 \mathrm{~N} 78.02 \mathrm{~W}$ & 3.8 & $43.68 \mathrm{~N} 78.24 \mathrm{~W}$ & 0.37 & 45 \\
\hline 8 & $2004 / 08 / 0521: 04: 44$ & 2.3 & $45.67 \mathrm{~N} 80.18 \mathrm{~W}$ & 2.3 & $45.37 \mathrm{~N} 79.75 \mathrm{~W}$ & 0.44 & 47 \\
\hline 9 & $2004 / 09 / 04$ 02:05:31 & 2.7 & $45.09 \mathrm{~N} 75.35 \mathrm{~W}$ & 3.1 & $44.89 \mathrm{~N} 74.92 \mathrm{~W}$ & -0.50 & 40 \\
\hline 10 & $2005 / 01 / 1312: 00: 58$ & 2.7 & $45.60 \mathrm{~N} 74.80 \mathrm{~W}$ & 2.7 & $45.69 \mathrm{~N} 74.89 \mathrm{~W}$ & 0.44 & 10 \\
\hline 11 & $2005 / 01 / 3018: 06: 45$ & 3.5 & $48.20 \mathrm{~N} 79.20 \mathrm{~W}$ & 3.8 & $48.13 \mathrm{~N} 77.97 \mathrm{~W}$ & 0.17 & 91 \\
\hline 12 & $2005 / 02 / 2611: 12: 00$ & 2.7 & $46.60 \mathrm{~N} 81.20 \mathrm{~W}$ & 2.9 & $46.53 \mathrm{~N} 80.99 \mathrm{~W}$ & 0.25 & 18 \\
\hline 13 & $2005 / 03 / 03$ 02:22:01 & 3.1 & $44.80 \mathrm{~N} 74.60 \mathrm{~W}$ & 3.5 & $45.06 \mathrm{~N} 74.20 \mathrm{~W}$ & 0.06 & 43 \\
\hline 14 & $2005 / 03 / 0601: 17: 49$ & 5.0 & $47.60 \mathrm{~N} 69.80 \mathrm{~W}$ & 5.4 & $47.75 \mathrm{~N} 69.73 \mathrm{~W}$ & 0.10 & 17 \\
\hline 15 & $2005 / 03 / 1317: 08: 14$ & 3.4 & $46.80 \mathrm{~N} 81.40 \mathrm{~W}$ & 3.6 & $46.54 \mathrm{~N} 80.98 \mathrm{~W}$ & 0.27 & 43 \\
\hline 16 & $2005 / 03 / 28 \quad 16: 39: 38$ & 3.2 & $43.40 \mathrm{~N} 79.00 \mathrm{~W}$ & 3.1 & $43.33 \mathrm{~N} 79.29 \mathrm{~W}$ & 0.56 & 25 \\
\hline 17 & $2005 / 03 / 3115: 13: 08$ & 3.0 & $45.80 \mathrm{~N} 76.80 \mathrm{~W}$ & 3.4 & $46.28 \mathrm{~N} 75.64 \mathrm{~W}$ & 0.06 & 104 \\
\hline 18 & $2005 / 06 / 2318: 32: 08$ & 3.0 & $46.46 \mathrm{~N} 75.49 \mathrm{~W}$ & 3.3 & $46.06 \mathrm{~N} 75.05 \mathrm{~W}$ & 0.15 & 56 \\
\hline 19 & $2005 / 07 / 0411: 47: 13$ & 3.3 & $45.83 \mathrm{~N} 77.90 \mathrm{~W}$ & 3.6 & $46.24 \mathrm{~N} 76.91 \mathrm{~W}$ & 0.16 & 89 \\
\hline 20 & $2005 / 09 / 0614: 10: 51$ & 3.2 & $46.00 \mathrm{~N} 75.51 \mathrm{~W}$ & 3.6 & $46.27 \mathrm{~N} 75.29 \mathrm{~W}$ & 0.06 & 34 \\
\hline 21 & $2005 / 10 / 2021: 16: 29$ & 4.0 & $44.72 \mathrm{~N} 81.03 \mathrm{~W}$ & 4.2 & $44.66 \mathrm{~N} 80.40 \mathrm{~W}$ & 0.27 & 50 \\
\hline 22 & $2005 / 10 / 2515: 29: 03$ & 3.0 & $46.26 \mathrm{~N} 78.50 \mathrm{~W}$ & 3.3 & $46.87 \mathrm{~N} 78.83 \mathrm{~W}$ & 0.16 & 72 \\
\hline
\end{tabular}




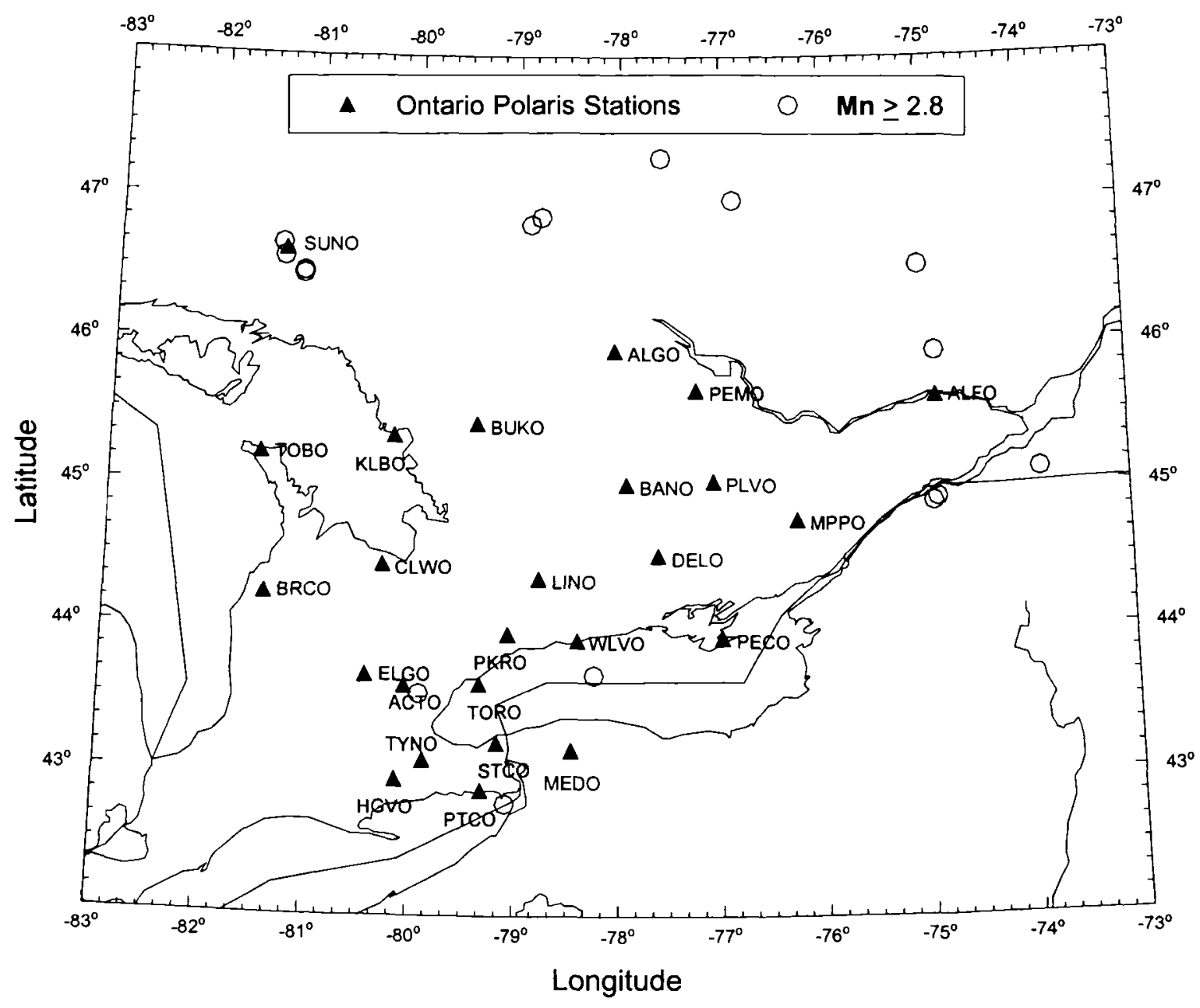

Figure 4.1. Locations of Ontario POLARIS stations along with $\mathrm{Mn} \geq 2.8$ events reported by the Geological Survey of Canada during 2004. 
a)

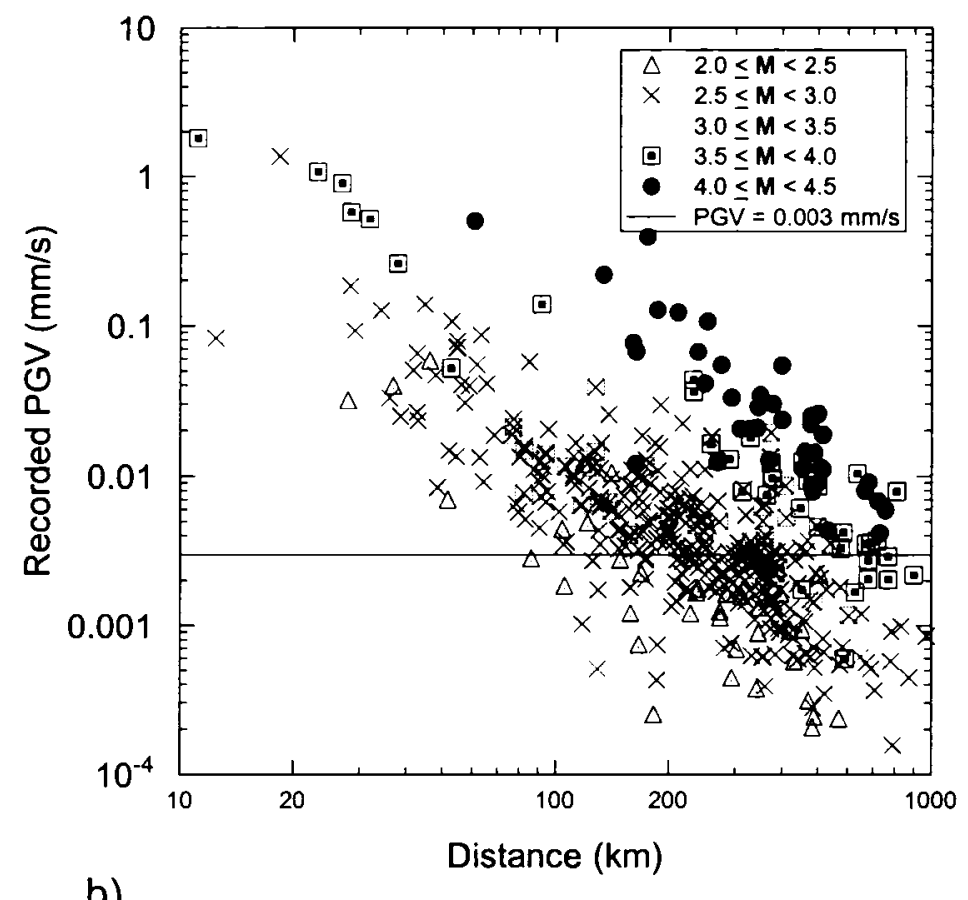

b)

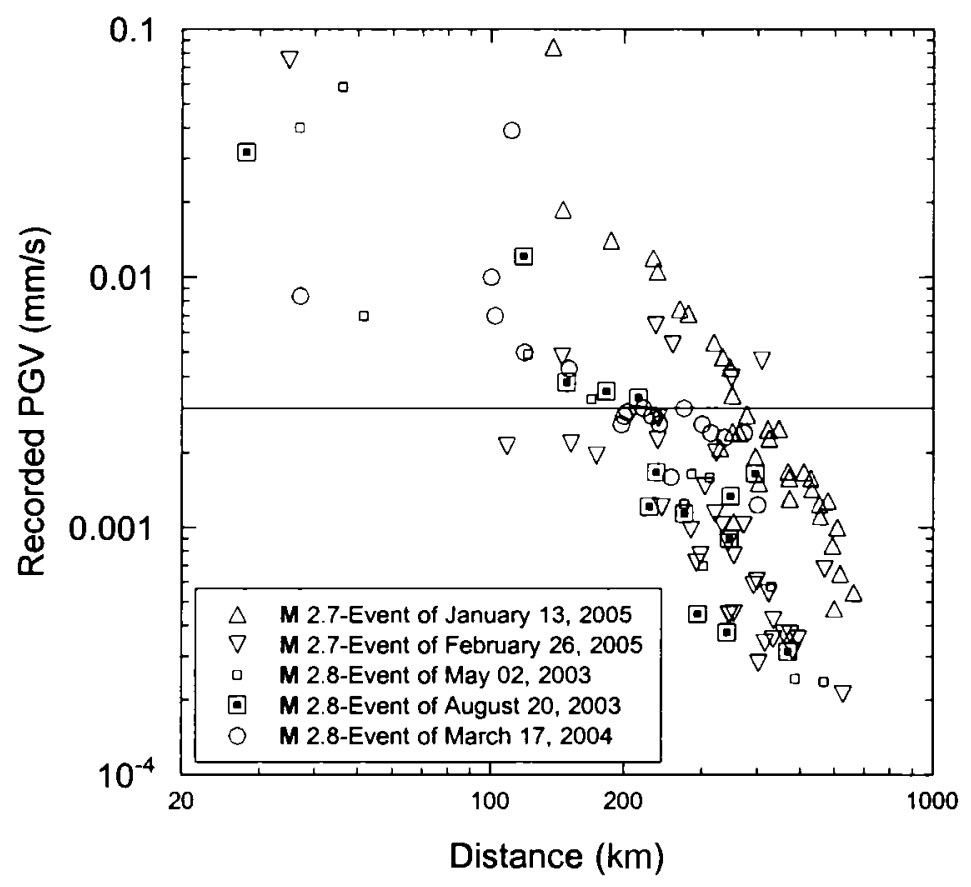

Figure 4.2. The recorded vertical component PGV is plotted as a function of magnitude and distance for:

a) more than 24 recorded events that occurred in the region since 2003

b) five typical felt-events in the region 


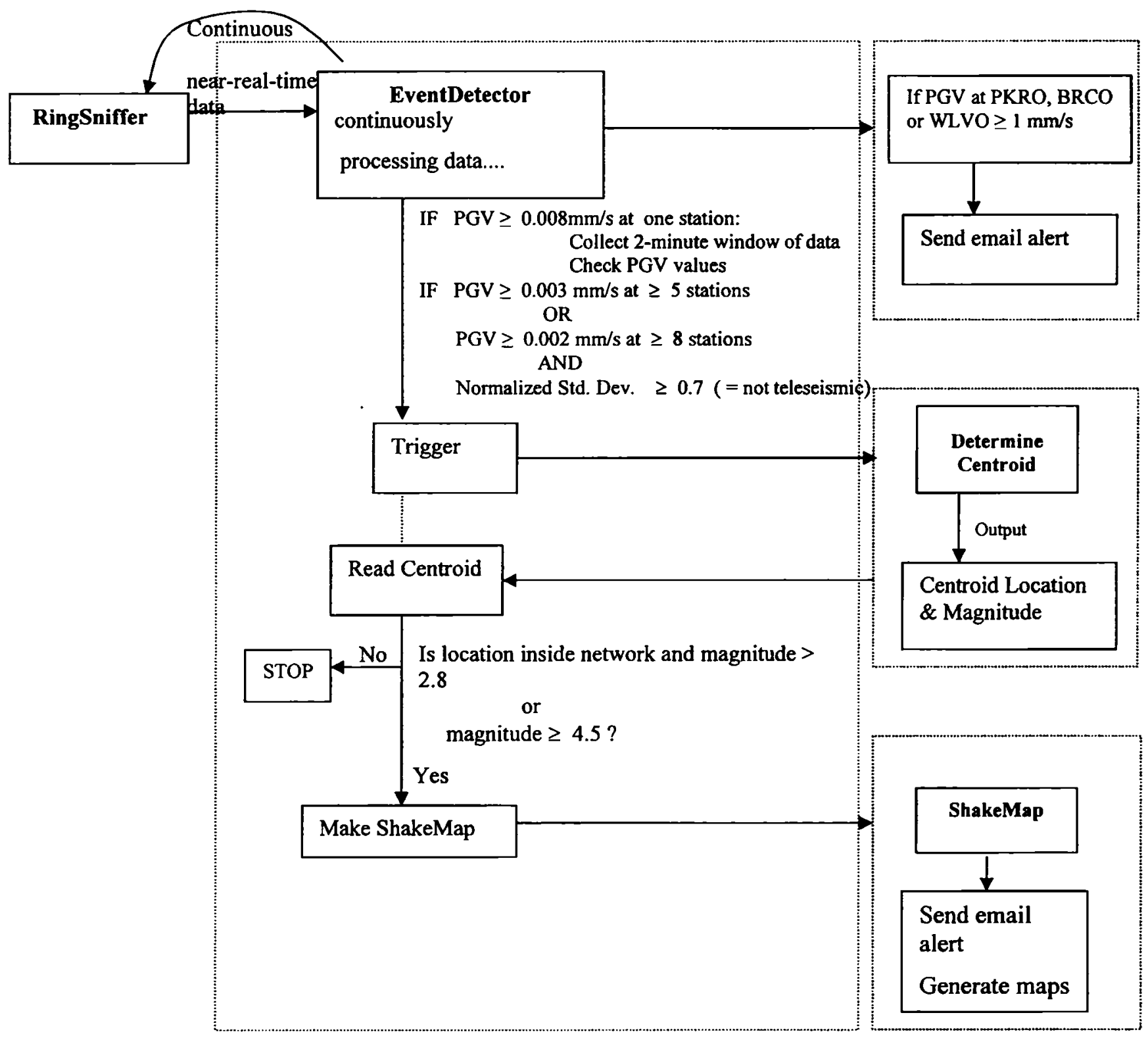

Figure 4.3 Flowchart of the automated procedures to produce ShakeMap in near-realtime. 


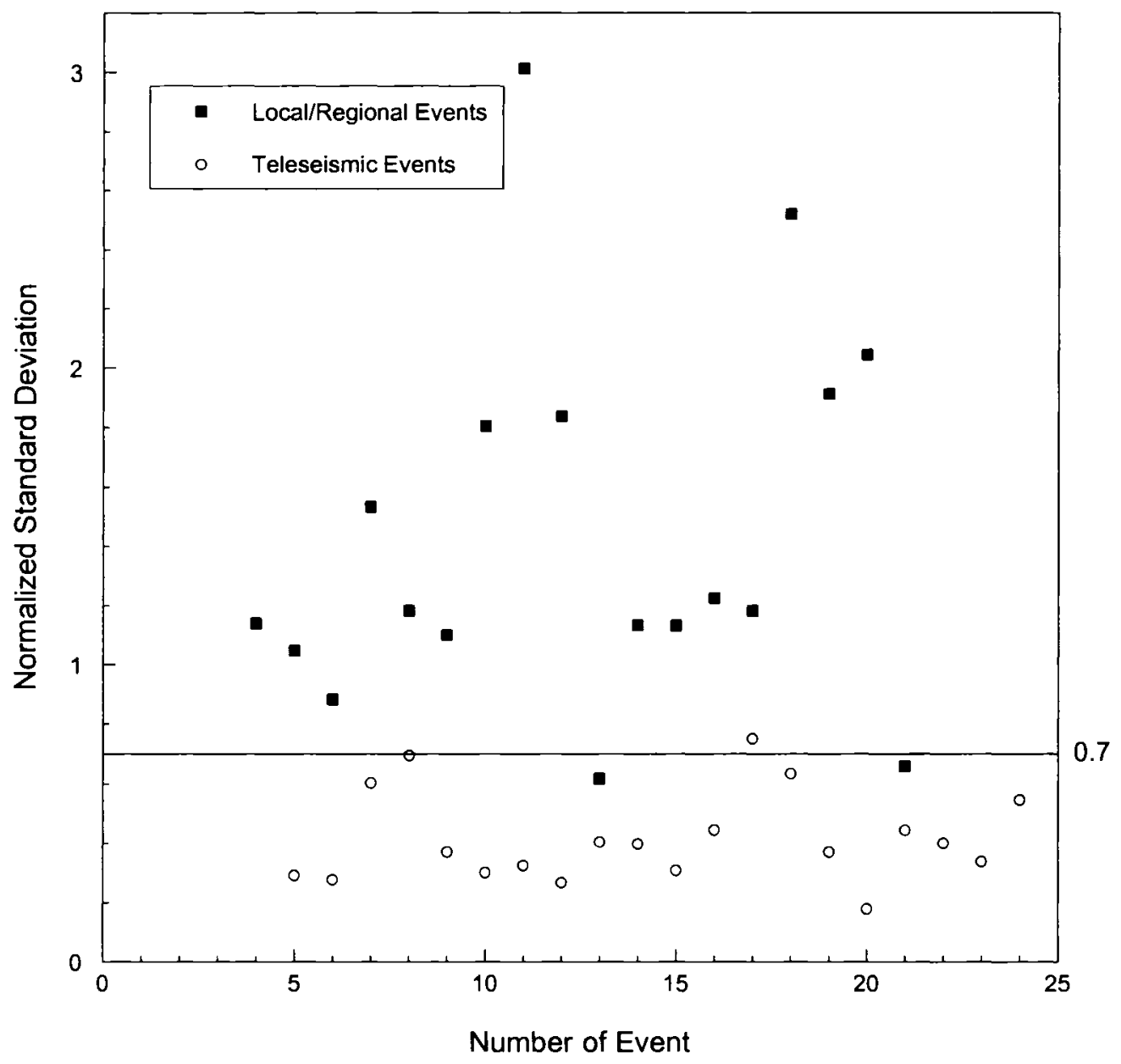

Figure 4.4 The normalized standard deviation of the PGV (normalized to the mean) plotted against local/regional events (filled square) and teleseismic events (circle) to discriminate between local/regional and teleseismic events. An event is considered teleseismic if NSD $\leq 0.7$. 

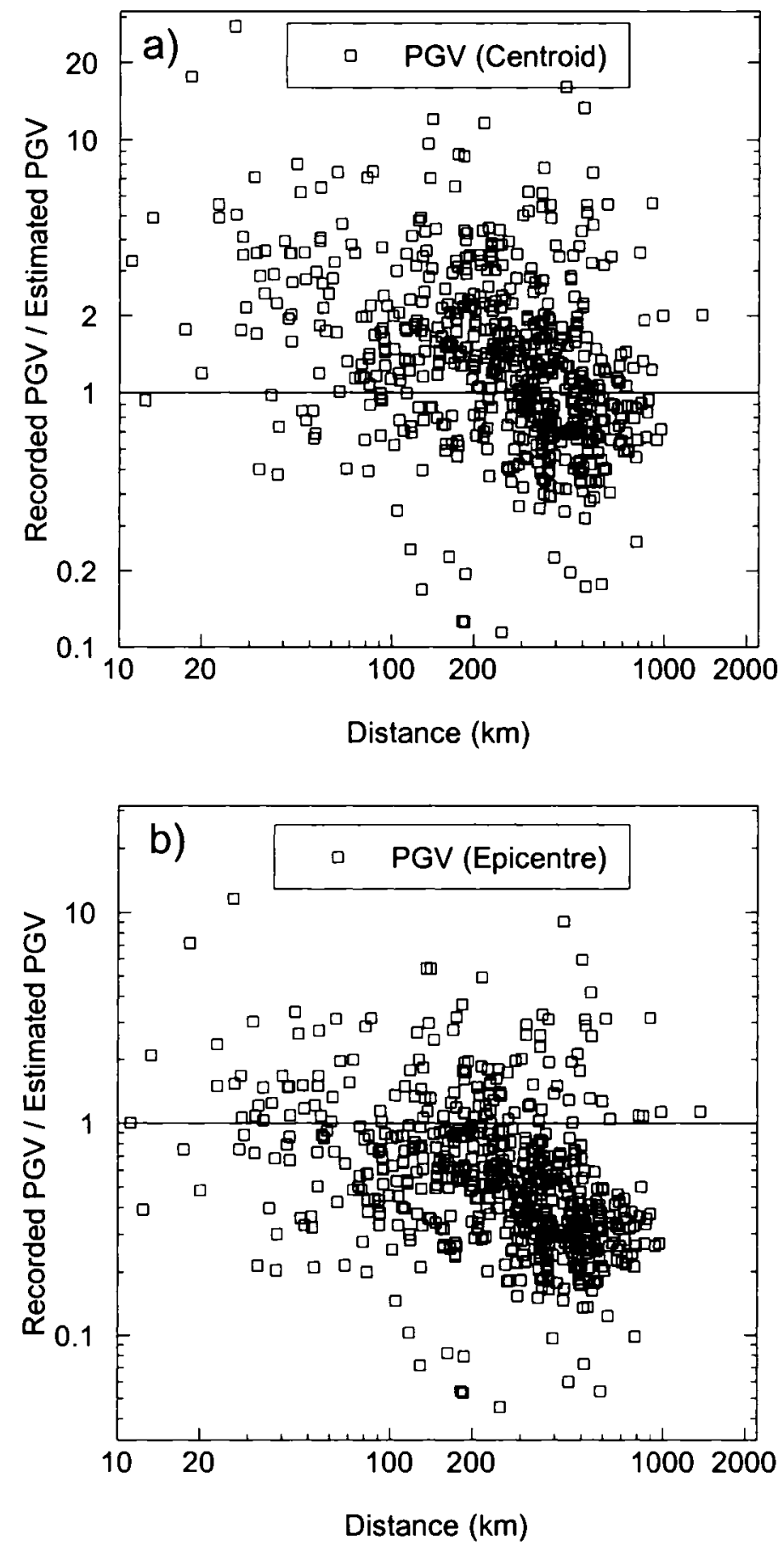

Figure 4.5 Ratio of actual recorded PGV to estimated PGV as a function of distance:

a) PGV- estimated from centroid location and magnitude

b) PGV-estimated from epicentre location and magnitude 

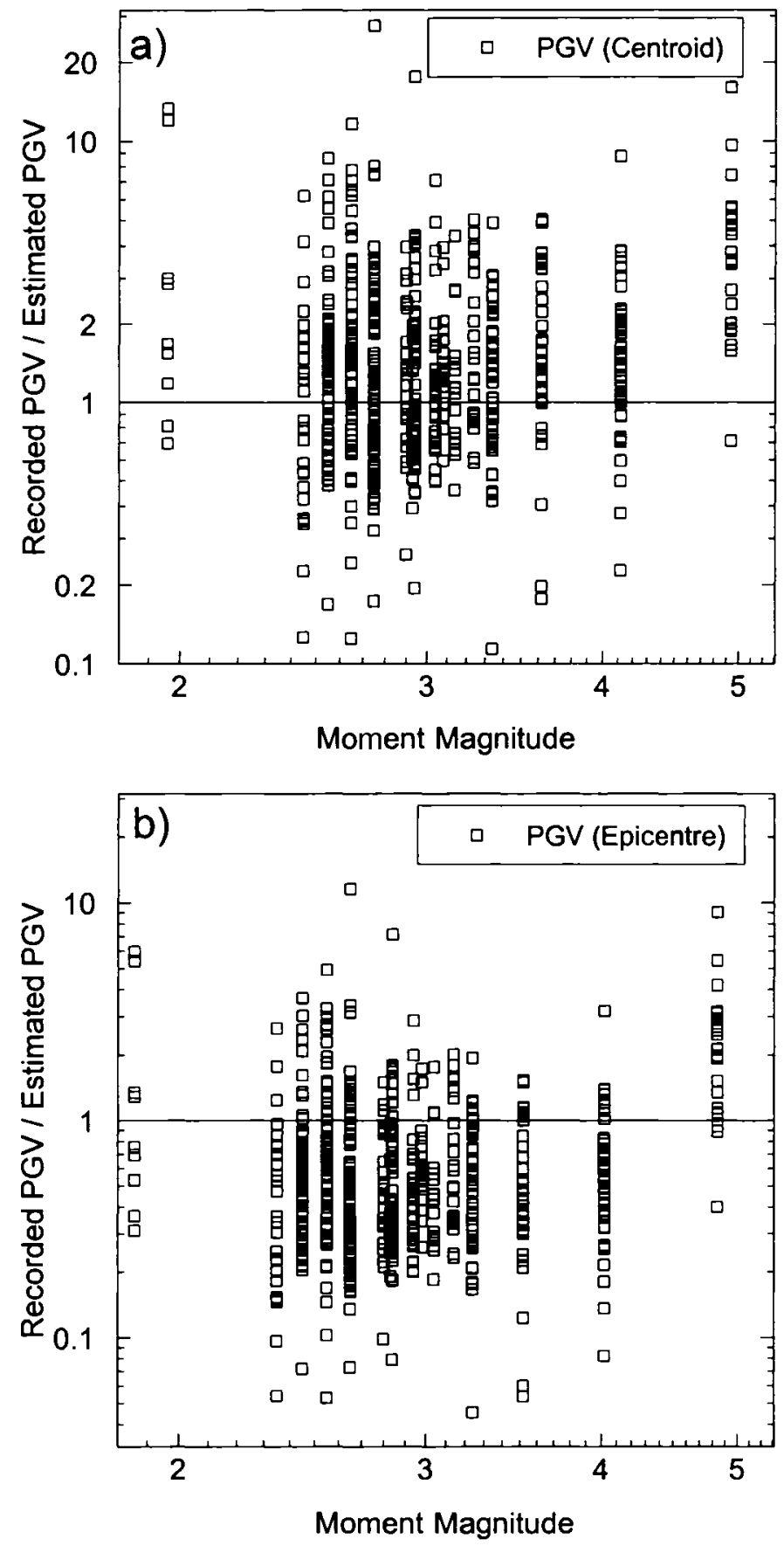

Figure 4.6 Ratio of actual recorded PGV to estimated PGV as a function of magnitude:

a) PGV-estimated from centroid location and magnitude

b) PGV-estimated from epicentre location and magnitude 

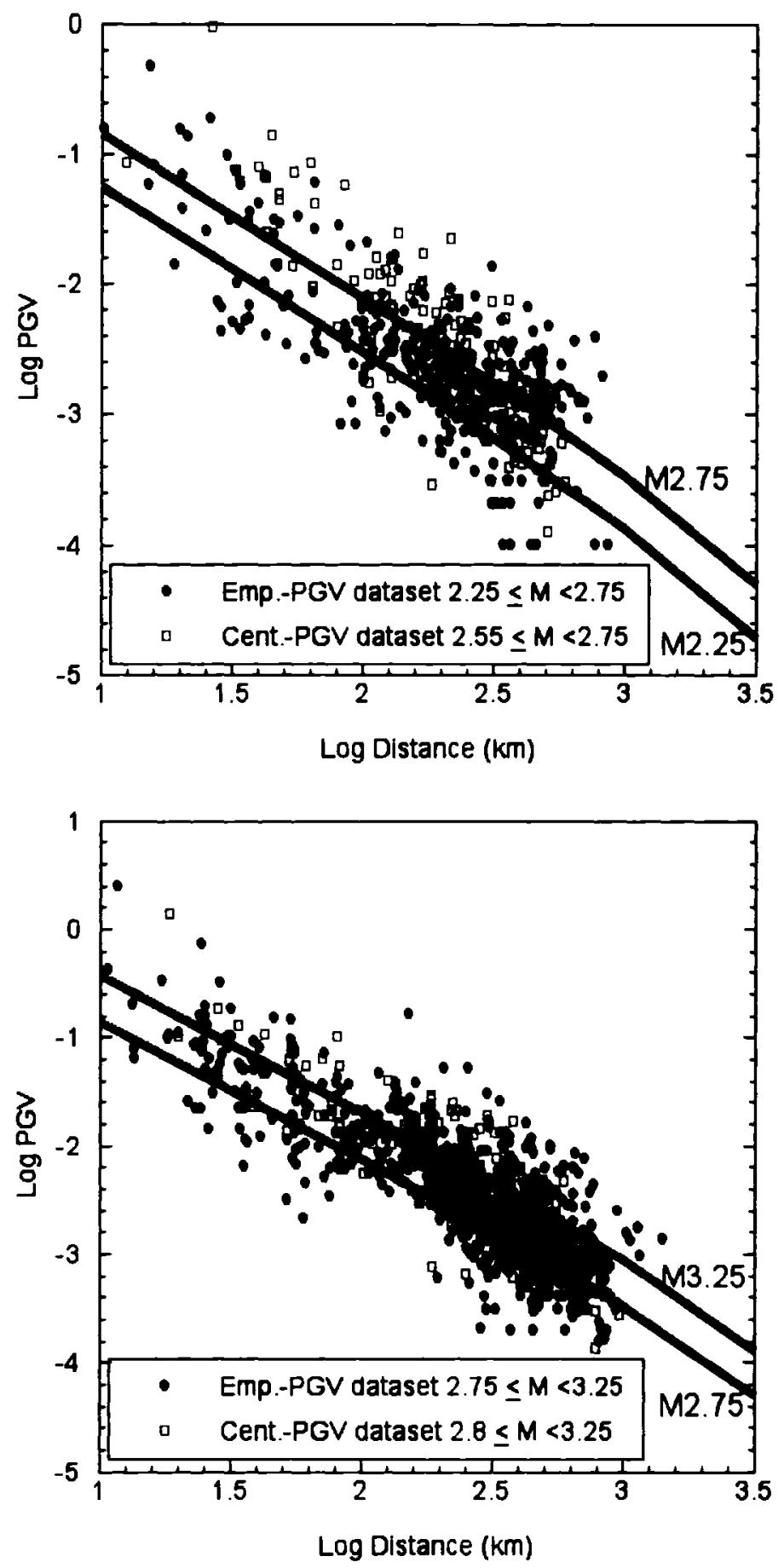

Figure 4.7 Observed PGV plotted as a function of distance. Filled circles denote PGV dataset used to derive empirical ground motion relations in Chapter 6 while open squares are regional dataset used in this chapter. 


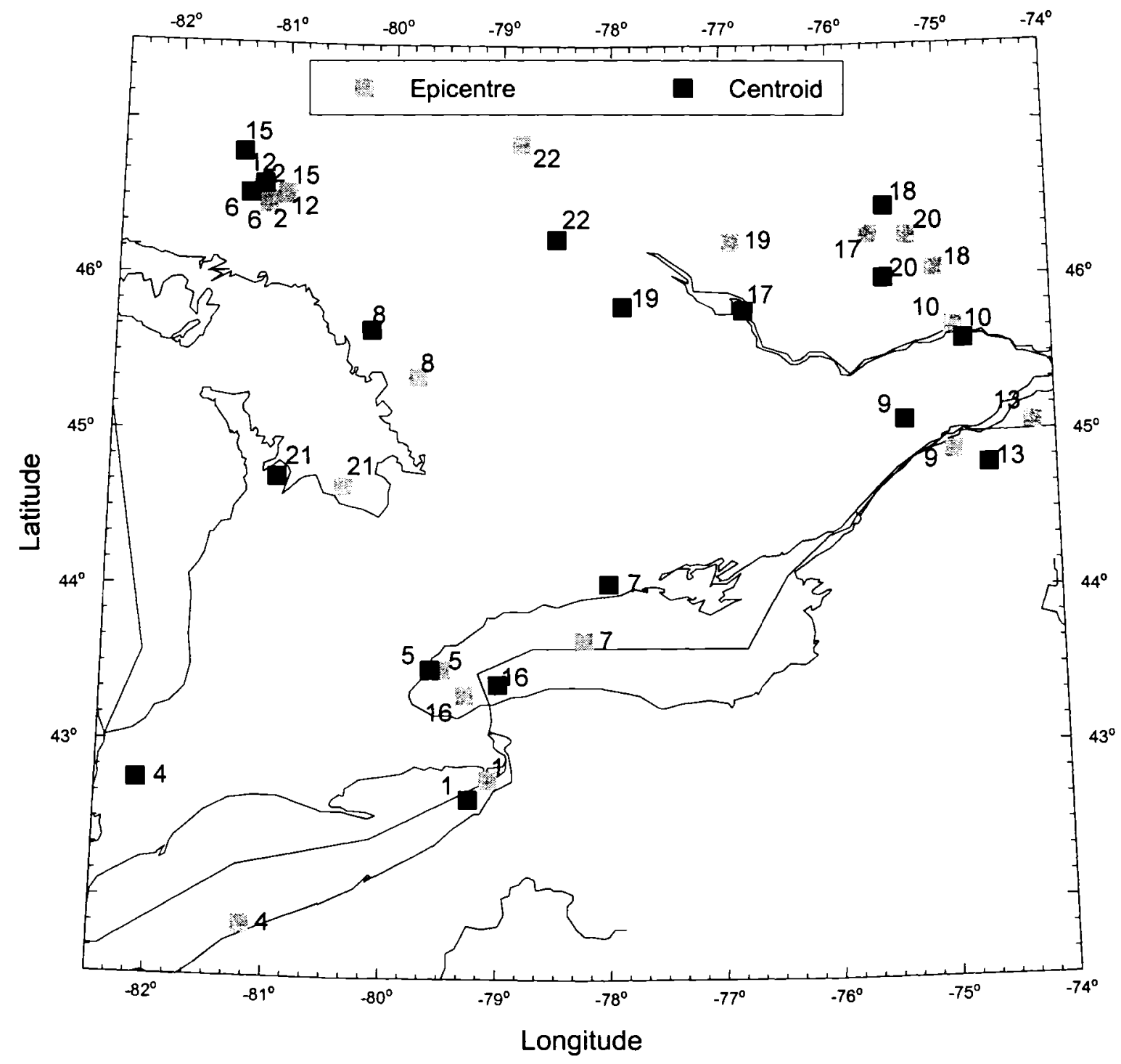

Figure 4.8 Comparing near-real-time ShakeMap location (centroid) with that of the Canadian National Earthquake Database (NEDB) solution (epicentre) to evaluate the performance of ShakeMap. The epicentre is plotted as gray square, while the ShakeMap centroid location is denoted as filled square. Number represents the corresponding event shown in Table 4.2. 
The Mn $3.1(M=2.8)$ Event of June 16, 2004

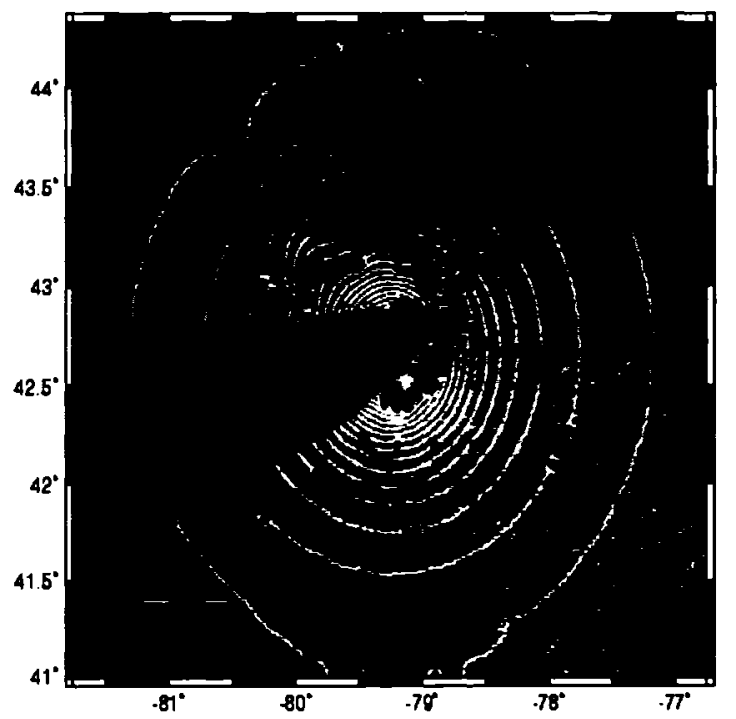

The Mn 3.5 (M=3.1) Event of March 3, 2005
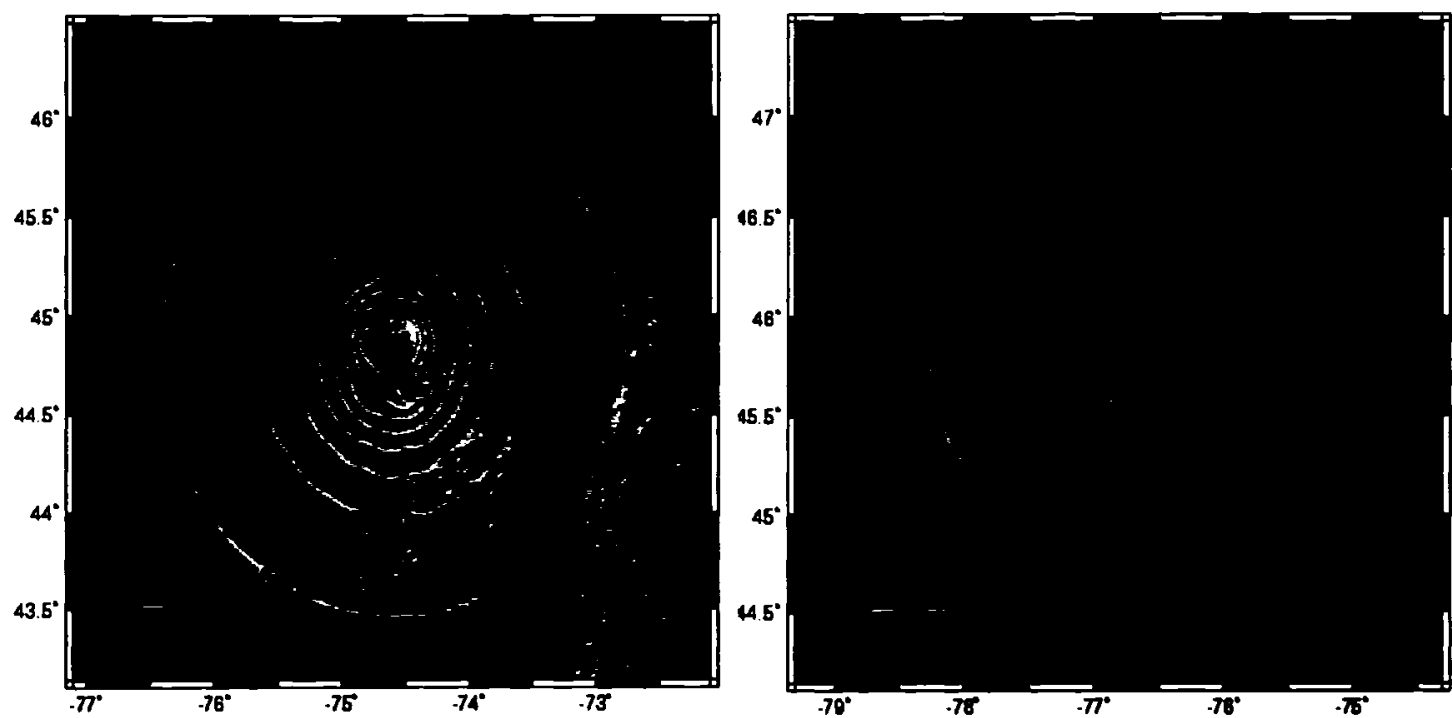

The Mn $3.8(M=3.7)$ Event of August 4, 2004

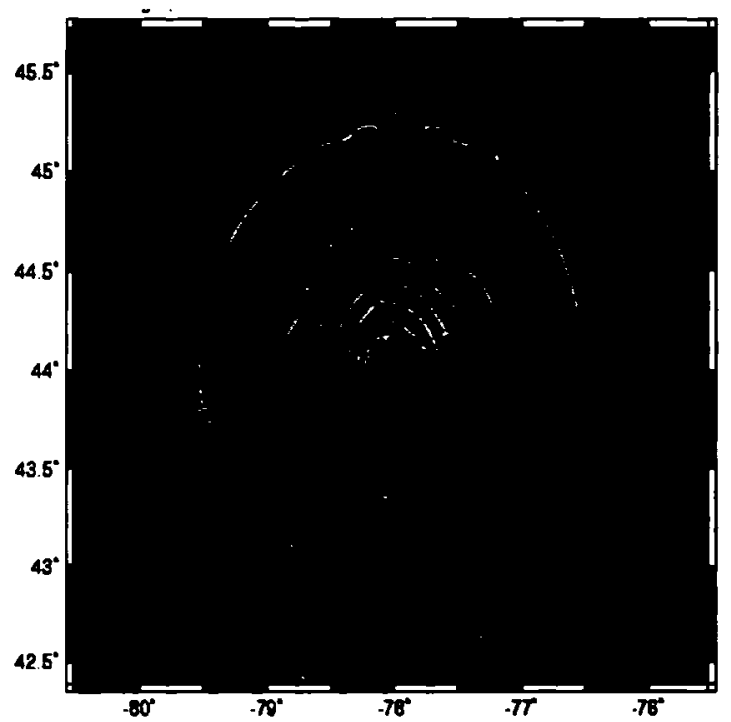

The Mn 3.4 (M=3.0) Event of March 31, 2005
日 Centroid

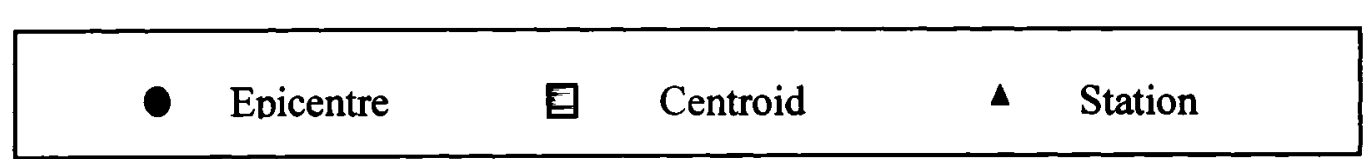

Figure 4.9. Solutions for local and regional events listed in Table 4.2, along with the contoured PGV values from ShakeMap. The epicentre is plotted as red circle, while the centroid is denoted as an orange square. Small red triangles are the location of recording station. Horizontal component PGV value at each station is given in $\mathrm{mm} / \mathrm{s}$. 


\section{Chapter 5}

\section{Relationships between Instrumental Ground-Motion Parameters and Modified Mercalli Intensity for ShakeMaps}

\subsection{Introduction}

In the California ShakeMaps, the intensity of ground shaking is inferred through an empirical relation between recorded peak ground acceleration (PGA), peak ground velocity (PGV) and Modified Mercalli Intensity (MMI) that was developed from observations in California (see Wald et al., 1999b). These relations between MMI and PGV/PGA (e.g. Wald et al., 1999a; Atkinson and Sonley, 2000) are not necessarily applicable to eastern North America (ENA). Earthquakes recorded in California have a lower frequency content than those recorded in ENA, and thus PGV and PGA have a different meaning in the two regions. Moreover, the Wald et al. (1999a) relationship is not suitable to estimate intensity based on PGV at low-to-moderate intensity level (see Wald et al., 1999b), which is of interest in ENA applications. Thus we require an appropriate relationship between ground motion and MMI for ENA events.

PGV is the ideal choice among the ground motion parameters for our ShakeMap applications, as it is the simplest and most rapidly available parameter from seismographic monitoring networks in ENA. It is also a parameter most directly related to kinetic energy, which in turns relates to damage. Wald et al. (1999a) showed that low levels of shaking intensity correlate fairly well with both peak ground acceleration (PGA) and PGV, while high intensities correlate best with PGV. Boatwright et al. (2001) demonstrated that PGV is significantly better correlated with intensity than PGA based 
on the correlation of the tagging intensity (based on building-inspection data) with observations of PGA and PGV in the 1994 Northridge earthquake.

In this chapter, I present empirical relationships between PGV and observed MMI by using data from eighteen significant earthquakes from ENA, as listed in Table 5.1. Recorded ground motion data are available for the post-1982 earthquakes. I supplement these data with inferred PGV values from a few large historical events, as described in the next section. The same data are used to derive relationships between $5 \%$ damped pseudo-acceleration (PSA) and MMI. These relationships are useful for engineering analyses keyed to a specific frequency.

\subsection{Data set for the study}

Most observed MMI data were obtained from the Geological Survey of Canada (GSC). In the case of the $1811 / 12 / 16$ and 1812/01/23 events (New Madrid earthquakes), MMI values were taken from Hough et al. (2000). MMI values for several historical earthquakes $(1925,1935,1940)$ are from the National Oceanic and Atmospheric Administration (NOAA) MMI database.

In general, MMI values are assigned based on a felt report, which is a description of the ground shaking experienced by the general public, or an assessment of damage level. For each instrumentally-recorded event, I assigned an MMI value to every seismographic monitoring station based on general proximity to one or more MMI observations. Visual inspection of maps showing station locations and MMI assignments in the surrounding area was the preferred method of assigning MMI values. I assigned an MMI value to the station only in cases for which I had reasonable confidence that actual 
MMI value at the site would be within one unit of the assigned value (after Atkinson \& Sonley, 2000). Some examples will illustrate the approach. Figure 5.1a shows the MMI observations for the 2002 Au Sable Forks, New York earthquake of M 5.0, together with the locations of seismographic monitoring stations that recorded the PGV and response spectra (PSA). For most recording stations, it is apparent that the MMI can be assigned to within an uncertainty of $1 \mathrm{MMI}$ unit. For example, the assigned MMI at HRV (Harvard) is 3, while at BINY it is 2. Figure 5.1b (MMI observations for the $1997 \mathbf{M} 4.2$ earthquake) illustrates the difficulty in assigning MMI with confidence in some cases. MMI 4 was assigned to station DAQ and the Charlevoix stations, but I could not assign MMI values to the remaining stations due to the lack of nearby MMI observations.

To obtain PGV and PSA values for events from 1993 and onwards, I obtained horizontal and vertical-component time series data from the GSC via their AUTODRM (Automatic Data Request Manager) facility (www.seismo.nrcan.gc.ca/nwfa/autodrm). I then processed the waveform data to remove instrument response and calculate PGV and PSA, using the strongest part of the record (see Atkinson, 2004). For events between 1982 and 1988, I used the existing database compiled by Atkinson and Mereu (1992). For the Saguenay earthquake of November 25, 1988, I obtained PGV values from strong motion instruments (Munro and Weichert, 1989). Horizontal component data were preferred when available. Where only vertical-component data were available, these were converted to equivalent horizontal component values using the relationship of Atkinson (1993a) (see also Siddiqqi and Atkinson, 2002; Atkinson, 2004). Vertical-component data (converted to horizontal) comprise $43 \%$ of the PGV database. Because the stations are on hard rock (little site amplification), the horizontal and vertical component motions 
are very similar and thus the horizontal to vertical $(\mathrm{H} / \mathrm{V})$ ratio is not a large factor (average $\mathrm{H} / \mathrm{V}=1.2$ ).

For historical earthquakes, I estimated the horizontal-component PGV and PSA from the ground-motion relations for ENA developed by Atkinson and Boore, 1995 (AB95), in order to allow expansion of our database to larger intensity. However, the AB95 relationship applies to hard rock sites while the historical intensity data generally correspond to observations on soil. I account for this effect by applying a soil response factor, applicable to generic stiff soil sites (NEHRP C), of 2.38 for PGV and 2.58, 1.94, 1.39 for PSA at $1 \mathrm{~Hz}, 5 \mathrm{~Hz}$ and $10 \mathrm{~Hz}$ respectively, as suggested by Adams and Halchuk (2003) (see also Chapter 7). These factors are based on the difference in shear-wave velocity between stiff soil and hard rock sites which causes an impedance-related amplification, as discussed by Boore and Joyner (1997). There is significant uncertainty in estimating ground motions for historical earthquakes by this process. Therefore, I checked these values carefully for consistency with those of the instrumentally- recorded data. As shown in Figure 5.2, for intensity levels less than 5, PGV values inferred using the $\mathrm{AB} 95$ relation are significantly higher than recorded values, while for $\mathrm{MMI} \geq 5$ the 2 sets of values are naturally consistent. It is apparent the estimated PGV values are not suitable to determine intensity for $\mathrm{MMI}<5$. From Figure 5.3, I conclude that the $\mathrm{AB} 95$ relations are significantly over-predicting PGV for events of $\mathbf{M} \leq 5$, which is causing the observed discrepancies at low MMI levels (MMI < 5). Thus for historical earthquakes I estimated PGV and PSA from AB95 using only those sites with $\mathrm{MMI} \geq 5$. At these intensity levels, the $\mathrm{AB} 95$-inferred values appear to be consistent with instrumental 
observations. However, I give these inferred values very little overall weight in view of these uncertainties.

On Figure 5.2, I also plot laboratory-based PGV ranges of some intensity levels, based on a study by McDaniel and Horton (2001). McDaniel and Horton performed shaketable tests to determine the velocity required to cause some of typical phenomena associated with various intensities. They report that a velocity range of 0.1 to $0.3 \mathrm{~mm} / \mathrm{s}$ causes swaying of liquids (MMI I to II), while a range of about 10 to $100 \mathrm{~mm} / \mathrm{s}$ may be associated with spilling of liquids or stopping of a pendulum (MMI V). Results for ringing a bell (MMI VI) are more difficult to interpret but would also be consistent with a 10 to $100 \mathrm{~mm} / \mathrm{s}$ velocity.

Moment magnitude (M) values for the study events are from Atkinson and Chen (1997) for most of the historical events, Hough et al. (2000) for the New Madrid events and Atkinson (2001) for most other events. For some small events, $\mathbf{M}$ values were estimated from the empirical relationship given by Atkinson (1993b).

\subsection{PGV versus MMI relations}

Observed MMI and PGV for all the study events are displayed on Figure 5.2; I use different symbols to distinguish between actual recorded PGV and values inferred using the $\mathrm{AB} 95$ relation for historical earthquakes. Because of the large scatter, the qualitative nature of observed MMI, and the uneven data distribution, a standard leastsquares regression of MMI against PGV will not provide an unbiased prediction of MMI. In order to develop a robust relationship, I proceeded as follows. 
1. I examined each MMI level independently and calculated the mean PGV corresponding to that particular MMI level (mean PGV values and corresponding standard deviations and number of observations are listed in Table 5.2). Inferred PGV values from $\mathrm{AB} 95$ are used in calculating the mean only for $\mathrm{MMI} \geq 5$.

2. I regressed $\mathrm{MMI}$ against the mean $\mathrm{PGV}$, as shown on Figure 5.4 to obtain a simple relationship to predict $\mathrm{MMI}$.

$$
\mathrm{MMI}=\mathrm{C}_{1}+\mathrm{C}_{2} \log \mathrm{PGV}
$$

Table 5.3 lists these $C_{1}$ and $C_{2}$ values along with their standard errors and the standard deviation of this prediction. MMI values of 9 and 10 were not used in the regression due to lack of data.

3. I evaluated magnitude and/or distance trends in the MMI-residuals, calculated by subtracting predicted MMI (Equation 5.1) from observed MMI. Figure 5.5 shows that there is a slight apparent trend to higher residuals at larger distances; this trend is more pronounced for PSA at high frequencies.

4. I regressed the MMI-residuals versus distance in order to calculate correction factors to account for distance. Table 5.3 shows the coefficients for these regressions where $\mathrm{C}_{3}$ and $\mathrm{C}_{\mathrm{R}}$ are the coefficients of the regression of MMI- residuals against distance:

$$
\text { MMI Residual }=\mathrm{C}_{3}+\mathrm{C}_{\mathrm{R}} \log \mathrm{D}
$$

I note that the trend with distance is significant for PGV and for PSA, especially at high frequencies.

5. I plotted distance-corrected residuals, obtained by subtracting off distance trends in MMI residuals as per equation 5.2, against magnitude. As shown on Figure 5.6, the corrected residuals are not significantly dependent on magnitude; thus, no magnitude 
term is necessary in our predictive relationship. I verified the lack of significance of magnitude trends by regression of corrected residuals versus magnitude.

6. I developed the final predictive equation:

$$
M M I=\left(C_{1}-C_{3}\right)+C_{2} \log Y-C_{R} \log D
$$

Table 5.3 provides for the coefficients and their standard errors, along with the standard deviation of MMI values.

I have repeated exactly the same procedure to obtain MMI-PSA relationships for PSA at $1-\mathrm{Hz}, 5-\mathrm{Hz}$ and $10-\mathrm{Hz}$. The final predictive relations are given in Table 5.3.

\subsection{Comparison to other relations}

I compare this new relationship for ENA (mainly southeastern Canada) between PGV and MMI with those developed by Wald et al. (1999a) and Atkinson and Sonley (2000) from California data. To the best of my knowledge, there are no comparable studies completed for ENA or similar tectonic settings for testing and comparison to this result. However, the laboratory studies of McDaniel and Horton (2001) are relevant, and lend support to my results.

On Figure 5.7 I plot the final MMI residuals (observed MMI - predicted MMI) for instrumental data in ENA (M 5.0 to 5.8) as a function of distance (less than $300 \mathrm{~km}$ ), where the residuals are defined with respect to both ENA and western North America (WNA) predictive relations. The residuals show that my ENA relation provides a relatively unbiased estimate of observed intensity, while the WNA relations do not. These figures demonstrate that predictive relationships between $\mathrm{MMI}$ and ground motion are significantly different in ENA than in WNA. Mean ground motion values associated with 
any particular MMI value in ENA are significantly lower than those in WNA (see Tables 5.2 of this study and 2 and 3 of Atkinson and Sonley, 2000 for details). WNA predictive relations between MMI and ground motion significantly under-predict MMI for moderate ENA earthquakes.

The discrepancy between relations between MMI and PGV or PGA in ENA as compared to California is not entirely surprising, due to the different frequency content of motions in the two regions. I expect both PGA and PGV to be carried by higher frequencies in ENA than in California, and this may well impact on their felt effects. However, the observed regional differences in relationships between MMI and response spectra at a specific frequency are surprising and difficult to explain. Possible factors might be a longer duration of motion in ENA, allowing more time for the effects to be developed or noticed. Another factor might be frequency-dependence of the effects associated with the intensity observations. Alternatively, there may be regional discrepancies in the way MMI observations are compiled. Finally, it is possible that the recorded motions at the seismographic sites are systematically low relative to motions experienced at nearby locations that reported the MMI value; this is a possibility because competent rock sites are sought for seismographic monitoring. At this time, these possibilities are presented as speculations only.

I examine the implications of the developed relations for ShakeMaps, using the 2002 Au Sable Forks, New York M 5.0 earthquake as an illustration. Figure 5.8 (a) shows the intensity map that is obtained using ground motion relations for eastern North America (Atkinson \& Boore, 1995) to predict PGA and PGV, along with the instrumental intensity relations (PGA/PGV) for California as prescribed by Wald et al. (1999a) and 
implemented in California ShakeMaps. (Note: An intensity map developed using ENA ground-motion relations (Atkinson \& Boore, 1995) and the relationship between MMI and PGV/PGA developed from California data by Atkinson and Sonley (2000) is very similar to 5.8 a). Figure 5.8 (b) is the intensity map using ENA ground-motion relations (Atkinson \& Boore, 1995) and the relationship between MMI and PGV developed in this study. The actual observed MMI map based on felt-reports submitted on-line (courtesy of U.S Geological Survey) is shown in the top panel of Figure 5.8. I conclude from Figure 5.8 that when the new relationship between MMI and PGV is implemented in ShakeMap, I obtain an MMI prediction that closely resembles the actual felt-reports. I note that local details are smoothed due to our lack of site-specific information on site response. By contrast, ShakeMap developed with the Wald et al. (1999a) PGA/PGV versus MMI relations (or the Atkinson and Sonley (2000) relations) for California significantly underestimates the intensities from this event. Thus predictive relations between MMI and ground motions are region-specific and these relationships should be carefully assessed for each region where ShakeMaps are to be implemented.

\subsection{Conclusion}

MMI values in ENA can be predicted, within about 1 MMI unit in most cases, from PGV or PSA, as shown in Table 5.3. PGV is the best predictive measure of MMI, based on the fact that it provides the lowest uncertainty in prediction (standard deviation of 0.65 MMI units). MMI can also be predicted from PSA; significantly higher MMI is predicted from a given PSA if the value was observed at distances close to the source. 
Uncertainty in predicting MMI from PSA is thus reduced if distance is included as a predictive variable (e.g. standard deviation of 0.76 versus 0.68 for PSA at $5 \mathrm{~Hz}$ ).

For ShakeMap applications in southeastern Canada and the eastern United States, I recommend the use of $\mathrm{PGV}$ as the predictive variable for $\mathrm{MMI}$, with the new relations developed in this study. Similar relations developed for California (e.g. Wald et al., 1999a; Atkinson and Sonley, 2000) significantly under-predict MMI for ENA. 
Table 5.1. Study Earthquakes

\begin{tabular}{|c|c|c|c|c|c|c|c|c|}
\hline No & $\begin{array}{c}\text { Date } \\
(\mathrm{y} / \mathrm{m} / \mathrm{d})\end{array}$ & $\begin{array}{c}\text { Moment } \\
\mathbf{M}\end{array}$ & $\begin{array}{l}\text { No. of } \\
\text { recorded } \\
\text { PGV- } \\
\text { values }\end{array}$ & $\begin{array}{l}\text { No. of } \\
\text { recorded } \\
\text { PSA- } \\
\text { values }\end{array}$ & $\begin{array}{c}\text { No. of } \\
\text { estimated } \\
\text { PGV- } \\
\text { values } \\
\text { (for } M \geq 5 \text { ) }\end{array}$ & $\begin{array}{c}\text { No. of } \\
\text { estimated } \\
\text { PSA-values } \\
\text { (for } \mathbf{M} \geq 5 \text { ) }\end{array}$ & $\begin{array}{c}\text { No. of } \\
\text { MMI } \\
\text { observations }\end{array}$ & $\begin{array}{c}\text { Distance } \\
\text { range for } \\
\text { actual or } \\
\text { inferred } \\
\text { ground } \\
\text { motion } \\
\text { (km) }\end{array}$ \\
\hline 1 & $1811 / 12 / 16$ & 7.25 & & & 31 & 31 & 73 & $6-700$ \\
\hline 2 & $1812 / 01 / 23$ & 7.0 & & & 16 & 16 & 49 & $6-700$ \\
\hline 3 & $1925 / 03 / 01$ & 6.4 & & & 12 & 12 & 185 & $5-665$ \\
\hline 4 & $1935 / 11 / 01$ & 6.2 & & & 28 & 28 & 1397 & $365-721$ \\
\hline 5 & $1940 / 12 / 20$ & 5.1 & & & 55 & 55 & 350 & $25-265$ \\
\hline 6 & $1944 / 09 / 05$ & 5.8 & & & 46 & 46 & 223 & $18-420$ \\
\hline 7 & $1982 / 01 / 11$ & 5.2 & 17 & 11 & & & 747 & $138-724$ \\
\hline 8 & $1982 / 01 / 19$ & 4.3 & 17 & 11 & & & 1154 & $209-537$ \\
\hline 9 & $1983 / 10 / 07$ & 5.0 & 16 & 16 & & & 2519 & $145-832$ \\
\hline 10 & $1988 / 11 / 25$ & 5.8 & 36 & 9 & & & 2569 & $51-708$ \\
\hline 11 & $1990 / 10 / 19$ & 4.5 & $\overline{9}$ & 15 & & & 2215 & $170-468$ \\
\hline 12 & $1993 / 11 / 16$ & 3.8 & 2 & 2 & & & 572 & $168-168$ \\
\hline 13 & $1997 / 10 / 28$ & 4.2 & 3 & 3 & & & 40 & $318-388$ \\
\hline 14 & $1997 / 11 / 06$ & $\overline{4.7}$ & 25 & 25 & & & 297 & $179-515$ \\
\hline 15 & $1999 / 03 / 16$ & 4.6 & 6 & 6 & & & 26 & $98-405$ \\
\hline 16 & $2000 / 01 / 01$ & 4.7 & 19 & 19 & & & 458 & $149-654$ \\
\hline 17 & $2002 / 04 / 20$ & 5.0 & 62 & 62 & & & 2169 & $73-897$ \\
\hline 18 & $2003 / 06 / 13$ & 3.6 & 20 & 20 & & & 23 & $23-100$ \\
\hline
\end{tabular}


Table 5.2. Mean PGV and PSA-values for each MMI level.

\begin{tabular}{|c|c|c|c|c|c|c|c|c|c|}
\hline \multirow{2}{*}{ MMI } & \multicolumn{2}{|c|}{ Log PGV } & \multicolumn{2}{|c|}{ Log PSA (1Hz) } & \multicolumn{2}{|c|}{ Log PSA (5Hz) } & \multicolumn{2}{|c|}{ Log PSA (10Hz) } & \multirow{2}{*}{$\begin{array}{c}\text { Number of } \\
\text { observations }\end{array}$} \\
\cline { 2 - 10 } & $\mathrm{mm} / \mathrm{s}$ & $\begin{array}{c}\text { Std. } \\
\text { Dev. }\end{array}$ & $\mathrm{cm} / \mathrm{s} / \mathrm{s}$ & $\begin{array}{c}\text { Std. } \\
\text { Dev. }\end{array}$ & $\mathrm{cm} / \mathrm{s} / \mathrm{s}$ & $\begin{array}{c}\text { Std. } \\
\text { Dev. }\end{array}$ & $\mathrm{cm} / \mathrm{s} / \mathrm{s}$ & $\begin{array}{c}\text { Std. } \\
\text { Dev. }\end{array}$ & \\
\hline 2 & -1.1568 & 0.30 & -1.2329 & 0.39 & -0.3385 & 0.36 & -0.4086 & 0.36 & 65 \\
\hline 3 & -0.4443 & 0.39 & -0.6530 & 0.48 & 0.3206 & 0.41 & 0.2854 & 0.41 & 92 \\
\hline 4 & -0.0120 & 0.27 & -0.1806 & 0.37 & 0.7663 & 0.25 & 0.9459 & 0.28 & 28 \\
\hline 5 & 0.8366 & 0.31 & 0.7459 & 0.27 & 1.3178 & 0.32 & 1.1900 & 0.46 & 155 \\
\hline 6 & 1.3642 & 0.19 & 1.3147 & 0.21 & 1.9620 & 0.15 & 1.9222 & 0.26 & 34 \\
\hline 7 & 1.6692 & 0.19 & 1.5949 & 0.12 & 2.1711 & 0.18 & 2.1070 & 0.29 & 15 \\
\hline 8 & 1.8549 & 0.23 & 1.8008 & 0.21 & 2.4095 & 0.26 & 2.3730 & 0.34 & 12 \\
\hline
\end{tabular}

Table 5.3. Coefficients of Equations (and their standard errors) to predict MMI from Instrumental Ground Motion Parameters

(1) $\quad \mathrm{MMI}=\mathrm{C}_{1}+\mathrm{C}_{2} \log \mathrm{Y}$, with standard deviation $\sigma_{1 \mathrm{MMI}}$

(3) $\quad \mathrm{MMI}=\left(\mathrm{C}_{1}-\mathrm{C}_{3}\right)+\mathrm{C}_{2} \log \mathrm{Y}-\mathrm{C}_{\mathrm{R}} \log \mathrm{D}$, with standard deviation $\sigma_{3 M M I}$

\begin{tabular}{|l|c|c|c|c|}
\hline \multicolumn{1}{|c|}{ Y } & PGV & PSA (1Hz) & PSA (5Hz) & PSA (10 Hz) \\
\hline $\mathrm{C}_{1}$ & 3.96 & 4.14 & 2.45 & 2.50 \\
\hline $\mathrm{C}_{1}$ Error & 0.02 & 0.18 & 0.21 & 0.24 \\
\hline $\mathrm{C}_{2}$ & 1.79 & 1.81 & 2.10 & 2.10 \\
\hline $\mathrm{C}_{2}$ Error & 0.02 & 0.15 & 0.13 & 0.16 \\
\hline $\mathrm{C}_{3}$ & -0.12 & 0.88 & -1.63 & -3.10 \\
\hline $\mathrm{C}_{3}$ Error & 0.17 & 0.18 & 0.18 & 0.19 \\
\hline $\mathrm{C}_{\mathrm{R}}$ & 0.28 & -0.44 & 0.67 & 1.33 \\
\hline $\mathrm{C}_{\mathrm{R}}$ Error & 0.07 & 0.07 & 0.07 & 0.08 \\
\hline$\sigma_{1 \mathrm{MMl}}$ & 0.72 & 0.83 & 0.76 & 0.90 \\
\hline$\sigma_{3 \mathrm{MMI}}$ & 0.65 & 0.68 & 0.68 & 0.68 \\
\hline
\end{tabular}


MMI Observations for the 2002 Au Sable Forks, N.Y Earthquake

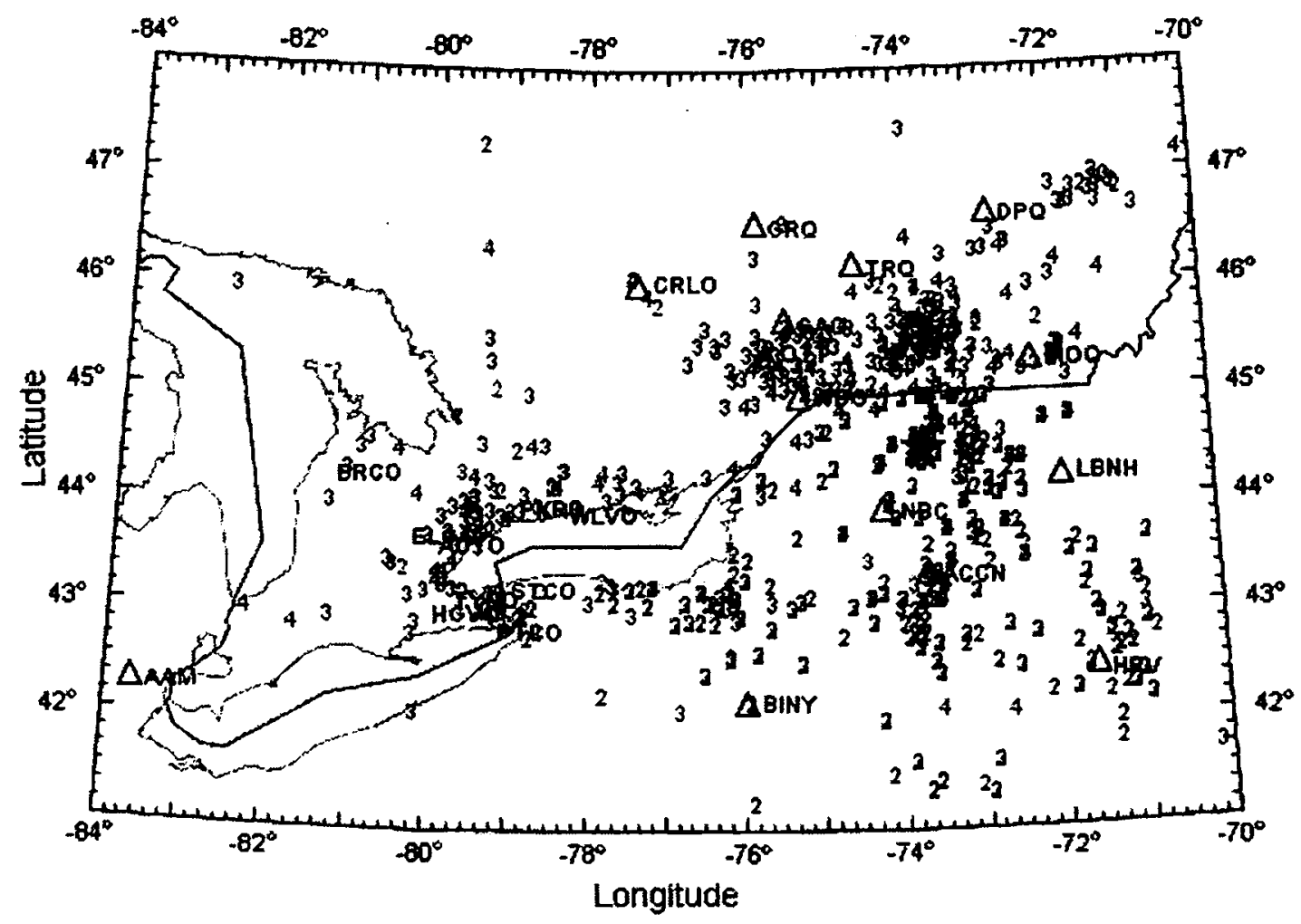

Figure 5.1a. MMI observations for the 2002 M 5.0 Au Sable Forks, N. Y Earthquake and locations of seismographic monitoring stations that recorded the PGV and PSA values. Star shows epicenter. Numbers are MMI values. Triangles are stations. 
MMI Observations for the 1997 M 4.2 Earthquake

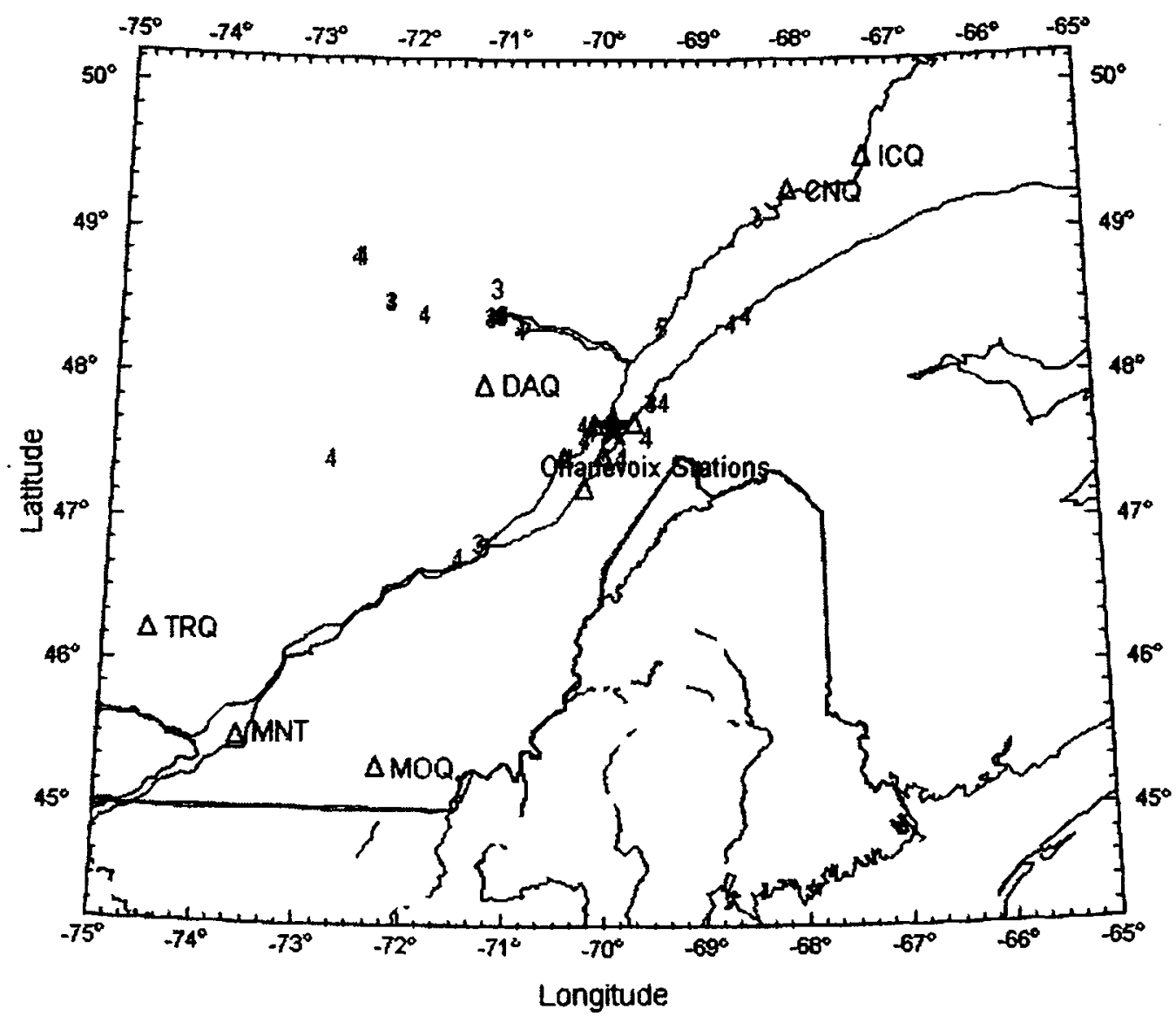

Figure 5.1b. MMI observations for the 1997 M 4.2, Charlevoix Earthquake and locations of seismographic monitoring stations that recorded the PGV and PSA values. Star shows epicenter. Numbers are MMI values. Triangles are stations. 
MMI plotted against PGV (all data)

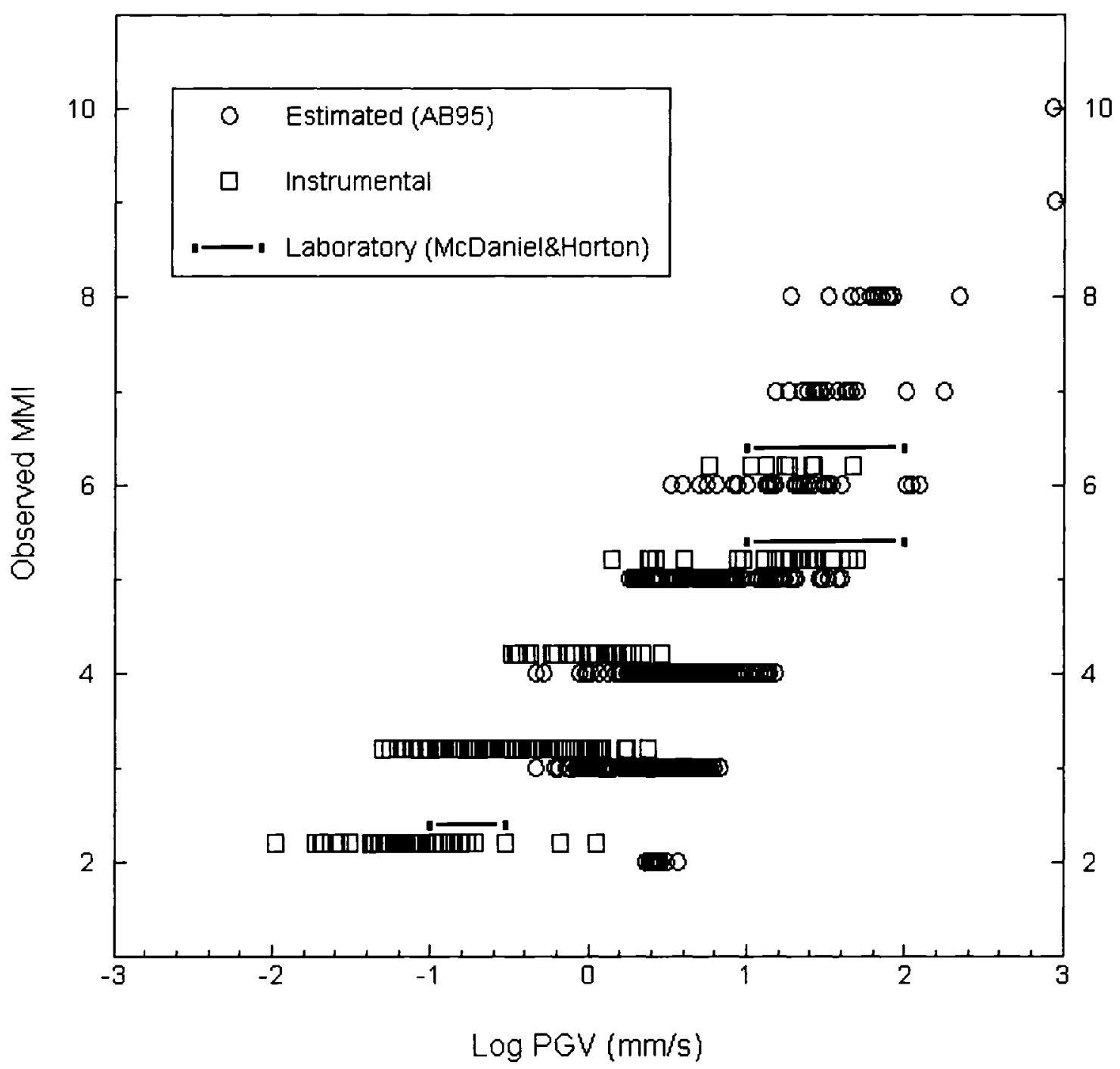

Figure 5.2. Observed MMI versus PGV for all data with squares representing recorded PGV and circles representing inferred values, using the Atkinson and Boore, 1995 (AB95) relations. PGV ranges based on laboratory measurements of McDaniel and Horton (2001) are also shown. Slight offsets from actual MMI values used for clarity. 
a)

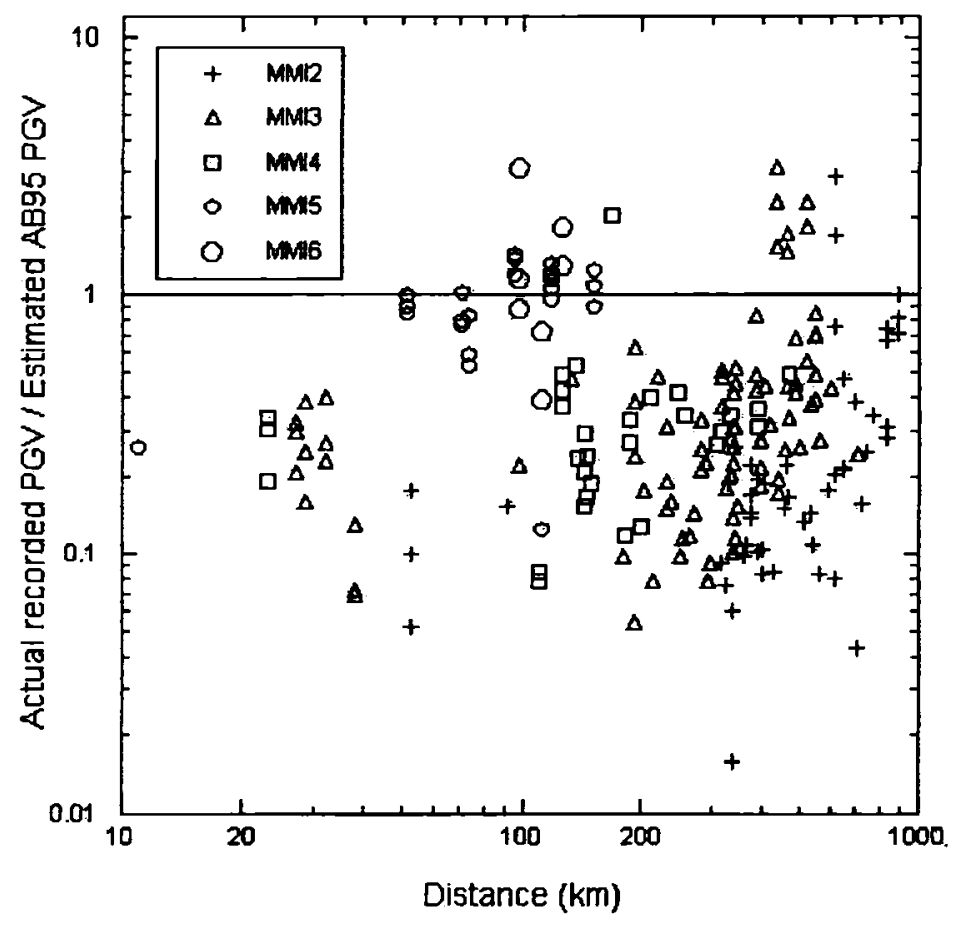

b)

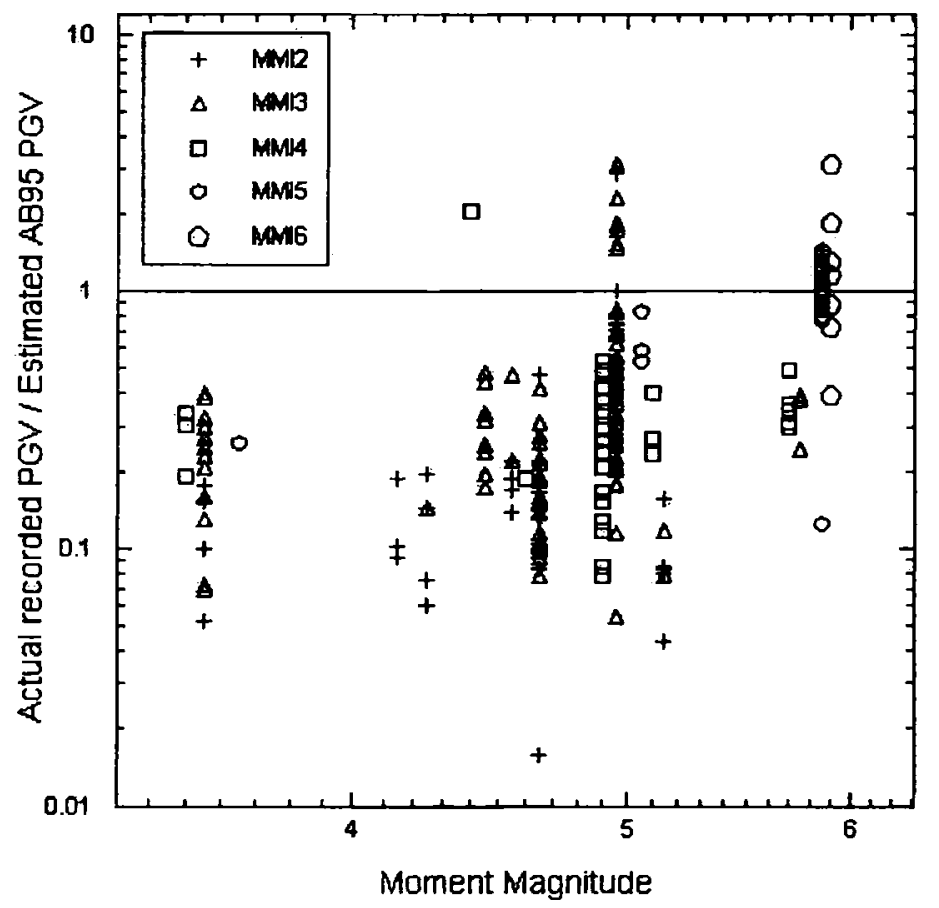

Figure 5.3. Ratio of actual recorded $\mathrm{PGV}$ to $\mathrm{PGV}$ value inferred using the $\mathrm{AB} 95$ relation: a) versus distance; b) versus magnitude. Slight offsets from actual magnitude values used for clarity. 


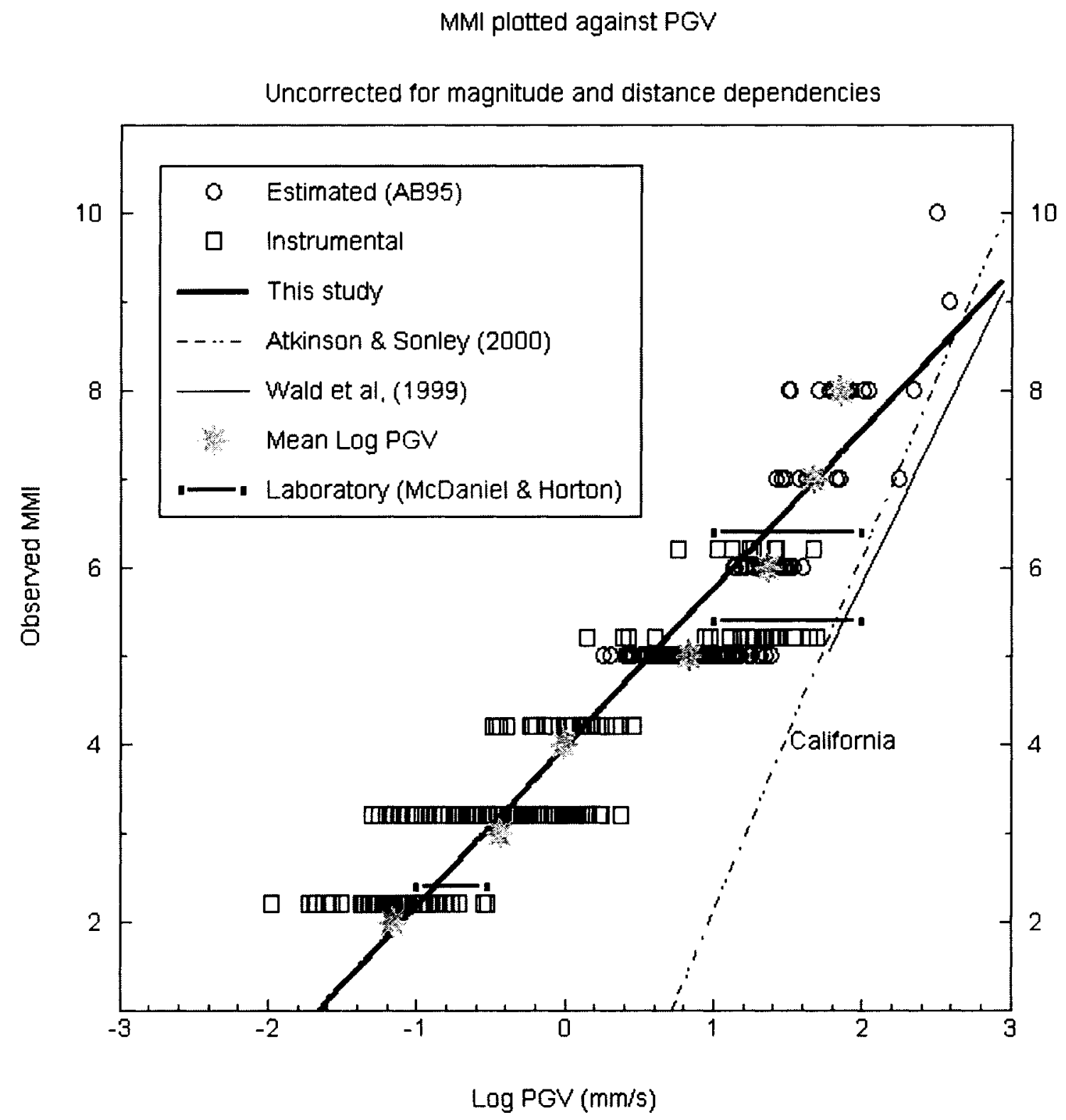

Figure 5.4. Observed MMI plotted against log PGV in order to obtain a simple MMIPGV relationship. As a comparison, MMI-PGV relationships developed by Wald et al. (1999a) and Atkinson and Sonley (2000) are also shown in the figure. The Wald et al. (1999a) relation is truncated at MMI 5 because it is not applicable for lower intensity levels). PGV ranges based on laboratory measurements of McDaniel and Horton (2001) are also shown. 


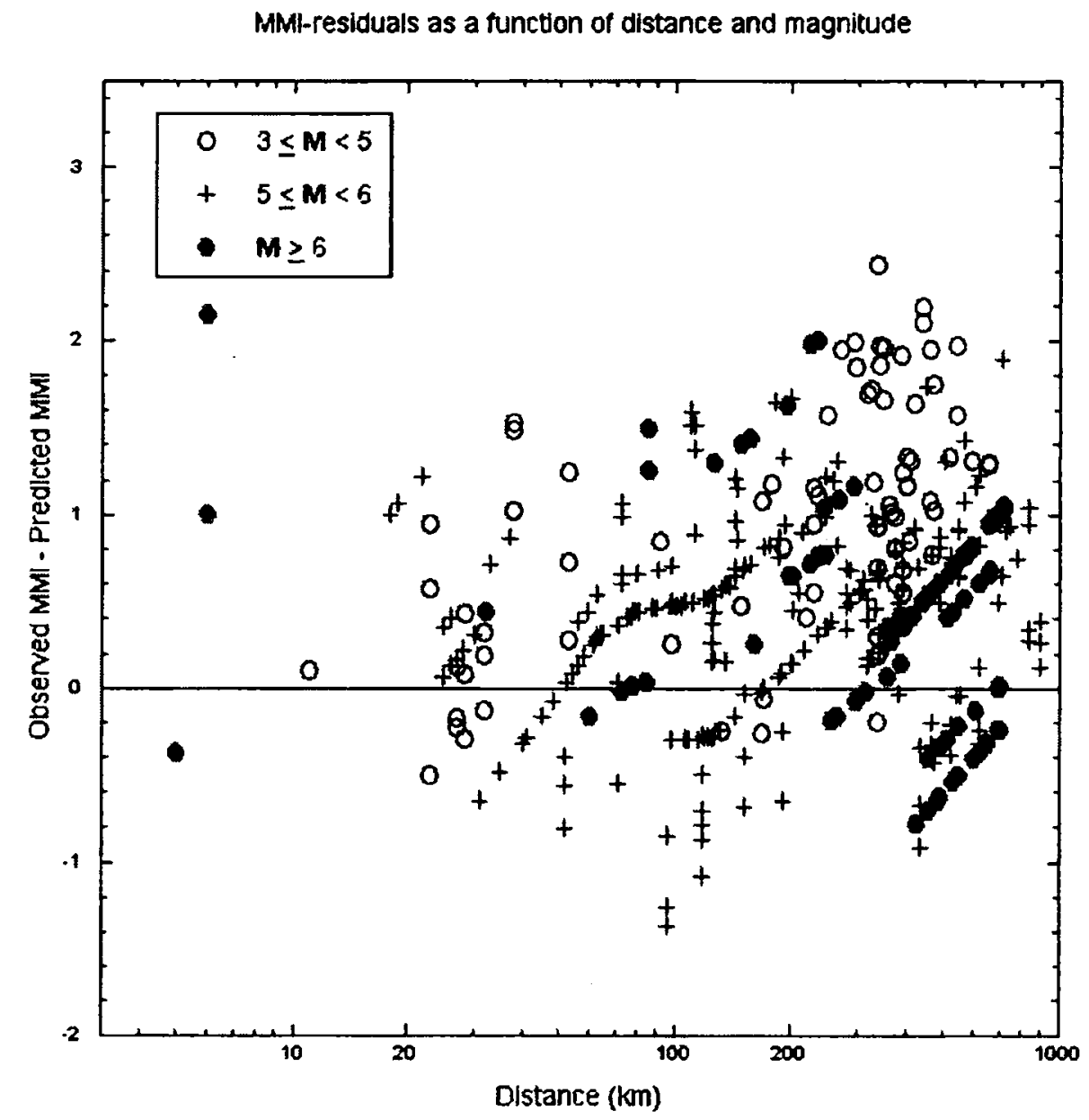

Figure 5.5. MMI-residuals (= Observed MMI - Predicted MMI from equation 5.1) plotted as a function of distance. 


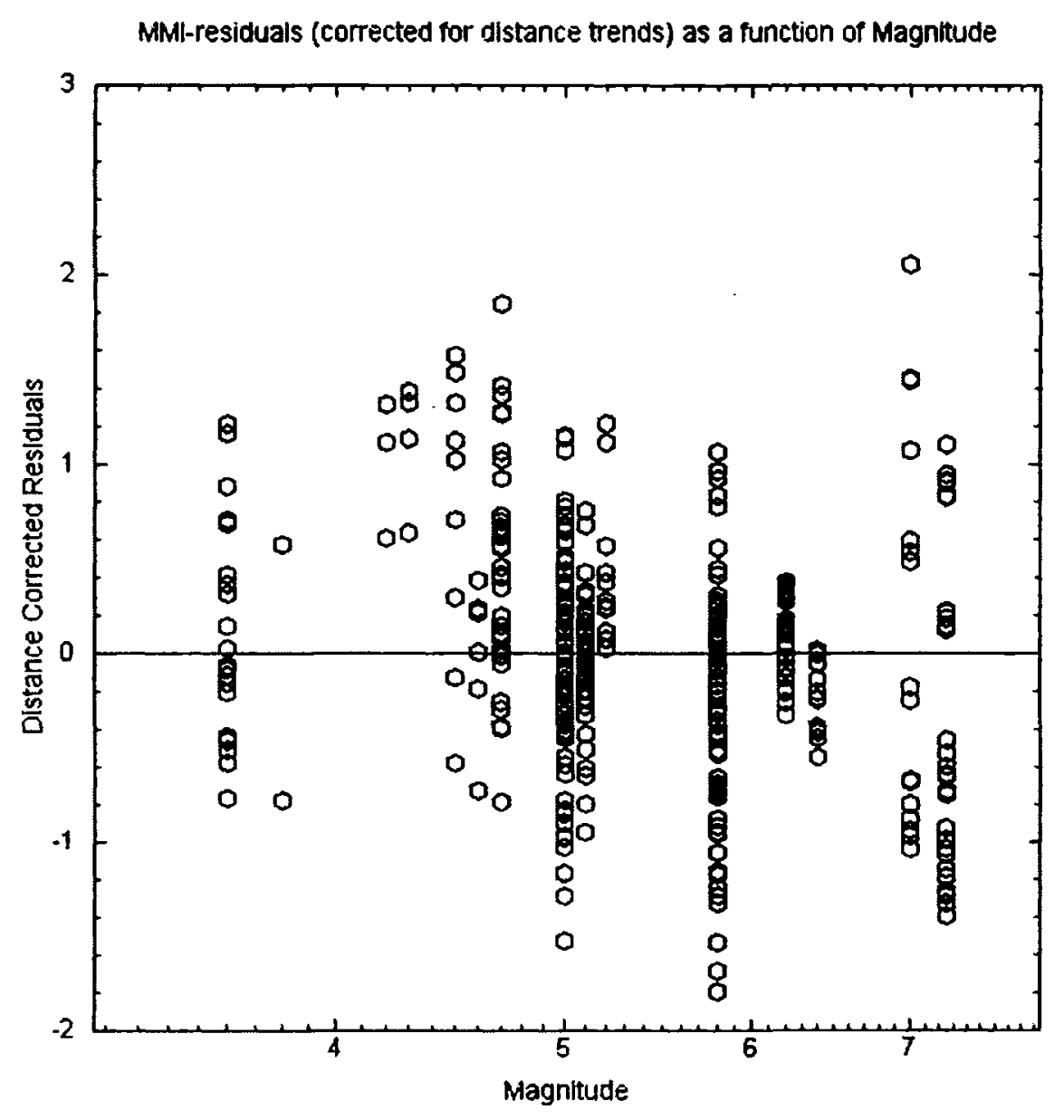

Figure 5.6. Distance corrected MMI residuals (obtained by subtracting off distance trends in MMI residuals as described in the text) as a function of magnitude. 
a) Residuals for PGV-based prediction of $M M$

(Instrumental Data- $R<300 ; 5.8 \geq M \geq 5.0$ )

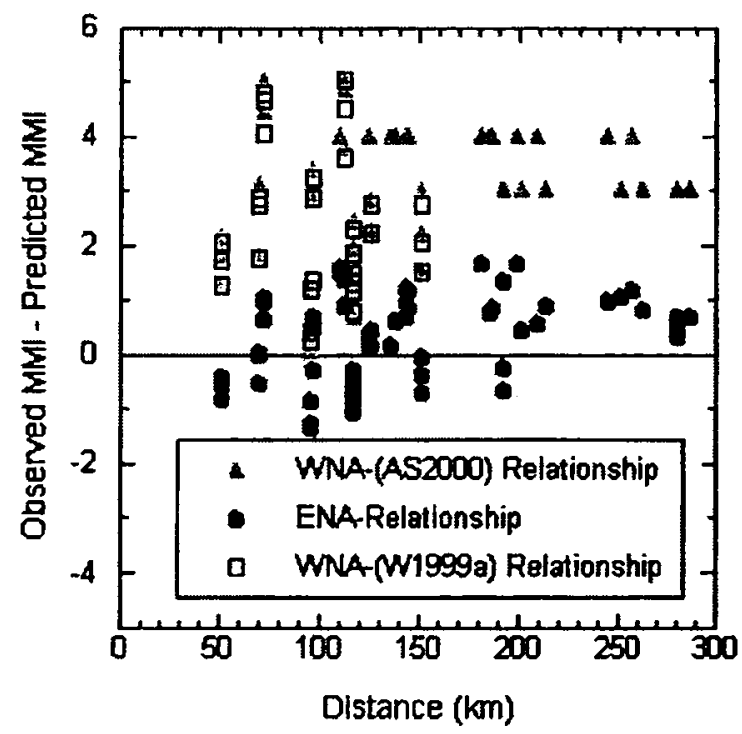

c) Residuals for PSA (5Hz)-based prediction of MMI (Instrumental Data- $R<300 ; 5.8 \geq M \geq 5.0$ )

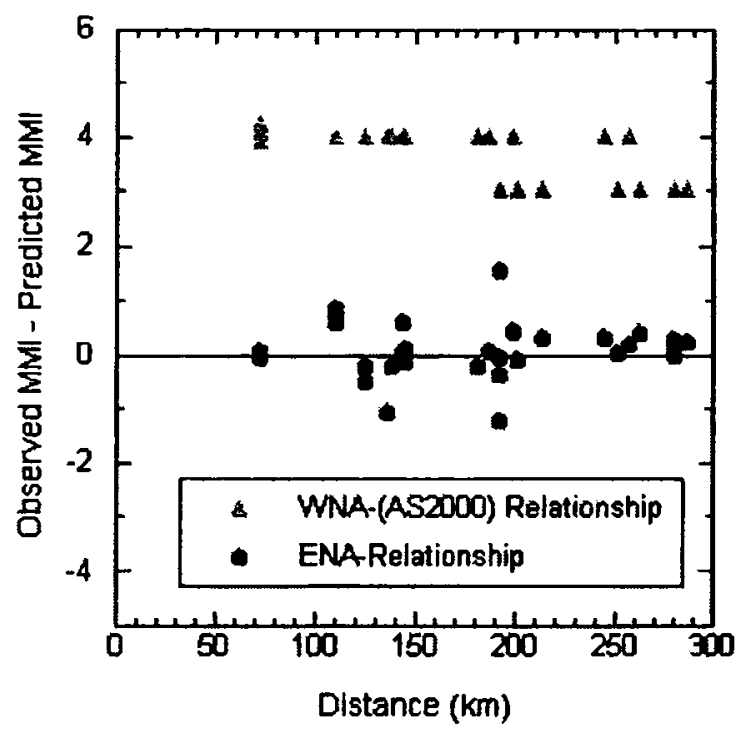

b) Residuals for PSA ( $1 \mathrm{~Hz}$ )-based prediction of MMI (Instrumental Data- $R<300 ; 5.8 \geq M \geq 5.0$ )

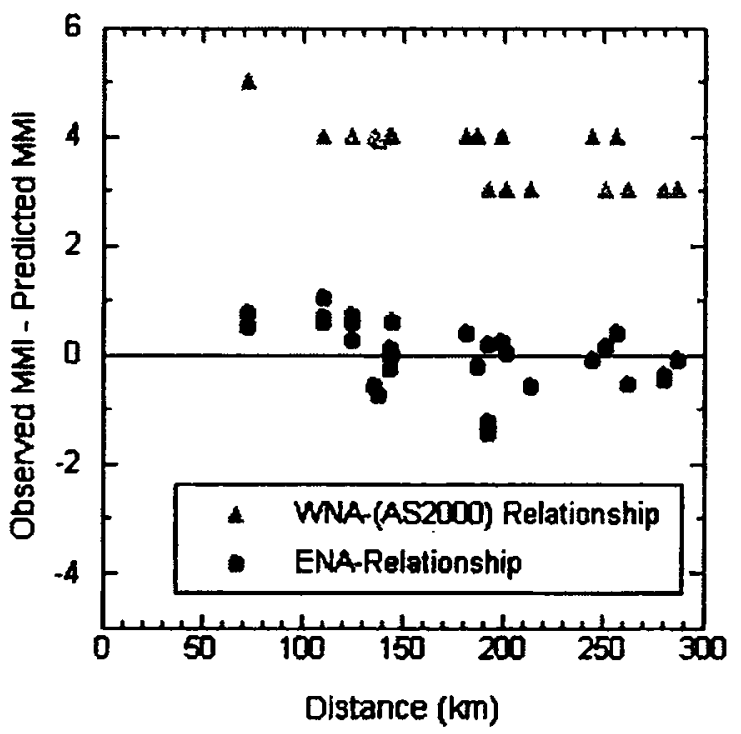

d) Residuals for PSA (10Hz)-based prediction of MMI (Instrumental Data- $R<300 ; 5.8 \geq M \geq 5.0$ )

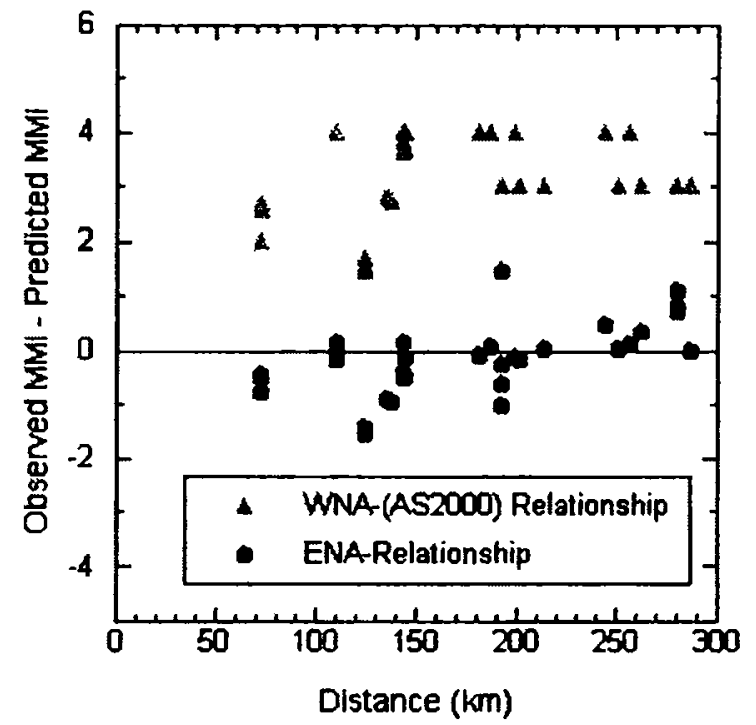

Figure 5.7. Comparison between MMI residuals for a) PGV-based predictions; b) PSA (1Hz)-based predictions; c) PSA (5Hz)-based predictions; d) PSA (10Hz)based predictions, using relations of this study (circles), and the California relations of Atkinson \& Sonley (triangles) and Wald et al., (squares). (The Wald et al. (1999a) relation was not applied for $\mathrm{MMI}<5)$. 


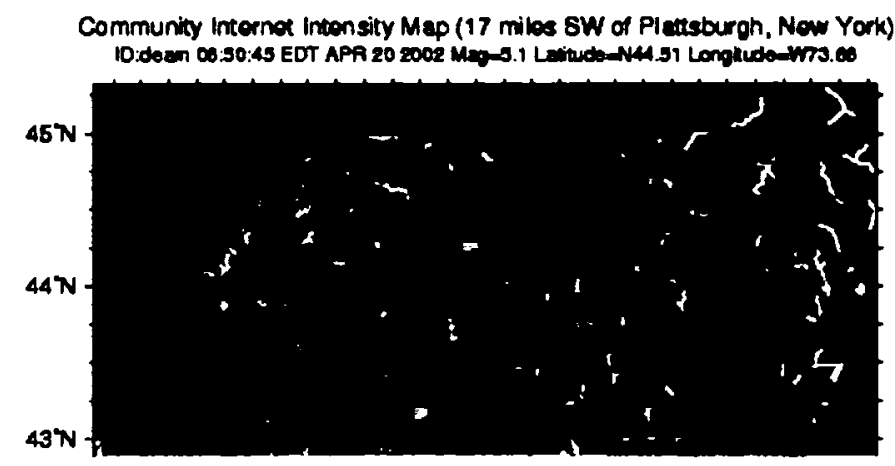

\begin{tabular}{|c|c|c|c|c|c|c|c|c|c|}
\hline $\begin{array}{l}\text { PERCENED } \\
\text { BRANKS }\end{array}$ & Not felt & Weak & Loht & Moderats & Strom & Very atrong & Enver & Violent & Extrem \\
\hline POTENTUL & nome & none & nono & Vory light & Ligh & Modorat & Modoraner Heavy & Heary & Very Heary \\
\hline PEAK $n \cos _{(x-1)}$ & $<.17$ & $.17-1.4$ & $1.4-30$ & 3.00 .2 & a.2-18 & $18-34$ & $34-6$ & 60.124 & $>124$ \\
\hline PEAK VEL (0m/a) & $<0.1$ & 0.1 .1 .1 & 1.1 .3 .4 & 3.48 .1 & 8.1-16 & 1251 & $31-\infty$ & $00-110$ & $>110$ \\
\hline INSTRYMENTAL & 1 & & & & & & & & \\
\hline
\end{tabular}

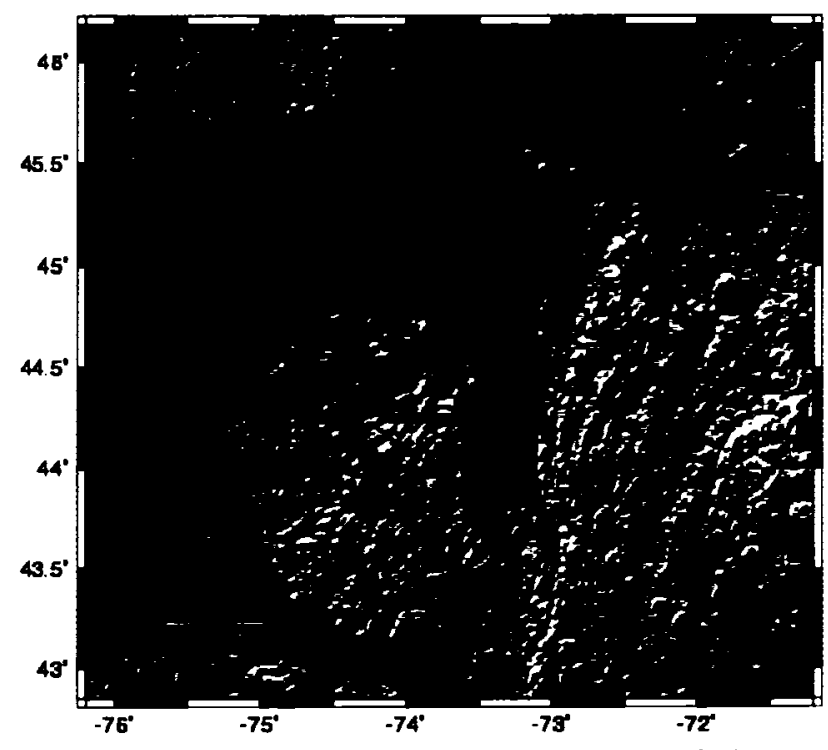

a) Intensity map based on ground-motion relations for eastern North America (Atkinson \& Boore, 1995) and relations between PGV/PGA and intensity developed by Wald, et al., (1999a)

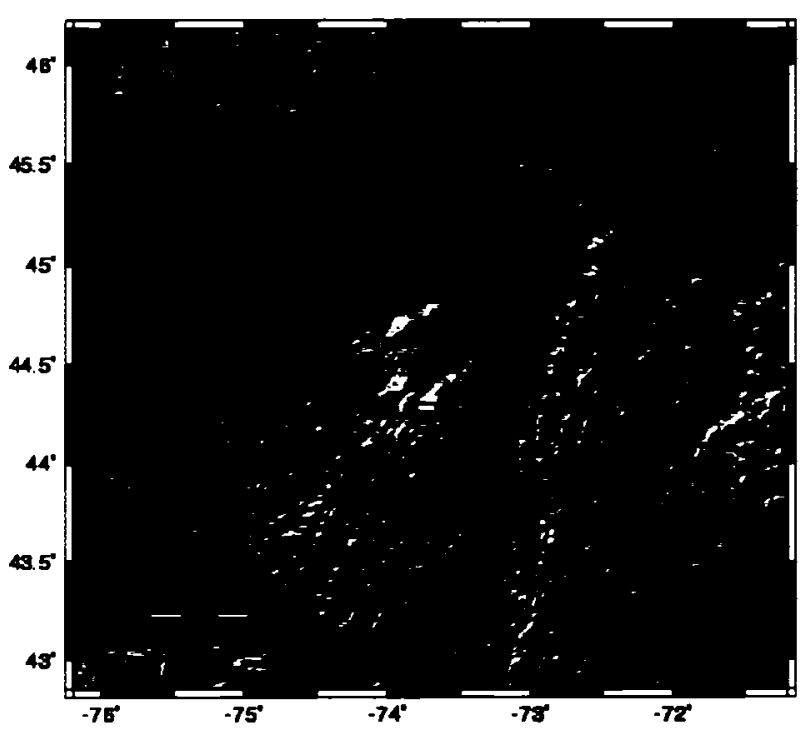

b) Intensity map based on ground-motion relations for eastern North America (Atkinson \& Boore, 1995) and relation between PGV and intensity developed in this study

Figure 5.8. ShakeMap intensities for the 2002 Au Sable Forks, New York M 5.0

earthquake. These maps use the AB95 ENA ground motion relations with a) relations between PGV/PGA and intensity developed by Wald, et al. (1999a); b) relation between PGV and intensity developed in this study. Top panel shows observed intensities. 


\section{Chapter 6}

\section{Empirical Ground-Motion Relations for ShakeMap Applications}

\subsection{Introduction}

ShakeMap requires ground-motion prediction equations to estimate ground motion at locations where no actual records are available; these equations provide amplitudes as a function of the event's magnitude and location. ShakeMap combines these estimated ground motions with the recorded values to produce contour maps of ground-motion parameters. These parameters are also used to estimate the associated felt intensity. In Ontario, ShakeMaps are required for the relatively frequent small-tomoderate events that are often felt, as well as for larger, potentially damaging events (M 5 to 6). Of course, very large events $(M>6)$ are also possible but occur only rarely (about once every hundred years) in most ENA regions. These rare events are important for engineering design, but are not the focus of our ShakeMap applications. Our ShakeMaps are based on seismographic instrumentation that may go off scale for such large events at close distances.

In Chapter 5, I showed that for small-to-moderate events (moment magnitude $\mathbf{M}$ $<5$ ), peak ground velocity (PGV) values estimated using common ENA ground-motion relations such as those of Atkinson and Boore (1995) (AB95), Toro et al. (1997), and Campbell (2003), are significantly higher than recorded values. This is a consequence of the focus of these relations, which aim to be most accurate for moderate-to large events (M 5-7) at close distance $(\mathrm{R}<100 \mathrm{~km})$. A new relation is required for ShakeMap applications, with better applicability to small-to-moderate events (M 3-5) over a broad range of distances ( 1 to $500 \mathrm{~km}$ ). 
In this chapter, I describe regression analyses to develop empirical relations for peak ground velocity (PGV), peak ground acceleration (PGA) and 5\% damped response spectra (PSA) at frequencies $1,2,5$ and $10 \mathrm{~Hz}$ for small-to-moderate events from southeastern Canada and the northeastern United States. The regression is based on a vertical-component database of 3097 digital seismograms from 205 earthquakes of Nuttli magnitude (Mn) greater than 2.0 that occurred between 1980 and 2004, mostly recorded on hard rock. The vertical-component is used as the basic ground-motion measure. Horizontal-component motions are predicted for ShakeMap based on the H/V ratio (see Chapter 7).

\subsection{Data set for the study}

My dataset is comprised of all available broadband three-component and shortperiod data from the Canadian National Seismographic Network (CNSN) and Portable Observatories for Lithospheric Analysis and Research Investigating Seismicity (POLARIS) network recorded from November 1993 through March 2004 in the study region, plus short-period vertical-component seismograms recorded from 1980 to 1990 on the Eastern Canada Telemetered Network (ECTN) as compiled by Atkinson and Mereu (1992). I also include data from the United States National Seismic Network stations (USNSN) in the study region. Figure 6.1 shows the locations of seismographic stations and study events. Figure 6.2 shows the distribution of the compiled database in magnitude and distance. Table 6.1 lists the date, latitude, longitude, depth, Nuttli magnitude (MN) and moment magnitude (M) for the 205 earthquakes analyzed in this study. All the information (except for the moment magnitude $\mathbf{M}$ ) is taken from the 
Canadian National Earthquake Database (NEDB) published by the Geological Survey of Canada and can be searched at their web site (http://www.seismo.nrcan.gc.ca/nedb/eq db e.php). M values are taken from Atkinson (2004), as calculated from the long-period spectral amplitudes. The regressions use $\mathbf{M}$ as the predictive magnitude variable, as do the relationships between instrumental groundmotion parameters and Modified Mercalli Intensity (MMI) (Chapter 5).

\subsection{Regression Results}

The ground-motion equations were obtained by a simple linear regression of the compiled dataset to obtain each ground-motion parameter as a function of $\mathbf{M}$ and hypocentral distance. The distribution of empirical data, as shown in Figure 6.2 , is insufficient to predict reliable ground motions for larger events $(\mathbf{M}>5)$. It is important that the predictive ground-motion relations predict not only ground-motion at low-tomoderate magnitudes but also be applicable for the larger magnitudes that occur infrequently in the region. Consequently, I add to the empirical database the predicted ground motion values for $5.0 \leq \mathbf{M} \leq 7$ (in 0.5 magnitude-unit increments, with hypocentral distance in increments of $0.1 \mathrm{log}$ units), as generated by Atkinson and Boore (1995) using the stochastic ground motion model for ENA. This will ensure that the relations are reasonable when extended to magnitudes greater than those in the recorded database. Thus the ground-motion equations I obtain are based on recorded groundmotion at low magnitudes, plus predictions from the Atkinson and Boore (1995) model for $\mathbf{M} \geq 5$. Table 6.2 lists the regression coefficients and their standard errors for the fit of the compiled dataset to the predictive ground-motion equations, which are of the form: 


$$
\log Y=C_{1}+C_{2}(M-4)+C_{3}(M-4)^{2}+C_{4} \log R+C_{5} R
$$

where $\mathrm{Y}$ is the vertical-component ground motion parameter $\mathrm{PGV}$ in $\mathrm{mm} / \mathrm{s}, \mathrm{PGA}$ and $\operatorname{PSA}(\mathrm{f})$ in $\left.\mathrm{cm} / \mathrm{s}^{2}\right), \mathrm{R}$ is hypocentral distance in $\mathrm{km}$, and $\mathbf{M}$ is moment magnitude.

To evaluate the performance of the regression equations, I analyzed the residuals, defined as the difference between the log of the observed ground-motion value and the $\log$ of the predicted value. Figure 6.3 plots the PGV residuals as a function of distance and moment magnitude. Plots for PGA and PSA(f) are similar in their trends. I use different symbols to distinguish between observed ground-motions values and those generated by the Atkinson and Boore (1995) (AB95) stochastic model. Notably, there is an apparent magnitude trend, attributable to the mismatch between the empirical predictions at low $\mathbf{M}$ and the AB95 stochastic model predictions at $\mathbf{M}>5$. These trends suggest that there is a strong likelihood that the new empirical relations might overestimate ground-motions values for $\mathbf{M} \geq 6$ events, as suggested by the decreasing residual trend at large magnitudes seen in Figure 6.3. This is not a great concern for us since these events are not the focus of the ShakeMap applications. For ShakeMap, I am interested in accurate prediction of ground motions for the more frequent small-tomoderate $(3<\mathbf{M}<5)$ events that are very typical in Ontario. Regression residuals in Figure 6.3 suggest that for $\mathbf{M} \leq 6$ events, we obtain reliable ground-motion estimates on average. We note the relatively high standard deviation ( $\sigma$ ) (from 0.31 to $0.37 \log$ units) of residuals for the regression analysis; this is expected due to the large magnitude and distance range of the compiled database (see Figure 6.2).

In Figure 6.4 I compare the developed empirical ground-motion relations with the AB95 model for an event of M 4.0 near Maniwaki, Quebec, which occurred on October 
12, 2003. The new empirical ground-motion equations closely predict the recorded ground motions, while the $\mathrm{AB} 95$ relations significantly over-predict ground-motion values for this event. This result is typical. Similar comparisons for other events (e.g. 1999/03/16 M4.5, 2003/08/20 M3.0, 2003/10/18 M3.0) also indicate over-prediction of recorded amplitudes for small events by the AB95 relations. This is not entirely surprising, since the AB95 relations were developed primarily for $\mathbf{M}>5$ events.

\subsection{Conclusions}

I have developed empirical ground-motion equations based on regression of a vertical component database of 3097 digital seismograms from 205 earthquakes of moment magnitude (M) 2 to 6 that occurred between 1980 and 2004. The relations are useful for the purpose of generating reliable ShakeMap in Ontario for small-to-moderate regional events. The predicted parameters are peak ground velocity (PGV), peak ground acceleration (PGA) and 5\% damped response spectra (PSA) at frequencies 1, 2, 5 and 10 Hz. My predictive equations differ from previous relations developed by Atkinson and Boore (1995) in their applicability to smaller events, and the emphasis on fit to empirical data rather than to model predictions (although model predictions are used to ensure reasonable ground motions for the larger magnitudes). The developed relations are appropriate for use as the interpolation basis in ShakeMaps for southeastern Canada and the northeastern United States. They are not intended for engineering ground-motion predictions for rare moderate-to-large events. 
Table 6.1. Study Earthquakes

Note: Depths that were assigned rather than determined are denoted by ' $g$ '.

\begin{tabular}{|c|c|c|c|c|c|}
\hline Date $(y / m / d)$ & Latitude & Longitude & Depth & $M N$ & $M$ \\
\hline 19800311 & 46.79 & 71.86 & $18.0 \mathrm{~g}$ & 3.7 & 3.53 \\
\hline 19800403 & 48.77 & 67.94 & $18.0 \mathrm{~g}$ & 4.0 & 3.53 \\
\hline 19800413 & 49.59 & 81.76 & $18.0 \mathrm{~g}$ & 4.1 & 3.63 \\
\hline 19800606 & 43.64 & 75.14 & $0.0 \mathrm{~g}$ & 3.5 & 3.04 \\
\hline 19810616 & 47.47 & 70.00 & 3.6 & 3.6 & 3.29 \\
\hline 19810704 & 45.14 & 74.62 & $13.0 \mathrm{~g}$ & 3.8 & 3.40 \\
\hline 19810713 & 49.91 & 66.92 & $18.0 \mathrm{~g}$ & 3.8 & 3.24 \\
\hline 19810918 & 49.53 & 66.10 & $18.0 \mathrm{~g}$ & 2.8 & 3.20 \\
\hline 19810930 & 46.32 & 75.59 & 10.3 & 3.4 & 3.14 \\
\hline 19811021 & 41.15 & 72.58 & $6.0 \mathrm{~g}$ & 3.8 & 3.33 \\
\hline 19811028 & 49.84 & 65.25 & $18.0 \mathrm{~g}$ & 3.9 & 3.43 \\
\hline 19811128 & 46.94 & 66.76 & $5.0 \mathrm{~g}$ & 3.8 & 3.55 \\
\hline 19820109 & 47.00 & 66.60 & $5.0 \mathrm{~g}$ & 3.9 & 3.60 \\
\hline 19820111 & 47.00 & 66.60 & $5.0 \mathrm{~g}$ & 5.4 & 4.95 \\
\hline 19820112 & 44.61 & 55.91 & $18.0 \mathrm{~g}$ & 3.7 & 3.24 \\
\hline 19820113 & 47.00 & 66.60 & $5.0 \mathrm{~g}$ & 4.0 & 3.38 \\
\hline 19820115 & 47.00 & 66.60 & $5.0 \mathrm{~g}$ & 3.8 & 3,33 \\
\hline 19820117 & 47.00 & 66.60 & $5.0 \mathrm{~g}$ & 3.6 & 3.47 \\
\hline 19820119 & 43.51 & 71.62 & $0.0 \mathrm{~g}$ & 4.5 & 4.14 \\
\hline 19820316 & 47.00 & 66.60 & $5.0 \mathrm{~g}$ & 3.5 & 3.40 \\
\hline 19820331 & 47.00 & 66.60 & $5.0 \mathrm{~g}$ & 5.0 & 4.23 \\
\hline 19820402 & 47.00 & 66.60 & $5.0 \mathrm{~g}$ & 4.3 & 3.82 \\
\hline 19820411 & 47.00 & 66.60 & $5.0 \mathrm{~g}$ & 4.0 & 3.76 \\
\hline 19820418 & 47.00 & 66.60 & $5.0 \mathrm{~g}$ & 4.1 & 3.71 \\
\hline 19820506 & 47.00 & 66.60 & $5.0 \mathrm{~g}$ & 4.0 & 3.62 \\
\hline 19820616 & 47.01 & 66.95 & $8.0 \mathrm{~g}$ & 4.7 & 4.21 \\
\hline 19820623 & 47.37 & 77.06 & $18.0 \mathrm{~g}$ & 3.5 & 3.05 \\
\hline 19820713 & 46.04 & 74.55 & $18.0 \mathrm{~g}$ & 3.8 & 3.37 \\
\hline 19820728 & 47.00 & 66.60 & $5.0 \mathrm{~g}$ & 3.7 & 3.52 \\
\hline 19820806 & 45.89 & 75.46 & $18.0 \mathrm{~g}$ & 3.7 & 3.24 \\
\hline 19820813 & 46.67 & 78.53 & $18.0 \mathrm{~g}$ & 4.3 & 3.70 \\
\hline 19820903 & 45.68 & 76.58 & $18.0 \mathrm{~g}$ & 3.7 & 3.34 \\
\hline 19821026 & 47.00 & 66.60 & $5.0 \mathrm{~g}$ & 3.5 & 3.22 \\
\hline 19821204 & 47.54 & 70.22 & 14.8 & 3.9 & 3.49 \\
\hline 19821204 & 47.54 & 70.22 & 14.8 & 3.9 & 3.80 \\
\hline 19830314 & 50.81 & 74.88 & $18.0 \mathrm{~g}$ & 3.6 & 3.14 \\
\hline 19830513 & 47.00 & 66.60 & $5.0 \mathrm{~g}$ & 3.5 & 3.28 \\
\hline 19830513 & 47.00 & 66.60 & $5.0 \mathrm{~g}$ & 3.9 & 3.91 \\
\hline 19830516 & 47.69 & 69.89 & 11.7 & 3.8 & 3.55 \\
\hline 19830527 & 45.56 & 69.51 & $10.0 \mathrm{~g}$ & 3.5 & 3.04 \\
\hline 19830529 & 44.48 & 70.42 & $2.0 \mathrm{~g}$ & 4.1 & 3.86 \\
\hline 19830812 & 44.96 & 67.72 & 14.9 & 3.5 & 3.19 \\
\hline 19831007 & 43.95 & 74.25 & $4.0 \mathrm{~g}$ & 3.6 & 3.39 \\
\hline 19831007 & 43.94 & 74.25 & $10.0 \mathrm{~g}$ & 5.6 & 4.82 \\
\hline 19831011 & 45.20 & 75.75 & $14.0 \mathrm{~g}$ & 4.1 & 3.77 \\
\hline 19831117 & 47.00 & 66.60 & $5.0 \mathrm{~g}$ & 3.7 & 3.46 \\
\hline 19831228 & 47.07 & 76.28 & $18.0 \mathrm{~g}$ & 3.5 & 3.06 \\
\hline 19840119 & 44.90 & 67.33 & 12.9 & 3.5 & 3.04 \\
\hline 19840224 & 47.00 & 66.60 & $5.0 \mathrm{~g}$ & 3.7 & 3.50 \\
\hline 19840411 & 49.30 & 67.52 & $18.0 \mathrm{~g}$ & 3.8 & 3.55 \\
\hline
\end{tabular}




\begin{tabular}{|c|c|c|c|c|c|}
\hline $\operatorname{Date}(\mathrm{y} / \mathrm{m} / \mathrm{d})$ & Latitude & Longitude & Depth & $M N$ & $\boldsymbol{M}$ \\
\hline 19840923 & 45.97 & 64.81 & $18.0 \mathrm{~g}$ & 3.6 & 3.50 \\
\hline 19841130 & 47.00 & 66.60 & $5.0 \mathrm{~g}$ & 3.8 & 3.64 \\
\hline 19850303 & 47.39 & 70.47 & 14.1 & 3.1 & 2.95 \\
\hline 19850410 & 47.52 & 69.96 & 12.7 & 3.1 & 2.65 \\
\hline 19850412 & 45.37 & 70.68 & 9.8 & 3.5 & 3.10 \\
\hline 19851005 & 47.00 & 66.60 & $5.0 \mathrm{~g}$ & 3.9 & 3.62 \\
\hline 19851019 & 41.21 & 73.98 & $18.0 \mathrm{~g}$ & 4.1 & 3.85 \\
\hline 19860111 & 47.70 & 70.12 & 6.4 & 4.0 & 3.54 \\
\hline 19860131 & 41.70 & 81.18 & $5.0 \mathrm{~g}$ & 5.0 & 4.69 \\
\hline 19860712 & 40.54 & 84.35 & $10.0 \mathrm{~g}$ & 4.5 & 4.50 \\
\hline 19860806 & 46.37 & 75.22 & 18.0 & 3.5 & 3.32 \\
\hline 19860818 & 47.53 & 70.02 & 5.6 & 3.0 & 2.55 \\
\hline 19860919 & 47.30 & 70.32 & 21.9 & 4.2 & 3.73 \\
\hline 19861025 & 43.42 & 71.56 & $8.5 \mathrm{~g}$ & 3.6 & 3.14 \\
\hline 19861109 & 49.24 & 67.41 & $18.0 \mathrm{~g}$ & 4.2 & 3.83 \\
\hline 19870318 & 47.72 & 70.19 & 4.2 & 3.3 & 2.84 \\
\hline 19870713 & 41.93 & 80.71 & $5.0 \mathrm{~g}$ & 4.1 & 3.63 \\
\hline 19870806 & 47.43 & 70.28 & $18.0 \mathrm{~g}$ & 3.4 & 3.02 \\
\hline 19870926 & 44.49 & 74.52 & $5.0 \mathrm{~g}$ & 3.8 & 3.42 \\
\hline 19871023 & 45.76 & 74.51 & 14.8 & 3.7 & 3.29 \\
\hline 19871111 & 45.77 & 75.34 & 17.1 & 3.2 & 3.17 \\
\hline 19880102 & 47.42 & 70.43 & 10.8 & 3.6 & 3.21 \\
\hline 19880124 & 47.44 & 70.46 & 10.5 & 3.1 & 2.65 \\
\hline 19880128 & 48.00 & 65.66 & $18.0 \mathrm{~g}$ & 3.8 & 3.62 \\
\hline 19880310 & 46.34 & 75.67 & 12.5 & 3.7 & 3.36 \\
\hline 19880313 & 47.44 & 70.38 & 6.8 & 3.1 & 2.84 \\
\hline 19880424 & 46.01 & 64.92 & $5.0 \mathrm{~g}$ & 3.7 & 3.41 \\
\hline 19880509 & 47.00 & 66.60 & $5.0 \mathrm{~g}$ & 3.5 & 3.23 \\
\hline 19880515 & 45.16 & 75.61 & 8.5 & 3.3 & 3.01 \\
\hline 19880809 & 45.01 & 74.99 & 9.5 & 3.4 & 2.97 \\
\hline 19880826 & 47.00 & 66.60 & $5.0 \mathrm{~g}$ & 3.8 & 3.57 \\
\hline 19881020 & 44.56 & 71.17 & $5.0 \mathrm{~g}$ & 3.9 & 3.55 \\
\hline 19881114 & 44.52 & 70.43 & $18.0 \mathrm{~g}$ & 3.7 & 3.24 \\
\hline 19881123 & 48.13 & 71.20 & $29.0 \mathrm{~g}$ & 4.6 & 4.26 \\
\hline 19881125 & 48.12 & 71.18 & 28.9 & 6.5 & 5.98 \\
\hline 19881126 & 48.14 & 71.30 & 26.4 & 4.1 & 3.57 \\
\hline 19881228 & 44.70 & 69.48 & $18.0 \mathrm{~g}$ & 3.5 & 3.04 \\
\hline 19890119 & 48.06 & 71.01 & 24.8 & 3.6 & 3.30 \\
\hline 19890131 & 47.44 & 70.67 & 19.7 & 3.1 & 2.84 \\
\hline 19890210 & 50.07 & 64.65 & $18.0 \mathrm{~g}$ & 4.3 & 3.91 \\
\hline 19890316 & 60.06 & 70.06 & $18.0 \mathrm{~g}$ & 5.7 & 5.20 \\
\hline 19890810 & 46.66 & 65.79 & $5.0 \mathrm{~g}$ & 3.5 & 3.36 \\
\hline 19891013 & 47.39 & 70.13 & 22.7 & 3.2 & 3.15 \\
\hline 19891104 & 46.22 & 75.72 & 7.9 & 3.4 & 2.76 \\
\hline 19891116 & 46.58 & 76.60 & $18.0 \mathrm{~g}$ & 4.0 & 3.57 \\
\hline 19891122 & 47.46 & 70.34 & 7.6 & 3.4 & 3.07 \\
\hline 19891225 & 60.12 & 73.60 & $5.0 \mathrm{~g}$ & 5.0 & 4.57 \\
\hline 19900105 & 60.12 & 73.60 & $5.0 \mathrm{~g}$ & 4.4 & 3.92 \\
\hline 19900303 & 47.86 & 69.98 & 20.8 & 3.6 & 3.41 \\
\hline 19900313 & 47.53 & 70.14 & 15.3 & 3.2 & 2.83 \\
\hline 19900421 & 47.55 & 70.07 & 9.6 & 3.1 & 2.88 \\
\hline 19900423 & 47.41 & 70.18 & 8.2 & 3.0 & 2.72 \\
\hline 19901007 & 46.31 & 75.19 & $18.0 \mathrm{~g}$ & 3.9 & 3.51 \\
\hline 19901019 & 46.47 & 75.59 & 13.1 & 5.1 & 4.49 \\
\hline
\end{tabular}




\begin{tabular}{|c|c|c|c|c|c|}
\hline $\operatorname{Date}(y / m / d)$ & Latitude & Longitude & Depth & $M N$ & $\mathbf{M}$ \\
\hline 19901021 & 47.40 & 70.36 & 15.8 & 3.3 & 2.92 \\
\hline 19931116 & 45.19 & 73.46 & 15.1 & 4.3 & 3.80 \\
\hline 19971028 & 47.67 & 69.91 & 11.3 & 4.7 & 4.20 \\
\hline 19971106 & 46.80 & 71.42 & $22.5 \mathrm{~g}$ & 5.1 & 4.23 \\
\hline 19990316 & 49.61 & 66.32 & $18.0 \mathrm{~g}$ & 5.1 & 4.50 \\
\hline 20000101 & 46.84 & 78.93 & $12.0 \mathrm{~g}$ & 5.2 & 4.54 \\
\hline 20020211 & 73.32 & 70.25 & $18.0 \mathrm{~g}$ & 4.1 & 3.32 \\
\hline 20020224 & 45.29 & 75.17 & $18.0 \mathrm{~g}$ & 3.1 & 2.66 \\
\hline 20020401 & 46.30 & 75.76 & $18.0 \mathrm{~g}$ & 3.1 & 2.68 \\
\hline 20020420 & 44.53 & 73.70 & $18.0 \mathrm{~g}$ & 3.0 & 2.66 \\
\hline 20020420 & 44.58 & 73.69 & $18.0 \mathrm{~g}$ & 3.1 & 2.66 \\
\hline 20020420 & 44.58 & 73.73 & $18 \mathrm{~g}$ & 4.1 & 3.55 \\
\hline 20020420 & 44.53 & 73.73 & $18.0 \mathrm{~g}$ & 5.5 & 4.84 \\
\hline 20020427 & 46.97 & 76.25 & $18.0 \mathrm{~g}$ & 3.1 & 2.60 \\
\hline 20020524 & 44.50 & 73.68 & $10.0 \mathrm{~g}$ & 3.5 & 3.13 \\
\hline 20020528 & 45.63 & 76.62 & $18.0 \mathrm{~g}$ & 3.4 & 2.98 \\
\hline 20020607 & 43.83 & 78.44 & $5.0 \mathrm{~g}$ & 2.2 & 1.77 \\
\hline 20020717 & 44.41 & 77.50 & $5.0 \mathrm{~g}$ & 2.4 & 1.96 \\
\hline 20020721 & 65.57 & 89.11 & $18.0 \mathrm{~g}$ & 3.1 & 2.65 \\
\hline 20020723 & 49.59 & 66.95 & $18.0 \mathrm{~g}$ & 4.0 & 3.50 \\
\hline 20020817 & 47.33 & 70.51 & 13.3 & 3.8 & 3.25 \\
\hline 20020829 & 45.11 & 73.32 & $18.0 \mathrm{~g}$ & 2.6 & 2.16 \\
\hline 20020907 & 46.96 & 76.29 & $18.0 \mathrm{~g}$ & 3.7 & 3.11 \\
\hline 20020921 & 46.07 & 74.84 & $18.0 \mathrm{~g}$ & 2.8 & 2.35 \\
\hline 20021031 & 48.89 & 67.97 & $18.0 \mathrm{~g}$ & 2.9 & 2.45 \\
\hline 20021107 & 44.07 & 77.44 & $5.0 \mathrm{~g}$ & 3.0 & 2.55 \\
\hline 20021222 & 49.93 & 75.52 & $18.0 \mathrm{~g}$ & 2.8 & 2.35 \\
\hline 20021225 & 44.57 & 73.78 & 10.9 & 3.3 & 2.84 \\
\hline 20030102 & 46.30 & 74.56 & $18.0 \mathrm{~g}$ & 2.8 & 2.35 \\
\hline 20030104 & 49.60 & 67.24 & $18.0 \mathrm{~g}$ & 3.4 & 2.94 \\
\hline 20030109 & 45.59 & 74.46 & $18.0 \mathrm{~g}$ & 2.9 & 2.45 \\
\hline 20030115 & 46.46 & 71.93 & $18.0 \mathrm{~g}$ & 2.5 & 2.06 \\
\hline 20030121 & 43.76 & 77.97 & $18.0 \mathrm{~g}$ & 2.9 & 2.45 \\
\hline 20030123 & 50.60 & 59.22 & $18.0 \mathrm{~g}$ & 3.5 & 3.04 \\
\hline 20030128 & 45.31 & 74.92 & $18.0 \mathrm{~g}$ & 3.0 & 2.55 \\
\hline 20030130 & 50.22 & 64.53 & $18.0 \mathrm{~g}$ & 2.7 & 2.26 \\
\hline 20030209 & 46.51 & 75.20 & $18.0 \mathrm{~g}$ & 3.3 & 2.84 \\
\hline 20030225 & 46.60 & 76.53 & $18.0 \mathrm{~g}$ & 3.0 & 2.55 \\
\hline 20030228 & 47.50 & 70.03 & 8.6 & 3.3 & 2.84 \\
\hline 20030314 & 45.66 & 77.36 & $18.0 \mathrm{~g}$ & 3.1 & 2.65 \\
\hline 20030322 & 51.00 & 65.60 & $18.0 \mathrm{~g}$ & 3.6 & 3.14 \\
\hline 20030323 & 48.86 & 67.87 & $18.0 \mathrm{~g}$ & 3.3 & 2.80 \\
\hline 20030408 & 44.62 & 74.37 & 11.9 & 3.7 & 3.24 \\
\hline 20030413 & 46.94 & 71.16 & $18.0 \mathrm{~g}$ & 3.4 & 2.94 \\
\hline 20030424 & 46.44 & 74.12 & $18.0 \mathrm{~g}$ & 2.6 & 2.16 \\
\hline 20030425 & 47.23 & 66.34 & $18.0 \mathrm{~g}$ & 2.8 & 2.35 \\
\hline 20030425 & 47.24 & 66.35 & $18.0 \mathrm{~g}$ & 3.2 & 2.75 \\
\hline 20030502 & 49.27 & 67.49 & $18.0 \mathrm{~g}$ & 2.8 & 2.35 \\
\hline 20030509 & 46.90 & 75.83 & $18.0 \mathrm{~g}$ & 2.6 & 2.16 \\
\hline 20030512 & 44.44 & 67.17 & $5.0 \mathrm{~g}$ & 2.8 & 2.35 \\
\hline 20030516 & 45.93 & 83.53 & $18.0 \mathrm{~g}$ & 2.2 & 1.77 \\
\hline 20030519 & 44.50 & 73.54 & $18.0 \mathrm{~g}$ & 2.1 & 1.67 \\
\hline 20030520 & 46.40 & 74.68 & $18.0 \mathrm{~g}$ & 2.1 & 1.67 \\
\hline 20030525 & 44.71 & 80.71 & $18.0 \mathrm{~g}$ & 2.0 & 1.57 \\
\hline
\end{tabular}




\begin{tabular}{lccccc}
\hline Date $(y / \mathrm{m} / \mathrm{d})$ & Latitude & Longitude & Depth & $\boldsymbol{M N}$ & $\boldsymbol{M}$ \\
\hline 20030610 & 49.58 & 66.97 & $18.0 \mathrm{~g}$ & 2.3 & 1.86 \\
20030611 & 49.44 & 66.44 & $18.0 \mathrm{~g}$ & 2.6 & 2.16 \\
20030613 & 47.70 & 70.09 & 11.1 & 4.1 & 3.52 \\
20030617 & 47.70 & 70.07 & 11.8 & 2.0 & 1.57 \\
20030619 & 49.17 & 67.77 & $18.0 \mathrm{~g}$ & 2.0 & 1.57 \\
20030630 & 41.70 & 81.11 & $18.0 \mathrm{~g}$ & 3.6 & 3.14 \\
20030701 & 49.10 & 67.58 & $18.0 \mathrm{~g}$ & 2.0 & 1.57 \\
20030704 & 50.49 & 64.94 & $18.0 \mathrm{~g}$ & 3.1 & 2.65 \\
20030709 & 48.69 & 83.62 & $18.0 \mathrm{~g}$ & 2.4 & 1.96 \\
20030715 & 47.47 & 70.05 & 6.22 & 2.2 & 1.77 \\
20030717 & 41.93 & 80.80 & $18.0 \mathrm{~g}$ & 2.5 & 2.06 \\
20030722 & 42.68 & 69.87 & $18.0 \mathrm{~g}$ & 3.7 & 3.24 \\
20030725 & 47.74 & 70.07 & 11.6 & 2.2 & 1.86 \\
20030805 & 47.50 & 70.01 & 16.1 & 2.1 & 1.67 \\
20030805 & 46.81 & 78.94 & $18.0 \mathrm{~g}$ & 2.8 & 2.35 \\
20030807 & 46.04 & 73.41 & $18.0 \mathrm{~g}$ & 2.4 & 1.96 \\
20030817 & 46.06 & 74.77 & $18.0 \mathrm{~g}$ & 2.2 & 1.77 \\
20030817 & 47.56 & 70.04 & 8.5 & 2.9 & 2.45 \\
20030820 & 46.01 & 74.95 & $18.0 \mathrm{~g}$ & 3.5 & 3.04 \\
20030821 & 47.67 & 69.90 & 9.5 & 2.2 & 1.77 \\
20030825 & 43.47 & 79.47 & $18.0 \mathrm{~g}$ & 2.1 & 1.86 \\
20030825 & 47.63 & 69.94 & 15.5 & 2.4 & 1.96 \\
20030831 & 45.46 & 74.00 & $18.0 \mathrm{~g}$ & 2.3 & 1.86 \\
20031001 & 47.00 & 75.64 & $18.0 \mathrm{~g}$ & 2.0 & 1.57 \\
20031001 & 46.36 & 76.64 & $18.0 \mathrm{~g}$ & 2.2 & 1.77 \\
20031011 & 47.53 & 69.86 & 23.2 & 3.1 & 2.65 \\
20031012 & 47.01 & 76.36 & $18.0 \mathrm{~g}$ & 4.5 & 4.02 \\
20031013 & 46.99 & 76.35 & $18.0 \mathrm{~g}$ & 2.1 & 1.67 \\
20031015 & 45.08 & 66.91 & $18.0 \mathrm{~g}$ & 3.1 & 2.65 \\
20031018 & 46.94 & 67.19 & $18.0 \mathrm{~g}$ & 3.5 & 3.04 \\
20031102 & 49.02 & 67.68 & $18.0 \mathrm{~g}$ & 2.0 & 1.57 \\
20031103 & 48.56 & 72.85 & $18.0 \mathrm{~g}$ & 2.1 & 1.67 \\
20031104 & 46.37 & 77.47 & $18.0 \mathrm{~g}$ & 2.6 & 2.16 \\
20031108 & 47.65 & 69.94 & 16.3 & 2.0 & 1.57 \\
20031109 & 45.21 & 73.91 & $18.0 \mathrm{~g}$ & 2.2 & 1.77 \\
20031120 & 47.47 & 70.11 & 11.0 & 2.4 & 1.96 \\
20031122 & 45.56 & 76.44 & $18.0 \mathrm{~g}$ & 2.6 & 2.16 \\
20031124 & 46.30 & 72.69 & $18.0 \mathrm{~g}$ & 2.6 & 2.16 \\
20031127 & 47.69 & 70.09 & 5.4 & 2.2 & 1.77 \\
20031130 & 44.06 & 77.43 & $18.0 \mathrm{~g}$ & 2.6 & 2.16 \\
20040118 & 47.36 & 76.01 & $18.0 \mathrm{~g}$ & 2.6 & 2.16 \\
20040121 & 45.95 & 75.01 & $18.0 \mathrm{~g}$ & 2.3 & 1.86 \\
20040216 & 44.55 & 76.33 & $18.0 \mathrm{~g}$ & 2.4 & 1.96 \\
20040226 & 46.38 & 76.95 & $18.0 \mathrm{~g}$ & 2.5 & 2.06 \\
20040305 & 46.42 & 75.16 & $18.0 \mathrm{~g}$ & 2.6 & 2.16 \\
20040317 & 44.92 & 74.88 & $18.0 \mathrm{~g}$ & 2.8 & 1.96 \\
20040317 & 45.05 & 75.66 & $18.0 \mathrm{~g}$ & 2.5 & 2.06 \\
\hline & & & & & \\
& & & & &
\end{tabular}


Table 6.2. Regression Coefficients (and their standard errors)

$\log \mathrm{Y}=\mathrm{C}_{1}+\mathrm{C}_{2}(\mathbf{M}-4)+\mathrm{C}_{3}(\mathbf{M}-4)^{2}+\mathrm{C}_{4} \log \mathrm{R}+\mathrm{C}_{5} \mathrm{R}$ with standard deviation $\sigma$

$\mathrm{Y}$ is the vertical-component ground motion parameter, $\mathrm{R}$ is hypocentral distance in $\mathrm{km}, \mathbf{M}$ is moment magnitude.

\begin{tabular}{|l|c|c|c|c|c|c|}
\hline \multicolumn{1}{|c|}{ Y } & $\begin{array}{c}\text { PGV } \\
(\mathbf{m m} / \mathbf{s})\end{array}$ & $\begin{array}{c}\text { PGA } \\
\left(\mathbf{c m} / \mathbf{s}^{2}\right)\end{array}$ & $\begin{array}{c}\text { PSA (1Hz) } \\
\left(\mathbf{c m} / \mathbf{s}^{2}\right)\end{array}$ & $\begin{array}{c}\text { PSA (2Hz) } \\
\left(\mathbf{c m} / \mathbf{s}^{2}\right)\end{array}$ & $\begin{array}{c}\text { PSA (5Hz) } \\
\left(\mathbf{c m} / \mathbf{s}^{2}\right)\end{array}$ & $\begin{array}{c}\text { PSA (10 Hz) } \\
\left(\mathbf{c m} / \mathbf{s}^{2}\right)\end{array}$ \\
\hline $\mathrm{C}_{1}$ & 1.496 & 2.779 & 0.209 & 1.185 & 1.891 & 2.524 \\
\hline $\mathrm{C}_{1}$ Error & 0.064 & 0.091 & 0.090 & 0.082 & 0.086 & 0.092 \\
\hline $\mathrm{C}_{2}$ & 0.899 & 0.855 & 1.047 & 1.068 & 0.943 & 0.825 \\
\hline $\mathrm{C}_{2}$ Error & 0.008 & 0.008 & 0.008 & 0.008 & 0.008 & 0.008 \\
\hline $\mathrm{C}_{3}$ & 0.029 & -0.050 & 0.015 & -0.060 & -0.074 & -0.061 \\
\hline $\mathrm{C}_{3}$ Error & 0.004 & 0.005 & 0.005 & 0.005 & 0.005 & 0.005 \\
\hline $\mathrm{C}_{4}$ & -1.268 & -1.433 & -0.854 & -0.963 & -0.922 & -1.094 \\
\hline $\mathrm{C}_{4}$ Error & 0.030 & 0.047 & 0.046 & 0.041 & 0.044 & 0.047 \\
\hline $\mathrm{C}_{5}$ & $-9.146 \mathrm{e}-5$ & $-7.563 \mathrm{e}-4$ & $7.091 \mathrm{e}-6$ & $-1.845 \mathrm{e}-4$ & $-9.77 \mathrm{e}-4$ & -0.0013 \\
\hline $\mathrm{C}_{5}$ Error & $4.313 \mathrm{e}-5$ & $9.325 \mathrm{e}-5$ & $9.211 \mathrm{e}-5$ & $8.45 \mathrm{e}-5$ & $8.82 \mathrm{e}-5$ & $9.42 \mathrm{e}-5$ \\
\hline$\sigma$ & 0.368 & 0.346 & 0.340 & 0.312 & 0.328 & 0.349 \\
\hline
\end{tabular}


Locations of the study earthquakes and recording stations

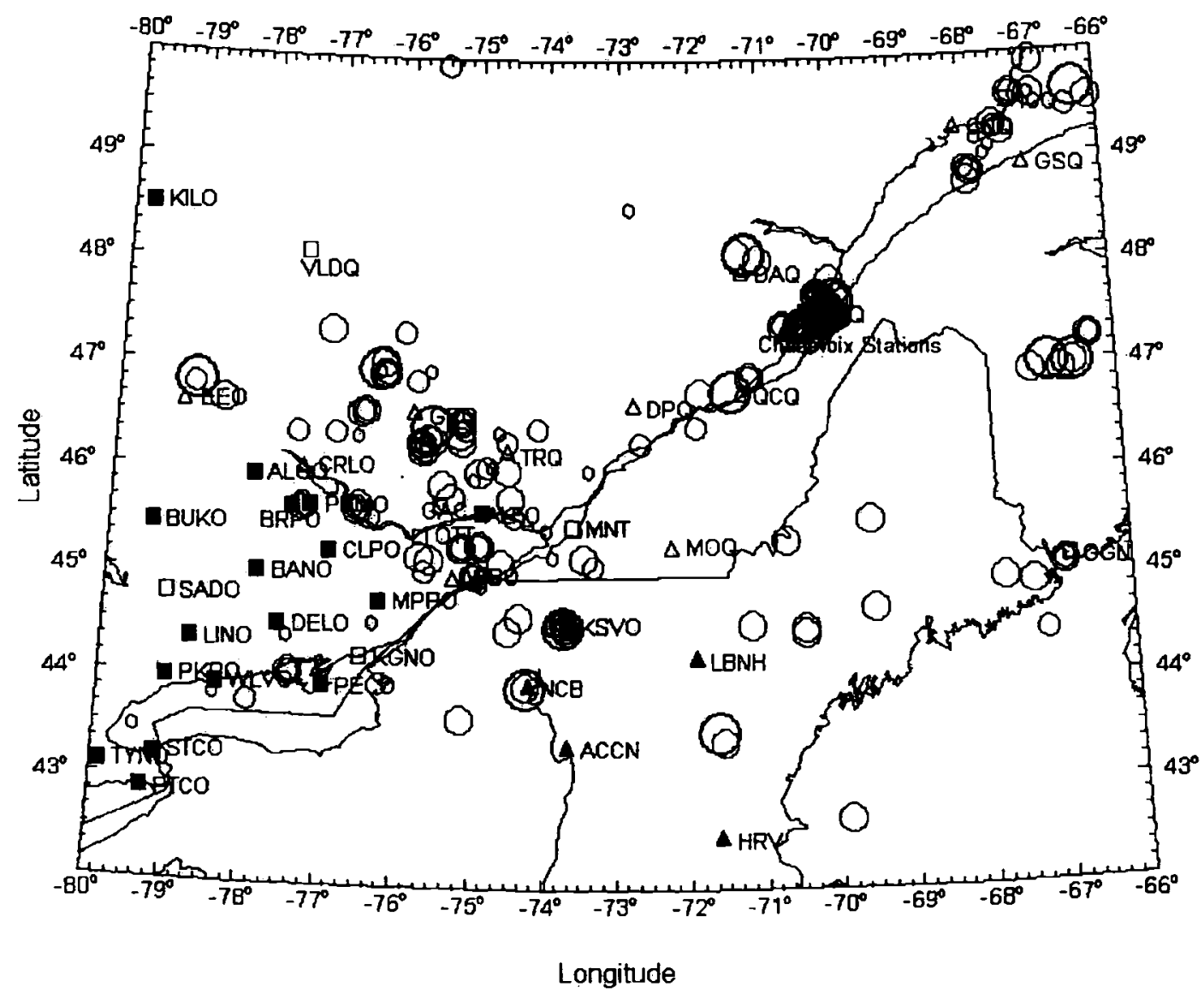

- $M<2 \quad 02 \leq M<3 \bigcirc 3 \leq M \leq 4 \bigcirc M>4$ a POLARIS $\square$ CNSN $\triangle$ ECTN $\triangle$ USNSN

Figure 6.1. Locations of the study earthquakes and recording stations. 
Distribution of Compiled Recorded Data Set

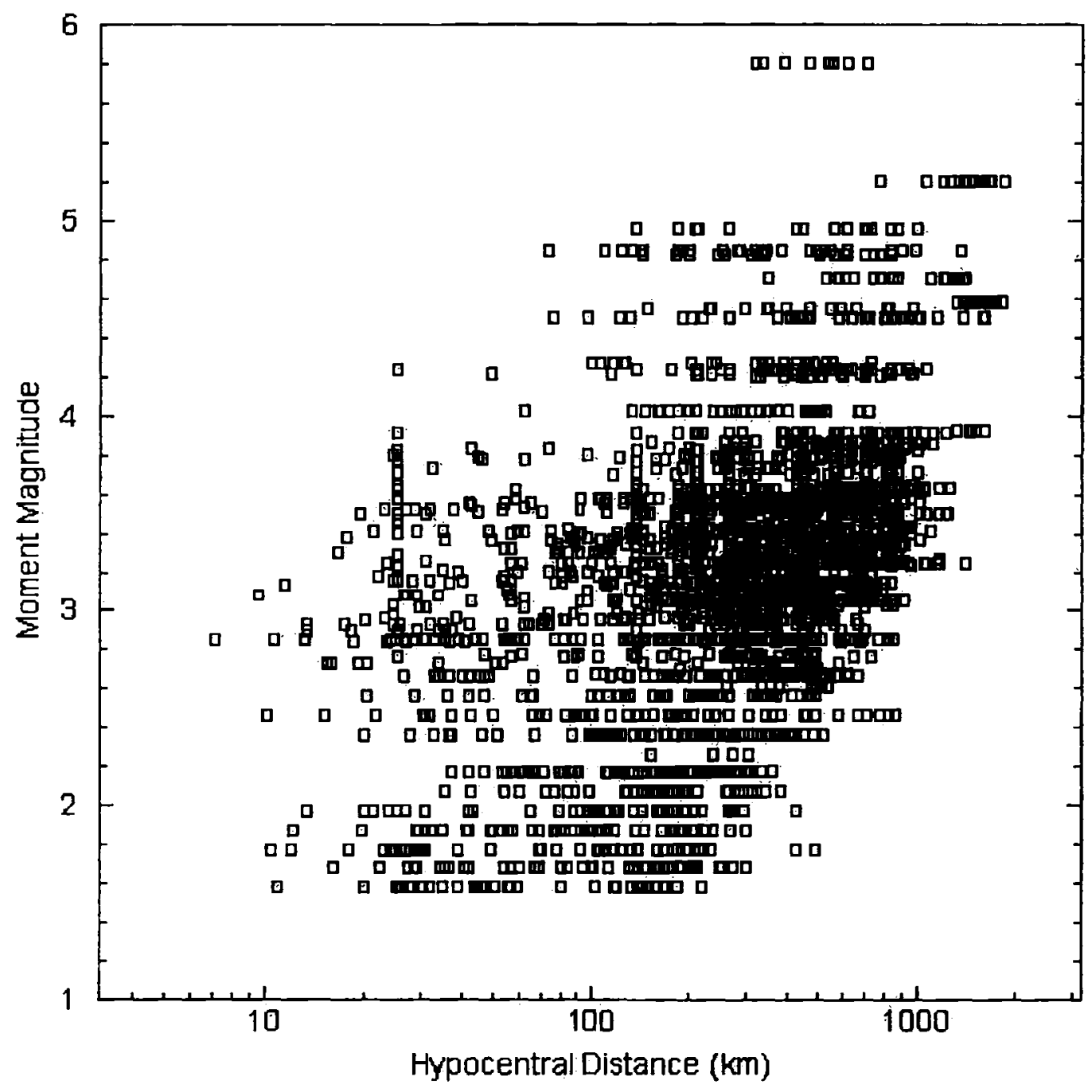

Figure 6.2. Distribution of compiled recorded ground-motion data set (verticalcomponent) in moment magnitude (M) and hypocentral distance (R). 

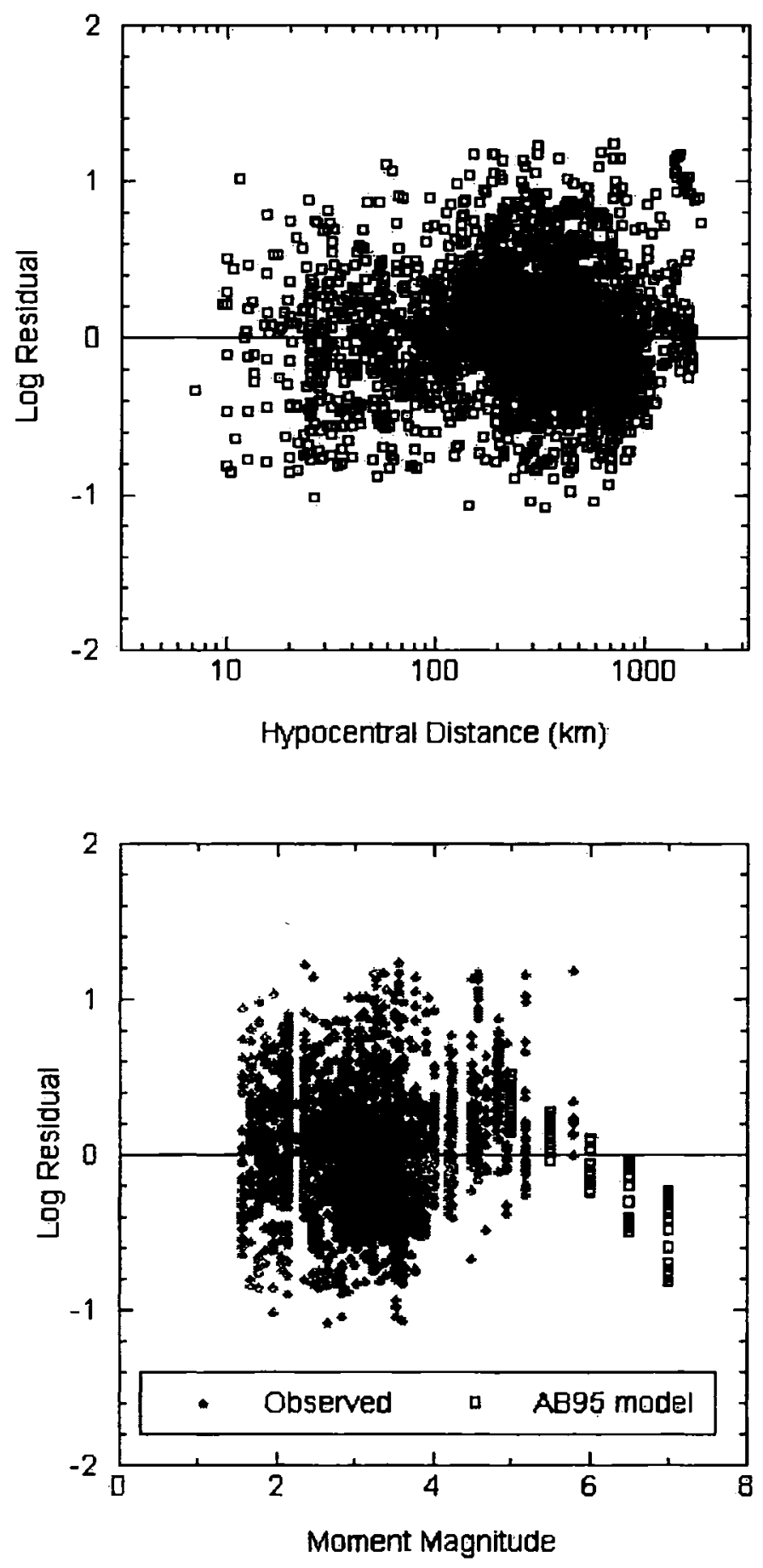

Figure 6.3. Log residuals (=log observed ground motion - log predicted ground motion) for the regression data plotted as a function of distance and moment magnitude. 

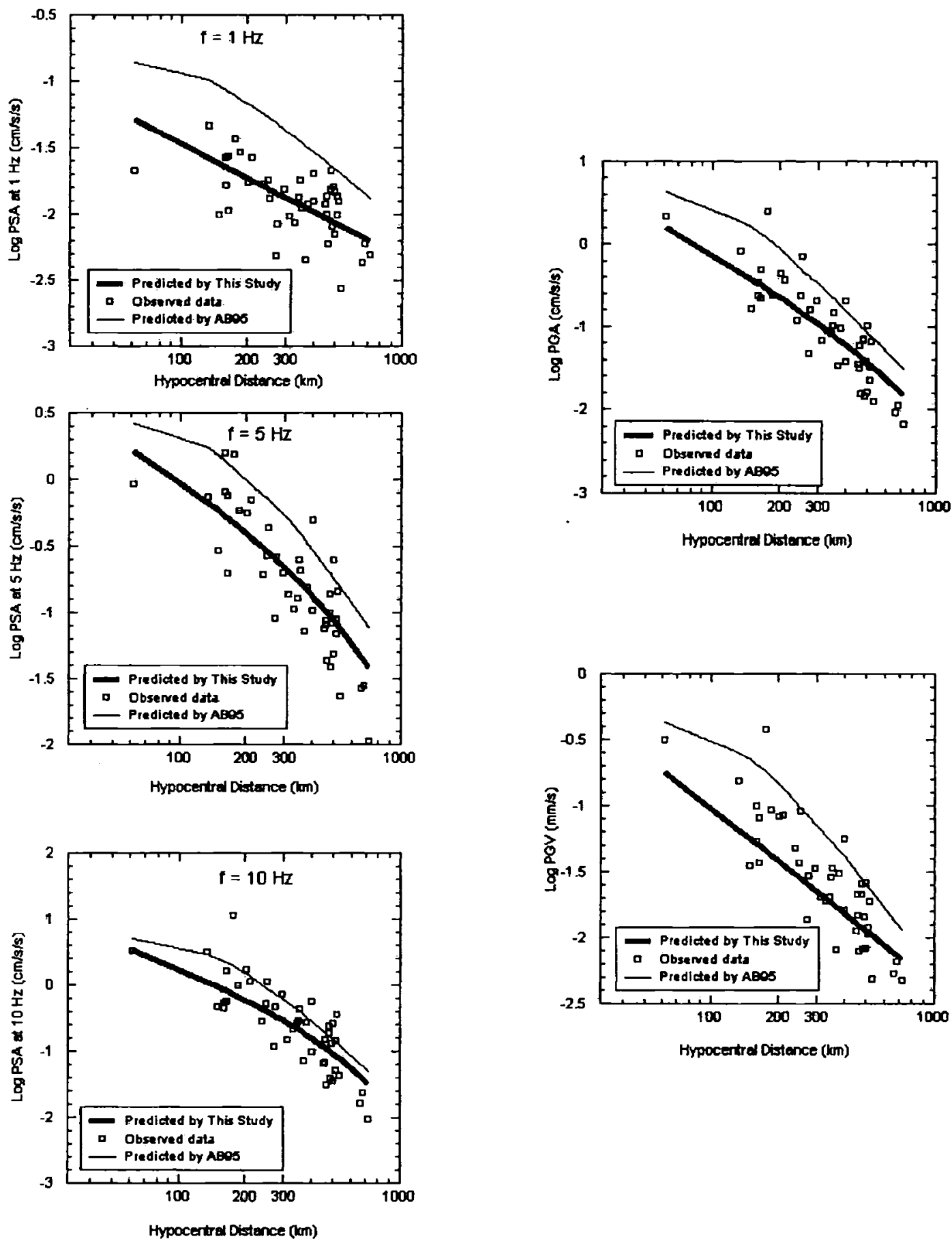

Figure 6.4. Comparison of ground-motion amplitudes predicted by the empirical relations developed in this study (thick line) with that of the Atkinson and Boore relations (thin line) using observed data of the 2003/10/12 M 4.0 earthquake near Maniwaki, Quebec. 


\section{Chapter 7}

\section{Estimation of Site Amplification Factors at Ontario POLARIS Stations for ShakeMaps}

\subsection{Introduction}

The intensity of earthquake shaking may vary significantly within small areas, and in some cases damage may occur at locations far from the epicenter, due to local site amplifications or site effects. Felt-intensity maps prepared after past damaging events (e.g. Mexico City earthquake of 1985, Loma Prieta earthquake of 1989, the 1994 Northridge earthquake, and the 1999 Izmit earthquake) show an irregular damage pattern. There is a correlation between damage patterns and near-surface materials, with motions being in general more severe on soil sites than on rock sites. Soft soils are particularly susceptible to amplification effects. Thus, understanding and characterizing site conditions and their effects on ground motion is a key step for the development of reliable ShakeMaps. The lack of site-specific information on site response is a limitation of current Ontario ShakeMaps. This chapter describes how site response is currently handled in ShakeMap and the steps required to improve this treatment in future.

\subsection{Methodology for Site Amplification Factors}

There are numerous methodologies for characterizing site amplification factors (see Field and Jacob 1995). The most accurate method is the borehole method, in which boreholes are drilled and seismometers placed in the boreholes in order to compare the ground-motion amplitudes at the surface to those at depth directly. However, this method 
is expensive due to drilling and instrumentation costs and thus not practical for regional site characterization. The standard spectral ratio method (see Borcherdt, 1970) is a popular technique which requires a pair of seismometers, one placed at a soil site under investigation and the other placed at a nearby reference rock site, which is assumed to have a flat spectral response within the frequency band of interest. Both seismometers simultaneously record the ground-motion amplitudes for a number of events. The soil effect at the site under investigation is then approximated by the spectral ratio of soil-torock site recordings. This method is also not practical for broad regional studies, due to the difficulty of finding nearby rock reference sites across the Ontario network.

Recently, a non-reference site-dependent horizontal-to-vertical spectral ratio $(\mathrm{H} / \mathrm{V})$ method has become very popular. By this method, site response is estimated from the Fourier spectral ratios of the horizontal components of a recording to the vertical one. One of the main advantages of this method is that it is applicable in areas with low-tomoderate seismicity (such as the Ontario ShakeMap network region) and it does not require a reference rock site. The site amplification is estimated from a single seismic station recording three components.

The $\mathrm{H} / \mathrm{V}$ method consists of taking the spectral ratio between the horizontal and the vertical components of the shear wave part of the recordings. The method assumes that the vertical component of ground-motion is not influenced by site effects and therefore can be used to deconvolve source and path effects from the site effects. Nakamura (1989) initially introduced the method for estimating site response from micro-tremor measurements and later Lermo and Chavez-Garcia (1994) generalized it to study the S-wave portion of the earthquake recordings at different sites in Mexico. This 
method has been applied by various researchers (Theodulidis et al., 1996; Theodulidis and Bard, 1995; Lermo and Chavez-Garcia, 1994; Atkinson and Cassidy, 2000; Siddiqqi and Atkinson, 2002 ), who suggest that the $\mathrm{H} / \mathrm{V}$ method is an effective if crude way to estimate site effects (Omachi et al. (1991); Field and Jacob (1995)). It has been shown that the H/V method results are stable with respect to magnitude, distance and depth, and hence it is implied that results are independent of shaking intensity (Yamazaki and Ansary, 1997). However, others (e.g., Lachet and Bard (1994)) suggest that while H/V is an effective technique for identifying the dominant period of response, it may be inaccurate in estimating the peak amplification factor. Also it lacks a firm theoretical basis.

In this study, $\mathrm{H} / \mathrm{V}$ is used to provide an initial estimate of site effects at POLARIS stations. These estimates can be refined in future as more information on regional site response becomes available.

\subsubsection{Amplification of Ground Motion Amplitude}

Site amplification can be computed from knowledge of the shear-wave velocity structure of the soil profile based on theoretical methods. Resonance effects within the soil column occur at seismic wave frequencies that equal the natural frequency of the layer. A simple estimate of the natural frequency of a layer is given by:

$$
f_{n}=\frac{V_{s}}{4 H}
$$

where $V_{s}$ is the shear-wave velocity and $H$ is the thickness of the layer (Aki and Richards, 1980). 
If the frequency of a seismic wave is equal to the natural frequency of the layer, amplification will occur increasing the amplitude of the ground motion at the natural frequency. The amplification is given by the ratio of seismic impedance between the two layers:

$$
A_{\text {resonant }}=\frac{\rho_{r} V_{r}}{\rho_{s} V_{s}}
$$

where $\rho_{r} V_{r}$ and $\rho_{S} V_{S}$ are the density and velocity of the rock layer and the soil layer respectively. Amplification increases as the impedance contrast between two layers increases.

The amplification from a gradual change in seismic impedance can be predicted using the quarter-wavelength approximation method of Boore and Joyner (1997) and Boore and Brown (1998). The amplification due to a velocity gradient is given by:

$$
A_{\text {gradient }}(f)=\sqrt{\frac{\rho_{i} V_{i} \cos \left(\theta_{i}\right)}{\rho_{s} V_{s} \cos \left(\theta_{s}\right)}}
$$

where $\rho$ is the density, $\mathrm{V}$ is the shear-wave velocity, $\theta$ is the angle of incidence and the subscripts s and i correspond to the properties at the earthquake source, and within layer $i$, respectively. The layer $i$ is taken to have a thickness corresponding to $1 / 4$ wavelength, and thus Equation 7.3 is frequency-dependent. Since the angle of incidence is generally assumed to be small, the cosine factors are neglected in the equation.

The procedure for computing the amplification as outlined by Boore and Joyner (1997) can be summarized as follows:

- The properties of the soil site, for each frequency, are travel-time-averaged over a depth equal to a quarter wavelength for that frequency 
- The amplification between the reference rock parameters and the site is determined by the Equation 7.3.

From Equation 7.1 and 7.2 the importance of determining $V_{s}$ for the surficial layer is apparent. If the velocity structure is known, we can compare the expected amplification. However, velocity profiles are available for very few sites in Ontario. Therefore we rely primarily on the $\mathrm{H} / \mathrm{V}$ method.

In this chapter, site amplification factors are determined across Ontario ShakeMap network from the $\mathrm{H} / \mathrm{V}$ method, using Fourier spectra as well as peak ground velocity (PGV). H/V values for PGV throughout the Ontario POLARIS network stations are required since the Ontario ShakeMap generates a near-real-time PGV-map, which is then used to derive a corresponding MMI- intensity ShakeMap (see Chapter 4).

\subsubsection{Ontario POLARIS Network Site Conditions}

In Ontario, there are forty-two POLARIS satellite-linked seismograph stations operating as of June 2005. The Ontario network stations are located on a variety of geological conditions. Some network stations are on bedrock of Precambrian or Paleozoic limestone and shale, while others are on soil sites with varying degrees of unconsolidated materials. Unconsolidated materials overlying bedrock in Ontario consist mainly of the following: sheets of till laid down directly on the ice during the last glaciation; sand and gravel deposited by streams of water draining from the melting glaciers; and the clays, silts and sands deposited in lakes which existed during the recession of the glacier (see Ontario Geological Survey physiography map by Chapman and Putnam 1984; also Chapter 3). Table 7.1 lists the POLARIS stations, their locations and known information 
on site conditions. Additional information on shear wave velocities at two sites was gathered for this study as described in the next section.

\subsection{Shear-wave Velocity Survey at two POLARIS sites}

Shear-wave velocity surveys were undertaken to provide a means for characterizing the site condition at two POLARIS soil sites (PEMO and ALGO). Beresnev and Atkinson (1997) and Murphy (2003) have previously determined the shearwave velocity profile for 8 other POLARIS sites (soil and rock). Determination of the shear-wave velocity profile at selected sites is important to enable theoretical calculations of amplification, and to enable calibration of site response factors for different site conditions across the network.

I collected shear-wave velocity data by using a steel I-beam dug into the soil and aligned along the axis of a geophone array. The I-beam was struck horizontally on alternating sides with a sledgehammer, using 8 stretches per side in order to excite shear waves while minimizing the excitement of non shear-wave velocity; this produces a record with the optimum signal-to-noise ratio. (Hunter et al., 1998; Benjumea et al., 2001). I used a 3 meter geophone spacing with a single spread of $24-4.5-\mathrm{Hz}$ horizontal geophones. I excited shear-wave velocity at the center of the spread and at offsets of 3 , $4.5,30,31.5 \mathrm{~m}$ from each end, for a total distance of $132 \mathrm{~m}$. Data were collected using a Geometrics StrataView ${ }^{\mathrm{TM}}$ seismograph with common recording parameters shown in Table 7.2. The seismograph was made available to me by James Hunter of the Geological Survey of Canada. 
The station locations along with the surficial geology information are listed in Table 7.3. Figure 7.1 shows an example of stacked raw data collected at ALGO.

\subsubsection{Data Processing and Results}

The refraction analysis was completed by using the seismic refraction interpretation software package (SIPx) created by Rimrock Geophysics. SIPIK, an interactive program, was used for picking first breaks on digitized seismic waveforms and SIPIN V-4.1 was used for creating data files for input into the seismic refraction interpretation program SIPT2. The software calculates layer depths by inversion of first arrivals. The basic concept of the interpretation rests on ray tracing and model-adjusting to minimize the discrepancies between measured and theoretical arrival times. SIPT2, the interpretation program, generates a table of layer depths and corresponding shear-wave velocity for each geophone. One-dimensional velocity models for both sites obtained from this study are shown in Table 7.4. Models are obtained for depths of up to 70 meters.

The shear-wave velocity profiles from this study as well as results from previous studies done by Beresnev and Atkinson (1997) and Murphy (2003) were compiled and used to classify sites as described in section 7.6.

\subsection{Data Processing and Calculation of $\mathrm{H} / \mathrm{V}$}

The dataset used in the computation of $\mathrm{H} / \mathrm{V}$ was recorded by 32 broadband stations from the POLARIS Ontario array. Figure 7.2 shows the locations of study earthquakes and recording stations for this aspect of the work. The recordings cover the 
time period of February 11, 2002 through May 25, 2005 and correspond to 81 earthquakes with Nuttli magnitude ranging from 1.8 to 5.5 and epicentral distance from 10 to $1000 \mathrm{~km}$. Table 7.5 lists the date, latitude, longitude, Nuttli magnitude (MN) of the earthquakes analyzed in the $\mathrm{H} / \mathrm{V}$ ratio study. Digital horizontal and vertical-component time series data were obtained from the Geological Society of Canada (GSC) via their AUTODRM (Automatic Data Request Manager) facility (www.seismo.nrcan.gc.ca/nwfa/autodrm). The data were decompressed and the waveforms analyzed to calculate the $\mathrm{H} / \mathrm{V}$ value for each record as a function of frequency from the Fourier spectra for the log-averaged horizontal component and the corresponding vertical component in log units (see Siddiqqi and Atkinson, 2002) using

$$
\log (H / V)=\left(\log H_{1}+\log H_{2}\right) / 2-\log V
$$

where $\mathrm{H}_{1}$ and $\mathrm{H}_{2}$ represent the two horizontal components and $\mathrm{V}$ is the vertical component. Both signal and noise windows were selected from each seismic record. The signal window includes all $\mathrm{S}$-wave signal and excludes as much $\mathrm{P}$-wave signal as possible. The noise window was selected from the waveform prior to the arrival of the Pwave. Figure 7.3 shows the signal and noise window selections for time-series data from the MN 5.4 Riviere-du-Loup, Quebec Earthquake of March 6, 2005, recorded at KLBO. Seismographic records from CNSN and POLARIS require a correction to remove instrument response. The correction was performed using a Fourier transformation to take the time series into the frequency domain where Fourier spectrum was divided by the instrument response function. The instrument response function was computed using the poles and zeros of the transfer function. The $\mathrm{H} / \mathrm{V}$ ratio is calculated only for frequency ranges over which the single to noise ratio exceeds a factor of 2 . 


\subsection{Amplification Results Based on $\mathrm{H} / \mathrm{V}$}

Table 7.6a lists the mean $\log \mathrm{H} / \mathrm{V}$ values for soil sites (Fourier spectra amplification factors) for various frequencies $(1.6 \mathrm{~Hz}, 5 \mathrm{~Hz}$ and $16 \mathrm{~Hz})$, along with their standard deviation, while Table 7.6b lists the same for rock sites. These particular frequencies range $(1.6 \mathrm{~Hz}, 5 \mathrm{~Hz}$ and $16 \mathrm{~Hz})$ were chosen because the peak value for most sites seem to fall into these three categories of frequency range.

Mean $\mathrm{H} / \mathrm{V}$ for all soil sites are plotted in Figure 7.4 whereas rock sites are plotted in Figure 7.5. Average mean $\mathrm{H} / \mathrm{V}$ as a function of frequency $(0.1$ to $20 \mathrm{~Hz})$, with $95 \%$ confidence limits on the mean, are also shown. The $95 \%$ confidence intervals indicate that we are $95 \%$ certain the true mean lies within this range, given the mean, standard deviation and size of the sample. Table $7.7 \mathrm{a}$ and $7.7 \mathrm{~b}$ present the average/maximum amplification factors and their standard deviation for soil and rock sites respectively. Note the difference in amplification characteristics for soil versus rock sites.

\subsubsection{Soil Sites}

Because much of southern Ontario is covered by thick quaternary till, many POLARIS stations are located on soil sites (e.g. ACTO, ALGO, BANO, BRCO, CLWO, LINO, MEDO, PEMO, PKRO, PLIO, STCO, TOBO, TORO, TYNO and WLVO). Most soil sites consist of a glacial till layer of variable thickness overlying Paleozoic rocks of the Michigan Basin (Hunter, pers. comm.)

Beresnev and Atkinson (1997) conducted a shear-wave velocity study at six POLARIS soil sites (ACTO, BRCO, PKRO, STCO, TYNO and WLVO) in an effort to obtain information that could be used to calculate the expected site amplification effects. 
They determined velocity structure to a depth of about $70-\mathrm{m}$; they found that POLARIS soil sites have shear-wave velocities $\left(V_{s}\right)$ of $240-740 \mathrm{~m} / \mathrm{sec}$ near the surface. BRCO, PKRO, STCO and TYNO have $\mathrm{V}_{\mathrm{s}}<400 \mathrm{~m} / \mathrm{s}$ near the surface. The fundamental site response frequency, based on soil velocity and depth information $\left(f_{o}=V_{s} / 4 H\right)$, should be in the range of 1.6 to $6 \mathrm{~Hz}$ for BRCO, PKRO, STCO, TYNO, and ALGO and in the range 10 to $12 \mathrm{~Hz}$ for ACTO and WLVO. This range of resonant frequencies agrees very well with the results obtained from this study based on H/V (see Figure 7.4 and Table 7.7a). As seen in Figure 7.4, most of the soil sites show fundamental site response peaks in the range of 1.6 to $5 \mathrm{~Hz}$, with the exception of ACTO, LINO, PEMO and WLVO, which peak at $12.6-20 \mathrm{~Hz}$ (see Table 7.7a). The PEMO site shows the least pronounced fundamental peak amplification of 2.6 at $20 \mathrm{~Hz}$, which reflects the shallow stiff soil present at this site; this is consistent with field observations and the average shear-wave velocity results measured over the top 30 meters $\left(V_{s}=591 \mathrm{~m} / \mathrm{s}\right)$.

Shear-wave velocity surveys were conducted in the course of this study for both PEMO and ALGO in 2004. Section 7.3 displays and discusses the results. During the measurement I noticed that PEMO is located on a shallow till layer, with bedrock outcrop at 15 meters from the site. By contrast, very well pronounced fundamental peaks at low frequency for $\mathrm{H} / \mathrm{V}$ at $\mathrm{ALGO}$ and TYNO suggest that these are deep soil sites. Field study at ALGO suggests that the site is located on top of a 25-30 meter thick sand deposit with some man-made fill; the average shear-wave velocity is $354 \mathrm{~m} / \mathrm{s}$ in the top 30 meter. The calculated mean $\mathrm{H} / \mathrm{V}$ peak amplitude of 6.25 at $4 \mathrm{~Hz}$ at ALGO agrees well with the values expected based on the soil profile as determined in the field study. A similar agreement is observed at TYNO, with a peak amplification of 6.11 at $4 \mathrm{~Hz}$. The average 
velocity of $404 \mathrm{~m} / \mathrm{s}$ over the top 30 meter (with $70 \mathrm{~m}$ depth) would theoretically produce a peak at $4 \mathrm{~Hz}$, which is in excellent agreement with the observed $\mathrm{H} / \mathrm{V}$ results at TYNO.

Overall, we observe an average amplification factor of 1.4 (with log standard deviation of 0.06$)$ over all frequencies $(0.1-20 \mathrm{~Hz})$, for soil sites. However, the average amplification factor varies significantly with frequency (e.g. 1.9 at $1.6 \mathrm{~Hz}, 2.5$ at $5 \mathrm{~Hz}$ and 1.6 at $16 \mathrm{~Hz}$ ) (see Figure 7.4). In fact, the average amplification factor does not provide a meaningful description of the site response because it smooths out the peaks across the frequency spectrum. A more appropriate amplification for soil sites, based on Figure 7.4, could be to take an average of the maximum amplifications which is found to be 4.2 , with $\log$ standard deviation of 0.13 . (Table 7.7a). This average value will likely control the intensity to a greater degree than will an average amplification over all frequencies. This average value can be refined to give the frequency at which amplification occurs for unknown soil sites with known thickness.

If I estimate shear wave velocity based on impedance effects, the typical amplification factor inferred from $\mathrm{H} / \mathrm{V}$ factor across soil sites (2.1 to 5.8 ) would suggest near-surface shear-wave velocities in the range of 96 to $850 \mathrm{~m} / \mathrm{s}$, which is consistent with the shear-wave velocities determined by Beresnev and Atkinson (1997), as well as with measurements done in summer of 2004 for this study. In fact, all observed H/V peak frequencies correlate fairly well with the theoretical results.

\subsubsection{Rock Sites}

In general, $\mathrm{H} / \mathrm{V}$ for most rock sites is characterized by an essentially flat spectral response up to $2 \mathrm{~Hz}$, which indicates competent bedrock sites. However, at higher 
frequencies, there is some amplification at all of the rock sites. This is not entirely surprising since Siddiqi and Atkinson (2002) found similar amplification, trending from 1.09 at $1 \mathrm{~Hz}$ to 1.48 at $5 \mathrm{~Hz}$ at eastern Canadian rock stations. Each of the rock sites shows wide variability in amplification at various frequencies. Particularly, stations ALFO, BUKO and HGVO have pronounced response peaks of, $1.7,1.8$ and 2.4 at $20 \mathrm{~Hz}$, $12.6 \mathrm{~Hz}$ and $16 \mathrm{~Hz}$ respectively. The high peak responses at higher frequency $(>10 \mathrm{~Hz})$, suggest a weak bedrock layer with lower velocity near the surface, possibly due to extensive fracturing or weathering. Alternatively, there may be shallow soil overlying the rock.

\subsubsection{H/V values for Peak Ground Velocity}

An important parameter for the Ontario ShakeMap is peak ground velocity (PGV) because ShakeMap uses PGV as the basic parameter to predict corresponding feltintensity. The felt-intensity is estimated by using the relation developed in Chapter 5 :

$$
\mathrm{MMI}=4.08+1.79 \log \mathrm{Y}-0.28 \log \mathrm{R}
$$

where MMI is Modified Mercalli Intensity, $\mathrm{Y}$ is the horizontal-component PGV in mm/s and $R$ is hypocentral distance in $\mathrm{km}$. Consequently, knowing $\mathrm{H} / \mathrm{V}$ values for PGV at various stations (soil and rock) is the key in estimating an appropriate level of increase in intensity due to soil response. Once the $\mathrm{H} / \mathrm{V}$ values are known for each station, we can simple multiply both the recorded and estimated PGV vertical-component values with the $\mathrm{H} / \mathrm{V}$ values to account for amplification at that particular station.

Figure 7.6 and Figure 7.7 show the $\mathrm{H} / \mathrm{V}$ for PGV and $95 \%$ confidence limits at soil and rock sites respectively. The $\mathrm{H} / \mathrm{V}$ values exhibit station- to -station variation of 
the site amplification factor reflecting the changes in soil conditions. Mean $\log \mathrm{H} / \mathrm{V}$ values along with their $95 \%$ confidence intervals for soil and rock sites are shown in both figures, and are given in Tables 7.8a and 7.8b. The right column of Tables 7.8a and 7.8b list the expected increase in intensity due to site amplification as derived from Equation 7.5 .

The average amplification factor for peak ground velocity (PGV) at Ontario Polaris stations was found to be 2.1 (with log standard deviation of 0.1 ) for soil stations and 1.3 (with log standard deviation of 0.07 ) for rock stations. The results suggest an average of $0.5 \mathrm{MMI}$ unit increases for soil sites and $0.2 \mathrm{MMI}$ unit increases for rock site relative to vertical component ground-motions. These may be an underestimate of actual effects, as experience in past earthquakes suggests larger differences in observed effects on rock versus soil. This requires further investigation as more intensity and groundmotion data are gathered.

\subsubsection{Conclusions}

Average $\mathrm{H} / \mathrm{V}$ ratios suggest station-to-station variation of the site amplification factor reflecting the site conditions. The average log amplification for peak ground velocity (PGV) at Ontario Polaris stations was found to be $0.3 \pm 0.1$ for soil stations (about a factor of 2) and $0.1 \pm 0.07$ for rock stations. These results correspond to an average increase of 0.5 Modified Mercalli Intensity (MMI) units for soil sites and 0.2 MMI unit increases for rock sites (relative to unamplified or vertical component ground motions). The average of the maximum amplification based on Fourier spectra $\mathrm{H} / \mathrm{V}$ is $0.6 \pm 0.1$ in $\log$ units for soil sites and $0.19 \pm 0.33$ for rock sites; this factor varies 
significantly with frequency, with peak amplification occurring anywhere from $1.6 \mathrm{~Hz}$ to $20 \mathrm{~Hz}$, depending on the site. The frequency-dependence of $\mathrm{H} / \mathrm{V}$ is strong even for some rock stations.

The average amplification factor for Ontario POLARIS stations was found to be 1.1 for rock sites and 1.4 for soil sites over the frequency range of $0.1 \mathrm{~Hz}$ to $20 \mathrm{~Hz}$. (log values of amplification 0.04 and 0.15 , respectively). The rock station $\mathrm{H} / \mathrm{V}$ factor depends weakly on frequency (increasing from 0.9 at $1 \mathrm{~Hz}$ to 1.3 at $10 \mathrm{~Hz}$ ) whereas soil station $\mathrm{H} / \mathrm{V}$ varies significantly with frequency $(1.9$ at $1.6 \mathrm{~Hz}, 2.5$ at $5 \mathrm{~Hz}$ and 1.61 at $16 \mathrm{~Hz}$ ). In general, soil sites amplify at lower frequencies $(\mathrm{f}<6 \mathrm{~Hz}$ ), while rock sites amplify at higher frequencies $(\mathrm{f}>10 \mathrm{~Hz})$.

Fourier spectra amplification factors for soil stations generally show welldeveloped fundamental peaks indicating varying thickness of near surface till layers in all stations, whereas rock stations indicate competent bedrock stations exhibiting near unity (at lower frequencies). Some less competent Paleozoic bedrock stations show some inherent site effect at high frequency indicating shallow soil or a weathered layer near the surface.

The most useful information from this study is the average $H / V$ values for PGV at soil sites. They are used to estimate the site effects in Ontario ShakeMaps for sites of unknown site condition. The results are implemented in Ontario ShakeMap to account for site response as well as to convert vertical to horizontal components ground-motion parameters before generating ShakeMaps in Ontario (see Section 7.6.3 and 7.7.2). 


\subsection{Site Classification for the Ontario ShakeMap Network (42-47 $N$ and 76-82 W)}

\subsubsection{Introduction}

Classifying the amplification characteristics of sites is a key step in obtaining a reliable portrayal of the extent of shaking. A simply way of classifying the site characteristics is to use the average shear-wave velocity of the top 30 meters $\left(\mathrm{V}_{\mathrm{s}}^{30}\right)$ of the site, which is computed by dividing 30 meters by the travel time from the surface to a depth of 30 meters. The use of the $\mathrm{V}_{\mathrm{s}}^{30}$ parameter in classifying sites has been discussed by various authors: including Boore et al. (1993, 1997), Borcherdt (1994), Boore, (2004), Wills et al., (2000), Finn and Wightman (2003) and BSSC (1998, 2001).

Borcherdt (1994) showed that observed amplification factors, as computed from the ratio of ground motions on soil sites to those on rock sites were proportional to the average shear-wave velocity of the top 30 meters $\left(V_{s}^{30}\right)$. Borcherdt (1994) recommended that site characterization of the top 30 meters may be based on geology, inferred shearwave velocity or direct measurement of shear-wave velocity. The U. S. National Earthquake Hazard Reduction Program (NEHRP) provisions of 1994 adopted the site characterization recommended by Borcherdt (1994). Since then, $\mathrm{V}_{\mathrm{s}}{ }^{30}$ has become widely used as a basic parameter for classifying sites to predict their potential to amplify ground shaking. Dobry et al. 2000, Wills et al. (2000) and Building Seismic Safety Council (BSSC, 2001), and the National Building Code of Canada (2005) have also used $\mathrm{V}_{\mathrm{s}}{ }^{30}$ parameter to classify sites. Sites are classified by their $\mathrm{V}_{s}{ }^{30}$ values into various "NEHRP site classes" as indicated in Table 7.9 (from Borcherdt, 1994). 
In Ontario ShakeMap, the site classification is based on the average shear-wave velocity of the top 30 meters wherever possible, supplemented by inferences based on the site-specific $\mathrm{H} / \mathrm{V}$ ratios (see Section 7.5).

The CNSN stations are known to be on hard-rock sites, with $\mathrm{V}_{\mathrm{s}}^{30}>1500 \mathrm{~m} / \mathrm{s}$ and thus I assume NEHRP A for these sites. For those sites where neither shear-wave velocity nor $\mathrm{H} / \mathrm{V}$ information are available, I assume a default firm ground site condition (NEHRP C). This is based on typical values of $V_{s}^{30}=500 \mathrm{~m} / \mathrm{s}$ in basal glacial till (James Hunter, personal communications).

It should be noted that the available shear-wave velocity measurements are not sufficient to develop site-specific information for the network. Hence, the proposed NEHRP site classification map is an attempt to capture geologically controlled differences in ground motions, in a manner that is only appropriate for an initial broad regional ShakeMap application in Ontario. This map should be refined as more shearwave velocity data become available across the province.

\subsubsection{Methodology in Classifying Sites}

I adopted the $\mathrm{V}_{s}^{30}$ parameter in developing a general site classification map for the Ontario ShakeMap grid (42-48 N and $76-82$ W). Shallow shear-wave velocity measurements made by Kaka and Atkinson in summer 2004 (KA04) as well as results from the previous studies done by Beresnev \& Atkinson (1997) (BA 97) and Murphy (2003) were complied and listed in Table 7.10 (the computed site classifications of 7.6.3 are also shown). Additional data from the Geological Survey of Canada (GSC) (provided by James Hunter) were also added to Table 7.10. 
For all sites, the average shear-wave velocity of the top 30 meters is calculated from the total time travel through the layer, (according to NEHRP guidelines) which is given as:

$$
V_{s}^{30}=\frac{\sum_{i=1}^{n} d_{i}}{\sum_{i=1}^{n} \frac{d_{i}}{V_{s i}}}------(7.6)
$$

where $d_{i}$ is the thickness of the layer $i, V_{s i}$ is the shear-wave velocity of layer $i$ and $\mathrm{n}$ is the number of layers.

The proposed site classification map, shown in Figure 7.8, is used to determine what amplification factors to apply to account for site conditions. Figure 7.8 is prepared using Table 7.10 by assigning to each grid point the NEHRP categories as shown in Table 7.10 based on each $\left(V_{s}^{30}\right)$, with a default of Class $C$ for other sites.

NEHRP A sites are hard rock with minimal amplification. NEHRP B sites are rock sites characterized by a softer rock. NEHRP C sites are very dense soil and soft rock. This condition is also referred to as "firm ground" (Atkinson 2001), or "stiff soil" (Frankel et al., 1996) and corresponds to the generic California "soft" rock of Boore and Joyner (1997). NEHRP site classes D and E represent the typical range of soil conditions from stiff to soft and have higher ground motion amplification.

\subsubsection{Site Amplification Factors}

Site amplification factors for each NEHRP site class, to be incorporated in the ShakeMap ground motion predictions, are given in Table $7.11 \mathrm{a}$ and described below. 
These factors are applied as indicated in the map on Figure 7.8. An exception is made for POLARIS sites, because we know the $\mathrm{H} / \mathrm{V}$ ratio for each site. The POLARIS sites are classified by their site-specific $\mathrm{H} / \mathrm{V}$ ratio, as given in Table $7.11 \mathrm{~b}$.

\section{NEHRPA $\left(V_{s}^{30}>1500 \mathrm{~m} / \mathrm{s}\right)$}

NEHRP A sites are hard rock with minimal amplification and are thus assigned an $\mathrm{H} / \mathrm{V}=1.21$ (hard-rock for PGV according to Atkinson, 1993b).

\section{NEHRP B $\left(V_{s}^{30}=760-1500 \mathrm{~m} / \mathrm{s}\right)$}

The site response factors for this site category are given in Table 7.12 with their standard deviation. They are derived from the mean $\mathrm{H} / \mathrm{V}$ ratio of four known NEHRP $B$ sites (ELGO, LINO, ACTO and WLVO). Based on the quarter-wavelength equation (Equation 7.3), these amplifications are consistent with what is expected for near-surface of velocities in the range of 945 to $1137 \mathrm{~m} / \mathrm{s}$.

\section{NEHRP $C\left(V_{s}^{30}=360-760 \mathrm{~m} / \mathrm{s}\right)$}

Site response factors for NEHRP $\mathrm{C}$ sites have been suggested by Adams and Halchuk (2003) based on calculations using a combination of empirical California factors and the quarter-wavelength approach. Factors given by Adams and Halchuk (2003) have been used in national seismic-hazard maps in Canada (NBCC 2005). However, these factors appear to be rather large at lower frequencies compared to the values inferred by $\mathrm{H} / \mathrm{V}$. Therefore, I checked these factors carefully for consistency with those computed using the quarter-wavelength approximation as well as the results from the $H / \mathrm{V}$ method 
for four known NEHRP C sites. The factors obtained from various approaches are listed in Table 7.13 .

Figures 7.9 shows various estimates of amplification versus frequency for the four known NEHRP C sites. The heavy solid line is the proposed factor to be used in our ShakeMap application. The thin solid line is calculated using the H/V method. The grayscale solid line is computed using the quarter-wavelength approximation. The dashed line is from Adams and Halchuck (2003). The amplification factors given by Adams and Halchuck (2003) are significantly higher for low frequency levels (less than $2 \mathrm{~Hz}$ ) than those suggested by $\mathrm{H} / \mathrm{V}$ or by quarter-wavelength computations. This is a concern for the $1-\mathrm{Hz}$ spectral ShakeMaps, but less so for PGV and frequency of $\geq 2 \mathrm{~Hz}$. These factors will require further calibration as more recorded ground motion data on NEHRP C sites in Ontario are gathered. Based on Figure 7.9 as well as Table 7.13, I adopted the NEHRP $\mathrm{C}$ amplification factors listed in Table 7.11a. Heavy solid lines in Figure 7.9 show the adopted amplification curve considering all three information sources.

\section{NEHRP D $\left(\mathrm{V}_{\mathrm{s}}^{30}=180-360 \mathrm{~m} / \mathrm{s}\right)$}

The site response factors for this site category are derived using the linear (weakmotion) component of the amplification from "firm ground" to soil as based on the factors given by Boore et al. (1993); these are empirical factors based on California strong-motion data. Table 7.11a lists the adopted NEHRP D factors. 


\subsection{Integration of Site Response Information in ShakeMaps}

In predicting the ground-motion pattern in ShakeMap, the first step is to create a rectangular grid of "phantom" stations; these are spaced at 0.3 degrees apart. Peak ground motions are predicted at each phantom grid point using the region-specific predictive ground-motion equation developed in chapter 6 for rock sites (NEHRP A):

$$
\log Y=C_{1}+C_{2}(M-4)+C_{3}(M-4)^{2}+C_{4} \log R+C_{5} R
$$

where $\mathrm{Y}$ is the vertical-component ground motion parameter $(\mathrm{PGV}$ in $\mathrm{mm} / \mathrm{s}, \mathrm{PGA}$ and $\operatorname{PSA}(\mathrm{f})$ in $\left.\mathrm{cm} / \mathrm{s}^{2}\right), \mathrm{R}$ is hypocentral distance in $\mathrm{km}$, and $\mathbf{M}$ is moment magnitude. Note that the application of Equation 7.7 first requires an estimate of event magnitude and distance. This is based on the centroid magnitude and location (distance between each grid point and ground motion centroid) as discussed in chapter 4 .

The prediction of ground motions at phantom stations is necessary to constrain ShakeMap interpolations in areas where no actual records are available. However, phantom stations are ignored if there is an actual record available within $10 \mathrm{~km}$ of a phantom station. ShakeMap then uses a combination of the predicted ground motion at phantom stations and the actual measured ground motion at all seismographic recording stations to create a to create a grid of ground motions that are contoured to produce ShakeMap (see section 7.7.2).

\subsubsection{Bias Correction}

An algorithm included in the ShakeMap code is implemented to make sure that the predicted ground motions are in accordance with the recorded values. The algorithm computes an event-specific bias factor by minimizing the difference between the 
observed values at the seismographic stations and the predicted values at phantom stations (see ShakeMap Manual available at http://pubs.usgs.gov/tm/2005/12A01/). The minimization can be done in either a least square sense or an absolute deviation sense. I use an absolute deviation minimization to reduce the effect of outliers. I compute the bias correction using stations within $120 \mathrm{~km}$ of the event. If there are less than 6 stations within $120 \mathrm{~km}$, no bias factor is calculated. I configure ShakeMap to use a maximum bias factor of 4 and minimum factor of 1.0 in order to avoid instability in the bias calculation due to bad stations or inadequate representation of some distances.

\subsubsection{Site Corrections}

There are several steps in incorporating site corrections into the ShakeMap program. These steps are taken for each grid point on the $0.3 \times 0.3$ degree grid:

- Observed peak ground motion amplitudes of vertical components at all stations are corrected to horizontal by using $\mathrm{H} / \mathrm{V}$ ratios given in Table $7.11 \mathrm{~b}$.

- Based on the site classification map (Figure 7.8), when correcting to horizontal, all sites with unknown soil conditions are considered NEHRP C (firm ground) and are thus assigned $H / V=2.1$, which is average $H / V$ for $C$ sites. Known hard rock sites are assigned an $\mathrm{H} / \mathrm{V}=1.2$ (according to Atkinson 1993b).

- Peak ground motion amplitudes of vertical components at phantom stations are estimated using Equation 7.7 and then corrected to horizontal by applying the amplification factors for the site class (based on the site classification map shown in Figure 7.8). Amplification factors, and the corresponding NEHRP site categories, are listed in Table 7.11 and discussed in 7.6.3. 
- An event-specific bias correction factor is applied to minimize the difference between the observed values at the seismographic stations and the predicted values at phantom stations (see 7.7.1).

- Both observed and estimated peak amplitudes are interpolated to define rock ground motion amplitude at all points along a "rock site" grid (0.3 degree spacing). The interpolation should produce reasonable estimates at grid points located far from recorded data, while preserving the detailed shaking information available for regions where there are stations nearby.

- Finally, maps are prepared by contouring the interpolated, site-corrected horizontal component ground motion amplitude values across the rectangular grid. Contouring ground motion amplitude values is done using tools available with Generic Mapping Tools (GMT, Wessel and Smith, 1991). The contouring consists of finding an adjustable-tension (interior and boundary tension factor, surface tension; of 0.9 ), continuous-curvature surface that fits the constraining data exactly (see Smith and Wessel, 1990).

In Figure 7.10 I show intensity ShakeMaps for the MN 5.4 March 6, 2005 Riviere-du-Loup, Quebec earthquake to illustrate the effects of applying the site correction factors. Figure $7.10 \mathrm{a}$ shows the inferred intensities before applying the site amplification factors. Figure $7.10 \mathrm{~b}$ was generated after applying the site correction factors. From Figure 7.10, it is apparent that the site correction has an important effect, especially where the station coverage is sparse. Where there are sufficient stations, the recorded amplitudes define both the amplitudes and site effects. In area with no recorded 
data, the predicted intensity variation reflects the site corrections, modifying an otherwise smooth predicted amplitude pattern. 
Table 7.1: POLARIS stations, their locations, and known information on site conditions

\begin{tabular}{|c|c|c|c|c|c|}
\hline Station & Name & Latitude & Longitude & Site Conditions & $V_{s}^{30}$ \\
\hline ACTO & Acton & 43.6087 & -80.0623 & till moraine & available \\
\hline ALFO & Alfred & 45.62828 & -74.88419 & bedrock & $\begin{array}{c}\text { not } \\
\text { available }\end{array}$ \\
\hline ALGO & $\begin{array}{l}\text { Algonquin } \\
\text { park }\end{array}$ & 45.9544 & -78.0509 & $\begin{array}{l}\text { spillway, sand, possibly } \\
\text { man-made fill }\end{array}$ & available \\
\hline ATKO & $\begin{array}{l}\text { Atikokan } \\
\text { Iron Mine }\end{array}$ & 48.82310 & -91.60045 & bedrock & $\begin{array}{c}\text { not } \\
\text { available }\end{array}$ \\
\hline BANO & Bancroft & 45.0198 & -77.9280 & $\begin{array}{l}\text { Shallow till, bedrock } \\
\text { outcrops within } 100 \mathrm{~m} \text { of } \\
\text { station }\end{array}$ & $\begin{array}{c}\text { not } \\
\text { available }\end{array}$ \\
\hline BRCO & Bruce & 44.2437 & -81.4421 & $\begin{array}{l}\text { glacial till plain- } \\
\text { undrumlinized overlying } \\
\text { Ordovician shale }\end{array}$ & available \\
\hline BRPO & $\begin{array}{l}\text { Bonnechere } \\
\text { River Park }\end{array}$ & 45.6506 & -77.5061 & Sand plain & $\begin{array}{c}\text { not } \\
\text { available }\end{array}$ \\
\hline BUKO & Buck Lake & 45.44228 & -79.39895 & Outcrop bedrock & $\begin{array}{c}\text { not } \\
\text { available }\end{array}$ \\
\hline CLPO & $\begin{array}{l}\text { Centennial } \\
\text { Lake Park }\end{array}$ & 45.24599 & -76.96416 & bedrock & $\begin{array}{c}\text { not } \\
\text { available }\end{array}$ \\
\hline CLWO & Collingwood & 44.44907 & -80.30132 & $\begin{array}{l}\text { Limestone bedrock beneath } \\
\text { shallow till plain / } \\
\text { escarpment }\end{array}$ & $\begin{array}{c}\text { not } \\
\text { available }\end{array}$ \\
\hline DELO & Deloro Mine & 44.5177 & -77.6186 & Bedrock & $\begin{array}{c}\text { not } \\
\text { available }\end{array}$ \\
\hline ELFO & Elginfield & 43.19300 & -81.31630 & unknown & $\begin{array}{c}\text { not } \\
\text { available }\end{array}$ \\
\hline ELGO & Elora Gorge & $43.67 \overline{56}$ & -80.4374 & till plain - drumlinized & available \\
\hline ELPO & $\begin{array}{l}\text { Experimenta } \\
\text { 1 Lakes }\end{array}$ & 49.67370 & -93.72582 & bedrock & $\begin{array}{c}\text { not } \\
\text { available }\end{array}$ \\
\hline HGVO & Hagersville & 42.9606 & -80.1266 & $\begin{array}{l}\text { Paleozoic bedrock at clay } \\
\text { plain }\end{array}$ & $\begin{array}{c}\text { not } \\
\text { available }\end{array}$ \\
\hline KILO & $\begin{array}{l}\text { Kirkland } \\
\text { Lake }\end{array}$ & 48.49702 & -79.72329 & bedrock & $\begin{array}{c}\text { not } \\
\text { available }\end{array}$ \\
\hline KLBO & $\begin{array}{l}\text { Killbear } \\
\text { provincial } \\
\text { Park } \\
\end{array}$ & 45.35657 & -80.21320 & Precambrian bedrock & $\begin{array}{c}\text { not } \\
\text { available }\end{array}$ \\
\hline LDIO & $\begin{array}{l}\text { Lac des Isle } \\
\text { Mine }\end{array}$ & 49.17499 & -89.59551 & bedrock & $\begin{array}{c}\text { not } \\
\text { available }\end{array}$ \\
\hline LNO & Lindsay & 44.354 & -78.780 & $\begin{array}{l}\text { till plain-drumlinized, } \\
\text { bedrock outcrops within } 3 \\
\text { km north of the station }\end{array}$ & available \\
\hline MALO & $\begin{array}{l}\text { McAlpine } \\
\text { Lake }\end{array}$ & 50.02440 & -79.76350 & bedrock & $\begin{array}{c}\text { not } \\
\text { available }\end{array}$ \\
\hline MEDO & Medina, NY & 43.16460 & -78.45462 & soil & $\begin{array}{c}\text { not } \\
\text { available }\end{array}$ \\
\hline
\end{tabular}




\begin{tabular}{|c|c|c|c|c|c|}
\hline Station & Name & Latitude & Longitude & Site Conditions & $\mathrm{V}_{3}^{30}$ \\
\hline MPPO & $\begin{array}{l}\text { Murphy's } \\
\text { point }\end{array}$ & 44.7699 & -76.2648 & Precambrian bedrock & $\begin{array}{c}\text { not } \\
\text { available }\end{array}$ \\
\hline MUMO & $\begin{array}{l}\text { Musselwhite } \\
\text { mine }\end{array}$ & 52.61279 & -90.39136 & $\begin{array}{l}\text { solid bedrock about } 100 \mathrm{~m} \\
\text { off from the runway }\end{array}$ & $\begin{array}{c}\text { not } \\
\text { available }\end{array}$ \\
\hline OTRO & Otter Rapids & 50.1818 & -81.62860 & $\begin{array}{l}\text { glacial moraine about } 100 \mathrm{~m} \\
\text { off from river }\end{array}$ & $\begin{array}{c}\text { not } \\
\text { available }\end{array}$ \\
\hline PECO & $\begin{array}{l}\text { Prince } \\
\text { Edward } \\
\text { County }\end{array}$ & 43.934 & -76.994 & $\begin{array}{l}\text { weathered limestone bedrock } \\
\text { with thin layer of till. }\end{array}$ & $\begin{array}{c}\text { not } \\
\text { available }\end{array}$ \\
\hline PEMO & Pembroke & 45.67732 & -77.2466 & $\begin{array}{l}\text { shallow till, bedrock outcrops } \\
\text { within } 20 \mathrm{~m} \text { from station }\end{array}$ & available \\
\hline PKLO & Pickle Lake & 51.49867 & -90.35219 & bedrock & $\begin{array}{c}\text { not } \\
\text { available }\end{array}$ \\
\hline PKRO & Pickering & 43.9643 & -79.0716 & soil & available \\
\hline PLIO & Peelee Island & 41.75053 & -82.62837 & $\begin{array}{l}\text { Limestone bedrock with } \\
\text { shallow soil }\end{array}$ & $\begin{array}{c}\text { not } \\
\text { available }\end{array}$ \\
\hline PLVO & Plevna & 45.03964 & -77.07538 & bedrock & $\begin{array}{c}\text { not } \\
\text { available }\end{array}$ \\
\hline PNPO & $\begin{array}{l}\text { Pukaskwa } \\
\text { National } \\
\text { Park } \\
\end{array}$ & 48.59568 & -86.28463 & bedrock & $\begin{array}{c}\text { not } \\
\text { available }\end{array}$ \\
\hline PTCO & $\begin{array}{l}\text { Port } \\
\text { Colborne } \\
\end{array}$ & 42.8845 & -79.3115 & bedrock & $\begin{array}{c}\text { not } \\
\text { available }\end{array}$ \\
\hline RDLO & Red Lake & 50.97448 & -93.91244 & bedrock & $\begin{array}{c}\text { not } \\
\text { available }\end{array}$ \\
\hline RSPO & $\begin{array}{l}\text { Restoule } \\
\text { Provincial } \\
\text { Park } \\
\end{array}$ & 46.07340 & -79.76020 & unknown & $\begin{array}{c}\text { not } \\
\text { available }\end{array}$ \\
\hline SILO & Sutton Inlier & 54.47918 & -84.91262 & hard solid bedrock & $\begin{array}{c}\text { not } \\
\text { available }\end{array}$ \\
\hline STCO & St. Catherine & 43.2095 & -79.1707 & $\begin{array}{l}\text { glacial till overlying } \\
\text { Ordovician shale }\end{array}$ & available \\
\hline SUNO & $\begin{array}{l}\text { Sudbury } \\
\text { Onaping }\end{array}$ & 46.64377 & -81.34416 & Precambrian bedrock & $\begin{array}{c}\text { not } \\
\text { available }\end{array}$ \\
\hline TOBO & $\begin{array}{l}\text { Tobermory, } \\
\text { Bruce } \\
\text { Penninsulla } \\
\text { National } \\
\text { Park }\end{array}$ & 45.22573 & -81.52337 & Limestone bedrock & $\begin{array}{c}\text { not } \\
\text { available }\end{array}$ \\
\hline TORO & $\begin{array}{l}\text { Leslie Street } \\
\text { Spit, Toronto }\end{array}$ & 43.61363 & -79.34330 & $\begin{array}{l}\text { till, landfill on beach } \\
\text { deposits, Paleozoic dolostone } \\
\text { outcrop } 3 \mathrm{~m} \text { from station }\end{array}$ & $\begin{array}{c}\text { not } \\
\text { available }\end{array}$ \\
\hline TYNO & Tyneside & 43.0949 & -79.8699 & $\begin{array}{l}\text { glacial till overlying Silurian } \\
\text { carbonate rocks }\end{array}$ & available \\
\hline VIMO & Victor Mine & 52.81726 & -83.74489 & unknown & $\begin{array}{c}\text { not } \\
\text { available }\end{array}$ \\
\hline WLVO & Wesleyville & 43.9235 & -78.3970 & $\begin{array}{l}\text { glacial till overlying } \\
\text { Paliozoic }\end{array}$ & available \\
\hline
\end{tabular}


Table 7.2. Shear-wave data recording parameters.

\begin{tabular}{|l|l|}
\hline Recording System & Geometrics StrataView \\
\hline Sampling Interval & $0.25 \mathrm{~ms}$ \\
\hline Record Length & $1024 \mathrm{~ms}$ \\
\hline Recording Format & $\mathrm{SEG}-2$ \\
\hline Geophones & $4.5 \mathrm{~Hz}$ (horizontal) \\
\hline Geophone Spacing & $3 \mathrm{~m}$ \\
\hline Source & Steel I-beam and sledgehammer \\
\hline Number of Stacks & $6-12$ \\
\hline
\end{tabular}

Table 7.3. Station locations and geology.

\begin{tabular}{|l|l|l|l|l|}
\hline Station & Location & Latitude & Longitude & Geology \\
\hline PEMO & Pembroke & 45.677 & -77.24 & Shallow till layer \\
\hline ALGO & Algonquin Park & 45.954 & -78.05 & $\begin{array}{l}\text { Deep sand layer with } \\
\text { some man-made fill }\end{array}$ \\
\hline
\end{tabular}

Table 7.4. One-dimensional velocity models.

\begin{tabular}{|c|c|c|c|}
\hline \multicolumn{2}{|c|}{ PEMO } & \multicolumn{2}{c|}{ ALGO } \\
\multicolumn{2}{|c|}{$\mathbf{V}_{\mathbf{s}}{ }^{30}=591 \mathrm{~m} / \mathrm{s}$} & \multicolumn{2}{c|}{$\mathbf{V}_{\mathbf{s}}{ }^{30}=354 \mathrm{~m} / \mathrm{s}$} \\
\hline $\begin{array}{c}\text { Depth } \\
(\mathrm{m})\end{array}$ & $\begin{array}{c}\text { Velocity } \\
(\mathrm{m} / \mathrm{s})\end{array}$ & $\begin{array}{c}\text { Depth } \\
(\mathrm{m})\end{array}$ & $\begin{array}{c}\text { Velocity } \\
(\mathrm{m} / \mathrm{s})\end{array}$ \\
\hline 1.8 & 300 & 2.2 & 78 \\
\hline 7.2 & 509 & 7.2 & 184 \\
\hline 15.0 & 691 & 9.6 & 209 \\
\hline 24.0 & 2180 & 14.5 & 368 \\
\hline 70.0 & 2180 & 29.8 & 828 \\
\hline & & 70.0 & 1237 \\
\hline
\end{tabular}


Table 7.5. List of events used in the H/V study

\begin{tabular}{|c|l|l|l|l|l|l|l|}
\hline Date & Latitude & Longitude & MN & Date & Latitude & Longitude & MN \\
\hline $2002 / 02 / 11$ & 46.06 & -73.46 & 3.8 & $2002 / 02 / 24$ & 45.29 & -75.17 & 3.1 \\
\hline $2002 / 04 / 01$ & 46.30 & -75.76 & 3.1 & $2002 / 04 / 20$ & 44.53 & -73.73 & 5.5 \\
\hline $2002 / 04 / 20$ & 44.53 & -73.73 & 4.1 & $2002 / 04 / 20$ & 44.53 & -73.70 & 3.0 \\
\hline $2002 / 04 / 20$ & 44.58 & -73.69 & 3.1 & $2002 / 04 / 27$ & 46.97 & -76.25 & 3.1 \\
\hline $2002 / 05 / 24$ & 44.50 & -73.68 & 3.5 & $2002 / 05 / 28$ & 45.63 & -76.62 & 3.4 \\
\hline $2002 / 06 / 07$ & 43.83 & -78.44 & 2.2 & $2002 / 07 / 17$ & 44.41 & -77.50 & 2.4 \\
\hline $2002 / 07 / 23$ & 49.59 & -66.95 & 4.0 & $2002 / 08 / 17$ & 47.33 & -70.51 & 3.8 \\
\hline $2002 / 08 / 29$ & 45.11 & -73.32 & 2.6 & $2002 / 09 / 07$ & 46.96 & -76.29 & 3.7 \\
\hline $2002 / 09 / 21$ & 46.07 & -74.84 & 2.8 & $2002 / 10 / 31$ & 48.89 & -67.97 & 2.9 \\
\hline $2002 / 11 / 07$ & 44.07 & -77.44 & 3.0 & $2002 / 12 / 15$ & 46.95 & -72.95 & 2.8 \\
\hline $2002 / 12 / 25$ & 44.57 & -73.78 & 3.3 & $2003 / 01 / 02$ & 46.30 & -74.56 & 2.8 \\
\hline $2003 / 01 / 21$ & 43.76 & -77.97 & 2.9 & $2003 / 01 / 28$ & 45.31 & -74.92 & 3.0 \\
\hline $2003 / 02 / 25$ & 45.52 & -75.36 & 2.5 & $2003 / 02 / 25$ & 46.60 & -76.53 & 3.0 \\
\hline $2003 / 03 / 14$ & 45.66 & -77.36 & 3.1 & $2003 / 04 / 08$ & 44.62 & -74.37 & 3.7 \\
\hline $2003 / 04 / 13$ & 46.94 & -71.16 & 3.4 & $2003 / 04 / 17$ & 46.08 & -75.69 & 2.9 \\
\hline $2003 / 04 / 24$ & 46.44 & -74.12 & 2.6 & $2003 / 05 / 09$ & 46.90 & -75.83 & 2.6 \\
\hline $2003 / 05 / 16$ & 45.93 & -83.53 & 2.2 & $2003 / 05 / 25$ & 44.71 & -80.71 & 2.0 \\
\hline $2003 / 06 / 13$ & 47.70 & -70.09 & 4.1 & $2003 / 06 / 30$ & 41.7 & -81.11 & 3.6 \\
\hline $2003 / 07 / 17$ & 41.93 & -80.80 & 2.5 & $2003 / 07 / 22$ & 42.68 & -69.87 & 3.7 \\
\hline $2003 / 08 / 05$ & 46.81 & -78.94 & 2.8 & $2003 / 08 / 17$ & 46.06 & -74.77 & 2.2 \\
\hline
\end{tabular}




\begin{tabular}{|c|l|l|l|l|l|l|l|}
\hline Date & Latitude & Longitude & MN & Date & Latitude & Longitude & MN \\
\hline $2003 / 08 / 20$ & 46.01 & -74.95 & 3.5 & $2003 / 08 / 25$ & 43.47 & -79.47 & 2.3 \\
\hline $2003 / 08 / 31$ & 45.46 & -74.00 & 2.3 & $2003 / 09 / 15$ & 45.28 & -74.09 & 2.1 \\
\hline $2003 / 10 / 01$ & 46.36 & -76.64 & 2.2 & $2003 / 10 / 13$ & 46.99 & -76.35 & 2.1 \\
\hline $2003 / 11 / 22$ & 45.56 & -76.44 & 2.6 & $2004 / 01 / 01$ & 46.57 & -76.29 & 2.5 \\
\hline $2004 / 02 / 16$ & 44.55 & -76.33 & 2.4 & $2004 / 03 / 05$ & 46.42 & -75.16 & 2.6 \\
\hline $2004 / 03 / 17$ & 44.92 & -74.88 & 2.8 & $2004 / 03 / 20$ & 50.01 & -66.57 & 3.0 \\
\hline $2004 / 05 / 05$ & 47.30 & -77.60 & 2.8 & $2004 / 06 / 06$ & 46.83 & -78.89 & 2.8 \\
\hline $2004 / 06 / 23$ & 45.95 & -74.86 & 2.6 & $2004 / 08 / 04$ & 43.68 & -78.24 & 3.8 \\
\hline $2004 / 12 / 03$ & 45.94 & -74.88 & 1.8 & $2003 / 08 / 20$ & 46.15 & -75.12 & 2.4 \\
\hline $2003 / 08 / 25$ & 43.47 & -79.47 & 2.1 & $2003 / 09 / 02$ & 46.37 & -81.25 & 2.5 \\
\hline $2003 / 09 / 19$ & 45.79 & -74.85 & 3.3 & $2003 / 10 / 12$ & 47.01 & -76.36 & 4.5 \\
\hline $2003 / 11 / 04$ & 46.37 & -77.47 & 2.6 & $2003 / 11 / 30$ & 44.06 & -77.43 & 2.6 \\
\hline $2004 / 01 / 18$ & 47.36 & -76.01 & 2.6 & $2004 / 02 / 26$ & 46.38 & -76.95 & 2.5 \\
\hline $2004 / 03 / 17$ & 45.05 & -75.66 & 2.5 & $2004 / 03 / 19$ & 43.95 & -75.61 & 2.4 \\
\hline $2004 / 03 / 24$ & 52.55 & -82.15 & 3.0 & $2004 / 05 / 24$ & 45.11 & -73.87 & 2.9 \\
\hline $2004 / 06 / 16$ & 42.79 & -79.08 & 3.1 & $2004 / 07 / 22$ & 46.64 & -75.02 & 3.1 \\
\hline $2004 / 09 / 04$ & 44.90 & -74.93 & 3.0 & $2005 / 01 / 13$ & 45.68 & -74.82 & 2.7 \\
\hline $2005 / 01 / 30$ & 48.13 & -77.97 & 3.8 & $2005 / 02 / 26$ & 46.53 & -80.99 & 2.9 \\
\hline $2005 / 03 / 03$ & 45.06 & -74.20 & 3.5 & $2005 / 03 / 06$ & -47.75 & -69.73 & 5.4 \\
\hline $2005 / 03 / 13$ & 46.54 & -80.98 & 3.6 & $2005 / 03 / 31$ & 46.28 & -75.64 & 3.4 \\
\hline $2005 / 05 / 25$ & 46.27 & -75.62 & 3.7 & & & & \\
\hline
\end{tabular}


Table 7.6a. Fourier Spectra Amplification Factors for Soil Sites

\begin{tabular}{|l|c|c|c|c|c|c|}
\hline Station & $\begin{array}{c}1.6 \mathrm{~Hz} \\
\text { Log Mean H/V }\end{array}$ & SD & $\begin{array}{c}\mathbf{5 ~ H z} \\
\text { Log Mean H/V }\end{array}$ & SD & $\begin{array}{c}16 \mathrm{~Hz} \\
\log \text { Mean H/V }\end{array}$ & SD \\
\hline ACTO & 0.026 & 0.11 & 0.334 & 0.09 & 0.181 & 0.04 \\
\hline ALGO & 0.187 & 0.11 & 0.767 & 0.07 & 0.198 & 0.07 \\
\hline BANO & 0.052 & 0.09 & 0.04 & 0.10 & 0.194 & 0.04 \\
\hline BRCO & 0.652 & 0.12 & 0.184 & 0.08 & 0.15 & 0.11 \\
\hline LINO & 0.136 & 0.11 & 0.062 & 0.07 & 0.364 & 0.10 \\
\hline PEMO & 0.042 & 0.14 & 0.071 & 0.21 & 0.228 & 0.28 \\
\hline PKRO & 0.727 & 0.09 & 0.069 & 0.23 & 0.125 & 0.21 \\
\hline STCO & -0.049 & 0.11 & 0.645 & 0.09 & -0.107 & 0.12 \\
\hline TYNO & 0.003 & 0.06 & 0.582 & 0.06 & -0.142 & 0.18 \\
\hline WLVO & 0.099 & 0.17 & 0.074 & 0.07 & 0.483 & 0.05 \\
\hline
\end{tabular}

Table 7.6b. Fourier Spectra Amplification Factors for Rock Sites

\begin{tabular}{|l|c|c|c|c|c|c|}
\hline Station & $\begin{array}{c}1.6 \mathrm{~Hz} \\
\text { Log Mean H/V }\end{array}$ & SD & $\begin{array}{c}\mathbf{5 ~ H z} \\
\text { Log Mean H/V }\end{array}$ & SD & $\begin{array}{c}\mathbf{1 6 H z} \\
\text { Log Mean H/V }\end{array}$ & SD \\
\hline ALFO & 0.021 & 0.08 & 0.109 & 0.10 & 0.143 & 0.02 \\
\hline BUKO & 0.006 & 0.07 & 0.079 & 0.06 & 0.246 & 0.04 \\
\hline CLPO & 0.004 & 0.10 & -0.029 & 0.06 & 0.023 & 0.02 \\
\hline DELO & 0.097 & 0.10 & 0.019 & 0.05 & 0.107 & 0.03 \\
\hline ELGO & -0.059 & 0.10 & 0.074 & 0.09 & 0.107 & 0.06 \\
\hline HGVO & 0.069 & 0.21 & 0.193 & 0.16 & 0.371 & 0.32 \\
\hline MPPO & 0.034 & 0.13 & -0.002 & 0.09 & 0.098 & 0.04 \\
\hline PECO & -0.047 & 0.13 & 0.061 & 0.05 & 0.120 & 0.05 \\
\hline PLVO & 0.008 & 0.17 & 0.057 & 0.07 & 0.186 & 0.05 \\
\hline PTCO & -0.136 & 0.12 & 0.103 & 0.12 & 0.196 & 0.05 \\
\hline
\end{tabular}


Table 7.7a. Average/Maximum Amplification Factors at Soil Sites

\begin{tabular}{|l|c|c|c|c|}
\hline Station & $\begin{array}{c}\text { Log Average } \\
\text { Amplification Factor }\end{array}$ & SD & $\begin{array}{c}\text { Log Maximum } \\
\text { Amplification Factor }\end{array}$ & $\begin{array}{c}\text { Maximum Amplification } \\
\text { at Frequency (Hz) }\end{array}$ \\
\hline ACTO & 0.20 & 0.19 & 0.57 & $12.6 \mathrm{~Hz}$ \\
\hline ALGO & 0.22 & 0.27 & 0.79 & $4 \mathrm{~Hz}$ \\
\hline BANO & 0.06 & 0.15 & 0.45 & $12.6 \mathrm{~Hz}$ \\
\hline BRCO & 0.18 & 0.19 & 0.73 & $2 \mathrm{~Hz}$ \\
\hline LINO & 0.09 & 0.17 & 0.53 & $20 \mathrm{~Hz}$ \\
\hline PEMO & 0.02 & 0.13 & 0.42 & $20 \mathrm{~Hz}$ \\
\hline PKRO & 0.15 & 0.23 & 0.72 & $1.6 \mathrm{~Hz}$ \\
\hline STCO & 0.14 & 0.26 & 0.64 & $5 \mathrm{~Hz}$ \\
\hline TYNO & 0.12 & 0.27 & 0.78 & $4 \mathrm{~Hz}$ \\
\hline WLVO & 0.12 & 0.20 & 0.61 & $16 \mathrm{~Hz}$ \\
\hline
\end{tabular}

Average maximum amplification factor $=0.62 \pm 0.13$

Table 7.7b. Average/Maximum Amplification Factors at Rock Sites

\begin{tabular}{|l|c|c|c|c|}
\hline Station & $\begin{array}{c}\text { Log Average } \\
\text { Amplification Factor }\end{array}$ & SD & $\begin{array}{c}\text { Log Maximum } \\
\text { Amplification Factor }\end{array}$ & $\begin{array}{c}\text { Maximum Amplification } \\
\text { at Frequency (Hz) }\end{array}$ \\
\hline ALFO & 0.07 & 0.08 & 0.24 & $20 \mathrm{~Hz}$ \\
\hline BUKO & 0.03 & 0.13 & 0.26 & $12.6 \mathrm{~Hz}$ \\
\hline CLPO & -0.02 & 0.07 & 0.06 & $2.5 \mathrm{~Hz}$ \\
\hline DELO & 0.01 & 0.06 & 0.13 & $20 \mathrm{~Hz}$ \\
\hline ELGO & 0.02 & 0.11 & 0.20 & $2.5 \mathrm{~Hz}$ \\
\hline HGVO & 0.10 & 0.15 & 0.37 & $16 \mathrm{~Hz}$ \\
\hline MPPO & -0.11 & 0.06 & 0.09 & $16 \mathrm{~Hz}$ \\
\hline PECO & 0.01 & 0.09 & 0.16 & $12.6 \mathrm{~Hz}$ \\
\hline PLVO & 0.01 & 0.09 & 0.19 & $20 \mathrm{~Hz}$ \\
\hline PTCO & 0.04 & 0.14 & 0.20 & $20 \mathrm{~Hz}$ \\
\hline
\end{tabular}

Average maximum amplification factor $=0.19 \pm 0.09$ 
Table 7.8a. Mean Log H/V Ratio for PGV at Soil Sites

\begin{tabular}{|c|c|c|c|}
\hline Station & Log Mean H/V & SD & Expected Increase in MMI \\
\hline ACTO & 0.26 & 0.10 & 0.5 \\
\hline ALGO & 0.50 & 0.10 & 0.9 \\
\hline BANO & 0.16 & 0.10 & 0.5 \\
\hline BRCO & 0.29 & 0.11 & 0.8 \\
\hline CLWO & 0.46 & 0.12 & 0.7 \\
\hline LINO & 0.37 & 0.20 & 0.7 \\
\hline MEDO & 0.39 & 0.20 & 0.5 \\
\hline PEMO & 0.26 & 0.14 & 0.4 \\
\hline PKRO & 0.23 & 0.08 & 0.2 \\
\hline PLIO & 0.08 & 0.07 & 0.6 \\
\hline STCO & 0.36 & 0.12 & 0.3 \\
\hline TOBO & 0.14 & 0.06 & 0.5 \\
\hline TORO & 0.28 & 0.17 & 0.7 \\
\hline TYNO & 0.39 & 0.13 & 0.5 \\
\hline WLVO & 0.25 & 0.14 & \\
\hline
\end{tabular}

Average maximum amplification factor $=0.3 \pm 0.1$ Average increase in MMI unit for soil sites due to amplification $=0.5$ 
Table 7.8b. Mean Log H/V Ratio for PGV at Rock Sites

\begin{tabular}{|c|c|c|c|}
\hline Station & $\log$ Mean H/V & SD & Expected Increase in MMI \\
\hline ALFO & 0.20 & 0.14 & 0.4 \\
\hline BUKO & 0.13 & 0.05 & 0.2 \\
\hline CLPO & 0.05 & 0.03 & 0.1 \\
\hline DELO & 0.08 & 0.07 & 0.1 \\
\hline ELGO & 0.11 & 0.06 & 0.2 \\
\hline HGVO & 0.17 & 0.08 & 0.3 \\
\hline KILO & 0.02 & 0.14 & 0.1 \\
\hline KLBO & 0.03 & 0.06 & 0.1 \\
\hline MALO & 0.16 & 0.06 & 0.3 \\
\hline MPPO & 0.12 & 0.10 & 0.2 \\
\hline MRHQ & 0.07 & 0.05 & 0.1 \\
\hline MUMO & 0.10 & 0.05 & 0.2 \\
\hline PECO & 0.15 & 0.10 & 0.3 \\
\hline PLVO & 0.09 & 0.03 & 0.2 \\
\hline PTCO & 0.15 & 0.10 & 0.3 \\
\hline RSPO & 0.30 & 0.05 & 0.5 \\
\hline SUNO & 0.05 & 0.01 & 0.1 \\
\hline
\end{tabular}

Average maximum amplification factor $=0.11 \pm 0.07$

Average increase in MMI unit for rock sites due to amplification $=0.20$ 
Table 7.9. Site Categories (BSSC, 1997)

\begin{tabular}{|c|l|c|}
\hline $\begin{array}{c}\text { NEHRP } \\
\text { Site Class }\end{array}$ & \multicolumn{1}{|c|}{ Generic Description } & Range for $\mathrm{V}_{\mathrm{s}}{ }^{30}(\mathrm{~m} / \mathrm{s})$ \\
\hline A & Hard rock & $>1500$ \\
\hline B & Rock & $760-1500$ \\
\hline C & Very dense soil and soft rock & $360-760$ \\
\hline D & Stiff soil & $180-360$ \\
\hline E & Soft soil & $<180$ \\
\hline F & $\begin{array}{l}\text { Special soils requiring site-specific } \\
\text { evaluation (i.e. geotechnical } \\
\text { investigations and dynamic site) } \\
\text { response analyses }\end{array}$ & \\
\hline
\end{tabular}

Table 7.10. Average Shear-wave Velocity in top $30 \mathrm{~m}\left(V_{s}{ }^{30}\right)$ for POLARIS sites

\begin{tabular}{|c|c|c|c|c|c|c|c|}
\hline Ref. & Location & $\begin{array}{c}\text { Station } \\
\text { Code }\end{array}$ & Lat. & Long. & $\begin{array}{l}V_{3}^{30} \\
(\mathrm{~m} / \mathrm{s})\end{array}$ & $\begin{array}{c}\text { NEHRP } \\
\text { Site Class }\end{array}$ & $\begin{array}{c}\text { Surficial } \\
\text { Materials }\end{array}$ \\
\hline BA97 & Ottawa & OTT & 45.39 & -75.72 & 1914 & A & $\begin{array}{l}\text { Limestone } \\
\text { (shallow bedrock) }\end{array}$ \\
\hline BA97 & Williamsburg & WBO & 45.00 & -75.28 & 1734 & A & $\begin{array}{l}\text { clay plain (shallow } \\
\text { bedrock) }\end{array}$ \\
\hline BA97 & Chalk River & CKO & 45.99 & -77.45 & 1203 & B & $\begin{array}{l}\text { till plain } \\
\text { (drumlinized) }\end{array}$ \\
\hline BA97 & $\begin{array}{l}\text { Grand } \\
\text { Remous }\end{array}$ & GRQ & 46.61 & -75.86 & 1889 & A & $\begin{array}{l}\text { shallow bedrock } \\
\text { surfaces }\end{array}$ \\
\hline BA97 & Bruce & $\mathrm{BRCO}$ & 44.24 & -81.44 & 282 & $\mathrm{D}$ & $\begin{array}{l}\text { till plain } \\
\text { (undrumlinized) }\end{array}$ \\
\hline BA97 & $\begin{array}{l}\text { Saint } \\
\text { Catharines }\end{array}$ & STCO & 43.21 & -79.17 & 415 & $\mathrm{C}$ & sand plain \\
\hline BA97 & Tyneside & TYNO & 43.09 & -79.87 & 404 & $\mathrm{C}$ & clay plain \\
\hline BA97 & Acton & ACTO & 43.61 & -80.06 & 966 & $\mathrm{~B}$ & till moraine \\
\hline BA97 & Pickering & PKRO & 43.96 & -79.07 & 403 & $\mathrm{C}$ & $\begin{array}{l}\text { till plain } \\
\text { (drumlinized) }\end{array}$ \\
\hline BA97 & Weselyville & WLVO & 43.92 & -78.40 & 1137 & B & $\begin{array}{l}\text { till plain } \\
\text { (drumlinized) }\end{array}$ \\
\hline BA97 & Pickering & N/A & 43.48 & -79.11 & 665 & $\mathrm{C}$ & $\begin{array}{l}\text { till plain } \\
\text { (drumlinized) }\end{array}$ \\
\hline Murphy & Elora Gorge & ELGO & 43.68 & -80.44 & 1078 & B & $\begin{array}{l}\text { till plain } \\
\text { (dumlinized) }\end{array}$ \\
\hline Murphy & Lindsay & LINO & 44.35 & -78.78 & 945 & B & $\begin{array}{l}\text { till plain } \\
\text { (drumlinized) }\end{array}$ \\
\hline GSC & Waterloo & N/A & 43.50 & -80.81 & 374 & $\mathrm{C}$ & $\begin{array}{l}\text { silt and sand or } \\
\text { silty clay }\end{array}$ \\
\hline GSC & Aurora & N/A & 43.99 & -79.42 & 496 & $\mathrm{C}$ & $\begin{array}{l}\text { silt, sand, gravel, } \\
\text { dimicton }\end{array}$ \\
\hline
\end{tabular}




\begin{tabular}{|l|l|c|c|c|c|c|l|}
\hline Ref. & Location & $\begin{array}{c}\text { Station } \\
\text { Code }\end{array}$ & Lat. & Long. & $\begin{array}{c}\mathbf{V}_{\mathbf{s}}^{30} \\
(\mathbf{m} / \mathbf{s})\end{array}$ & $\begin{array}{c}\text { NEHRP } \\
\text { Site Class }\end{array}$ & \multicolumn{1}{|c|}{$\begin{array}{c}\text { Surficial } \\
\text { Materials }\end{array}$} \\
\hline GSC & Caledon & N/A & 43.75 & -79.84 & 288 & D & sand, silt and clay \\
\hline GSC & Uxbridge & N/A & 44.10 & -79.13 & 430 & C & sand, silt and clay \\
\hline GSC & Waterloo & N/A & 43.50 & -80.54 & 445 & C & $\begin{array}{l}\text { silt and sand or } \\
\text { silty clay }\end{array}$ \\
\hline GSC & Ottawa & N/A & 45.41 & -75.56 & 138 & E & sand, silt and clay \\
\hline GSC & Lefevre & N/A & 45.63 & -74.85 & 180 & D & silt and clay \\
\hline GSC & Casselman & N/A & 45.32 & -75.10 & 100 & E & $\begin{array}{l}\text { silt, clay, gravel } \\
\text { and till }\end{array}$ \\
\hline GSC & Ottawa & N/A & 45.37 & -75.55 & 130 & E & $\begin{array}{l}\text { silt, clay, gravel } \\
\text { and till }\end{array}$ \\
\hline KA04 & Pembroke & PEMO & 45.68 & -77.25 & 591 & C & shallow till \\
\hline KA04 & Algonquin & ALGO & 45.95 & -78.05 & 354 & D & $\begin{array}{l}\text { deep sand layer } \\
\text { with some man- } \\
\text { made fill }\end{array}$ \\
\hline
\end{tabular}

Table 7.11a General Soil Response Factors Adopted for ShakeMap Amplifications (Horizontal-component)

\begin{tabular}{|c|c|c|c|c|c|c|}
\hline Site & PGV & PGA & $\mathbf{1 ~ H z}$ & $\mathbf{2 H z}$ & $\mathbf{5 H z}$ & $\mathbf{1 0 ~ H z}$ \\
\hline B & 1.57 & 1.33 & 1.08 & 1.34 & 1.56 & 1.33 \\
\hline C & 2.06 & 1.81 & 2.58 & 2.81 & 3.2 & 2.51 \\
\hline D & 4.64 & 3.04 & 4.87 & 4.64 & 4.19 & 3.04 \\
\hline
\end{tabular}

Table 7.11b Specific Soil Response Factors for POLARIS Stations based on H/V ratios

\begin{tabular}{|l|c|c|c|c|c|c|c|}
\hline \multicolumn{1}{|c|}{ Site } & PGV & PGA & $\mathbf{1 ~ H z}$ & $\mathbf{2 H z}$ & $\mathbf{5 H z}$ & $\mathbf{1 0 H z}$ & $\begin{array}{c}\text { NEHRP } \\
\text { Class }\end{array}$ \\
\hline ACTO & 1.81 & 1.66 & 1.19 & 1.34 & 2.15 & 3.27 & $\mathrm{~B}$ \\
\hline ALFO & 1.38 & 1.89 & 1.20 & 1.17 & 1.28 & 1.34 & $\mathrm{~B}$ \\
\hline ALGO & 3.18 & 2.62 & 1.14 & 1.94 & 5.84 & 1.73 & $\mathrm{D}$ \\
\hline BANO & 1.44 & 1.39 & 1.13 & 1.16 & 1.11 & 2.07 & $\mathrm{~B}$ \\
\hline BRCO & 1.94 & 1.79 & 1.11 & 5.48 & 1.53 & 1.32 & $\mathrm{D}$ \\
\hline BUKO & 1.35 & 1.02 & 1.08 & 1.09 & 1.20 & 1.56 & $\mathrm{~B}$ \\
\hline CLWO & 2.71 & 3.39 & 1.72 & 1.90 & 1.57 & 2.18 & $\mathrm{C}$ \\
\hline CBRQ & 1.09 & 1.07 & 1.07 & 1.10 & 1.14 & 1.28 & $\mathrm{~A}$ \\
\hline DELO & 1.20 & 1.10 & 1.08 & 1.03 & 1.04 & 1.05 & $\mathrm{~A}$ \\
\hline ELFO & 1.97 & 1.02 & 1.07 & 2.48 & 2.37 & 1.55 & $\mathrm{~B}$ \\
\hline
\end{tabular}




\begin{tabular}{|l|c|c|c|c|c|c|c|}
\hline \multicolumn{1}{|c|}{ Site } & PGV & PGA & $\mathbf{1 ~ H z}$ & $\mathbf{2 H z}$ & $\mathbf{5 H z}$ & $\mathbf{1 0 H z}$ & $\begin{array}{c}\text { NEHRP } \\
\text { Class }\end{array}$ \\
\hline ELGO & 1.28 & 1.49 & 1.07 & 1.13 & 1.19 & 1.23 & $\mathrm{~B}$ \\
\hline HGVO & 1.48 & 1.35 & 1.07 & 1.48 & 1.56 & 1.37 & $\mathrm{~B}$ \\
\hline KLBO & 1.06 & 1.04 & 1.30 & 1.27 & 1.08 & 1.09 & $\mathrm{~A}$ \\
\hline KILO & 1.05 & 1.09 & 1.09 & 1.42 & 1.41 & 1.18 & $\mathrm{~A}$ \\
\hline LINO & 1.76 & 2.49 & 1.19 & 1.48 & 1.15 & 1.52 & $\mathrm{~B}$ \\
\hline MEDO & 2.51 & 1.21 & 1.24 & 1.14 & 1.55 & 2.21 & $\mathrm{C}$ \\
\hline MPPO & 1.32 & 1.08 & 1.08 & 1.05 & 1.09 & 1.01 & $\mathrm{~A}$ \\
\hline MALO & 1.44 & 1.29 & 1.49 & 1.35 & 1.09 & 1.26 & $\mathrm{~B}$ \\
\hline MRHQ & 1.18 & 1.38 & 1.70 & 1.10 & 1.26 & 1.38 & $\mathrm{~A}$ \\
\hline PECO & 1.41 & 1.21 & 1.09 & 1.1 & 1.15 & 1.42 & $\mathrm{~B}$ \\
\hline PEMO & 1.82 & 2.3 & 1.08 & 1.09 & 1.19 & 1.22 & $\mathrm{C}$ \\
\hline PKRO & 1.69 & 1.6 & 2.27 & 4.18 & 1.17 & 1.56 & $\mathrm{C}$ \\
\hline PLIO & 1.21 & 1.09 & 1.07 & 1.33 & 1.36 & 1.04 & $\mathrm{~A}$ \\
\hline PLVO & 1.23 & 1.46 & 1.09 & 1.02 & 1.14 & 1.09 & $\mathrm{~A}$ \\
\hline PTCO & 1.41 & 1.56 & 1.06 & 1.28 & 1.27 & 1.19 & $\mathrm{~B}$ \\
\hline RSPO & 1.32 & 1.38 & 1.08 & 1.12 & 1.09 & 1.16 & $\mathrm{~B}$ \\
\hline STCO & 2.29 & 1.92 & 1.10 & 1.15 & 4.42 & 1.47 & $\mathrm{C}$ \\
\hline SUNO & 1.13 & 1.22 & 1.17 & 1.19 & 1.03 & 1.13 & $\mathrm{~A}$ \\
\hline TOBO & 1.39 & 2.10 & 1.70 & 1.48 & 1.96 & 1.53 & $\mathrm{~B}$ \\
\hline TYNO & 2.45 & 2.39 & 1.62 & 2.39 & 3.82 & 1.47 & $\mathrm{C}$ \\
\hline WLVO & 1.77 & 1.98 & 1.02 & 1.13 & 1.19 & 1.97 & $\mathrm{~B}$ \\
\hline
\end{tabular}

Table 7.12 Soil Response Factors for NEHRP B, based on H/V at 4 NEHRP B sites

\begin{tabular}{|c|c|c|c|c|c|c|c|}
\hline Site & PGV & PGA & $0.5 \mathrm{~Hz}$ & $1 \mathrm{~Hz}$ & $2 \mathrm{~Hz}$ & $5 \mathrm{~Hz}$ & $10 \mathrm{H}$ \\
\hline B & 1.57 & 1.33 & 1.03 & 1.08 & 1.34 & 1.56 & 1.33 \\
\hline
\end{tabular}

Table 7.13 Comparing Soil Response Factors for NEHRP C

\begin{tabular}{|c|c|c|c|}
\hline $\begin{array}{c}\text { Frequency } \\
(\mathrm{Hz})\end{array}$ & $\begin{array}{c}\text { Adams and Halchuk } \\
(2003)\end{array}$ & Mean H/V & $\begin{array}{c}\text { The quarter-wavelength } \\
\text { Approximation }\end{array}$ \\
\hline 0.5 & 2.86 & 0.99 & 1.45 \\
\hline 1.0 & 2.58 & 1.22 & 1.91 \\
\hline 2.0 & 2.38 & 2.30 & 2.03 \\
\hline 5.0 & 1.94 & 3.59 & 2.96 \\
\hline 10.0 & 1.39 & 1.43 & 2.46 \\
\hline PGV & 2.38 & 2.06 & N/A \\
\hline PGA & 1.39 & 1.81 & N/A \\
\hline
\end{tabular}



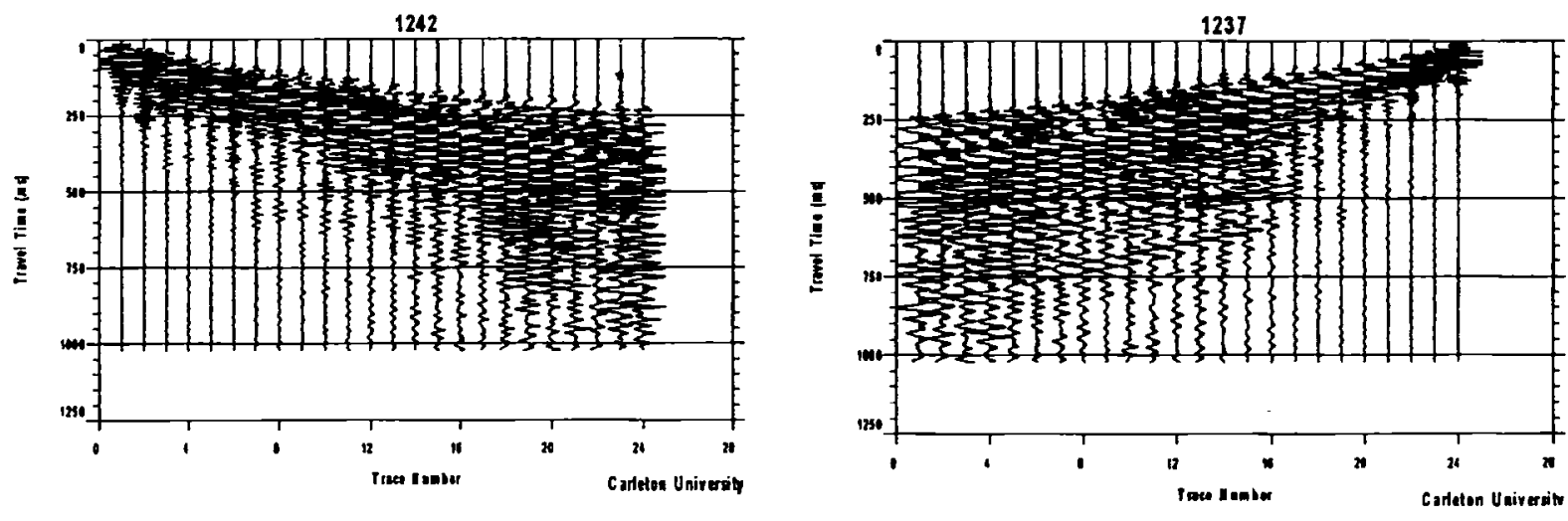

Figure 7.1 Example of stacked raw data collected from source impacts in the two opposite directions at ALGO site. 
Locations of the study earthquakes and recording stations

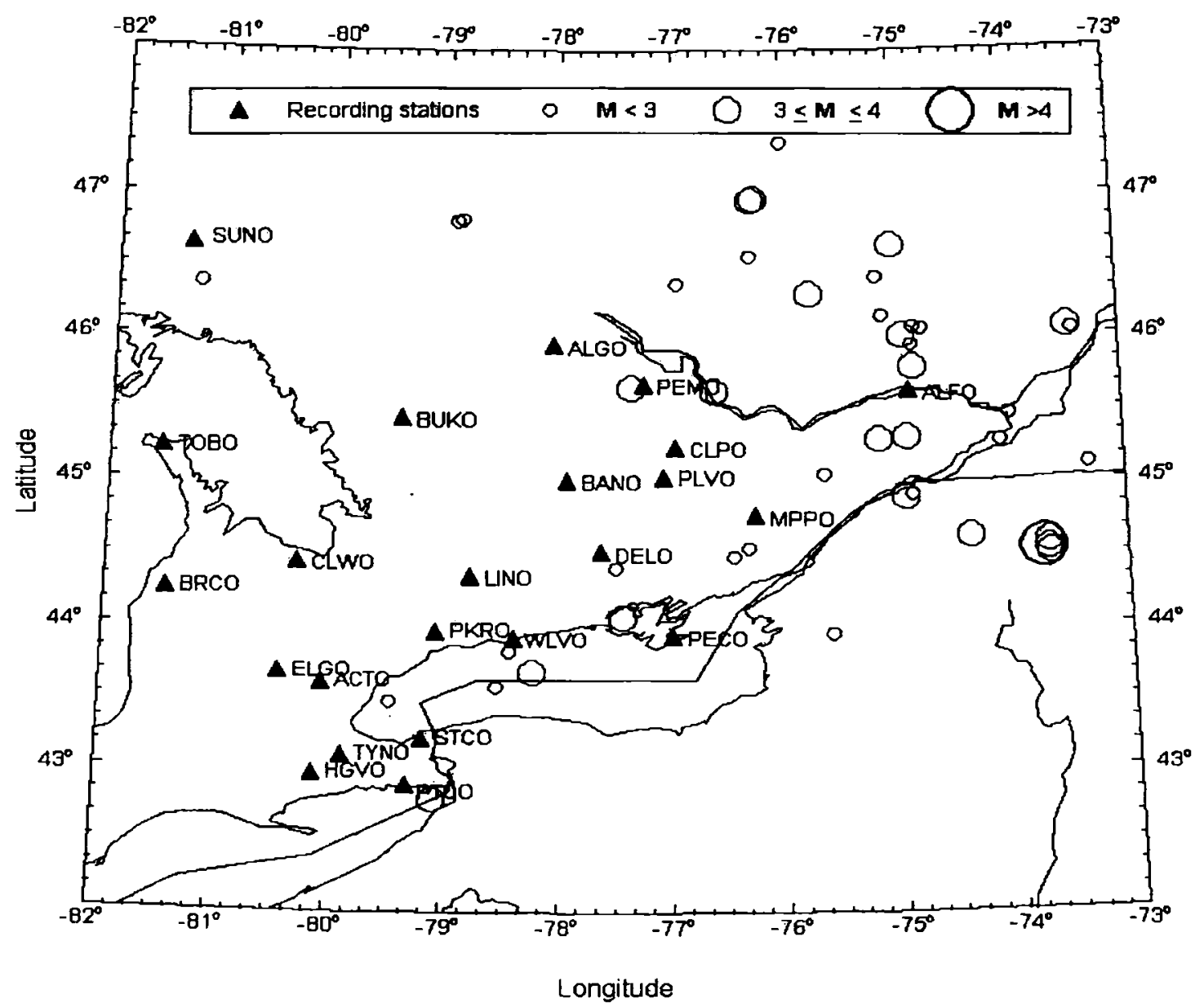

Figure 7.2. Locations of the study earthquakes and recording stations for $H / V$ analyses. 
6SC: 2005/03/06 06:17:49 47.75N 69.75W 13.3 5.1WS GSC CHARLEVOIX SESWIC LONE, QUE. FELT.

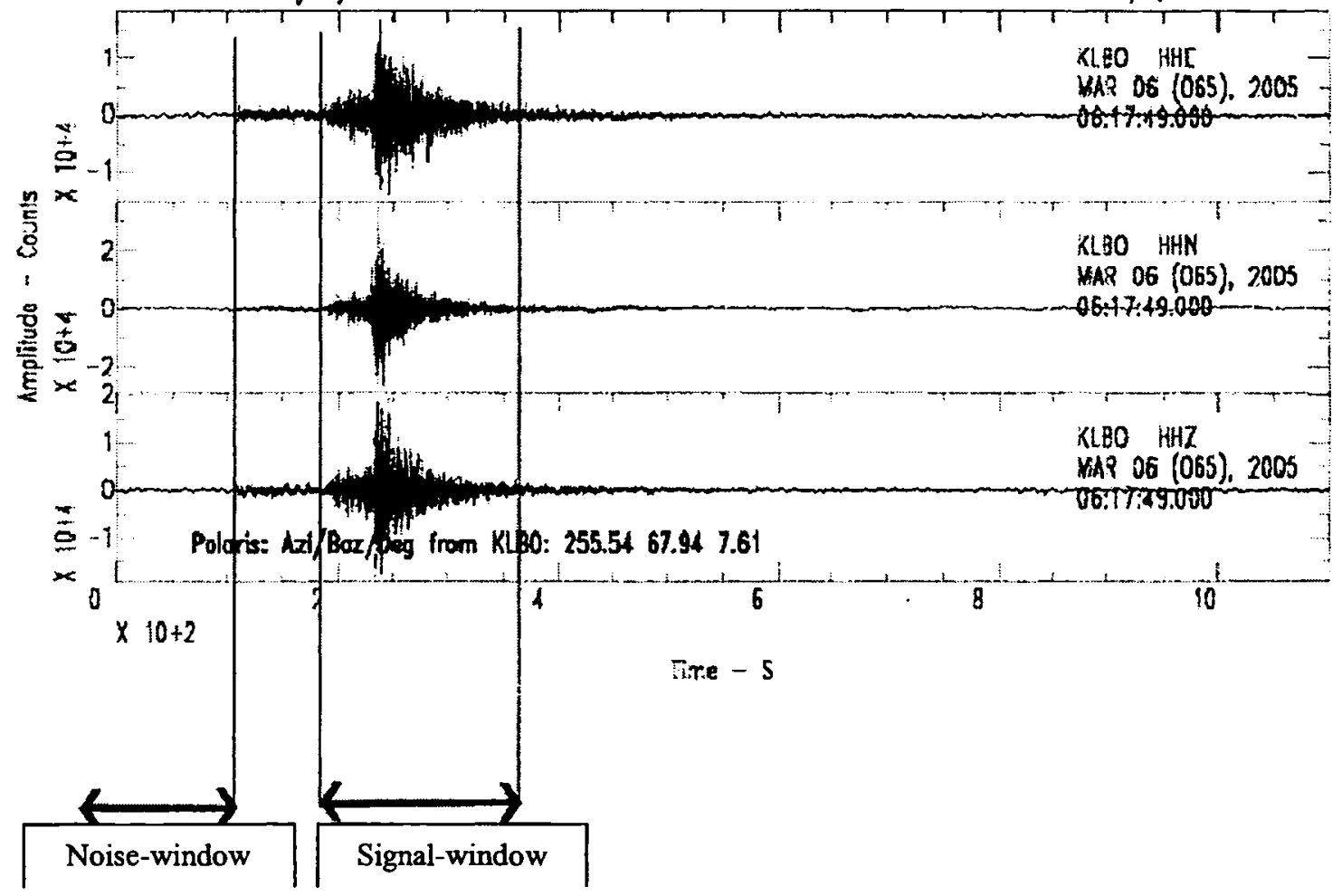

Figure 7.3. Signal and noise window selections of time series data from MN 5.4 March 6, 2005 Riviere-du-Loup, Quebec Earthquake 


\section{$\mathrm{H} / \mathrm{V}$ for Soil Sites}

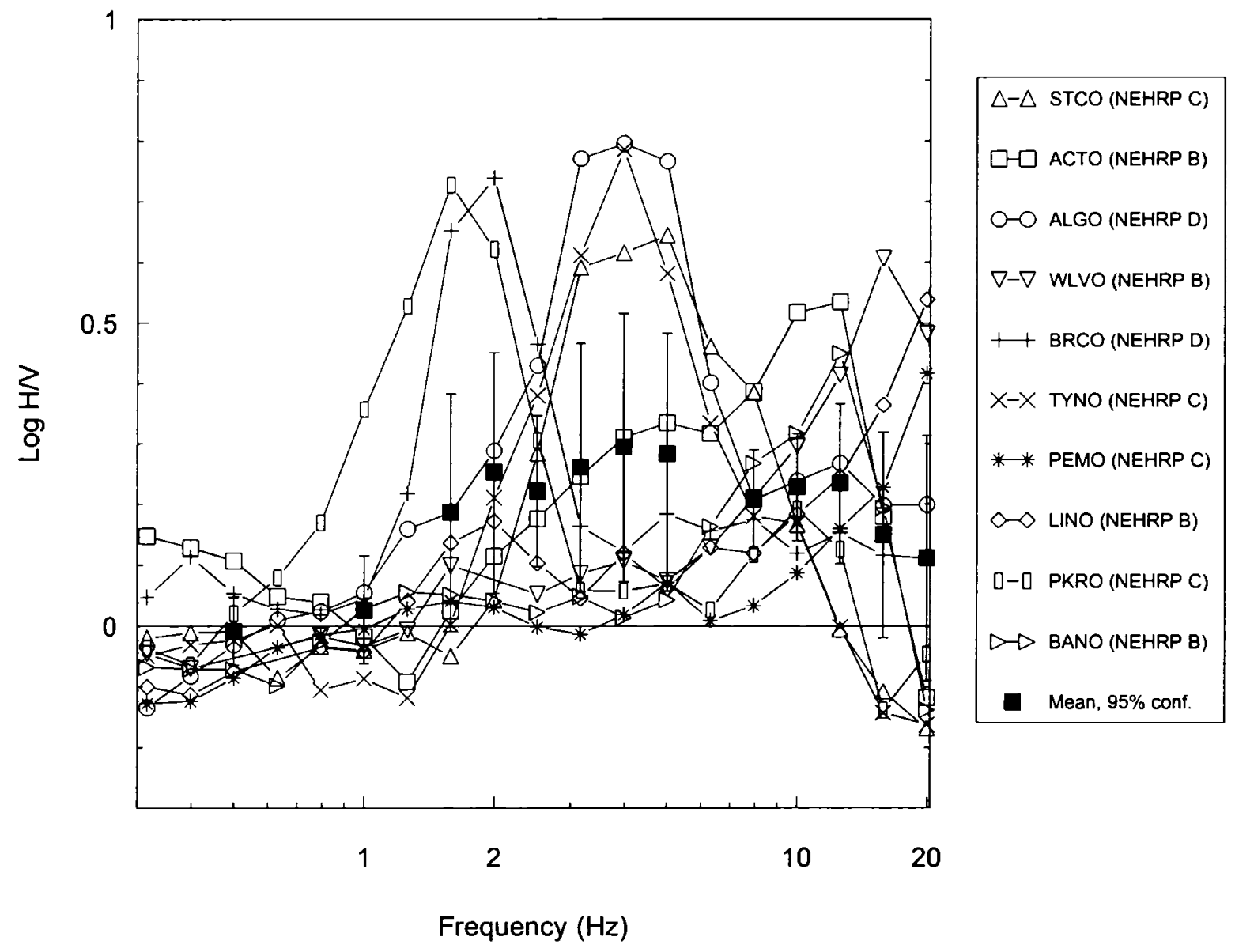

Figure 7.4. $\log \mathrm{H} / \mathrm{V}$ for soil sites. Mean $\log \mathrm{H} / \mathrm{V}$ and $95 \%$ confidence limits on mean for Soil Sites also shown. 
$H /$ for Rock Sites

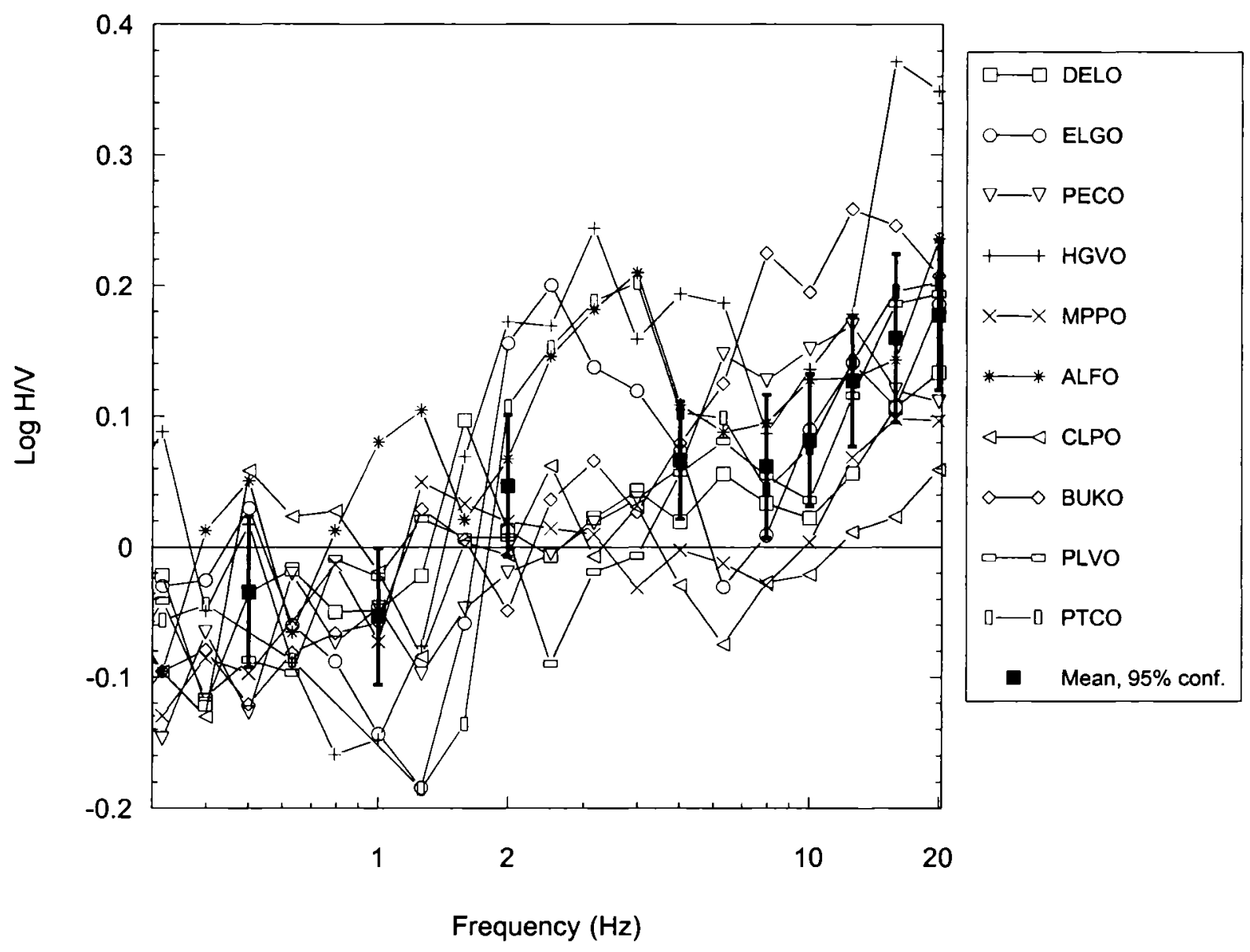

Figure 7.5. $\log \mathrm{H} / \mathrm{V}$ for rock sites. Mean $\log \mathrm{H} / \mathrm{V}$ and $95 \%$ confidence limits on mean for Rock Sites also shown. 


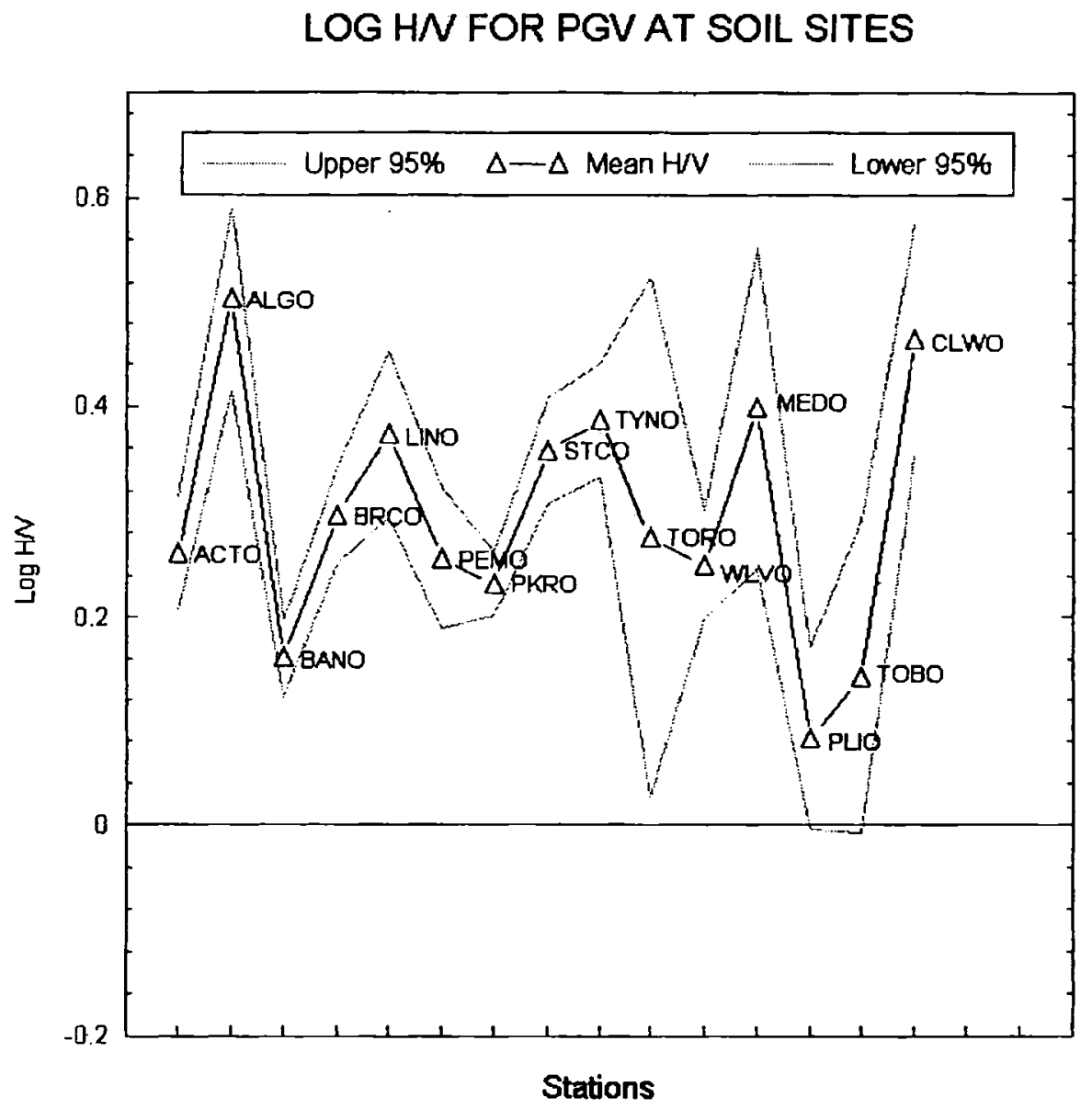

Figure 7.6. Log H/V for PGV and 95\% confidence limits for Soil Sites. 


\section{LOG HN FOR PGV AT ROCK SITES}

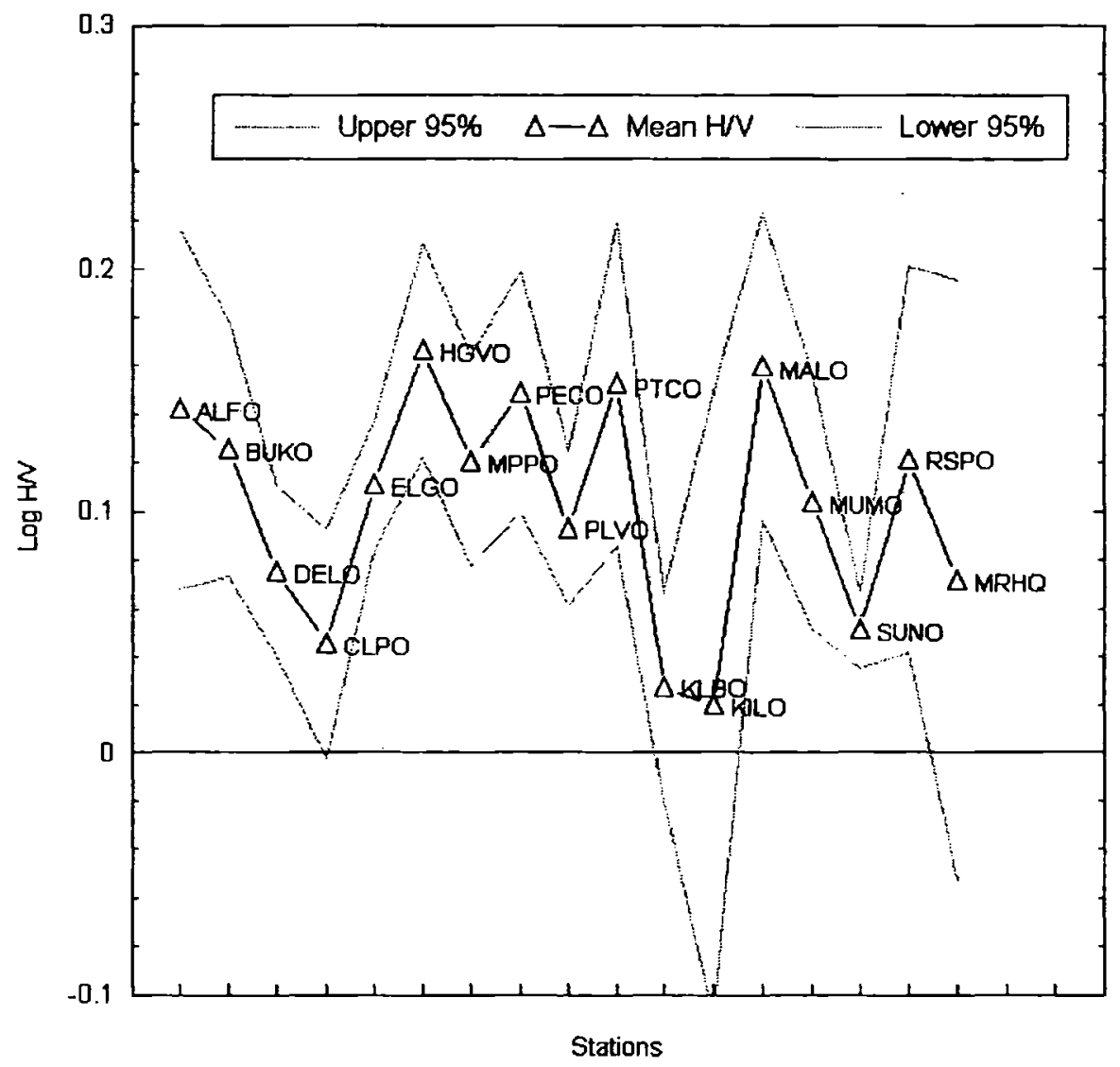

Figure 7.7 Log H/V for PGV and 95\% confidence limits for Rock Sites. 


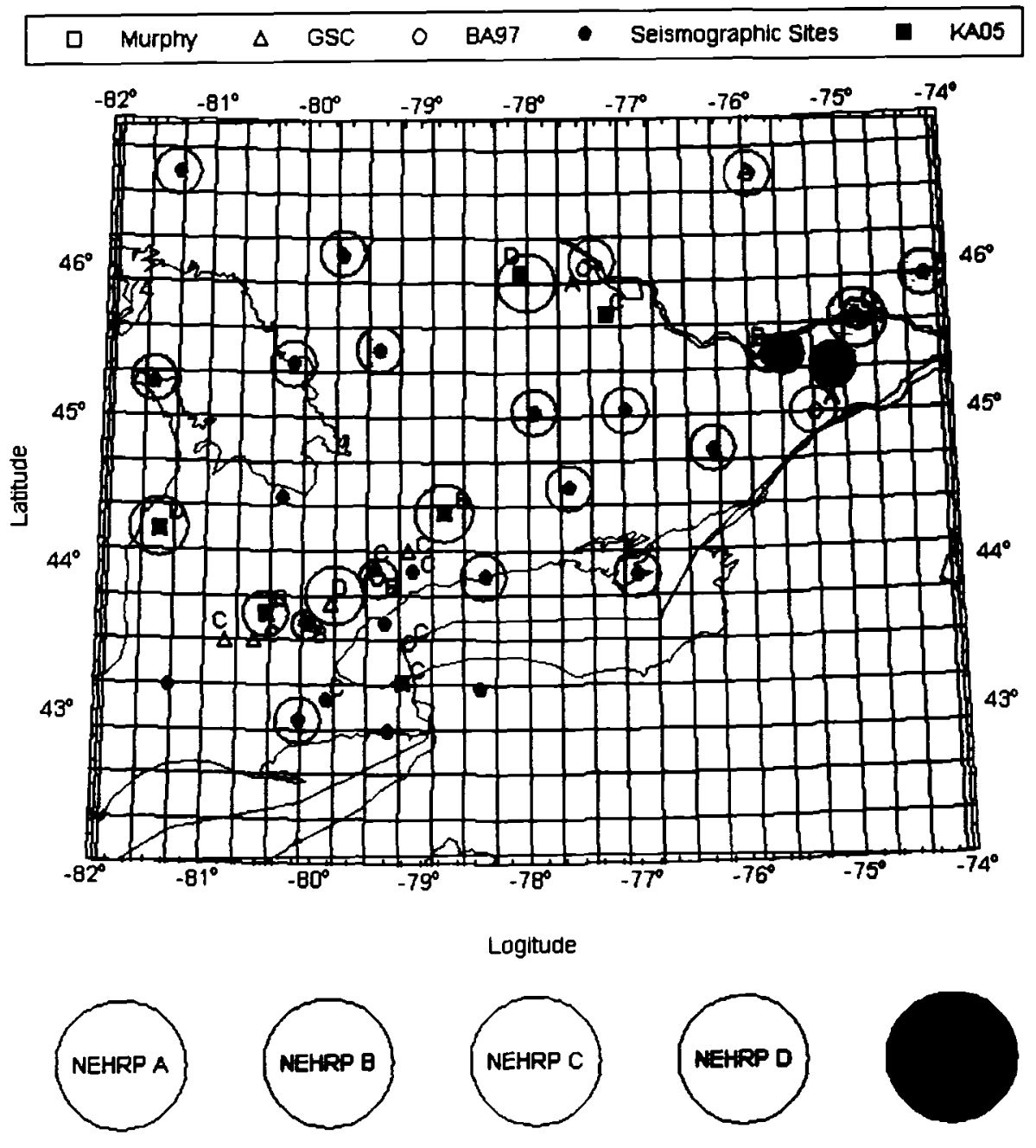

Figure 7.8 Site Classification Map for Ontario ShakeMap Grid 


\section{Amplification versus Frequency (NEHRP C sites)}
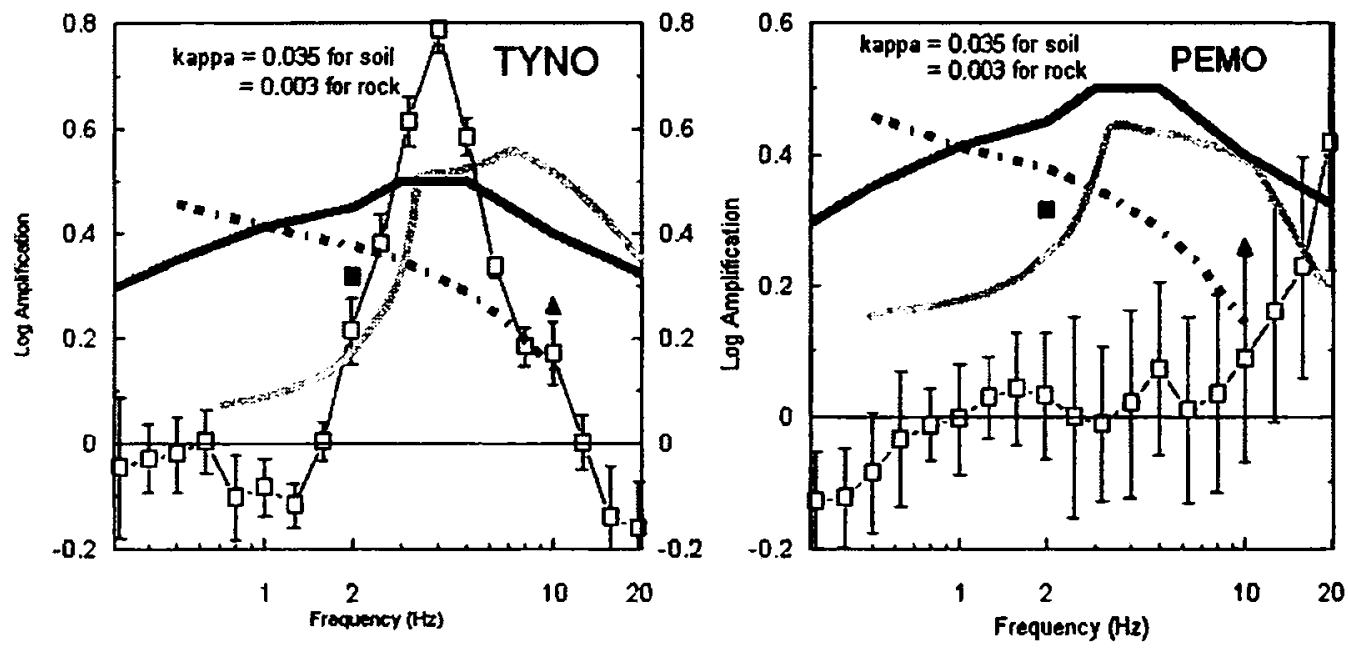

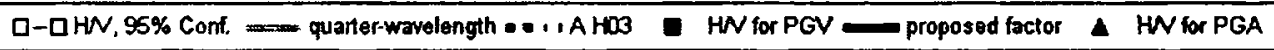
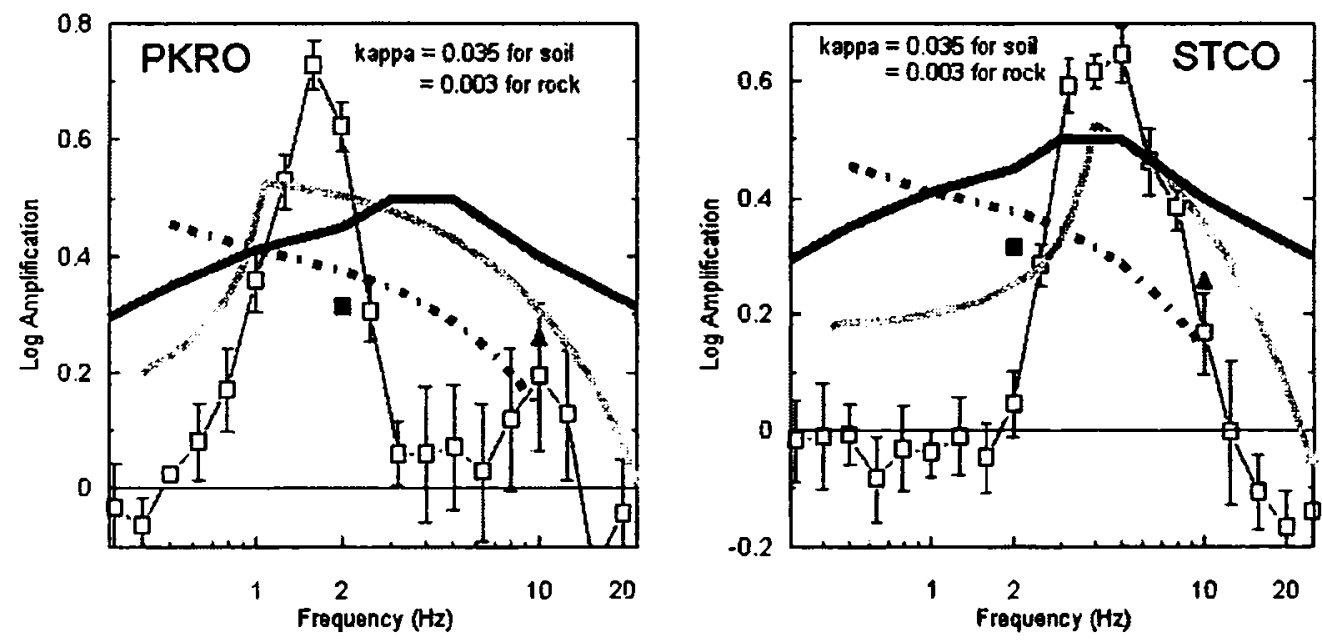

Figure 7.9 Amplification versus Frequency for NEHRP C sites by various methods. The heavy solid line is the proposed factor to be used in our ShakeMap application. The thin solid line with $95 \%$ confidence level is calculated using the $\mathrm{H} / \mathrm{V}$ method. The gray-scale solid line is computed using the quarter-wavelength approximation. The dashed line is from Adams and Halchuck (2003). 
a)

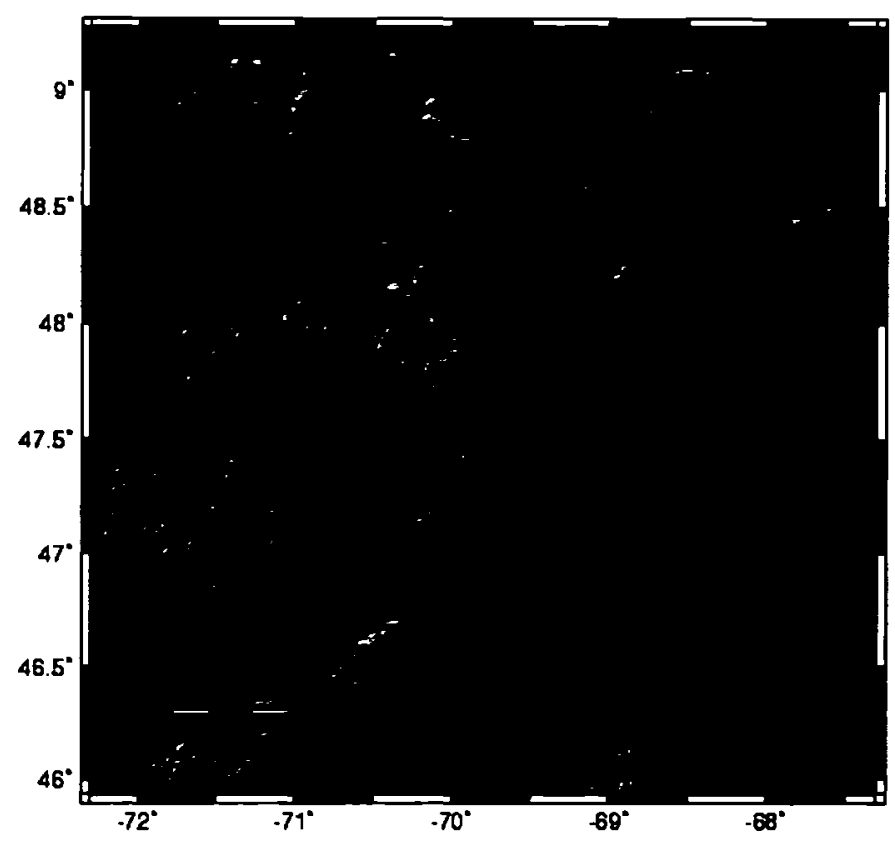

\begin{tabular}{|c|c|c|c|c|c|c|c|c|c|}
\hline $\begin{array}{l}\text { PEACEIVED } \\
\text { SHAKWO }\end{array}$ & Not felt & Weak & Light & Moderate & Strong & Very strong & Severe & Violent & Extreme \\
\hline POTERTML & none & none & none & Very light & Lght & Moderale & ModerateAleavy & Heavy & Very Heavy \\
\hline EAK ACC_(cm/s"-2 & $<.17$ & $.17 \cdot 1.4$ & $1.4-3.9$ & $3.9-9.2$ & $9.2-18$ & $18-34$ & $34-65$ & $65-124$ & $>124$ \\
\hline PEAK VEL_(mm/a) & $<0.1$ & $0.1 \cdot 1.1$ & $1.1-3.4$ & 3.4-8.1 & $8.1-16$ & $16-31$ & $31-\infty 0$ & $60-116$ & $>116$ \\
\hline MUSTRY STIAL & I & & & & $\mathbf{n}$ & & & & \\
\hline
\end{tabular}

b)

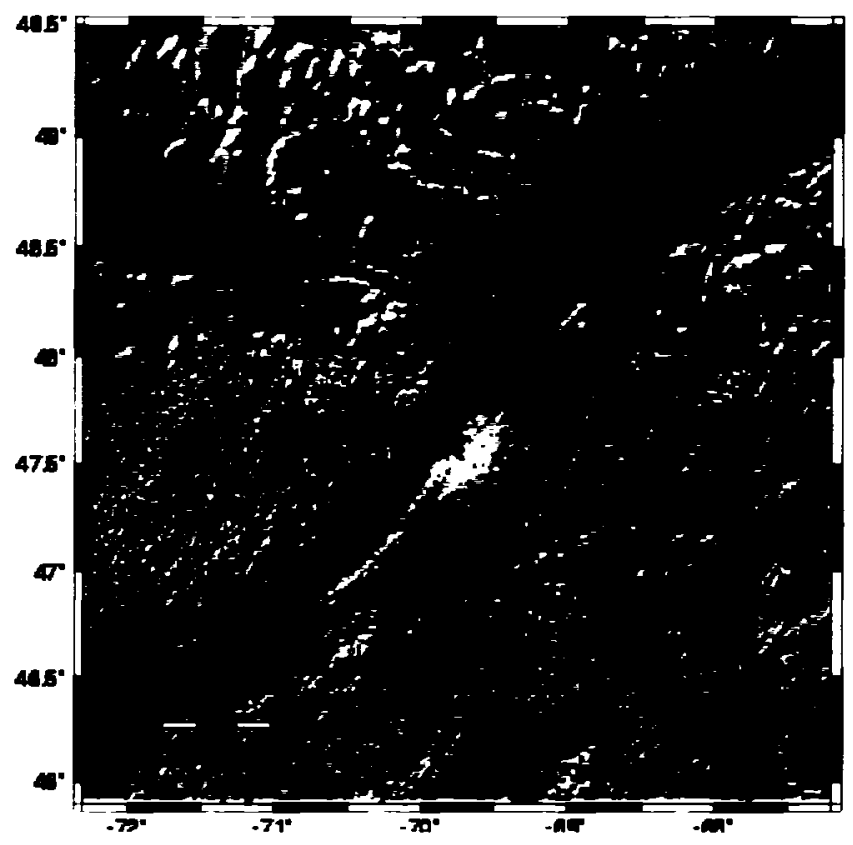

Figure 7.10 Intensity ShakeMaps for the MN 5.4 March 6, 2005 Riviere-du-Loup, Quebec Earthquake. Generated (a) before and (b) after applying the site correction factors. 


\section{Chapter 8}

ShakeMap for the

\section{MN 5.4 March 6, 2005 Riviere-du-Loup, Quebec Earthquake}

\subsection{Introduction}

A moderate earthquake of MN5.4 occurred in the Charlevoix seismic zone on March 6, 2005 (01:17:49 EST) at 47.75N 69.73W (Geological Survey of Canada at http://www.seismo.nrcan.gc.ca/nedb/eq_db_e.php). The earthquake was felt strongly in Riviere-du-Loup, Saint-Pascal and La Malbaie and Saint-Pacome regions. It was also felt widely throughout Quebec, eastern Ontario and the border regions of the northeastern United States. No significant structural damage has been reported.

The Riviere-du-Loup event was the first moderate well-recorded event in eastern Canada since the implementation of the Ontario ShakeMap project. The Riviere-du-Loup event provided a good test of the performance of ShakeMap and an opportunity to examine the validity of different relations that are implemented in Ontario ShakeMaps.

ShakeMap sent email notifications within 3 minute of the event and maps were automatically produced and posted within 7 minutes. Initial maps were not accurate because real-time ShakeMaps are currently based only on POLARIS stations (within Ontario, far from the earthquake). However, the event was post-processed to include all of the available CNSN (Canadian National Seismograph Network) stations, to give an indication of the performance of the system that can be obtained if all eastern Canadian stations are used. As of the end of 2005, all CNSN stations will be available in real-time for ShakeMap applications, in addition to the POLARIS stations. Thus the use of all 
stations is indicative of the ShakeMap performance that can be readily obtained with the current eastern Canadian station distribution.

\subsection{Performance of ShakeMap}

\subsubsection{Location and magnitude}

In Figure 8.1, the ShakeMap centroid location is compared to the epicentral location determined by the Geological Survey of Canada; the centroid is located approximately $17 \mathrm{~km}$ from the epicenter. The ShakeMap estimate of moment magnitude (M) is 5.0, whereas the GSC value of MN5.4 provides an estimated value of $\mathbf{M} 4.9$, using empirical relations (Atkinson, 1993a) to convent MN to $\mathbf{M}$. Preliminary moment tensor evaluations of the event provide a value of $\mathbf{M} 4.7$ to 4.8 (D. Boore, pers. comm., 2005, based on estimates made by W.Y. Kim and R. Herrmann, respectively). Thus the magnitude determined by the ground-motion centroid approach appears to be accurate, while there is an offset in the location of the centroid from the epicentre, attributable to the effects of ground-motion amplitude variability on the centroid for a sparse station distribution.

\subsubsection{Ground Motions}

Recorded ground motions include broadband three-component and short-period data from the Canadian National Seismographic Network (CNSN) and Portable Observatories for Lithospheric Analysis and Research Investigating Seismicity (POLARIS) network (see Figure 8.1). Instrument response is removed as described Chapter 7.3. Ground motion parameters, listed in Table 8.1 , include peak ground velocity 
(PGV), peak ground acceleration (PGA) and 5\% damped pseudo-acceleration (PSA) at various frequencies.

An important element of ShakeMap is the combination of recorded ground motions with predicted values based on location and magnitude. The use of the predicted values is particularly important in eastern Canada to "fill out" the ground-motion pattern, due to the sparse distribution of seismograph stations. Ground motion values in between stations are predicted using the empirical ground-motion equations developed in chapter 6 (Equation 4.1), using the magnitude and location of the centroid. Figure 8.2 shows that the ground-motion amplitudes predicted by Equation 4.1 agrees well with the recorded amplitudes; the predictions of Atkinson and Boore (1995) based on a stochastic model are also in close agreement with observations. Only vertical-component data are shown on Figure 8.2, as Equation 4.1 is specified for vertical-component amplitudes. The Atkinson and Boore (1995) horizontal-component predictions were converted to the equivalent vertical-component using a relation for hard-rock sites given by Atkinson (1993b). Note that when predicting intensities from the ground motions, the verticalcomponent amplitudes are converted to equivalent horizontal values based on $\mathrm{H} / \mathrm{V}$ ratios that depend on site soil condition, using site-specific $\mathrm{H} / \mathrm{V}$ ratios for the recording stations.

\subsubsection{Felt-Intensity ShakeMap}

In our ShakeMap implementation, felt intensity is derived from an empirical relation between PGV and Modified Mercalli intensity (MMI) for ENA as developed in Chapter 5:

$$
\mathrm{MMI}=4.08+1.79 \log \mathrm{PGV}-0.28 \log \mathrm{R}
$$


where $\mathrm{PGV}$ is the horizontal-component $\mathrm{PGV}$ in $\mathrm{mm} / \mathrm{s}$ and $\mathrm{R}$ is hypocentral distance in $\mathrm{km}$. As described in Chapter 7, it is assumed when predicting intensity that all sites with unknown soil condition are NEHRP C (firm ground), and are accordingly assigned an $\mathrm{H} / \mathrm{V}=2.38$ (the amplification of PGV for NEHRP $\mathrm{C}$ according to Adams and Halchuk, 2003). An exception is made for the POLARIS stations, which are classified by their site-specific $\mathrm{H} / \mathrm{V}$ ratio (Table $7.9 \mathrm{~b}$ ). The CNSN stations are hard-rock sites, and are thus assigned an $\mathrm{H} / \mathrm{V}=1.21$ (hard-rock for PGV according to Atkinson, 1993b); this ratio is also assumed for POLARIS stations sited on rock with unknown $\mathrm{H} / \mathrm{V}$.

Comparing observed and predicted intensities is difficult for this event because there is not yet in place a comprehensive Canadian internet intensity reporting system. Canadians can report their experiences in descriptive format at the GSC website (www.seismo.nrcan.gc.ca), but these responses need to be manually processed to provide a reliable intensity. This processing is in progress but will take time as there were about 3000 responses (mostly in French). Americans in the northeast who felt the earthquake reported their observations on the USGS "Did You Feel It" (DYFD) site (http://pasadena.wr.usgs.gov/shake/), while some Canadians reported to the USGS international DYFI site (also available at http://pasadena.wr.usgs.gov/shake/). Overall the reported intensities of IV to VI near the epicentre, with intensities of II to IV in northern Maine, New Hampshire and Vermont, agree well with ShakeMap intensities, which are shown in Figure 8.3. The contour map of PGV from which these intensities were derived is shown in Figure 8.4.

In Figure 8.5, the predicted ShakeMap intensities are compared to MMI based on felt-reports submitted on-line to the automated USGS sites. It is concluded that the 
agreement between observed and predicted intensity appears to be satisfactory. However, it is noted that observed MMI data are preliminary in nature; efforts are underway to evaluate intensity in more detail. An interesting observation is that there may be a bias in the internet intensities to high values at large distances, due to the greater tendency of those that felt the event to report their observations on-line, as compared to those that did not feel the event.

Given the vast area covered and the relatively small number of seismographic recording stations, ShakeMap offers a reasonable picture of ground shaking across the region. The performance of ShakeMap for this event is very encouraging and can be viewed as a significant step forward in the development of reliable near-real-time seismic information relevant to post-earthquake rapid warning systems in eastern Canada. However, improvements are needed to reflect specific local variation in ground shaking due to soil conditions. 
Table 8.1. Observed Ground Motion Amplitudes

\begin{tabular}{|c|c|c|c|c|c|c|c|c|c|}
\hline Station & Comp & $\begin{array}{c}\text { PGV } \\
(\mathrm{mm} / \mathrm{s})\end{array}$ & $\begin{array}{l}\text { PGA } \\
\text { (cgs) }\end{array}$ & $\begin{array}{c}\text { PSA(cgs) } \\
0.5 \mathrm{~Hz}\end{array}$ & \begin{tabular}{|c|} 
PSA(cgs) \\
$1 \mathrm{~Hz}$
\end{tabular} & $\begin{array}{c}\text { PSA(cgs) } \\
2 \mathrm{~Hz}\end{array}$ & $\begin{array}{c}\text { PSA(cgs) } \\
5 \mathrm{~Hz}\end{array}$ & \begin{tabular}{|c} 
PSA(cgs) \\
$10 \mathrm{~Hz}$
\end{tabular} & \begin{tabular}{|c|} 
Hypocentral \\
Distance (km)
\end{tabular} \\
\hline \multirow[t]{3}{*}{$\mathrm{A} 21$} & HHE & 7.81 & 68.4 & 1.19 & 4.44 & 14.1 & 75.5 & 107 & 18.9 \\
\hline & HHN & 8.15 & 73.2 & 2.24 & 4.8 & 17.1 & 35.1 & 131 & 18.9 \\
\hline & HHZ & 7.89 & 75.3 & 1.13 & 3.51 & 19.3 & 73.1 & 72.5 & 18.9 \\
\hline \multirow[t]{3}{*}{ A64 } & HHE & 3.86 & 22.9 & 0.331 & 2.22 & 4.44 & 11.4 & 31.3 & 23.3 \\
\hline & HHN & 2.91 & 32.2 & 0.278 & 1.8 & 2.78 & 10.6 & 28.5 & 23.3 \\
\hline & HHZ & 2.89 & 13 & 0.493 & 2.61 & $\overline{4.4}$ & 7.69 & 22 & 23.3 \\
\hline \multirow[t]{3}{*}{ A61 } & HHE & 7.68 & 56.3 & 0.426 & 2.14 & 9.86 & 41.2 & 112 & 33 \\
\hline & $\mathrm{HHN}$ & 9.06 & 69.9 & 1.65 & 4.26 & 11.5 & 53.3 & 79 & 33 \\
\hline & HHZ & 8.16 & 31.6 & 0.871 & 3.54 & 18.7 & 36.2 & 46.8 & 33 \\
\hline \multirow[t]{3}{*}{ A16 } & HHE & 3.36 & 20.8 & 0.329 & 0.909 & 4.49 & 24.9 & 33.9 & 41.4 \\
\hline & HHN & 6.06 & 32.9 & 0.176 & 0.948 & 5.28 & 33.1 & 82 & 41.4 \\
\hline & HHZ & 2.8 & 13.4 & 0.165 & 1.08 & 3.42 & 29.2 & 35.5 & $\overline{41.4}$ \\
\hline \multirow[t]{3}{*}{ LMQ } & BHE & 3.11 & 17.7 & 0.127 & 0.747 & 3.89 & 18.7 & 23.4 & 53.2 \\
\hline & BHN & 3.81 & 27.5 & 0.236 & 1 & 3.09 & 26.2 & 37.3 & 53.2 \\
\hline & $\mathrm{BHZ}$ & 2.39 & 11.9 & 0.193 & 1.12 & 4.93 & 26.5 & 22.9 & 53.2 \\
\hline \multirow[t]{3}{*}{ A54 } & HHE & 2.44 & 10.8 & 0.113 & 0.594 & 2.7 & 19 & 33.9 & 63.2 \\
\hline & HHN & 3.52 & 16 & 0.266 & 0.985 & 5.25 & 37.8 & 22.8 & 63.2 \\
\hline & HHZ & 5.26 & 19.7 & 0.203 & 1.16 & 7.22 & 17.4 & 49.4 & 63.2 \\
\hline \multirow[t]{3}{*}{ A11 } & HHE & 1.67 & 8.65 & 0.0848 & 0.496 & 1.56 & 10.5 & 28.3 & 68.8 \\
\hline & HHN & 1.65 & 8.39 & 0.0888 & 0.367 & 2.98 & 11.2 & 20.8 & 68.8 \\
\hline & HHZ & 1.46 & 6.15 & 0.117 & 0.507 & 3.03 & 8.64 & 17.9 & 68.8 \\
\hline DAQ & $\mathrm{EHZ}$ & 0.427 & 2.08 & 0.0873 & 0.453 & 0.997 & 2.74 & 4.08 & 116.7 \\
\hline CNQ & EHZ & 0.155 & 0.664 & 0.0286 & 0.111 & 0.245 & 1.22 & 1.97 & 211.9 \\
\hline GSQ & EHZ & 0.222 & 0.549 & 0.0587 & 0.11 & 0.321 & 1.29 & 1.37 & 233.4 \\
\hline$\overline{\mathrm{DPQ}}$ & EHZ & 0.314 & 0.876 & 0.0613 & 0.23 & 1.06 & 2.65 & 2.44 & 259.5 \\
\hline \multirow[t]{3}{*}{ ICQ } & BHE & 0.129 & 0.696 & 0.023 & 0.0645 & 0.258 & 1.01 & 1.67 & 267.7 \\
\hline & BHN & 0.155 & 0.355 & 0.0272 & 0.0751 & 0.201 & 0.638 & 1.06 & 267.7 \\
\hline & BHZ & 0.134 & 0.518 & 0.0191 & 0.0845 & 0.315 & 0.882 & 1.53 & 267.7 \\
\hline MNQ & EHZ & 0.0477 & 0.209 & 0.00914 & 0.0406 & 0.123 & 0.518 & 0.49 & 317.5 \\
\hline MOQ & EHZ & 0.202 & 0.702 & 0.0427 & 0.128 & 0.464 & 1.62 & 1.42 & 333.1 \\
\hline SMQ & EHZ & 0.0663 & 0.269 & 0.0102 & 0.0558 & 0.114 & 0.454 & 0.812 & 352.8 \\
\hline MNT & BHE & 0.149 & 0.37 & 0.0218 & 0.106 & 0.28 & 1.4 & 0.88 & 388.5 \\
\hline
\end{tabular}




\begin{tabular}{|c|c|c|c|c|c|c|c|c|c|}
\hline Station & Comp & $\begin{array}{c}\text { PGV } \\
(\mathrm{mm} / \mathrm{s})\end{array}$ & $\begin{array}{l}\text { PGA } \\
\text { (cgs) }\end{array}$ & $\begin{array}{c}\text { PSA } \\
0.5 \mathrm{~Hz}\end{array}$ & $\begin{array}{l}\text { PSA } \\
1 \mathrm{~Hz} \\
\end{array}$ & $\begin{array}{l}\text { PSA } \\
2 \mathrm{~Hz} \\
\end{array}$ & $\begin{array}{l}\text { PSA } \\
\text { 5Hz } \\
\end{array}$ & $\begin{array}{l}\text { PSA } \\
10 \mathrm{~Hz} \\
\end{array}$ & $\begin{array}{c}\text { Hypocentral } \\
\text { Distance (km) }\end{array}$ \\
\hline \multirow[t]{2}{*}{ MNT } & BHN & 0.153 & 0.63 & 0.0203 & 0.0834 & 0.435 & 1.45 & 1.36 & 388.5 \\
\hline & BHZ & 0.147 & 0.396 & 0.0233 & 0.0992 & 0.474 & 1.12 & 1.05 & 388.5 \\
\hline TRQ & EHZ & 0.211 & 0.41 & 0.0204 & 0.0837 & 0.646 & 1.16 & 0.722 & 403.6 \\
\hline \multirow[t]{3}{*}{ LMN } & BHE & 0.0707 & $0 . \overline{214}$ & 0.032 & 0.0979 & 0.198 & 0.314 & 0.748 & 430.1 \\
\hline & BHN & 0.104 & 0.212 & 0.0273 & 0.138 & 0.324 & 0.276 & 0.57 & 430.1 \\
\hline & $\overline{\mathrm{BHZ}}$ & 0.0664 & 0.146 & 0.0293 & 0.0988 & 0.146 & 0.214 & 0.292 & 430.1 \\
\hline \multirow[t]{3}{*}{ ALFO } & HHE & 0.118 & 0.298 & 0.0299 & 0.0879 & 0.411 & 1.11 & 0.523 & 458.2 \\
\hline & HHN & 0.158 & 0.286 & 0.04 & 0.158 & 0.471 & 0.899 & 0.608 & 458.2 \\
\hline & $\mathrm{HHZ}$ & 0.143 & 0.184 & 0.0348 & 0.111 & 0.37 & 0.512 & 0.452 & 458.2 \\
\hline GRQ & EHZ & 0.164 & 0.335 & 0.0309 & 0.152 & 0.397 & 0.744 & 0.507 & 480.3 \\
\hline \multirow[t]{3}{*}{ GAC } & BHE & 0.829 & 1.41 & 0.0648 & 0.243 & 1.9 & 3.61 & 1.73 & 493.6 \\
\hline & BHN & 0.498 & 0.825 & 0.0465 & 0.186 & 1.09 & 1.55 & 1.85 & 493.6 \\
\hline & BHZ & 0.556 & 0.795 & 0.0478 & 0.202 & 0.76 & 1.7 & 1.12 & 493.6 \\
\hline GAC & EHZ & 0.17 & 0.362 & 0.0335 & 0.107 & 0.437 & 0.931 & 0.591 & 493.6 \\
\hline WBO & EHZ & 0.0681 & 0.159 & 0.0224 & 0.0796 & 0.201 & 0.528 & 0.364 & 523.7 \\
\hline OTT & EHZ & 0.102 & 0.206 & 0.0158 & 0.0736 & 0.554 & 0.812 & 0.346 & 527.1 \\
\hline \multirow[t]{3}{*}{ VLDQ } & BHE & 0.0416 & 0.0651 & 0.0149 & 0.0685 & 0.185 & 0.135 & 0.0891 & 576.5 \\
\hline & BHN & 0.134 & 0.137 & 0.0354 & 0.176 & 0.491 & 0.253 & 0.164 & 576.5 \\
\hline & $\mathrm{BHZ}$ & 0.067 & 0.0889 & 0.0288 & 0.105 & 0.175 & 0.141 & 0.0973 & 576.5 \\
\hline CRLO & EHZ & 0.0988 & 0.143 & 0.0176 & 0.0911 & 0.29 & 0.535 & 0.247 & 611.3 \\
\hline \multirow[t]{3}{*}{ KGNO } & BHE & 0.0421 & 0.0882 & 0.0264 & 0.0537 & 0.154 & 0.298 & 0.18 & 652.5 \\
\hline & BHN & 0.0502 & 0.131 & 0.0308 & 0.0439 & 0.164 & 0.371 & 0.198 & 652.5 \\
\hline & $\mathrm{BHZ}$ & 0.0425 & 0.0809 & 0.00654 & 0.0265 & 0.114 & 0.181 & 0.114 & 652.5 \\
\hline \multirow[t]{3}{*}{ MPPO } & HHE & 0.0581 & 0.111 & 0.0186 & 0.0494 & 0.217 & 0.331 & 0.222 & 601.3 \\
\hline & HHN & 0.0794 & 0.147 & 0.0164 & 0.0829 & 0.203 & 0.468 & 0.304 & 601.3 \\
\hline & $\mathrm{HHZ}$ & 0.0605 & 0.123 & 0.0163 & 0.0555 & 0.172 & 0.358 & 0.299 & 601.3 \\
\hline \multirow[t]{3}{*}{ PEMO $^{*}$} & HHE & 0.318 & 0.461 & 0.0726 & 0.218 & 1.05 & 1.09 & 0.742 & 929.5 \\
\hline & HHN & 0.378 & 0.555 & 0.115 & 0.252 & 1.3 & 1.4 & 0.823 & 929.5 \\
\hline & $\mathrm{HHZ}$ & 0.247 & 0.384 & 0.0691 & 0.325 & 0.931 & 1.2 & 0.548 & 929.5 \\
\hline \multirow[t]{3}{*}{ PLVO } & HHE & 0.062 & 0.134 & 0.0246 & 0.0539 & 0.223 & 0.318 & 0.237 & 638.6 \\
\hline & HHN & 0.0745 & 0.124 & 0.023 & 0.137 & 0.239 & 0.436 & 0.218 & 638.6 \\
\hline & $\mathrm{HHZ}$ & 0.0841 & 0.137 & 0.0388 & 0.0706 & 0.276 & 0.333 & 0.208 & 638.6 \\
\hline EEO & $\mathrm{EHZ}$ & 0.0765 & 0.109 & 0.0322 & 0.14 & 0.268 & 0.311 & 0.148 & 715.9 \\
\hline
\end{tabular}

* Site located on soil; all others on hard rock 


\begin{tabular}{|c|c|c|c|c|c|c|c|c|c|}
\hline Station & Comp & $\begin{array}{c}\text { PGV } \\
(\mathrm{mm} / \mathrm{s})\end{array}$ & $\begin{array}{l}\text { PGA } \\
\text { (cgs) }\end{array}$ & $\begin{array}{c}\text { PSA } \\
0.5 H z \\
\end{array}$ & $\begin{array}{l}\text { PSA } \\
\text { 1Hz } \\
\end{array}$ & $\begin{array}{l}\text { PSA } \\
2 \mathbf{H z} \\
\end{array}$ & $\begin{array}{l}\text { PSA } \\
\text { 5Hz } \\
\end{array}$ & $\begin{array}{l}\text { PSA } \\
10 \mathrm{~Hz} \\
\end{array}$ & \begin{tabular}{|c|} 
Hypocentral \\
Distance (km)
\end{tabular} \\
\hline \multirow[t]{3}{*}{ ALGO* } & HHE & 0.46 & 1.01 & 0.0369 & 0.185 & 1.02 & 2.77 & 1.77 & 663 \\
\hline & HHN & 0.495 & 1.07 & 0.0548 & 0.184 & 1.14 & 3.14 & 1.45 & 663 \\
\hline & $\mathrm{HHZ}$ & 0.119 & 0.354 & 0.0168 & 0.0735 & 0.321 & 0.708 & 0.717 & 663 \\
\hline \multirow[t]{3}{*}{ BANO* } & HHE & 0.0637 & 0.126 & 0.0184 & 0.0418 & 0.179 & 0.34 & 0.325 & 698 \\
\hline & HHN & 0.0814 & 0.187 & 0.0334 & 0.069 & 0.331 & 0.346 & 0.276 & 698 \\
\hline & HHZ & 0.0468 & 0.0903 & 0.00915 & 0.0535 & 0.144 & 0.269 & 0.155 & 698 \\
\hline \multirow[t]{3}{*}{ PECO } & ḦHE & 0.0489 & 0.0835 & 0.0163 & 0.0556 & 0.136 & 0.333 & 0.165 & 703.8 \\
\hline & HHN & 0.0621 & 0.114 & 0.0192 & 0.0734 & 0.143 & 0.38 & 0.219 & 703.8 \\
\hline & $\overline{\mathrm{HHZ}}$ & 0.0447 & 0.0864 & 0.0146 & 0.0411 & 0.193 & 0.283 & 0.138 & 703.8 \\
\hline \multirow[t]{3}{*}{ DELO } & HHE & 0.0495 & 0.0863 & 0.0135 & 0.0413 & 0.212 & 0.256 & 0.13 & 705.5 \\
\hline & HHN & 0.0715 & 0.109 & 0.0223 & 0.0737 & 0.208 & 0.28 & 0.154 & 705.5 \\
\hline & HHZ & 0.0579 & 0.0891 & 0.0108 & 0.0616 & 0.14 & 0.221 & 0.143 & 705.5 \\
\hline \multirow[t]{3}{*}{ SADO } & BHE & 0.038 & 0.0651 & 0.00833 & 0.0415 & 0.121 & 0.178 & 0.0919 & 794.9 \\
\hline & BHN & 0.0881 & 0.107 & 0.0291 & 0.0984 & 0.273 & 0.245 & 0.14 & 794.9 \\
\hline & BHZ & 0.059 & 0.105 & 0.0124 & 0.0691 & 0.222 & 0.226 & 0.122 & 794.9 \\
\hline \multirow[t]{3}{*}{ KILO } & HHE & 0.0772 & 0.0854 & 0.0307 & 0.154 & 0.276 & 0.22 & 0.144 & 745.4 \\
\hline & HHN & 0.215 & 0.169 & 0.0919 & $\overline{0.27}$ & 0.534 & 0.403 & 0.199 & 745.4 \\
\hline & HHZ & 0.0877 & 0.132 & 0.0367 & 0.133 & 0.252 & 0.208 & 0.182 & 745.4 \\
\hline \multirow[t]{3}{*}{ MALO } & HHE & 0.0564 & 0.0593 & 0.0275 & 0.095 & 0.182 & 0.0961 & 0.12 & 774.7 \\
\hline & HHN & 0.193 & 0.148 & 0.109 & 0.302 & 0.382 & 0.172 & 0.159 & 774.7 \\
\hline & HHZ & 0.0723 & 0.0729 & 0.0453 & 0.0879 & 0.215 & 0.12 & 0.108 & 774.7 \\
\hline \multirow[t]{3}{*}{ BUKO } & HHE & 0.0514 & 0.0679 & 0.0172 & 0.0629 & 0.138 & 0.158 & 0.12 & 781.2 \\
\hline & $\mathrm{HHN}$ & 0.0881 & 0.13 & 0.033 & 0.149 & 0.282 & 0.231 & 0.175 & 781.2 \\
\hline & HHZ & 0.0697 & 0.093 & 0.0332 & 0.0709 & 0.221 & 0.187 & 0.121 & 781.2 \\
\hline \multirow[t]{3}{*}{ LINO* } & HHE & 0.0622 & 0.101 & 0.0208 & 0.054 & 0.229 & 0.347 & 0.138 & 792.9 \\
\hline & HHN & 0.0929 & 0.134 & 0.0389 & 0.0932 & 0.255 & 0.321 & 0.172 & 792.9 \\
\hline & HHZ & 0.076 & 0.115 & 0.0174 & 0.101 & 0.227 & 0.287 & 0.147 & 792.9 \\
\hline \multirow[t]{3}{*}{ PKRO* } & HHE & 0.467 & 0.519 & 0.0575 & 0.252 & 1.64 & 1.22 & 0.634 & 835.8 \\
\hline & HHN & 0.345 & 0.494 & 0.0438 & 0.213 & 1.63 & 1.18 & 0.639 & 835.8 \\
\hline & HHZ & 0.141 & 0.262 & 0.0265 & 0.0644 & 0.503 & 0.702 & 0.337 & 835.8 \\
\hline \multirow[t]{3}{*}{$\bar{K} \perp \overline{B O}$} & HHE & 0.107 & 0.151 & 0.0332 & 0.153 & 0.321 & 0.38 & 0.243 & 843.3 \\
\hline & HHN & 0.22 & 0.236 & 0.0703 & 0.302 & 0.54 & 0.564 & 0.28 & 843.3 \\
\hline & HHZ & 0.121 & 0.178 & 0.0309 & 0.188 & 0.568 & 0.384 & 0.24 & 843.3 \\
\hline
\end{tabular}

* Site located on soil; all others on hard rock 


\begin{tabular}{|c|c|c|c|c|c|c|c|c|c|}
\hline Station & Comp & $\begin{array}{c}\text { PGV } \\
(\mathrm{mm} / \mathrm{s})\end{array}$ & $\begin{array}{l}\text { PGA } \\
\text { (cgs) }\end{array}$ & $\begin{array}{c}\text { PSA } \\
0.5 H z\end{array}$ & $\begin{array}{l}\text { PSA } \\
\text { 1Hz } \\
\end{array}$ & $\begin{array}{l}\text { PSA } \\
2 \mathrm{~Hz} \\
\end{array}$ & $\begin{array}{l}\text { PSA } \\
\text { 5Hz } \\
\end{array}$ & $\begin{array}{c}\text { PSA } \\
10 \mathrm{~Hz} \\
\end{array}$ & $\begin{array}{l}\text { Hypocentral } \\
\text { Distance (km) }\end{array}$ \\
\hline \multirow[t]{3}{*}{ MEDO* } & HHE & 0.0694 & 0.0794 & 0.018 & 0.058 & 0.197 & 0.255 & 0.0978 & 849.4 \\
\hline & HHN & 0.0446 & 0.0743 & 0.023 & 0.0543 & 0.21 & 0.195 & 0.126 & 849.4 \\
\hline & $\mathrm{HHZ}$ & 0.0388 & 0.0519 & 0.0132 & 0.0543 & 0.15 & 0.11 & 0.0717 & 849.4 \\
\hline \multirow[t]{3}{*}{ TORO* } & HHE & 0.825 & 0.669 & 0.125 & 2.24 & 1.03 & 1.51 & 0.801 & 875.5 \\
\hline & HHN & 0.504 & 0.531 & 0.0589 & 1.11 & 0.638 & 1.09 & 0.618 & 875.5 \\
\hline & HHZ & 0.188 & 0.242 & 0.0219 & 0.202 & 1.06 & 0.507 & 0.315 & 875.5 \\
\hline \multirow[t]{3}{*}{ SUNO } & HHE & 0.103 & 0.125 & 0.025 & 0.206 & 0.366 & 0.231 & 0.159 & 884.5 \\
\hline & HHN & 0.225 & 0.241 & 0.0847 & 0.468 & 0.629 & 0.461 & 0.269 & 884.5 \\
\hline & HHZ & 0.132 & 0.168 & 0.0397 & 0.194 & 0.412 & 0.363 & 0.225 & 884.5 \\
\hline \multirow[t]{3}{*}{ STCO $^{*}$} & HHE & 0.0913 & 0.166 & 0.0137 & 0.0972 & 0.253 & 0.773 & 0.248 & 891.2 \\
\hline & HHN & 0.11 & 0.22 & 0.0114 & 0.0488 & 0.259 & 0.779 & 0.306 & 891.2 \\
\hline & HHZ & 0.0557 & 0.068 & 0.0114 & 0.0539 & 0.24 & 0.239 & 0.0914 & 891.2 \\
\hline \multirow[t]{3}{*}{ CLWO* } & HHE & $0 . \overline{41}$ & 0.561 & 0.0602 & 0.498 & 1.38 & 1.13 & 0.627 & 892.5 \\
\hline & HHN & 0.755 & 1.09 & 0.13 & 0.768 & 2.32 & 2.06 & 1.22 & 892.5 \\
\hline & HHZ & 0.162 & 0.241 & 0.0559 & 0.224 & 0.803 & 0.632 & 0.295 & 892.5 \\
\hline \multirow[t]{3}{*}{ OTRO } & HHE & 0.205 & 0.43 & 0.0283 & 0.126 & 0.45 & 0.786 & 0.785 & 908.3 \\
\hline & $\mathrm{HHN}$ & 0.2 & 0.414 & 0.0576 & 0.231 & $0 . \overline{672}$ & 1.06 & 0.879 & 908.3 \\
\hline & HHZ & 0.105 & 0.169 & 0.0322 & 0.0991 & 0.233 & 0.403 & 0.506 & 908.3 \\
\hline \multirow[t]{3}{*}{ PTCO } & HHE & 0.0297 & 0.0458 & 0.011 & 0.0348 & 0.115 & 0.127 & 0.0575 & 922.7 \\
\hline & HHN & 0.0378 & 0.0533 & 0.0114 & 0.0547 & 0.12 & 0.131 & 0.065 & 922.7 \\
\hline & HHZ & 0.0313 & 0.0313 & 0.00822 & 0.0359 & 0.0878 & 0.0853 & 0.0447 & 922.7 \\
\hline \multirow[t]{3}{*}{ ACTO* } & HHE & 0.0812 & 0.121 & 0.0159 & 0.0841 & 0.275 & 0.359 & 0.156 & 923.9 \\
\hline & HHN & 0.132 & 0.117 & 0.0163 & 0.13 & 0.404 & 0.322 & 0.168 & 923.9 \\
\hline & HHZ & 0.0609 & 0.087 & 0.0157 & 0.0683 & 0.219 & 0.17 & 0.107 & 923.9 \\
\hline \multirow[t]{3}{*}{ KAPO } & BHE & 0.0273 & 0.0269 & 0.016 & 0.0637 & 0.0906 & 0.0567 & 0.0355 & 956.8 \\
\hline & BHN & 0.0627 & 0.0637 & 0.0335 & 0.121 & 0.193 & 0.0963 & 0.065 & 956.8 \\
\hline & BHZ & 0.0313 & 0.0259 & 0.0195 & 0.0507 & 0.0864 & 0.0577 & 0.0317 & 956.8 \\
\hline \multirow[t]{3}{*}{ TOBO* } & HHE & 0.137 & 0.141 & 0.032 & 0.197 & 0.463 & 0.353 & 0.152 & 943.7 \\
\hline & HHN & 0.139 & 0.18 & 0.035 & 0.328 & 0.598 & 0.328 & 0.17 & 943.7 \\
\hline & HHZ & 0.108 & 0.13 & 0.0345 & 0.188 & 0.481 & 0.185 & 0.15 & 943.7 \\
\hline \multirow[t]{3}{*}{ TYNO* } & HHE & 0.102 & 0.197 & 0.0156 & 0.0739 & 0.283 & 0.797 & 0.294 & 944.1 \\
\hline & HHN & 0.161 & 0.325 & 0.021 & 0.0779 & 0.332 & 0.945 & 0.353 & 944.1 \\
\hline & $\mathrm{HHZ}$ & 0.0382 & 0.0641 & 0.00893 & 0.0661 & 0.108 & 0.157 & 0.114 & 944.1 \\
\hline
\end{tabular}

* Site located on soil; all others on hard rock 


\begin{tabular}{|l|l|c|c|c|c|c|c|c|c|}
\hline Station & Comp & $\begin{array}{c}\text { PGV } \\
(\mathbf{m m} / \mathbf{s})\end{array}$ & $\begin{array}{c}\text { PGA } \\
(\mathbf{c g s})\end{array}$ & $\begin{array}{c}\text { PSA } \\
\mathbf{0 . 5 H z}\end{array}$ & $\begin{array}{c}\text { PSA } \\
\text { 1Hz }\end{array}$ & $\begin{array}{c}\text { PSA } \\
\mathbf{2 H z}\end{array}$ & $\begin{array}{c}\text { PSA } \\
\mathbf{5 H z}\end{array}$ & $\begin{array}{c}\text { PSA } \\
\mathbf{1 0 H z}\end{array}$ & $\begin{array}{c}\text { Hypocentral } \\
\text { Distance (km) }\end{array}$ \\
\hline ELGO & HHE & 0.0563 & 0.0726 & 0.0124 & 0.0819 & 0.254 & 0.123 & 0.0854 & 945.2 \\
\hline & HHN & 0.0634 & 0.0913 & 0.0185 & 0.0885 & 0.206 & 0.176 & 0.101 & 945.2 \\
\hline & HHZ & 0.0549 & 0.0492 & 0.0111 & 0.12 & 0.15 & 0.106 & 0.0668 & 945.2 \\
\hline HGVO & HHE & 0.0421 & 0.0537 & 0.0164 & 0.0611 & 0.14 & 0.121 & 0.0595 & 969.6 \\
\hline & HHN & 0.0367 & 0.0531 & 0.0118 & 0.0519 & 0.153 & 0.106 & 0.0658 & 969.6 \\
\hline & HHZ & 0.0379 & 0.0408 & 0.0108 & 0.0663 & 0.098 & 0.0896 & 0.0638 & 969.6 \\
\hline TBO & EHZ & 0.00618 & 0.0169 & 0.00658 & 0.0196 & 0.0223 & 0.0115 & 0.00901 & 1457 \\
\hline BRCO & EHZ & 0.00568 & 0.00718 & 0.0054 & 0.0178 & 0.026 & 0.00931 & 0.00722 & 1646.4 \\
\hline & HHE & 0.281 & 0.339 & 0.0298 & 0.137 & 1.63 & 0.8 & 0.402 & 983.4 \\
\hline & HHN & 0.223 & 0.307 & 0.0409 & 0.175 & 1.14 & 0.755 & 0.364 & 983.4 \\
\hline PLIO* & HHZ & 0.0535 & 0.111 & 0.0149 & 0.0777 & 0.327 & 0.372 & 0.152 & 983.4 \\
\hline & HHE & 0.0229 & 0.0324 & 0.0102 & 0.0304 & 0.0913 & 0.047 & 0.0365 & 1214.6 \\
\hline & HHZ & 0.0262 & 0.0259 & 0.00939 & 0.036 & 0.0655 & 0.0572 & 0.0303 & 1214.6 \\
\hline SILO & HHE & 0.0126 & 0.00722 & 0.00667 & 0.0177 & 0.023 & 0.0138 & 0.01 & 1236.4 \\
\hline & HHN & 0.0361 & 0.0217 & 0.0297 & 0.0656 & 0.0636 & 0.0254 & 0.0233 & 1236.4 \\
\hline & HHZ & 0.0226 & 0.0124 & 0.0146 & 0.033 & 0.0291 & 0.0187 & 0.0143 & 1236.4 \\
\hline MUMO & HHE & 0.00854 & 0.00676 & 0.00322 & 0.012 & 0.0135 & 0.00612 & 0.0104 & 1559.7 \\
\hline & HHN & 0.0232 & 0.0155 & 0.0103 & 0.0337 & 0.031 & 0.0162 & 0.0164 & 1559.7 \\
\hline & HHZ & 0.0111 & 0.00903 & 0.00713 & 0.013 & 0.0162 & 0.00601 & 0.0145 & 1559.7 \\
\hline
\end{tabular}

* Site located on soil; all others on hard rock 


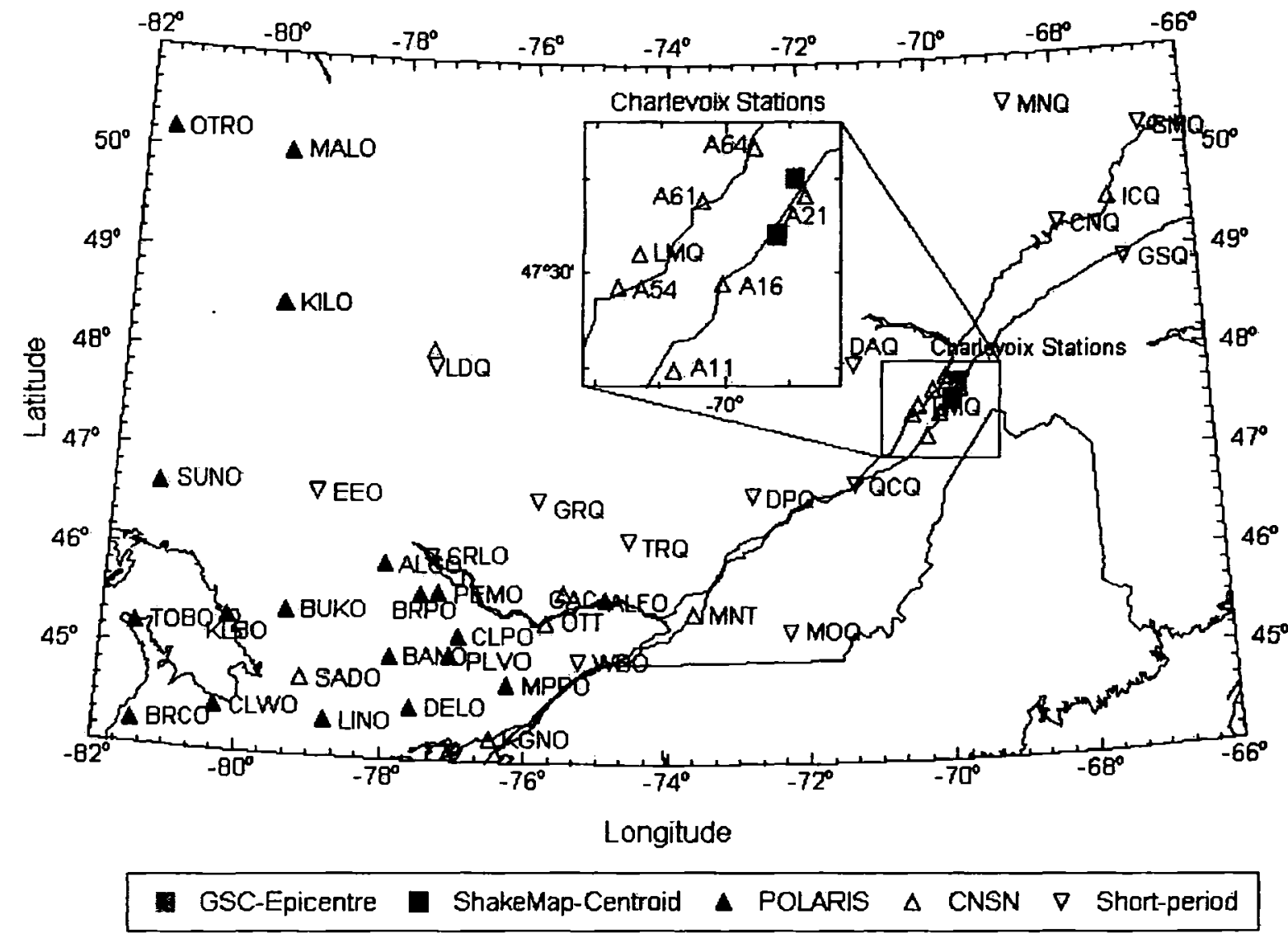

Figure 8.1. Location of Riviere-du-Loup epicenter (gray square) and ShakeMap centroid (filled square). Triangles show station locations. Inset is zoomed Charlevoix region. 

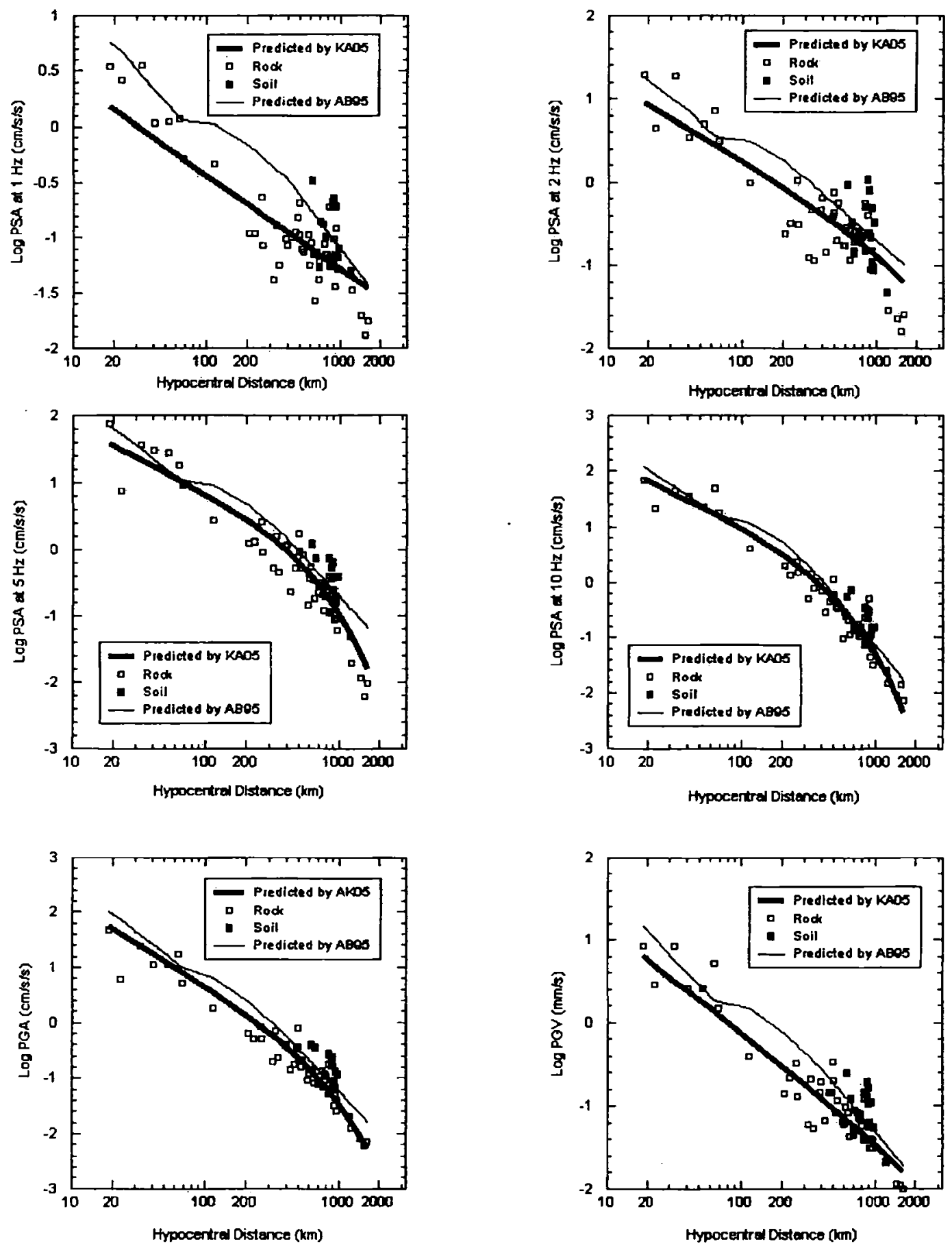

Figure 8.2. Ground-motion amplitudes for the M5.0 Riviere-du-Loup earthquake compared to the predictions (for rock) of Equation 4.1 (thick line) and Atkinson and Boore, 1995 (thin line). 
Polaris Rapid Instrumental Intensity Map for event: 20050306.061700 Sun Mar 6, 2005 01:18:46 AM EST M 5.0 N47.60 W69.60 I0:20050306.061700

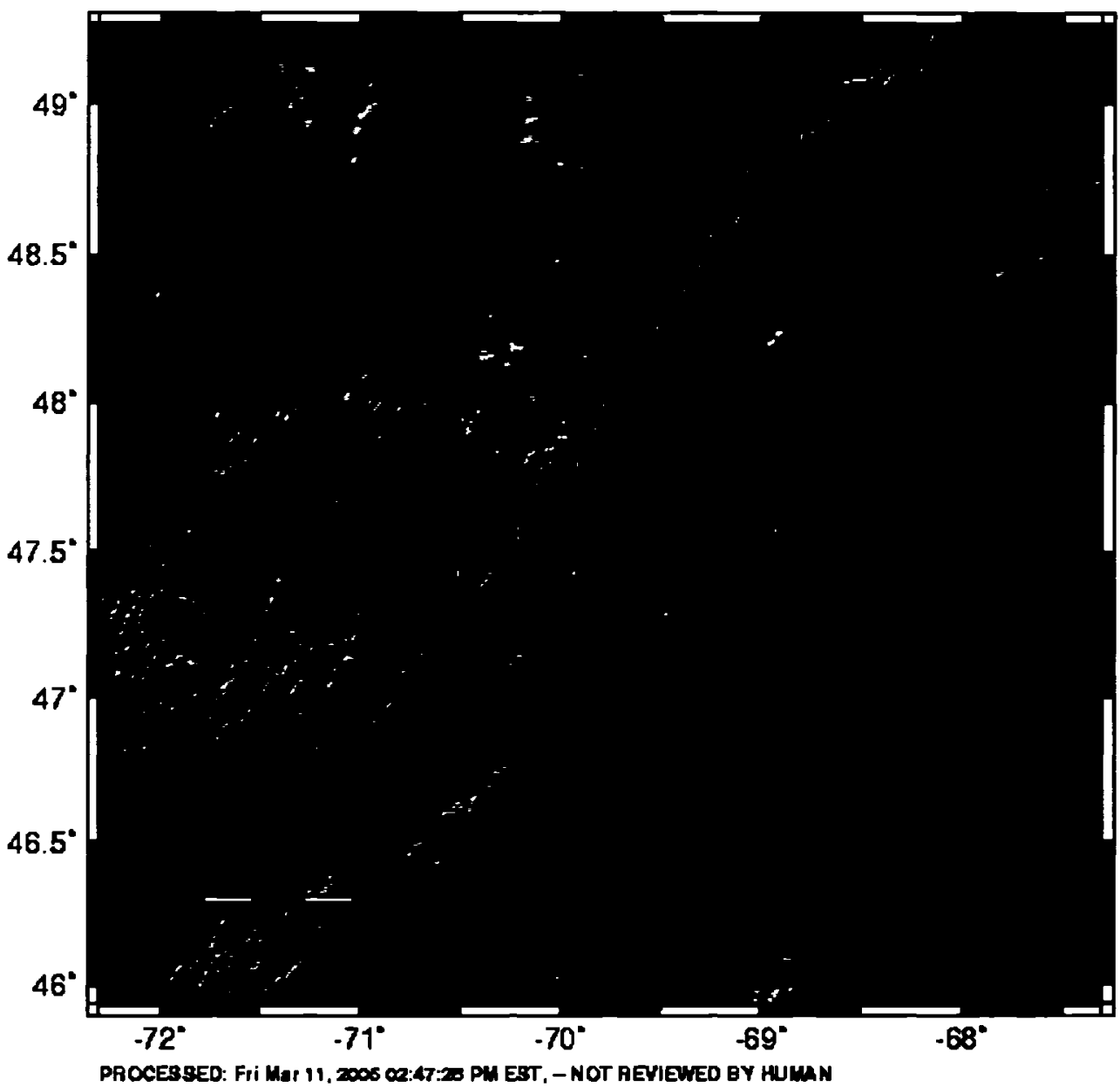

\begin{tabular}{|c|c|c|c|c|c|c|c|c|c|}
\hline 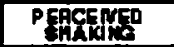 & Noilall: & Wark & Loht & Modenth & Stron & Very strong & Somen & Violent & Exinem \\
\hline PQTFWTAL & none & nons & none & Vory light & Ligh & Modoresto & Modan w/theny & Heavy & Vory then \\
\hline $\operatorname{sen} \operatorname{ecc}_{\{\mathrm{cms}}=2$ & $<.17$ & $.17-1.4$ & 1.439 & 3.00 .2 & $0.2-18$ & $18-34$ & $34-66$ & $\infty .124$ & $>124$ \\
\hline PEAK VELfmnty & $<0.1$ & $0.1 \cdot 1.1$ & 1.13 .4 & 3.48 .1 & 8.1 .10 & $10-31$ & $31-60$ & $60-110$ & $\$ 116$ \\
\hline W-THUWFTAL & I & & & & & 18 & & & \\
\hline
\end{tabular}

Figure 8.3 Felt-intensity ShakeMap for M5.0 Riviere-du-Loup earthquake. 


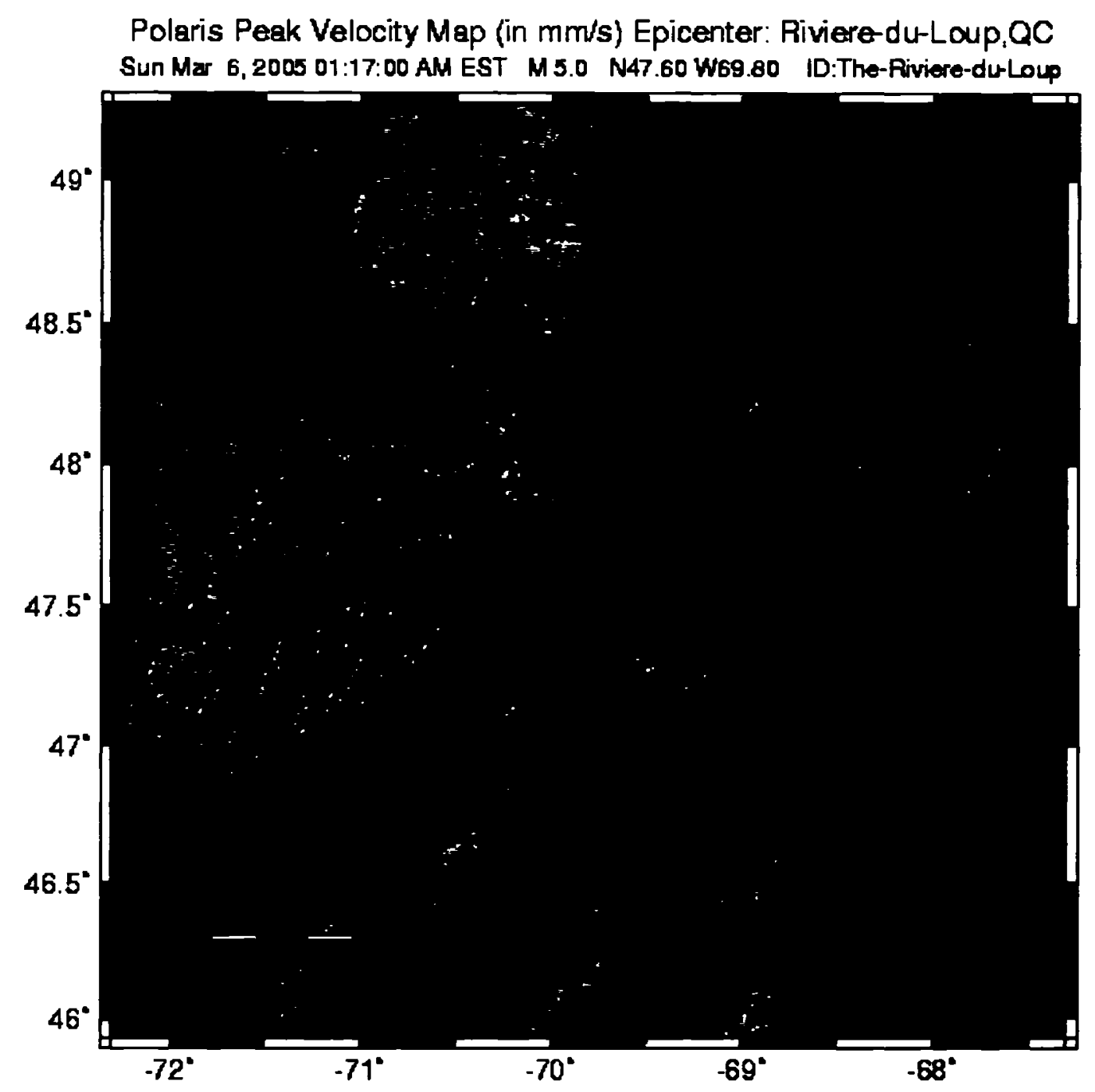

Figure 8.4 PGV ShakeMap for M5.0 Riviere-du-Loup earthquake. 


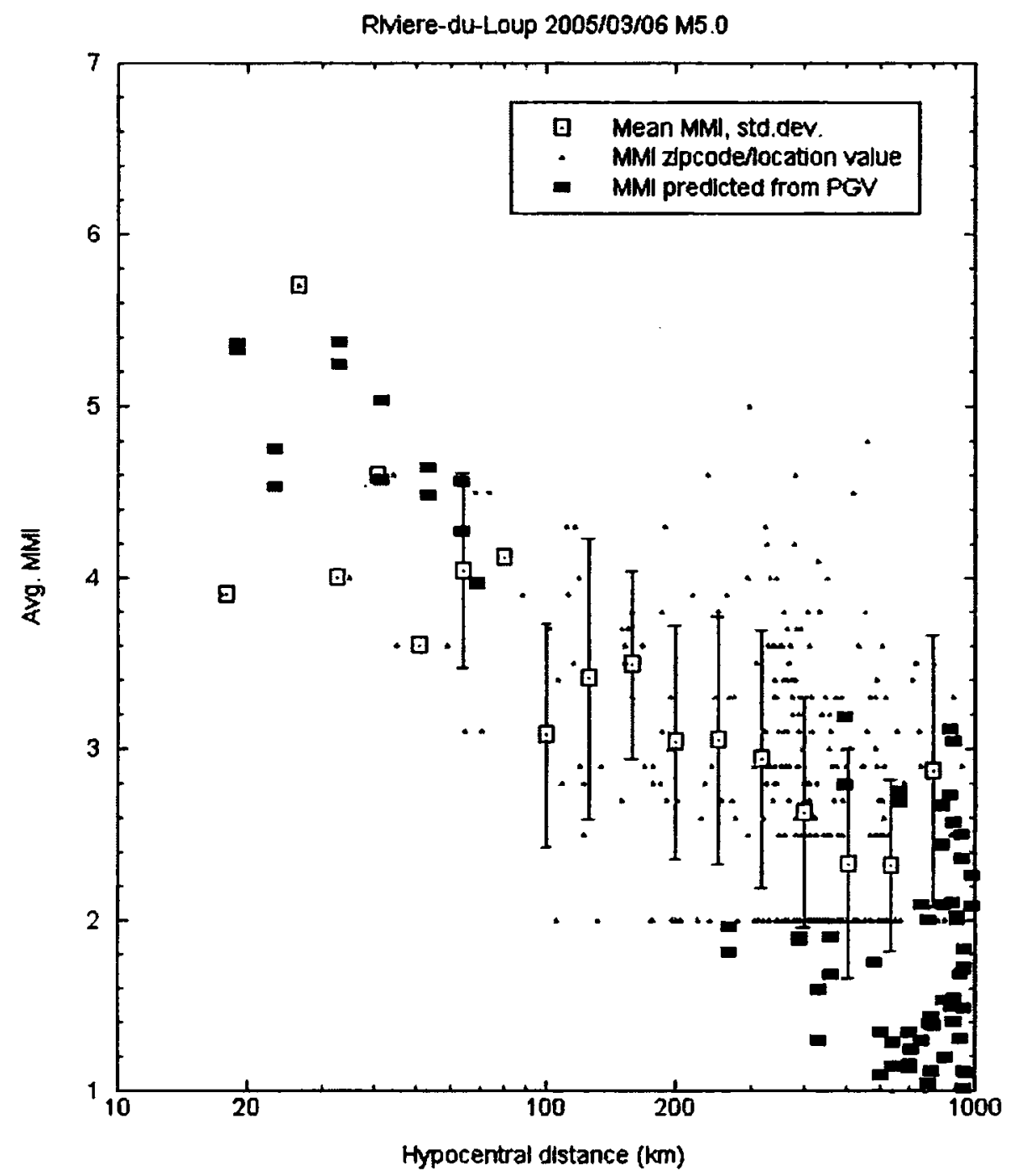

Figure 8.5. Mean MMI and standard deviation for observations grouped in distance bins $0.1 \mathrm{log}$ units in width (open squares), based on the mean MMI for each zip code or city location (grey dots), weighted by the number of observations for that location. Filled symbols show MMI predicted from horizontalcomponent PGV values based on Equation 8.1. 


\section{Chapter 9 \\ Scenario ShakeMaps}

\subsection{Introduction}

The purpose of this chapter is to explore the earthquake ground shaking effects that might be experienced in eastern Canada for various possible regional earthquakes. For example, a M5 event occurs in the western Lake Ontario basin about once per century based on historical seismicity; such events are more frequent in eastern Ontario. If today a M5 earthquake were to occur in Toronto or Ottawa, what would its effects be? Similarly, some of the larger historic and instrumentally monitored events include events such as the 1925 M6.4 earthquake of Charlevoix-Kamouraska region, Quebec, the 1929 M7.2 earthquake south of Newfoundland, the 1935 M6.2 earthquake of the Temiskaming region and the 1944 M5.8 of Cornwall-Massena. Similar events will undoubtedly happen in the future. Generating scenario earthquake can be extremely useful for planning and educating the public for earthquake preparedness. Scenario earthquakes are not earthquake predictions; no one knows when a future event will occur or how big it will be. However, if the size and location of a hypothetical earthquake is assumed, a ground shaking prediction can be made, using ShakeMap. Such predictions are referred to as "Scenario ShakeMaps". Scenario ShakeMaps describe the expected peak ground velocity and felt intensity for a specific hypothetical earthquake. They are developed using the methodology of this study, for specified earthquake scenarios. While no scenario will prove accurate in detail, scenario ShakeMaps provide a regional pattern of expected damage and give a more complete understanding of earthquake hazards; this is a first step towards developing response plans to cope with them. 
In this chapter I explore a range of scenario events with ShakeMap. These maps give an indication of the range of potential effects, which will vary by site according to actual conditions.

\subsection{Magnitude $M=5$ Scenario}

Case 1, Figure 9.1a: A magnitude $\mathbf{M}=5.0$ at $45.41 \mathrm{~N} 75.76 \mathrm{~W}$, near Ottawa, Ontario. The event is placed near a site with NEHRP E soil, to illustrate likely soil effects on soft sites (Table 7.10, Figure 7.8). Generally, $\mathbf{M}=5$ events are considered to be of relatively small hazard, particularly if centered some distance from populated regions. They are below the threshold at which substantial damage would occur. Modern buildings and bridges in Ontario are designed to withstand such an event. The maximum expected intensity is only $\mathrm{MMI}=\mathrm{V}-\mathrm{VI}$ (predicted $\mathrm{MMI}=5.8$ at epicentre and $\mathrm{MMI}=5$ at $30 \mathrm{~km}$ ), meaning the event would be felt outdoors; sleepers wakened, liquids disturbed, some spilled, small unstable objects displaced or upset, doors swing, close, open, shutters, pictures move, etc. There may be some cracked plaster, some heavy furniture may move; there could be a few instances of fallen plaster, but only slight damage. Such an event would be at or just below the threshold of minor damage (similar to the experience during the 2005 M5 Riviere-du-Loup event). The earthquake would be felt up to $750 \mathrm{~km}$ distance. (MMI unit of 2 would be reported as far as $750 \mathrm{~km}$ ).

Case 2, Figure 9.1b: A magnitude $\mathbf{M}=5.0$ at $43.75 \mathrm{~N} 79.84 \mathrm{~W}$, near Toronto, Ontario. The event is placed near a site with NEHRP D site (firm soil). Such an earthquake would be widely felt, and have locally a maximum felt intensity on the Modified Mercalli Intensity scale of MMI $=\mathrm{V}$ to VI. The effects would be similar to 
those given above for the Ottawa M5 scenario. However, if the event were to occur directly under the city, a maximum intensity of up to VII would be expected due to site response on poor sites. This suggests negligible damage in buildings of good design and construction; slight to moderate damage to well-built ordinary structures, and considerable damage in poorly built or badly designed structures; some chimneys may be broken.

\subsection{Magnitude $M=6$ Scenario}

Case 3, Figure 9.2a: A magnitude $\mathrm{M}=6.0$ at $45.41 \mathrm{~N} 75.56 \mathrm{~W}$, near Ottawa, Ontario. The epicentre was assumed to be directly under a region of NEHRP E soil in order to see the extent of shaking amplified due to site response. An MMI of up to VIII (predicted MMI = 7.5) would be experienced. This suggests slight damage in specially designed structures; considerable in ordinary substantial buildings with partial collapse; fall of chimneys, factory stacks, columns, monuments, walls.

The earthquake would be strongly felt (with predicted $\mathrm{MMI}=\mathrm{IV}$ ) as far as $300 \mathrm{~km}$ from the epicentre. Such an event will be likely to have significant impact. In order to better understand the impact of such scenario event, it is useful to compare with the M6.5 San Simeon earthquake. This event occurred on December 22, 2003 along the coast of central California and had similar epicentral MMI levels to those projected for this scenario. Shaking was felt from San Francisco to Los Angeles to distances of $>300 \mathrm{~km}$. Most of the damage occurred to older unreinforced masonry structures in Paso Robles, at a distance of approximately $30 \mathrm{~km}$. Throughout the felt-region, there were reports of 
minor damage to utility systems, roads, contents and equipment, chimneys, and wine storage at several of the wineries in the regions. Figure $9.2 \mathrm{c}$ shows damage caused by the December 22, 2003 San Simeon, California earthquake (see details at http://www.eeri.org/lfe/usa_san_simeon.html).

Case 4, Figure 9.2b: A magnitude $M=6.0$ at $43.75 \mathrm{~N} 79.84 \mathrm{~W}$, near Toronto, Ontario (placed near a site with NEHRP D site). An event of this size near Toronto is possible but has a low probability. However, Toronto is a densely populated area, containing numerous high-rise apartments and office buildings. Such an event would be widely felt, and have locally a maximum felt intensity of MMI VII (predicted MMI = 6.8), implying slight to moderate damage in well-built ordinary structures; with considerable damage in poorly built or badly designed structures.

The effects would be similar to those given above for the Ottawa M6 scenario.

\subsection{Magnitude $M=7$ Scenario}

Case 5 Figure 9.3: A magnitude $M=7.0$ at $47.40 \mathrm{~N} 70.10 \mathrm{~W}$ located in the Charlevoix seismic zone, Quebec. Note NEHRP C site conditions are assumed throughout the mapped area. Thus damage could be greater at locations with poor soil. Figure 9.3 shows the intensity ShakeMap based on the ground motion relations developed in Chapter 6. As discussed in Chapter 6 (based on Figure 6.3), these empirical relations might overestimate gourd-motion values for $\mathbf{M}>6$. Therefore, I checked this effect on the maps by re-generating the intensity ShakeMap based on one of the widely used eastern North America ground-motion relations (Atkinson and Boore, 1995). The intensity ShakeMap that is obtained using the Atkinson and Boore (1995) relations to 
predict PGV, along with intensity relations (relationship between MMI and PGV) developed in Chapter 5, is very similar to that in Figure 9.3. However, the predicted MMI values near epicentre based on relations developed in Chapter 6 are slightly higher than those inferred based on Atkinson and Boore (1995). (MMI of 9.6 compared to MMI of 8.7). Thus, I conclude the maximum intensity would likely be about MMI=9.

Maximum predicted shaking of MMI IX near the epicentral region would be strong enough to cause considerable damage, especially to poorly designed structures; there would be significant damage in substantial buildings with partial collapse. Underground pipes could also be broken and the ground may crack. The earthquake would be widely felt throughout Quebec and eastern Ontario and the border regions of the northeastern United States. MMI levels greater than VI (the damage threshold) will generally occur within $100 \mathrm{~km}$ from the assumed epicentre. Strong shaking intensity (MMI IV) would be experienced at distances up to $900 \mathrm{~km}$.

The effects could be compared to the M6.9 1989 Loma Prieta earthquake of California which caused severe damage as far away as $100 \mathrm{~km}$. Most damage was located in isolated pockets, and was severe only where it affected older buildings constructed on fill material or on unconsolidated strata. In Santa Cruz, Watsonville, and Los Gatos, a much higher percentage of structures was affected; these cities were located only about 15 to $30 \mathrm{~km}$ from the epicentre. There were at least 66 deaths, mostly due to the collapse of the Cypress viaduct of interstate Nimitz Freeway and on $15 \mathrm{~m}$ section of the San Francisco-Oakland Bay Bridge (see Figure 9.3b) (see details at http://pubs.usgs.gov/dds/dds-29/). 


\subsection{Repeat of Historical Cornwall-Massena and Temiskaming Earthquakes}

The M5.8 Cornwall-Massena earthquake of September 5, 1944 and the M6.2 Temiskaming earthquake of November 1, 1935 were two of the most significant historical events in eastern Canada. Figures 9.4 and 9.5 present felt-intensity maps for a repeat of the Cornwall-Massena and Temiskaming earthquakes, respectively, based on ShakeMap. Actual isoseismal maps, taken from the Geological Survey of Canada website (http://www.seismo.nrcan.gc.ca//damage/1935_e.php), are plotted on similar geographic scale in the lower panel. The resulting felt-intensity ShakeMaps reasonably depict the overall damage potential for both events. However, the ShakeMaps cannot reproduce the irregular intensity patterns that were observed, due to our limited knowledge of regional site effects. This illustrates the need to improve this aspect of ShakeMap in future.

Tables 9.1 and 9.2 show an approximate comparison of total felt- area between the isoseismal map and ShakeMaps for the Cornwall-Massena and Temiskaming earthquakes respectively. This shows that the total area of potentially damaging shaking for both earthquakes is reasonably well predicted by ShakeMap. However, the pocket of high-intensity shaking for the Cornwall-Massena earthquake is not predicted in ShakeMap.

The Cornwall-Massena earthquake knocked down more than $90 \%$ chimneys in both Cornwall and Massena, and several structures were unsafe for occupancy until repaired. Most residents throughout the region experienced "very strong" shaking (characteristics of intensity rating VII) but there were no reports of severe or violent 
shaking (characteristics of intensity rating VIII or IX), even in those places nearest the epicentre.

Effects of the Temiskaming earthquake as reported by Hodgson (1936) indicate that $80 \%$ of all chimneys were damaged in epicentral region which suggest a maximum MMI of VII. Many chimneys were reported to have been thrown down in Mattawa and North Bay (about $70 \mathrm{~km}$ from the epicentre). Near Parent, Quebec (some $300 \mathrm{~km}$ from the epicentre), a $30 \mathrm{~m}$ railroad embankment slid. It should be noted that population density is much greater now than at the time of these historical events, and thus the past damage patterns likely underestimate effects of a modern repeat of these events.

Reports from both of the earthquakes showed that residents in the epicentral region (and some areas farther) reported shaking intensity up to VII, while communities farther away experienced more moderate intensities (Bruneau and Lamontagne 1994). Agreement between ShakeMap intensities, earthquake reports and isoseismal maps appears to be satisfactory for both events, both in terms of maximum MMI and the extent of the strongly-shaken area. Thus, Scenario ShakeMaps are a useful way to provide a perspective on the potential consequences of regional earthquakes. 
Table 9.1. A comparison of total felt- area between Isoseismal map and ShakeMap for Cornwall-Messena earthquake.

\begin{tabular}{|c|c|c|}
\hline Area MMI $\geq$ & Isoseismal $\left(\mathbf{k m}^{2}\right)$ & ShakeMap $\left(\mathbf{k m}^{2}\right)$ \\
\hline & Maximum MMI $=7$ & Maximum MMI $=6.7$ \\
\hline VII & $\approx 140$ & $\approx 122$ \\
\hline VI & $\approx 200$ & $\approx 260$ \\
\hline V & $\approx 440$ & $\approx 409$ \\
\hline VI & $\approx 900$ & $\approx 642$ \\
\hline II-III & $\approx 1,100$ & $\approx 988$ \\
\hline
\end{tabular}

Table 9.2. A comparison of total felt- area between Isoseismal map and ShakeMap for Temiskaming earthquake.

\begin{tabular}{|c|c|c|}
\hline Area MMI $\geq$ & Isoseismal $\left(\mathbf{k m}^{2}\right)$ & ShakeMap $\left(\mathbf{k m}^{2}\right)$ \\
\hline & Maximum MMI $=6$ & Maximum $\mathrm{MMI}=6.9$ \\
\hline VI & $\approx 200$ & $\approx 160$ \\
\hline V & $\approx 350$ & $\approx 400$ \\
\hline IV & $\approx 1,000$ & $\approx 900$ \\
\hline III & $\approx 1,300$ & $\approx$ N/A \\
\hline
\end{tabular}


M 5 Scenario Earthquake Near a) Ottawa; b) Toronto

a)

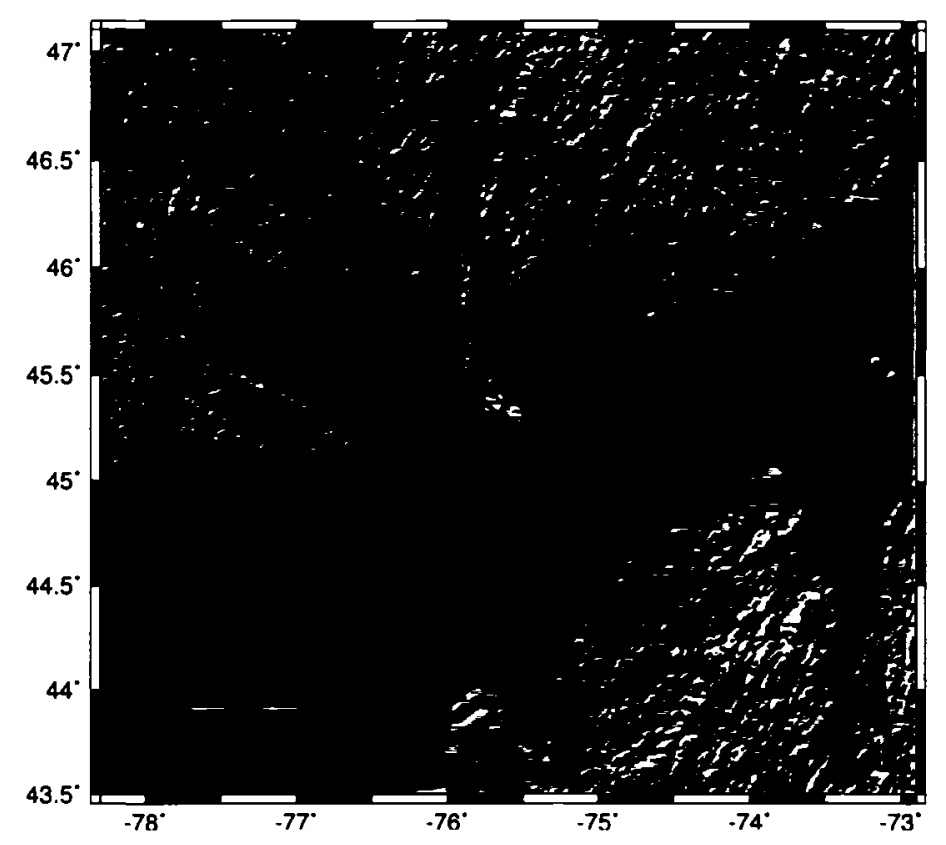

\begin{tabular}{|c|c|c|c|c|c|c|c|c|c|}
\hline 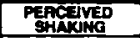 & Not felt & Weak & Light & Moderate & Strong & Very strong & Severe & Violent & Extreme \\
\hline POHENTAL & none & none & none & Very light & Light & Moderale & Moderale/teavy & Hoavy & Very Heavy \\
\hline 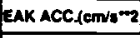 & $<.17$ & $.17-1.4$ & $1.4-3.9$ & 3.9 .2 & $9.2-18$ & $18-34$ & $34-65$ & $65-124$ & $>124$ \\
\hline PEAK VEL (mmva) & $<0.1$ & $0.1-1.1$ & $1.1-3.4$ & $3.4-8.1$ & 8.1.16 & $16-31$ & $31-\infty$ & 60.116 & $>116$ \\
\hline WSTRLESTIAL & 1 & & & & $n$ & & & & \\
\hline
\end{tabular}

b)

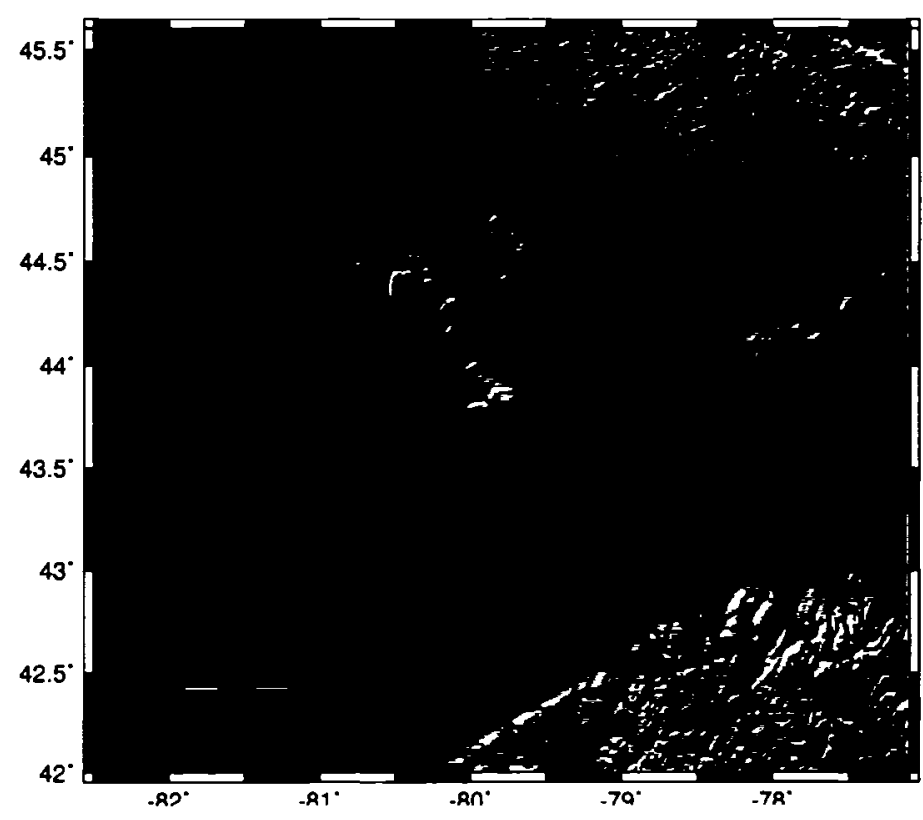

Figure 9.1 Scenario Intensity ShakeMap based on ground-motion relations developed in Chapter 6 and relation between PGV and MMI developed in Chapter 5. 


\section{6 Scenario Earthquake Near a) Ottawa; b) Toronto}

a)

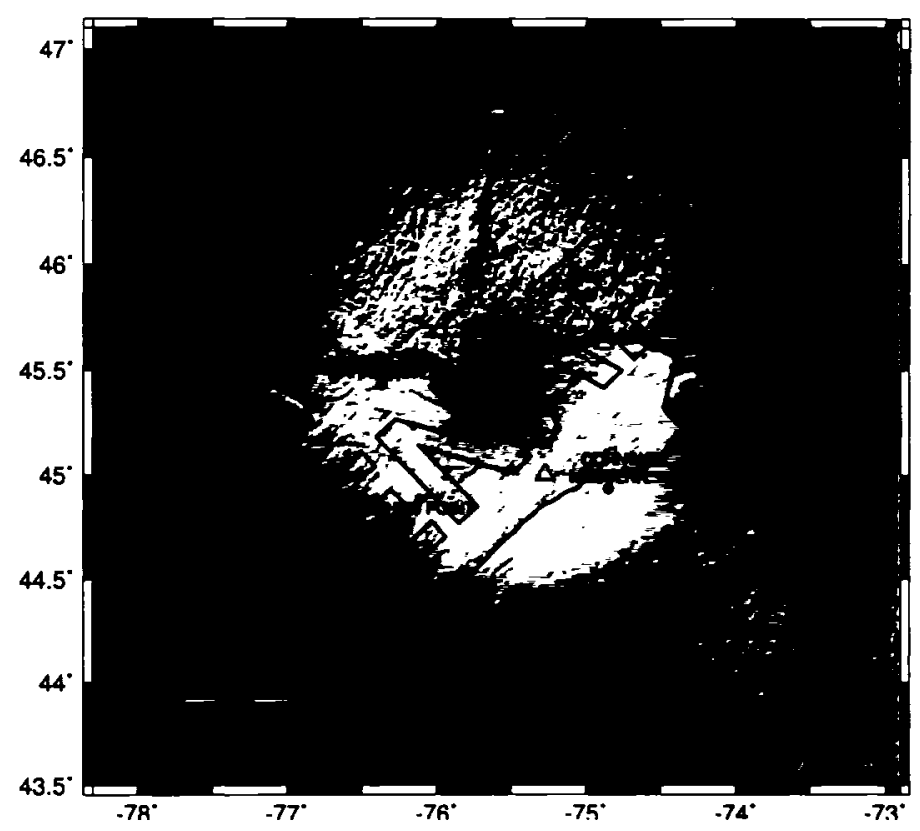

\begin{tabular}{|c|c|c|c|c|c|c|c|c|c|}
\hline 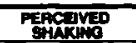 & Not feht & Weak & Light & Moderate & Strong & Very strong & Severe & Volent & Extreme \\
\hline PoTentulut & none & none & none & Very light & Light & Moderale & Moderatentaeny & Heany & Very Heavy \\
\hline EAK ACC. & $<17$ & $.17-1.4$ & 1.43 .9 & $3.9-9.2$ & $9.2-18$ & $18-34$ & 3465 & $65-124$ & $>124$ \\
\hline DEAK VEL(morva) & $<0.1$ & $0.1-1.1$ & $1.1-3.4$ & $3.4-8.1$ & $8.1-16$ & $16-31$ & $31-\infty$ & $00-116$ & $>116$ \\
\hline NSTRU & I & & & & $\boldsymbol{v}$ & & & & \\
\hline
\end{tabular}

b)

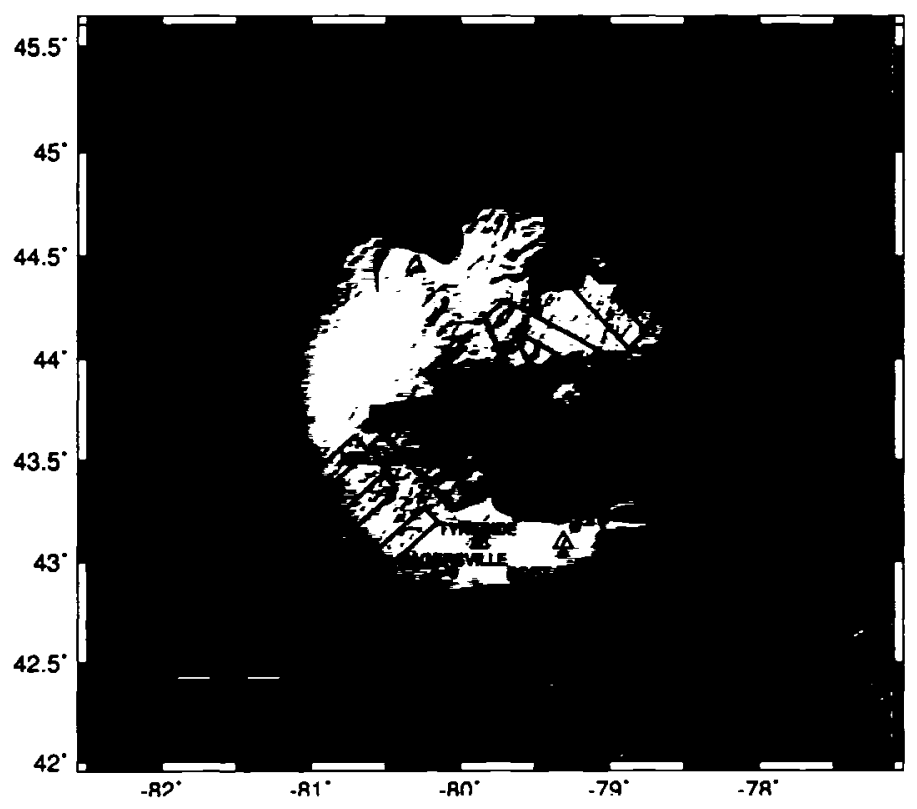

Figure 9.2 Scenario Intensity ShakeMap based on ground-motion relations developed in Chapter 6 and relation between PGV and MMI developed in Chapter 5. 
a)

b)

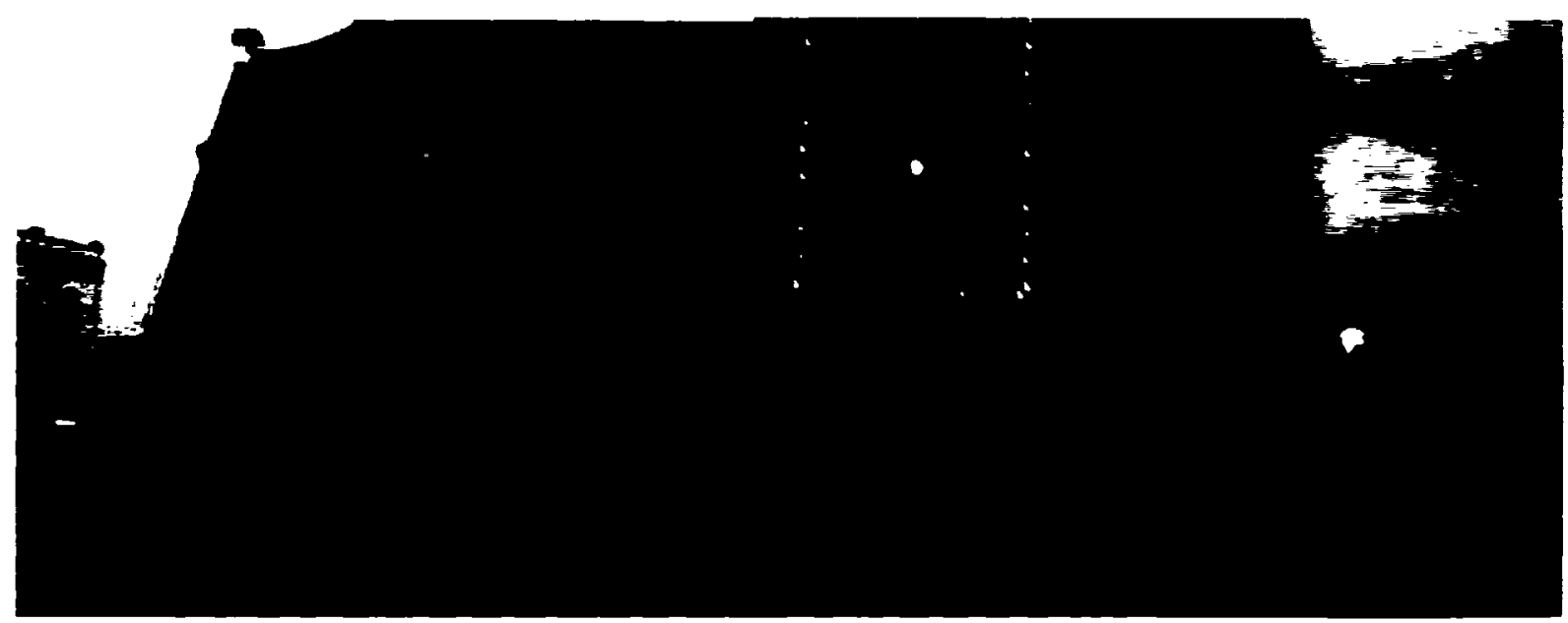

c)

d)

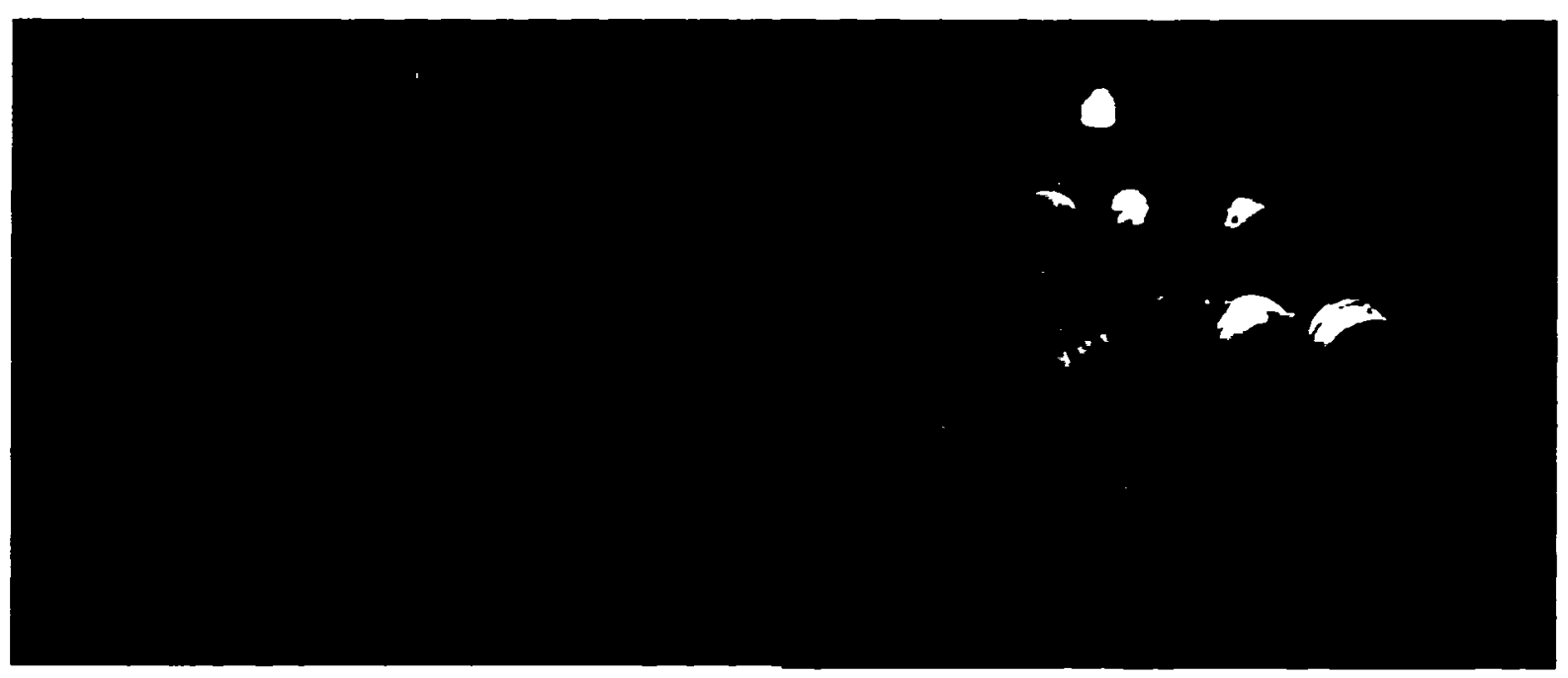

Figure 9.2c. Damage caused by the M6.5 San Simeon earthquake. Photos by Joshua Marrow, Simpson Gumpertz Heger (taken from http://www.eeri.org/lfe/usa_san_simeon.html)

a) Collapsed Mastagni Building, Paso Robles

b) Cracking in brick in downtown Paso Robles building

c) Collapsed roof from Mastagni Building in Paso

d) Non-structural damage to Paso Robles area wineries 


\section{7 Scenario Earthquake in the Charlevoix Seismic Zone}

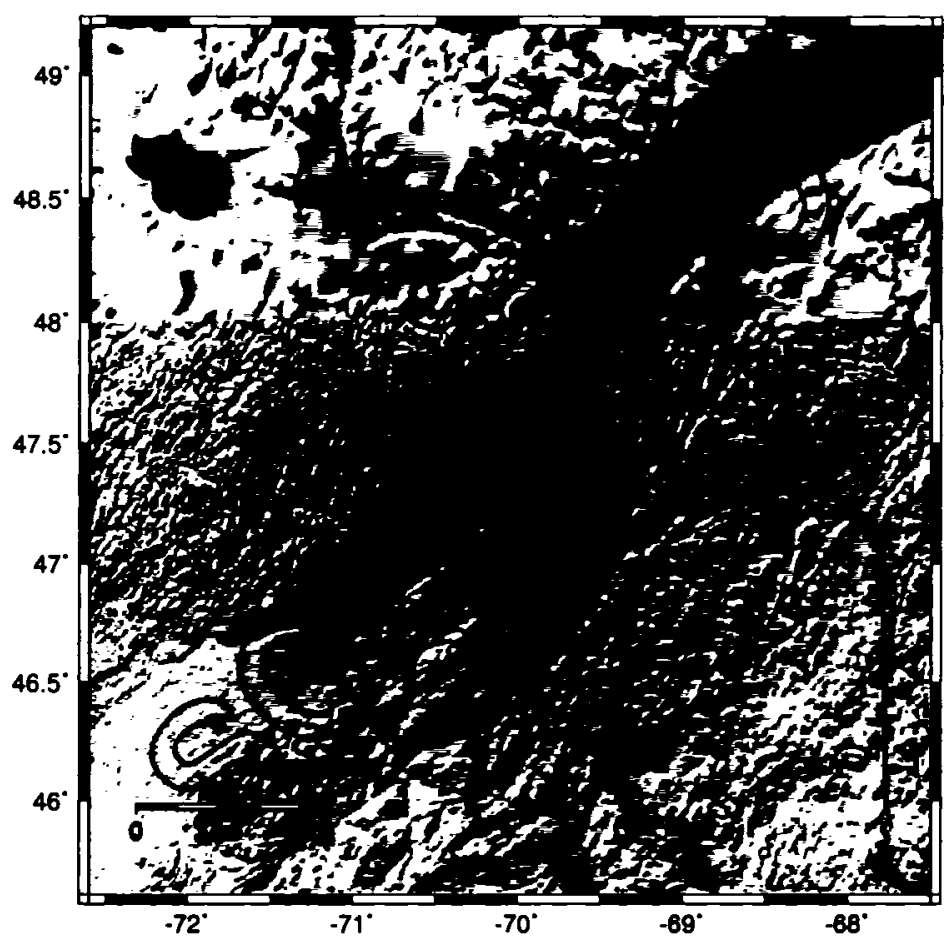

\begin{tabular}{|c|c|c|c|c|c|c|c|c|c|}
\hline $\begin{array}{l}\text { PEACEIVED } \\
\text { SHAKIMO }\end{array}$ & Not felt & Weak & Light & Moderate & Strong & Very strong & Severe & Violent & Extreme \\
\hline POTEEMAL & none & none & none & Very light & Light & Moderate & Moderate/Heavy & Heavy & Very Heavy \\
\hline EAK ACC_(cm/s $=2$ & $<.17$ & $.17-1.4$ & $1.4-3.9$ & $3.9-9.2$ & $9.2-18$ & $18-34$ & $34-65$ & $65-124$ & $>124$ \\
\hline PEAK VEL $(\mathrm{mm} / \mathrm{s})$ & $<0.1$ & $0.1-1.1$ & $1.1-3.4$ & 3.4-8.1 & $8.1 \cdot 16$ & $16-31$ & $31-60$ & $60-116$ & $>116$ \\
\hline $\begin{array}{l}\text { INSTRUMENTAL } \\
\text { INTENSTY }\end{array}$ & I & & & & $\mathbf{n}$ & & & & \\
\hline
\end{tabular}

Figure 9.3. Scenario Intensity ShakeMap based on ground-motion relations developed in Chapter 6 and relation between PGV and MMI developed in Chapter 5. 
a)

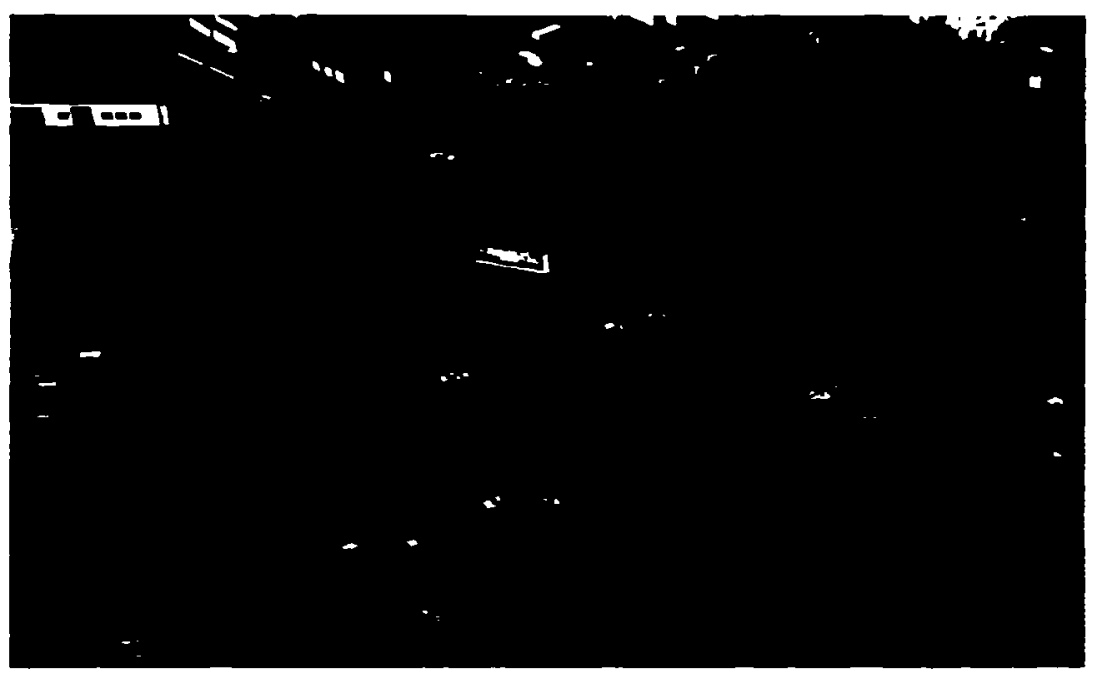

b)

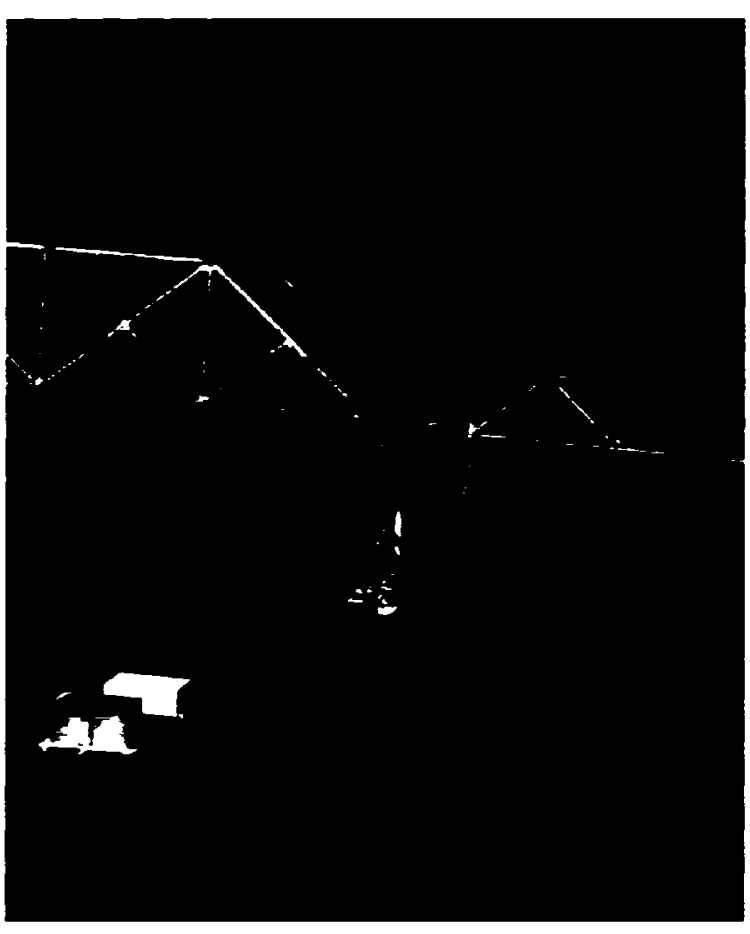

Figure 9.3 b. Damage caused by the M6.9 1989 Loma Prieta earthquake. Photographs (taken from http://wrgis.wr.usgs.gov/dds/dds-

29/web_pages/oakland.html) showing aerial view of:

a) collapsed sections of the Cypress viaduct of Interstate Highway 880

b) collapsed section of the San Francisco-Oakland Bay Bridge 


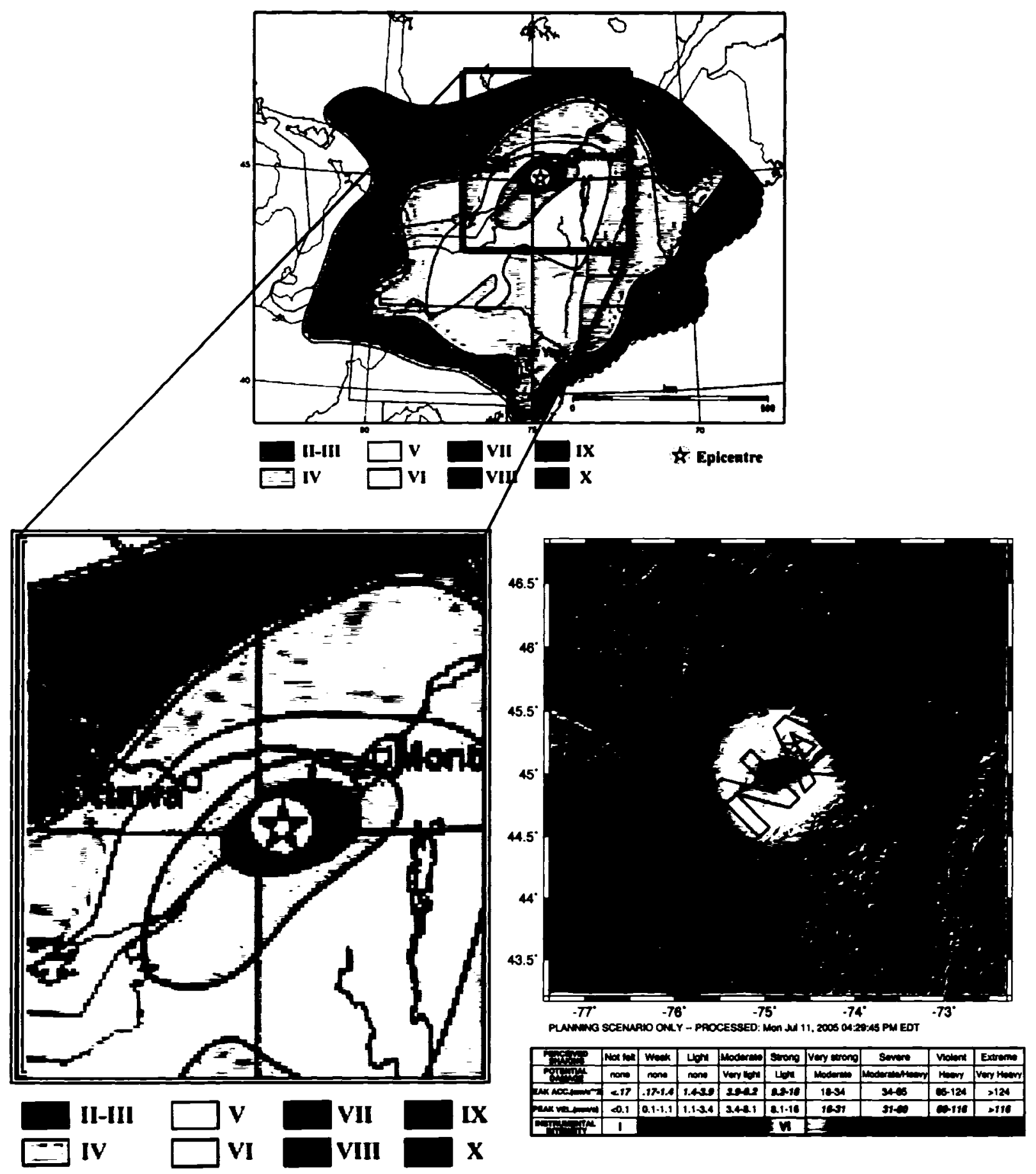

Figure 9.4 Repeat of Cornwall Earthquake compared to Isoseismal Map taken from the GSC (http://www.seismo.nrcan.gc.ca//damage/1935 e.php). Note the differences in colour scheme between the historical and ShakeMap intensities. Lower panels plotted on similar geographic scale. 


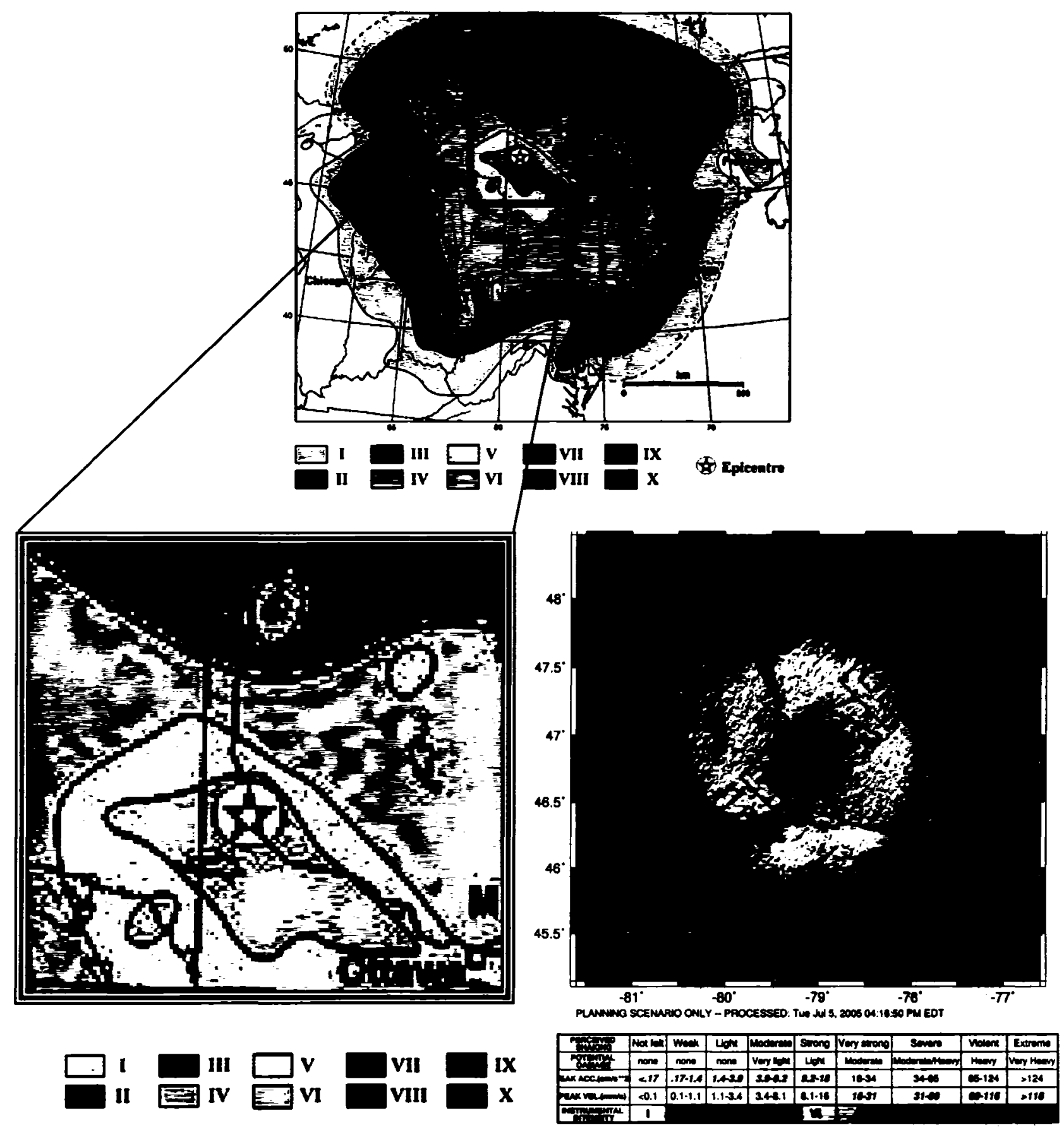

Figure 9.5 Repeat of Temiskaming Earthquake Compared to Isoseismal map taken from the GSC (http://www.seismo.nrcan.gc.ca//damage/1944 e.php) Note the differences in colour scheme between the historical and ShakeMap intensities. Lower panels plotted on similar geographic scale. 


\section{Chapter 10}

\section{Outstanding Problems and Future Directions for ShakeMaps}

In this chapter, outstanding problems and future directions for ShakeMaps are discussed.

\subsection{Broadening the Station Coverage for Ontario ShakeMaps}

Near-real time ShakeMaps that provide timely information on ground shaking in Ontario have been developed and put into practice in Ontario based on POLARIS stations. It remains to broaden the spatial station coverage to include all stations of the Canadian National Seismic Network (CNSN) within eastern Canada. The performance of ShakeMap will improve as the network improves.

\subsection{Addressing Uncertainties in ShakeMaps}

There are many uncertainties in generating near-real-time ShakeMaps. They include uncertainties in terms of event triggering, calculations of the recorded groundmotion amplitudes, and translation of peak ground velocity amplitude to felt-intensity. The interpolation and application of site amplification correction factors is a particularly large uncertainty. There is a need to make these uncertainties clear to the users, while working to reduce them.

Uncertainty in event triggering could be reduced by working closely with GSC to verify every single triggered event, and then sending a follow-up e-mail to the subscribers to update information on the event.

To prevent errors in calculation of the recorded ground motion amplitudes, it is essential to keep up-to-date instrument response function information in the program 
operation for each recording station. This requires extra efforts from the station operators to review and update information in near-real-time.

Reducing uncertainties in site response is discussed below.

\subsection{More Shear-wave Velocity Data Across Ontario}

As discussed in Chapter 7, local site conditions amplify ground motions; suitable correction factors must be introduced to account for the appropriate level of amplification when recorded ground-motion amplitudes are interpolated to adjacent areas. Available near-surface amplifications and shear-wave velocity data (Table 7.11) are extremely limited across Ontario. More shear-wave velocity data are needed to produce reliable a NEHRP site classification map for Ontario (Figure 7.8). Hence, a major research project needs to be undertaken to conduct shear-wave velocity surveys across the province. Shear-wave velocity surveys can be used to provide information on the near surface velocity structure, to identify major acoustic impedances within the soil layer, to estimate the bedrock depth, and to delineate any local subsurface structure. I would recommend an expansion of the pilot study conducted by Benjumea, et al., 2001. They conducted nearsurface seismic velocity studies in the Delaware area southwest of London, Ontario to image subsurface structure and obtain estimates of elastic parameters. They showed that the detailed information on the subsurface could be obtained from simple, cost-effective shallow seismic surveys. Such information can be significant not only for the Ontario ShakeMap project but also for earthquake hazard evaluation at thick soil sites.

Overall, the most important issue for future ShakeMap development in Ontario is improving our knowledge of site response in all populated regions. 


\subsection{Linking ShakeMap with "Did you feel it" website}

It would be helpful to link ShakeMap more closely to the intensity information collected on the GSC website (http://www.seismo.nrcan.gc.ca/felt e.php) "Did you feel the Earthquake?" One way of achieving is to implement a system known as Community Internet Intensity Map (CIIM) developed by Wald et al (1999c). CIIM is a fully automated system in which people report felt earthquake effects via an internet form. Thousands of responses are typically reported for moderate events, allowing robust intensity data to be collected. The users' responses to the forms (developed by Dengler and Dewey, 1998) trigger automatic processing which generates felt intensity maps comparable to instrumental ShakeMaps. The maps are automatically updated as new data are received. These felt-intensity maps serve as a very rapid means of portraying the pattern of shaking independent of recorded ground motion amplitudes. Hales and Dengler (1998) show that local variations in intensity can be recovered with sufficiently distributed responses. As David Wald pointed out in his presentation at Carleton University in 2004 , the interactive nature of the system also provides an avenue for feedback among the earthquake-affected-communities, and agencies responding to the disasters (Wald, pers. comm., 2004).

\subsection{Possibility of Providing other Earthquake Parameters along with ShakeMaps}

ShakeMap, as developed and implemented to date, provides information regarding the severity of ground shaking. The possibility of providing more detailed information on event mechanism, ground motion spectrum and time series needs to be explored. For example, Scrivner and Helmberger (1995) studied the possibility of 
determining the earthquake mechanism using the waveforms from stations close to the source of the M5.6 1991 Sierra Madre, California event and showed that even with a relatively limited amount of information from the beginning of waveforms, the mechanism and seismic moment can be estimated. As the data from further stations become available, the solution can be refined and updated progressively. It may be feasible to add new scientific modules to ShakeMaps in future that would allow rapid computation of a number of significant earthquake parameters. These could be provided through the ShakeMap interface as additional downloadable data products.

\subsection{Implementing ShakeMaps in Western Canada}

To date, Ontario is the only region of Canada that has implemented ShakeMap. Large earthquakes are relatively rare in Ontario, but more frequent in western Canada. ShakeMap would be particularly useful in southwestern British Columbia. The ShakeMap concept should be implemented in western Canada in conjunction with the Pacific Geosciences Centre. Perhaps the most basic issue involving the application of ShakeMap in the West is whether it can be used as a tool that can contribute to emergency response decision making in the minutes and hours following a significant earthquake. Furthermore, scenario ShakeMaps will make a significant contribution in communicating information to the media and public, enhancing emergency response planning. While implementing ShakeMap in the west, additional near-real-time information on ground failures including landslides, liquefaction, and other secondary features of shaking which contribute to damage after a major earthquakes, should be explored and incorporated. 


\section{References}

Abrahamson, N.A., and W.J. Silva (1997). Empirical response spectral attenuation relations for shallow crustal earthquakes, Seis. Res. Letts., 68, 94-127.

Adams, J., and P. Basham (1989). The seismicity and seismotectonics of Canada east of the Cordillera. Geoscience Canada, 16, 3-16.

Adams, J., and S. Halchuk (2003). Fourth generation seismic hazard maps of Canada: values for over 650 Canadian localities intended for the 2005 National Building Code of Canada. Geological Survey of Canada Open File 4459, 155 pp. Available from http://www.seismo.nrcan.gc.ca/hazards/recpubs_e.php

Aki, K., and P. G. Richards (1980). Quantitative Seismology: Theory and Methods. San Francisco California: W. H. Freeman.

Atkinson, G. (1993a). Notes on ground motion parameters for eastern North America: Duration and H/V ratio. Bulletin of the Seismological Society of America, 83, 587596.

Atkinson, G. (1993b). Source spectra for earthquakes in eastern North America. Bulletin of the Seismological Society of America, 83, 1778-1798.

Atkinson, G. M. (2001). Linking historical intensity observations with ground-motion relations for eastern North America, Seismological Research Letter, 72, 560-574.

Atkinson, G. M. (2004). Empirical Attenuation of Ground Motion Spectral Amplitudes in Southeastern Canada and the Northeastern United States, Bulletin of the Seismological Society of America, 94, 1079-1095.

Atkinson, G. M., and D. M. Boore (1995). Ground-motion relations for eastern North America, Bulletin of the Seismological Society of America, 85, 17-30. 
Atkinson, G. M., and J. F. Cassidy (2000). Integrated use of seismograhy and strong motion data to determine soil amplification: Response to the Fraser River Delta to the Duvall and Georgia Strait earthquakes, Bulletin of the Seismological Society of America, 90, 1028-1040.

Atkinson, G. M and S. Z. Chen (1997). Regional seismograms from historical earthquakes in southeastern Canada, Seismological Research Letter, 68, 797-807.

Atkinson, G., and R. Mereu (1992). The shape of ground motion attenuation curves in southeastern Canada. Bulletin of the Seismological Society of America, 82, 2014-2031.

Atkinson, G., M and E. Sonley (2000). Empirical relationships between modified Mercalli intensity and response spectra, Bulletin of the Seismological Society of America, 90, 537-544.

Benjumea, B., S.E. Pullan, J.A Hunter, R.A. Burns, M. Douma, and D. Eaton (2001). Near-Surface seismic methods applied to site-response characterization at an earthquake monitoring station near London, Ontario. Current Research 2001-E7, Geological Survey of Canada, 9 p.

Beresnev, I., and G. Atkinson (1997). Shear wave velocity survey of seismographic sites in eastern Canada: Calibration of empirical regression method of estimating site response. Seismological Research Letter, 68, 981-987.

Boatwright, J., K.Thywissen, and L. Seekins (2001). Correlation of ground motion and intensity for the 17 January 1994 Northridge, California, Earthquake, Bulletin of the Seismological Society of America, 91, 739-752. 
Boore, D. M. (2004). Can site response be predicted?, J. Earthquake Engineering 8 Special Issue 1, 1-41

Boore, D., and W. Joyner (1997). Site amplifications for generic rock sites, Bulletin of the Seismological Society of America, 87, 327-341.

Boore, D. M., and W. B. Joyner, and T. E Fumal (1997). Equations for estimating horizontal response spectra and peak acceleration from western North American earthquakes: A summary of recent work, Seismological Research Letter, 68, 128-153.

Boore, D. M., and L. T. Brown (1998). Comparing Shear-wave Velocity Profiles from Inversion of Surface-wave Phase Velocities with Downhole Measurements: Systematic Differences between the CXW Method and Downhole Measurements at Six USC Strong-motion Sites, Seismological Research Letter, 69, 222-229.

Borcherdt, R. D. (1970). Effects of local geology on ground motion near San Francisco Bay, Bull. Seism. Soc. Am., 60, 29-61.

Borcherdt, R. D. (1994). Estimates of site-dependent response spectra for design (methodology and justification), Earthquake Spectra, 10, 617-654.

Bruneau, M. and M. Lamontagne (1994). Damage from 20th century earthquakes in eastern Canada and seismic vulnerability of unreinforced masonry buildings. Can. J. of Civil Engineering, 21, no. 4, p. 643-662.

Building Seismic Safety Council (BSSC) (1998). 1997 Edition NEHRP recommended provisions for seismic regulations for new buildings and other structures. Part 1 (provisions) and part 2 (commentary). FEMA 302/303, Building Seismic Safety Council, Federal Emergency Management Agency, Washington, D. C. 
Building Seismic Safety Council (BSSC) (2001). 2000 Edition NEHRP recommended provisions for seismic regulations for new buildings, 2 volumes and maps. FEMA 368/369, Building Seismic Safety Council, Federal Emergency Management Agency, Washington, D. C.

Campbell, K. (2003). Prediction of strong-ground motion using the hybrid-empirical method and its use in the development of ground-motion (attenuation) relations in eastern North America, Bulletin of the Seismological Society of America, 93, 1012-1033.

Chapman, L. J., and D.F Putnam (1984). Physiography of Southern Ontario; Ontario Geological Survey, Map P. 2715 (coloured). Scale 1: 600,000.

Daneshfar, B. and K. Benn (2002). Spatial relationships between natural seismicity and faults, southeastern Ontario and north-central New York State. Tectonophysics 353, 31-44.

Dengler, L. A. and J. W. Dewey (1998).An intensity survey of housholds affected by the Northridge, California, earthquake of 17 January, 1994, Bull. Seism. Soc. Am. 88, 441-462.

Dobry, R., R. D. Borcherdt, C. B. Crouse, I. M. Idriss, W. B. Joyner, G. R. Martin, M. S. Power, E. E. Rinne, and R. B. Seed (2000). New site coefficients and site classification system used in recent building seismic code provisions, Earthquake Spectra 18, 41-67.

Ellsworth, C. L. (2000). A study of fault reactivation. B.Sc. Thesis, Carleton University, Department of Earth Science. 
Field, E. H. and K. H. Jacob (1995). A comparison and test of various site-response estimation techniques, including three that are not reference-site dependent. Bull. Seism. Soc. Am., 85, 1127-1143.

Finn, L. W. D. and A. Wightman (2003). Ground motion amplification factors for the proposed 2005 edition of the National Building Code of Canada, Can. J. Civ. Eng., 30, 272-278.

Forsyth, D. A. (1981). Characteristics of Western Quebec Seismic Zone. Canadian Journal of Earth Science, 18, 103-119.

Frankel, A., C. Mueller, T. Barnahard, D. Perkins, E. Leyendecker, N. Dickman, S. Hanson, and M. Hopper (1996). National seismic hazard maps: documentation June 1996, U.S. Geological Survey Open-File Report 96-532, 110 pages, available through our website at geohazards.cr.usgs.gov/eq/ Click on "documentation."

Goltz, J. M. (2003). Application for new real-time seismic information: The TriNet project in Southern California. Seismological Research Letters, 74; 516-521.

Hales, K, and L. A. Dengler (1998). Detailed intensity map of the Jan. 17, 1994 Northridge earthquake, Eos, Trans. Am. Geophys. U. 77, F 493.

Hodgson, E.A. 1936. The Temiskaming earthquake of November 1st, 1935. The location of epicentre and determination of focal depth, Royal Astronomical Society of Canada Journal, 30, No. 4, 113- 123.

Hough, S., J. Armbruster, L. Seeber, and J. Hough (2000). On the Modified Mercalli intensities and magnitudes of the 1811-1812 New Madrid earthquakes, Journal of Geophysical Research, 105, no. B10, 23,839-23,864. 
Hunter, J.A., M. Douma, R.A. Burns, R.L. Good, S.E. Pullan, J.B. Harris, J.L. Luternauer, and M.E. Best (1998). Testing and application of near-surface geophysical techniques for earthquake hazards studies, Fraser river delta, British Columbia, in Geology and Natural Hazards of the Fraser River Delta, British Columbia, (ed.) J.J. Clague, J.L. Luternauer, and D.C. Mosher, Geological Survey of Canada, Bulletin 525, 123-145.

Kaka, S. I., and G. M. Atkinson (2004). Relationships between Instrumental Ground Motion Parameters and Modified Mercalli Intensity in Eastern North America, Bulletin of the Seismological Society of America, 94, 1728-1736.

Kaka, S. I. and G. M. Atkinson (2005). Empirical Ground-Motion Relations for ShakeMap Applications in Southeastern Canada and the Northeastern United States, ES-SSA Section of Seismological Research Letters, 76, 274-282.

Kanamori, H. (1993). Locating earthquakes with amplitude: Application to real-time seismology, Bulletin of the Seismological Society of America 83, 264-268.

Lachet, C., and P. Bard (1994). Numerical and theoretical investigations on the possibilities and limitations of Nakamura's technique. J. Phy. Earth. 42, 337-397.

Lamontagne, M., M S. Hasegawa, D. A. Forsyth, G. G. R. Buchbinder, and M. Cajka (1994). The Mont-Laurier, Quebec, earthquake of 19 October 1990 and its seismotectonic environment Bulletin of the Seismological Society of America, 84: 1506-1522. 
Lamontagne, M. and G. Ranalli (1997). Faults and spatial clustering of earthquakes near La Malbaie, Charlevoix Seismic Zone, Canada. Seismological Research Letters, $68,337-352$.

Lermo, J and F. J. Chavez-Garcia (1994). Are Microtremors useful in site response evaluation? Bulletin of the Seismological Society of America, 84, 1350-1364.

McDaniel, R and S. Horton (2001). Project SG-12: Calibrating intensity with ground motions, Center for Earthquake Research and Information, Student Leadership Council Online Magazine, University of Illinois at Urbana-Champaign, http://mae.ce.uiuc.edu/Education/Student/Graduate/SCOJ/V2N2/RMcDaniel.pdf

Mohajer, A., A. Eyles, and C. Rogojina (1992). Neotectonic faulting in metropolitan Toronto: implications for earthquake hazard assessment in the Lake Ontario region. Geology 20 (11): 1003-1006.

Munro, P. S., and D. Weichert (1989). The Saguenay Earthquake of November 25, 1988 Processed Strong Motion Records, Geological Survey of Canada Open File 1996, $150 \mathrm{pp}$.

Murphy, C. (2003). Near Surface Characterization and Estimated Site Response at POLARIS Seismograph Stations in Southern Ontario, Canada. Master of Science Thesis, Department of Earth Sciences, University of Western Ontario.

Nakamura, Y. (1989). A method for dynamic characteristics estimation of subsurface using microtremor on the ground surface, $Q R R T R I, 30,25-33$.

Omachi, T., Y. Nakamura, and T. Toshinawa (1991). Ground motion characteristics of the San Francisco bay area detected by microtremor measurements, Proceedings 
of the $2^{\text {nd }}$ International Conference on Recent Advances in Geotechnical Earthquake Engineering and Soil Dynamics, 1643-1648.

Richter, C.F. (1958). Elementary Seismology. W.H. Freeman and Company, San Francisco, pp. 135-149; 650-653.

Scrivner, C. W and D.V Helmberger (1995). Preliminary work on an early warning and rapid response program for moderate earthquakes. Bull. Seismol. Soc. Am. $85: 1257-65$

Siddiqqi, J. and G. Atkinson (2002). Ground motion amplification at rock sites across Canada, as determined from the horizontal-to-vertical component ratio. Bull. Seism. Soc. Am., 92, 877-884.

Smith, W. H. F, and P. Wessel (1990). Gridding with continuous curvature splines in tension, Geophysics, 55, 293-305.

Snider, A. J. (2005). Site amplification measurements for Ontario seismic stations based on ground motion relations and horizontal to vertical ratios. B.SC. (Honours) Thesis, Carleton University, Department of Earth Science.

Theodulidis, N., and P.Y. Bard (1995). H/V spectral ratio and geological conditions: an analysis of strong motion data from Greece and TaiWan (SMART-1), Soil Dyn. and Earthq. Engng, 14, 177-197.

Thodulidis, N., P. Y. Bard., R. J. Archuleta and M. Bouchon (1996). Horizontal to vertical spectral ratio and geological conditions: the case of Garner Valley downhole array in Southern Califomia, Bull. Seism. Soc. Am., 86, 306-319. 
Toro, G., N. Abrahamson, N., and J. Schneider (1997). Model of strong ground motions from earthquakes in central and eastern North America: best estimates and uncertainties. Seismological Research Letter, 68, 41-57.

Wald, D. J., V. Quitoriano, T. H. Heaton, H. Kanamori (1999a). Relationships between peak ground acceleration, peak ground velocity and Modified Mercalli Intensity in California, Earthquake Spectra, 15, 557-564.

Wald, D. J., V. Quitoriano, T. H. Heaton, H. Kanamori, C. W. Scrivner, and C. B. Worden (1999b). 'Trinet ShakeMaps': Rapid Generation of Instrumental Ground Motion and Intensity Maps for Earthquakes in Southem California, Earthquake Spectra, 15, 537-556.

Wald, D. J, V. Quitoriano, L.A. Dengler., and J.W. Dewey (1999c). Utilization of the Internet for Rapid Community Internet Maps. Seismological Research Letters, 70, 680-693.

Wessel, P., and W. H. F. Smith (1991). Free software helps map and display data, Eos Trans., $A G U, \mathbf{7 2}, 441$.

Wills, C. J., M. Petersen, W.A. Bryant, M. Reichle, G. J. Saucedo, S. Tan, G. Taylor and J. Treiman (2000). A site-conditions map for California based on geology and shear-wave velocity, Bulletin of the Seismological Society of America 90, 187208.

Wood, H. O., and F. Newmann (1931). Modified Mercalli Intensity Scale of 1931, Bulletin of the Seismological Society of America 21, 277-238. 
Wu, P., and H. S. Hesegawa (1996). Induced stresses and fault potential in Eastern Canada due to realistic load: a preliminary analysis, Geophys. J. Int., 127, 215229.

Yamazaki, F., and M. A. Ansary (1997). Horizontal-to-vertical spectrum ratio of earthquake ground motion for site characterization, Earthquake Eng. Struct. Dyn. 26, 671- 689 . 